\title{
Institutions, Incentives And Local Policies
}

\section{Evidence from Education and Media Markets.}

\author{
Dissertation \\ zur Erlangung des wirtschaftswissenschaftlichen Doktorgrades \\ der Wirtschaftswissenschaftlichen Fakultät der Universität Göttingen
}

\author{
vorgelegt von \\ Oliver Himmler \\ aus Neumarkt i.d. Opf.
}

2009 



\section{Contents}

1 Aвоut this BoOK 1

2 Institutions in Educhtion (I) - Standards

3 Disadvantaged Students and the Setting of Local

Educational Standards

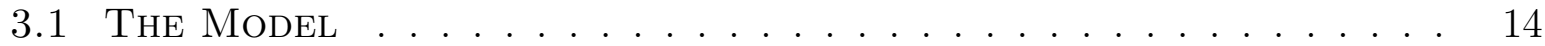

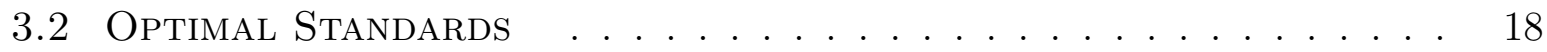

3.3 DATA AND ESTIMATION APPROACH . . . . . . . . . . . . . . 22

3.3.1 The Dutch Educhtion SYSTEM . . . . . . . . . . . . . . 22

3.3.2 EstimATION APPROACH . . . . . . . . . . . . . 24

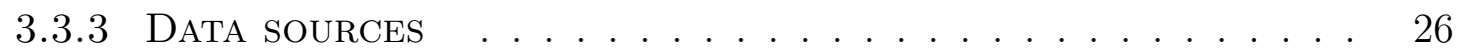

3.4 EMPIRICAL RESUlts _. . . . . . . . . . . . . . . . . . 28

3.4.1 Determinants of Standards in Dutch Schools . . . . . . 28

3.4 .2 ENdOGENEITY ISSUES . . . . . . . . . . . . . . . . . 33

3.4 .3 LONGITUDINAL DATA . . . . . . . . . . . . . . . 36

3.5 Summary AND OUtloOK . . . . . . . . . . . . . . . . 37

ApPendix to Chapter $3 \ldots \ldots \ldots \ldots$

4 Institutions in Educhtion (II) - Competition $\quad 42$ 
5 Choice in Local Education Markets: A Driver of High Academic Achievement or of Low Grading Standards?

5.1 School Choice, Centralized Funding and Exams . . . . . . . 49

5.2 Empirichl Strategy And Data Sources . . . . . . . . . . . 51

5.2 .1 ESTIMATION APPROACH . . . . . . . . . . . . 51

5.2 .2 Measuring Competition and Achievement . . . . . . . . . 52

5.2 .3 DAta Sources . . . . . . . . . . . . . . . 54

5.3 Estimation Results . . . . . . . . . . . . . . . . 56

5.3.1 Endogeneity of Competition . . . . . . . . . . . . . 60

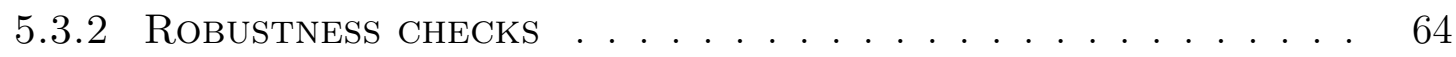

5.3.3 Alternative outcome VARIABles . . . . . . . . . . . . 68

5.4 Distributional Analysis - QR And IVQR . . . . . . . . . . 70

5.4 .1 QR AND IVQR ESTIMATES .................. 74

5.5 Summary and OutloOK . . . . . . . . . . . . . . . 75

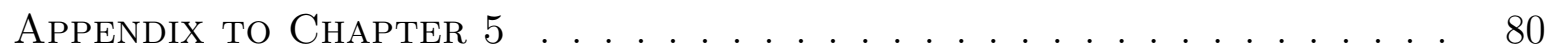

6 An Introduction to the Links Between Information, Media and Political Economics

7 Local Television Markets and the Distribution of Public Spending

7.1 MODEL . . . . . . . . . . . . . . . . . . . . . 96

7.1.1 LOCAL TV NEWS . . . . . . . . . . . . . . . . 97

7.1 .2 Strategic Allochtion of Grants . . . . . . . . . . . . . 99 
7.2 Data AND estimation APPROACH . . . . . . . . . . . . . . 102

7.2.1 EMPIRICAl Strategy . . . . . . . . . . . . . . 103

7.2.2 OMitted VARIABles And Endogeneity of TV STATION LOCATION . . . . . . . . . . . . . 109

7.2.3 Spatial Autocorrelation _. . . . . . . . . . . . . 111

7.2 .4 DAtA Sources . . . . . . . . . . . . . . . . 113

7.3 EMPIRICAL Results . . . . . . . . . . . . . . . . . . . . . . . . . . 114

7.3.1 THE LiNK BETWEen MEDIA ACTIVITY

AND SPENDING . . . . . . . . . . . . . . . . . . . 114

7.3 .2 2SLS RESULTS . . . . . . . . . . . . . . . . . 121

7.3.3 RoBUSTNESS CHECKS . . . . . . . . . . . . . . . . . 122

7.3.4 SpATIAL REGRESSION RESUlts . . . . . . . . . . . . . . 123

7.4 Summary and Outlook . . . . . . . . . . . . . . . . . . 125

ApPendix to ChAPter $7 \ldots \ldots \ldots \ldots \ldots \ldots$

8 How Newspaper Circulation Enhances Local

Government EFFICIENCY

8.1 Media and Efficiency: Theoretical Links . . . . . . . . . . . . . 134

8.2 The Norwegian Situation . . . . . . . . . . . . . . . 141

8.2.1 Data Sources And media Measures . . . . . . . . . . 143

8.3 EMPIRICAL STRATEGY . . . . . . . . . . . . . . . 150

8.4 Results . . . . . . . . . . . . . . . . . . . . . 152

8.4.1 Robustness Checks And 'Placebo' tests . . . . . . . . . 157

8.4.2 Municipality Size, CENTRALITY AND MEDIA EFFECTS . . . . . . . . . . . . . . . . . . . . . . 158

8.5 Summary and OutloOK $\ldots \ldots \ldots \ldots \ldots$

ApPendix to Chapter $8 \ldots \ldots \ldots \ldots \ldots \ldots$ 


\section{List of Figures}

TAble $\quad 3-1$ Graduation standards and thresholds . . . . . . . . 21

TABle $\quad 5-1 \quad$ QR and IVQR estimates, Central exam. . . . . . . . . 77

TABle $\quad 5-2$ QR And IVQR estimates, GRAdE INFLation. . . . . . . 78

TABle A5-1 Rotterdam, DeElgemeenten. . . . . . . . . . . 80

TABlE $\quad 7-1$ DMAs AND STATE BORDERS. . . . . . . . . . . . . 106

Table $\quad 7-2$ Counties by Sample (metro/micro) $\ldots \ldots \ldots \ldots$

TABle $\quad 8-1 \quad$ Reach, All/REgional neWsPapers . . . . . . . . . 147

TABle $\quad 8-2$ EfFiciency, REgional REACH/CONTENT/CONGRUENCE . . 148 


\section{List of Tables}

TABle $\quad 3-1 \quad$ Descriptive Statistics. . . . . . . . . . . . . . . . . . . 28

Table $\quad 3-2 \quad$ Summary statistics $\Delta G_{i} \ldots \ldots \ldots \ldots \ldots$

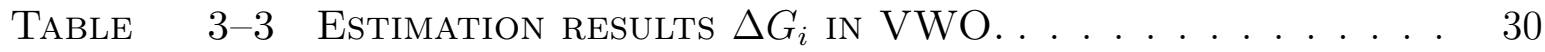

Table $\quad 3-4$ Estimation Results $\Delta G_{i}$ in HaVo, MaVO, VBO. . . . 32

TABLE $\quad 3-5$ 2SLS COEFFICIENTS BY SCHOOL BRANCH AND INSTRUMENT. 35

TABle $\quad 3-6 \quad$ Fixed and RAndom effects, VWO. . . . . . . . . . . . 37

TABle $\quad 5-1$ Summary Statistics, DePEndent VARIABles. . . . . . . . 58

TABle $\quad 5-2$ Summary Statistics, COMPETItion VARIABles. . . . . . . . 58

TABle 5-3 OlS eXAM GRAde, (PARTly) CATHOLIC COMPETition. . . . 61

TABle 5-4 OLS EXAM GRAde, (ROMAN) CATHOLIC COMPETition. . . . 62

TABle $\quad 5-5 \quad$ First Stage Statistics. . . . . . . . . . . . . . 63

TABle $\quad 5-6$ 2SLS, Dependent VARIABle eXAM GRAde. . . . . . . . 64

TABle $5-7$ Robustness CHECKS, DEPENDENT VARIABlE EXAM GRADE. . . . . . . . . . . . . . . . 66

TABle $\quad 5-8$ Other measures of COMPetition. . . . . . . . . . . . 67

TABle $\quad 5-9$ Fixed effects estimates, eXAm GRAdE. . . . . . . . . 67

TABle $\quad 5-10 \quad$ Alternative outcome measures. . . . . . . . . . . . . 68

TABle $\quad 5-11$ Fixed efFeCts estimates, GRAde inflation. . . . . . . . 69

TABle 5-12 QR AND IVQR COEFFICIENTS, COMPETITION VARIABLE CATHOLIC SCHOOLS IN MUNICIPALITY. . . . . . 76

Table A5-1 Summary statistics, nOn-CATHOlic schools. . . . . . . 81

TABle A5-2 Summary Statistics, NOn ROMAn-CATHOliC SCHOOls. . . 81

TABle A5-3 First stage, additional instrument. . . . . . . . . . . 82

TABle A5-4 2SLS Central EXAM, ADD'L InSTRUMEnT . . . . . . . . . 82

Table $\quad 7-1 \quad$ Summary Statistics. . . . . . . . . . . . . . . 116

TABle 7-2 MeAn distance RAtio to NeAREST Media City. . . . . . . 117

TABle 7-3 RAW CORRELATIONS GRANTS/DistanCE, GRANTS/TV STATIONS. . . . . . . . . . . . . . 117

TABle $\quad 7-4$ MeAn gRANTS PER CAPITA. . . . . . . . . . . . . 117

TABle $\quad 7-5$ OlS estimates, media variable TV stations. . . . . . 119

TABle $\quad 7-6$ OLS ESTIMATES, MEDia VARIABLE DistanCE TO MEDIA CITY. . . . . . . . . . . . . . . . 120

Table $\quad 7-7$ OLS estimates, metro/micro sample. . . . . . . . . 121 
Table $\quad 7-8$ First stage, Dependent variable tv Stations. . . . . . 123

TABle $\quad 7-9$ 2SLS Estimates, DEPEndEnt VARIABle Grants PER CAPITA. . . . . . . . . . . . . . . . . 124

Table $\quad 7-10 \quad$ Spatial ML and GS2SLS estimations. . . . . . . . . . 125

TABle A7-1 Counties by number of full power TV stations. . . . 127

Table A7-2 OLS metro/Micro, media variable TV Stations. . . . . 128

TABle A7-3 OLS MEtro/Micro, MEdia VARiable Distance TO MEDIA CITY. . . . . . . . . . . . . . . 129

TABle A7-4 State CAPital SAMPle, DePEndent VARIABle GRANTS PER CAPITA. . . . . . . . . . . 130

Table A7-5 Sample excluding Medicaid. Dependent VARIABLE (LOG) GRANTS PER CAPITA. . . . . . . . . . 130

TABle $\quad 8-1$ Media ReACH in NorWAY. . . . . . . . . . . . . . . 143

TABle $\quad 8-2$ Summary Statistics. . . . . . . . . . . . . . . . . . . . . 149

TABle $\quad 8-3$ EFFECT OF REACH/CONTENT ON PUbliC SECTOR EFFICIENCY. . . . . . . . . . . . . . 154

TABle 8-4 EFFECT OF REACH/CONTENT ON PUbliC SECTOR PRODUCTION. . . . . . . . . . . . . 155

TABle $\quad 8-5$ Robustness Checks and 'Placebo' tests. . . . . . . . . 156

TABle $\quad 8-6 \quad$ CENTRAL MUnicipalities EXCluded. . . . . . . . . . . . . . 159

TABle $\quad 8-7 \quad$ LARGE MUNICIPALITIES EXCLUDED. . . . . . . . . . . 159

TABle $\quad 8-8$ CENTRAL MUNicipalities ABOVE 10,000 IN POPULATION EXCLUDED. . . . . . . . . . . . . . . . 160

TABle A8-1 Description of VARIABles. . . . . . . . . . . . . 165

TABle A8-2 NewsPAPERS BY ClASSIFICATION. . . . . . . . . . . 166 



\section{List of Abbreviations}

\begin{tabular}{|c|c|}
\hline 2SLS & Two Stage Least Squares \\
\hline $\mathrm{ABC}$ & AMERICAN BRoAdCASTING COMPANy \\
\hline $\mathrm{BB}$ & BASISBEROEPSGERICHTE LEERWEG \\
\hline CBS (A) & Centraal Bureau voor de Statistiek, through Chapter 5 \\
\hline \multirow[t]{2}{*}{ CBS (B) } & CBS Broadcasting InC. - FORMerly: Columbia \\
\hline & Broadcasting System, From Chapter 6 \\
\hline $\mathrm{EVO}$ & Centrale Examencommissie Vaststelling Opgaven \\
\hline CFFR & Consolidated Federal Funds Report \\
\hline CITO & Centraal Instituut voor Toetsontwikkeling \\
\hline $\mathrm{CPB}$ & Corporation for Public Broadcasting \\
\hline CUMI & Culturele Minderheden \\
\hline DMA & Designated Market Area \\
\hline FCC & FEDERAL COMmunications COMmission \\
\hline FE & FIXED EFFECTS \\
\hline FERA & FEDERAl EMERGEnCy Relief Administration \\
\hline FOX & Fox Broadcasting COMPANy \\
\hline $\mathrm{L}$ & Gemengde LEERWEG \\
\hline GS2SLS & Generalized Spatial Two Stage Least Squares \\
\hline $\mathrm{HAVO}$ & Hoger Algemeen Voortgezet OnderwiJs \\
\hline $\mathrm{HBO}$ & Higher Professional Education \\
\hline \multirow[t]{2}{*}{ ICPSR } & Interuniversity CONSORTIUM FOR POLITICAL \\
\hline & AND Social ReSEARCH \\
\hline IV & INSTRUMENTAL VARIABLE \\
\hline \multirow[t]{2}{*}{ IVQR } & InSTRUMENTAL VARIABLE QUANTILE REGRESSION OR \\
\hline & InVERSE QUANTILE REGRESSION \\
\hline KASKI & KATHOLIEK SOCIAAL-KERKELIJK INSITUUT \\
\hline $\mathrm{KB}$ & KADERBEROEPSGERICHTE LEERWEG \\
\hline LLA & LANDSLAGET FOR LOKALAVISER \\
\hline MAVO & MiddelbaAR Algemeen Voortgezet OnderWiJs \\
\hline MBL & MEDIEBEDRIFTENES LANDSFORENING \\
\hline $\mathrm{BC}$ & NATIONAL BROADCASTING COMPANY \\
\hline SD & Norsk Samfunnsvitenskapelig Datatjeneste \\
\hline
\end{tabular}


OCW Ministerie van Onderwijs, Cultuur en Wetenschappen

OECD Organisation for EConomic Cooperation and Development

OIC ONDERWIJS IN CIJFERS

OlS ORdinary Least Squares

PBS Public Broadcasting Service

Pisa Programme for International Student Assessment

QR Quantile Regression

RE RANDOM EFFECTS

SaT Scholastic Aptitude Test

SCP Sociaal en Cultureel Planbureau

timss Trends in International Mathematics and Science Study

TL Theoretische LEERWEG

TS TegemoetKoming Studiekosten

UTD University of TEXas at Dallas

VBO VOORBEREIDEND BEROEPSONDERWIJS

VMBO VoORBEREIDENd MiddelbaAr BeroepsonderWiJs

VMBO-BK VMBO, Basisberoepsgerichte LeERWeg (BB) AND

KADERBEROEPSGerichte LeERWEG (KB)

VMBO-GT VmbO, Gemengde Leerweg (GL) And

Theoretische LeERWeg (TL)

VO VOORTGEZET ONDERWIJS

VWO VOORBEREIDEND WetenschappeliJK OnderWiJs 



\section{CHAPTER 1}

\section{About this book}

Education and the media are two important aspects of everyday life. Everyone has an opinion on them, because almost everyone has had at least some education and virtually everyone uses mass media to some extent. This book analyzes the incentives that various institutions in media and education markets create for economic agents.

There is no arguing, be it among economists or in the general public, that education is important. At the macro level, for most countries the accumulation of human capital is imperative as they have little natural resources to rely on. Of course, education is essential at the individual level, too. When it comes to wages, the positive returns to education are well documented. Education is also the crucial factor in creating social mobility, and so everyone agrees that having a good education system is desirable. Despite this broad consensus, it is often overlooked that measures to improve an education system need not be very costly. A few tweaks in the institutional setup may go a long way in generating incentives that lead to superior educational outcomes. Central exit examinations and school choice - which is is still hotly debated in economics - are two such institutions that often fail to attract due attention in the general public. Both play a major role in the following chapters: the central exam as a benchmark against which local grading standards are measured and school choice as an appealing policy of improving educational achievement.

Things are somewhat different with media use. Considering that almost everyone consumes mass media on a daily basis in one form or the other, surprisingly little research has 
been done by economists on the effects this has on public policy. Even though ever since Lazarsfeld, Berelson and Gaudet (1944) political scientists have investigated whether the media matters for politics, their approach has traditionally centered on how the media shapes opinions, beliefs and voting behavior - neglecting quite intriguing questions that spring to mind: Does reading the newspaper or even switching on the television have an impact on public policies? Does the increasing use of mass media create incentives for politicians to act in a certain way? It has taken political economy quite a while to pick up on the issue and show that for the media to have an impact on public policy, it may not be necessary to change people's opinions on issues but rather it might suffice that the consumers simply receive political information. Accordingly, two chapters in this book are devoted to showing that there actually are incentives for politicians to gear their actions towards informed voters and that a more informed electorate leads to better politics.

So above all, this book is about incentives. Of course just about any economics book is. They are what shapes the behavior of economic agents and they enable us to predict how people will act. The book is also about institutions because it would be pointless to talk about incentives without considering the institutions that create them. In the end this means that understanding what drives behavior can only be accomplished by acknowledging and investigating the role of institutions.

The chapters in this book also share common ground in other ways that may not be so obvious at first glance. One important link is that aside from engaging in research questions that are interesting in their own right, all outcomes considered in this book are deeply rooted in public economics. This is obvious in chapter 7 , which deals with the impact of media activity on the distribution of public spending across local jurisdictions. The same goes for chapter 8 , where the effect of newspaper readership on the efficiency of local governments is examined. The public economics dimension is also quite evident in the first half of the book, as education is a major task of local governments in most countries, with a large portion of public spending devoted to it. In addition, the setting of educational standards is indivisibly connected to a central issue in fiscal and regulatory federalism: the question of which level of government decision-making should be allocated to. Whether there should be decentralized decisions, i.e. competition of standards or whether a central standard would prove to be superior is not quite the point in chapter 3 , yet it does deal with the effects of social composition of a school on standards under a regime of decentralized standard setting. Competition for students among educational institutions, 
which is considered in chapter 5 , is closely related to the literature on the competition of local jurisdictions that started with Tiebout (1956). The Dutch setup considered in this book, however, resembles a voucher scheme more than it does a classic Tiebout setup where choice works through the migration of voter-taxpayers to another school district. In both the educational standards and school competition case, the individual decisionmakers (schools) are not a typical federal unit. They are, however, the smallest logical unit that a federation can assign standard setting and autonomy on education policies to.

Another fascinating feature is that there is a distinct spatial or geographical aspect to all the issues considered. In the case of school competition and the effect of media on grant spending, proximity is an important factor. Whereas in the school choice example the number of schools on offer within close range determines school quality, in chapter 7 the proximity of a county to the nearest television station has an effect on the amount of government grants the county is awarded. In chapter 8, a better geographical fit of newspaper markets and local jurisdictions turns out to lead to higher government efficiency. The geographical aspect is a bit more subtle in chapter 3, yet it is one of the results that grade inflation should increase with the geographical size of the labor market that the school's graduates are bound for.

The literature reviews and introductory remarks concerning the media and education matters covered in the book are relegated to stand-alone chapters. These short chapters are placed right ahead of the respective main parts of the book, thus affording a more coherent read. Chapter 2 provides an introduction to educational standards, a general overview on school choice is given in chapter 4 and the two studies concerned with the effects of mass media on local policies share the common introductory chapter 6 . Since all are at heart topics in local public economics, the issues contemplated in this book also share a common literature on local public economics. To provide a survey of this vast and very diverse field of economics is, however, way beyond the scope of this book and the reader is referred to Wildasin (1987) and Helsley (2004) as a starting point. 


\section{Summary of Results}

A quick rundown of the structure of this book is given here. The chapters summarized here are interspersed with the above mentioned introductory sections.

Chapter 3 presents a model of decentralized graduation standards. Lower graduating standards are shown to be applied in schools whose students are disadvantaged on the labor market. The reason is that such students have less incentives to graduate. Empirically, this is tested using Dutch school-level data. Since students in the Netherlands have to participate both in a central and in a school specific examination, it is possible to identify the grading policy of individual schools. Lower graduating standards are set by schools with greater shares of disadvantaged students. The effect is largest in the university-preparatory branch of secondary education.

The focus is still on institutions in secondary education in chapter 5, which exploits the fact that Dutch students enjoy nationwide school choice. In combination with fixed perstudent governmental funding this provides incentives for schools to perform well. In this empirical investigation, we find a positive link between competition intensity and academic achievement in pre-university education. Since roughly one third of pre-university schools are of catholic denomination, we consider the effect of catholic competition on noncatholic school performance. In addition to raising academic achievement, higher levels of competition do not precipitate the deterioration of grading standards but rather exert a restraining effect on grade inflation. Finally, there is no evidence of schools at the bottom of the achievement distribution being hurt by competition.

Moving on to a political economy approach to local public policies, a simple model in chapter 7 explains the allocation of public spending across jurisdictions contingent on media activity. Incentives to spend more money where media coverage is higher arise from the fact that incumbents seeking reelection need voters to know what they have done for them. Maximizing the probability of reelection will shift more money to jurisdictions where an extra dollar gains more votes because a larger share of the electorate is informed about the incumbents policies. This prediction is supported by US data on county-level public spending and local media markets, where media activity is approximated by the proximity of licensed television stations. 
The efficient use of public funds by elected agents is an issue that matters to voters and is studied in chapter 8 . In order to establish accountability, they are in need of information. This information can be provided by newspapers as we show in an agency model with imperfect monitoring and it is shown that an informed electorate is more likely to hold an incumbent accountable. Panel data from Norwegian municipalities show that increases in local newspaper circulation are associated with higher levels of local government efficiency as measured by an index introduced by the Norwegian authorities. 



\section{CHAPTER 2}

\section{Institutions in Education (I) - Standards}

This section and the following chapter 3 deal with the first of two educational policies or institutions that are at the core of the first half of this book: educational standards and school choice. While school choice will be thoroughly examined in chapters 4 and 5 , the aim of this brief introduction and literature survey is to (i) give an idea as to why educational standards are an important tool when it comes to improving student performance and school quality in general, and (ii) to point out that not only does the effect of standards on achievement matter, but in addition it is important to gain an understanding of what drives the setting of standards.

The policy instrument of grading standards can be decided on either at the central or decentral level. Upon cursory examination one might be inclined to view decentralized standard setting as desirable in a sense that e.g. the individual school is best fit to decide which standard is best suited given the specific circumstances it operates under. There is, however, a broad consensus in the economics of education that the setting of standards should not be entirely up to teachers or individual schools. Allocating the decisions on standards to these levels would not take into account the incentives faced by teacher as well as students who are not confronted with external exams at the end of their school career. Specifically, both teachers and students are interested in attaining or awarding a degree with the least effort possible and may thus, according to Juerges, Richter and Schneider (2005), "tacitly" agree to form a "low-achievement cartel". The setting of grading or educational standards is not an issue that is directly linked to public spending or revenue, yet because standards may be set at different federal levels, it is in essence an 
issue of regulatory federalism. ${ }^{1}$ As in fiscal federalism, there is a broad consensus that the optimal allocation of responsibilities to the various levels of government should be based on congruence. i.e. those being affected by a policy should be the ones that decide on the terms of its (non-)implementation. At first glance, a grading standard affects only the group to which it is applied. This is true only if everyone in the population is subjected to the exact same standard, i.e. in the case of centralization. Whenever there are subgroups that apply differing educational standards, a lower standard for attaining a degree in one group may lead to a devaluation of the degrees awarded in other groups, and hence warrant shifting the decisions on educational standards to the central level. ${ }^{2}$

The effects of grading standards have been the subject of many studies, with a majority of the research taking an empirical approach to the issue. It has been well established by this strand of research that central standard setting in education paired with centrally devised and graded examinations leads to higher achievement in standardized tests. Crosscountry studies typically make use of the large datasets that have been accumulated in the course of various waves of the Trends in International Mathematics and Science Study (TIMSS) as well as the Programme for International Student Assessment (PISA). The unanimous approach here is to compare the outcomes in countries that conduct central exit examinations with countries that rely on decentralized grading standards. The notion that central examinations lead to higher achievement is backed by Bishop (1997, 1999), Jürges, Schneider and Büchel (2005) as well as Wößmann (2003a, 2003b). While all of the just mentioned works are based on the TIMSS data, Fuchs and Wößmann (2004) as well as Jürges, Richter and Schneider (2005) reach the same conclusion of beneficial central standards when PISA data is employed.

Possibly somewhat less problematic and less prone to criticism than cross-country research are those papers making use of United States microdata. The main question asked in this strand of research is the same as above, i.e. whether higher educational standards can

\footnotetext{
${ }^{1}$ In a way then, individual schools may be viewed as a "federal level", even though they are not jurisdictions in a conventional sense. Another example for regulatory federalism is the setting of environmental standards (Oates and Portney, 2001).

${ }^{2}$ Wößmann (2003b) even goes so far as to draw an analogy between central banks and a central institution that monitors grading standards. Similar to a central bank which is mainly concerned with ensuring monetary stability in order to prevent a devaluation of the currency, the value of attainable educational degrees needs to be monitored.
} 
induce higher student achievement. As Betts and Costrell (2001) show in their survey, the empirical evidence based on microdata also supports this notion. Betts (1998b) provides evidence that tying consequences - such as being forced to repeat a grade - to the failure to meet standards increases student performance. Raising the stakes may also lead to superior teacher performance: Jacob (2005) provides evidence that holding teachers accountable for students' performance in standardized tests increased student achievement. Work by Betts and Grogger (2003), and Figlio and Lucas (2004) concludes that tougher grading by individual schools or teachers leads to an improvement in standardized test performance. Bishop and Mane (2004) find a strong positive effect of central exams on the graduation rate of a cohort. They also state that central examinations do not widen the gap between students of high social status and those hailing from lower social classes. There are also some purely theoretical papers that model the impact of standards on educational achievement (Iyigun 1999, and Oettinger 2002).

Chapter 3 is the first of two major parts in this book that are concerned with educational policies and institutions. While it contributes - in a very general sense - to the broad literature in education economics which analyzes the effects of the social composition of schools (see, for example, Epple and Romano, 1998, Nechyba, 1999, Epple, Newlon and Romano, 2002, and Hanushek, 2002: 2078-2081), it is specifically related to the above described branch of economics analyzing examination standards. As has been laid out above, most of the research is concerned with the impact of different institutional arrangements for testing and examining students on students' achievement. We will not go down that road but rather attempt to answer a question that has been asked much more infrequently: How are standards set and why? In particular, we ask whether the social composition of a school's student body influences the setting of standards. To this end, a theoretical model is presented that suggests higher shares of students from the lower social class lead to lower school-level grading standards. This prediction is put to the test empirically and supported by Dutch school-level data. We use a central test as a benchmark against which local grading is measured in order to determine the local grading standard.

The theory in the following section is related to a very thin theoretical literature on the actual determinants of educational standards: Brunello and Rocco (2008) show that contrary to popular belief - private schools may set lower standards than public schools in an attempt to attract low-ability students with a high willingness to pay for the attainment of a degree. The basic theoretical approach followed in chapter 3 has been advanced 
by Betts (1998a) and Costrell (1994, 1997). More recently, Chan, Li and Suen (2007) have endogenized pooling across several types of schools in a signalling model of grading standards. None of these papers addresses the role of social class for the determination of standards, which is a major issue in the latest PISA report on student achievement in the OECD. According to Prenzel at al. (2005: 24), children from lower social classes in Germany are much less likely to attend the branch of secondary schooling preparing for university than those from higher classes. Since this allegedly holds even if one controls for the individual student's intelligence, the result suggests that the grading and examination system discriminates against disadvantaged students, i.e. applies higher standards to students of lower social origin. As will become clear in the course of the following pages, this is diametrically opposite to our findings, which are indicative of a lower class student body inducing a deterioration in standards. Given the different sort of data and the different, rather descriptive approach that Prenzel et al. (2005) use - it is, however, difficult to discern the origin of these diverging conclusions.

Theoretical work on the setting of standards is rare, yet empirical papers concerned with this question are even more scant. Wikström and Wikström (2005) analyze the determinants of grading standards in Sweden. Their approach is similar to ours since it also uses a central test as a benchmark against which local grading is measured. Still, the Dutch central examination is possibly more attractive as a benchmark since it is compulsory thus avoiding self-selection issues - and since its grades are measured on the same scale as the score of the local examination. Moreover, Wikström and Wikström focus on variables which differ across municipalities such as the intensity of competition among schools, whereas we directly address differences in the characteristics of the schools' student populations. 



\section{CHAPTER 3}

\section{Disadvantaged Students and the Setting of Local Educational Standards}

Education policy is widely seen as a means to promote social policy goals. Good schooling is supposed to help the children of disfavored members of society to earn higher incomes than their parents and to gain social status. In most countries, however, students do not reap the benefits of formal education just by attending. Instead, they need to obtain the appropriate degree, preferably with good grades. Therefore, any social impact of education policy is filtered through the grading and examination system. Whether good schools will contribute much to social mobility depends on the way standards are chosen, and whether this choice depends on the social origin of students. In this chapter, we therefore examine, both theoretically and empirically, the interaction of the social status of a school's students and the standards applied at examination.

In the first part of the chapter we introduce status into a model of the choice of examination standard provided by Costrell $(1994,1997)$. In this model, each school sets its graduation standard so as to maximize the sum of the wages earned by its students. This decision is governed by the trade-off between the number of graduates, which decreases if the standard is more demanding, and the wage earned by each graduate, which increases in the standard. We extend Costrell's formulation by assuming that, in addition to the standard, also the social origin affects the wage earned by graduates. For a given standard, students from disadvantaged backgrounds obtain a lower wage than students from other social classes. We show that in this setup, schools with a disadvantaged student body set lower standards 
than other schools, even if the abilities of the disfavored students are identical to those of others. Standards are inflated in this way because the wage discount experienced by graduates from unfavorable backgrounds depresses the return to learning effort for these students. They are thus less willing to satisfy any given standard than students from average social origins. To make up for the resulting loss in the numbers of graduates schools with disadvantaged students choose less demanding standards.

If the standard applied by a single school is not observable by employers, the graduates from several schools are pooled together in a common labor market, earning the same wage. We show that in such a scenario the equilibrium standard is decreasing in the size of the relevant labor market, that is, the number of schools whose graduates are pooled together. Our model thus confirms the well-known grading externality induced by locally determined but unobservable standards: Schools have an incentive to free-ride on high wages brought about by the other schools' tough grading. This mechanism has an implication for social policy, which is our focus here. It is plausible that the students from different social backgrounds are not equally mobile when applying for jobs. Specifically, it may be that disadvantaged students on average stay closer to their original residence. We show that, if this is true, the externality will be smaller in the case of disadvantaged schools, counteracting the tendency to set lower standards induced by unequal job prospects.

In the second part of the chapter, we test the theoretical model using data from the Netherlands. This choice of subject is motivated by several features of the Dutch education system. Most importantly, students must pass central exams as well as school specific exams in order to receive a diploma. The average grades obtained by the final class in both examinations in each subject are published annually for all schools in the Netherlands in the so-called Kwaliteitskaarten (quality cards). Thus, we are able to use the grades earned in the central examination as a benchmark against which to measure standards employed by individual schools in the school specific examination. In addition, secondary education in the Netherlands is organized in several branches directed towards different further careers, from pre-university education to practical vocational training. This allows us to differentiate our analysis of grading standards according to different labor markets targeted by the different branches.

The empirical analysis aims at explaining differences in standards chosen by different schools. To do this, we use the difference between the average grade of the school specific 
and the central examination as the dependent variable. The key explanatory variables are two proxies for the social status of a school's students, the percentage of cultural minority students and the percentage of students eligible for financial aid. It turns out that these variables in most specifications indeed have a significant positive impact on the grade difference. Thus, the empirical analysis generally backs the main prediction of the theoretical model: Schools with a higher percentage of disadvantaged students use a more lenient grading scheme than other schools. The effect is largest for the school branch which leads to university, smaller but still significant for the branches of intermediate academic level, and insignificant in the case of the most practically oriented branch. Since it is plausible that graduates are the more mobile the higher the academic level achieved, we take these results as an, albeit weak, evidence for the importance of a school's market size on the grading standard applied.

The remainder of the chapter on educational standards is organized as follows. The following two sections contain the theoretical analysis. The model is presented in section 3.1 and the optimal standards are derived in section 3.2. In section 3.3 we give a brief overview of the institutional setup of the Dutch education system, describe the data, and present the estimation approach. Section 3.4 then contains the results of the empirical analysis. The concluding section 3.5 discusses policy implications and possible future lines of research.

\subsection{The Model}

In our model, schools set graduation standards which determine wages, and students choose how much learning effort to expand. Students have identical preferences over the wage $w \geq 0$ they will receive after leaving school and the learning effort $e \geq 0$ they expand at school. The learning effort is meant to reflect not only time spent in school or doing homework but also, and possibly more importantly, the intensity of unpleasant schoolrelated activities such as paying attention to the teacher, behaving well in class, thinking hard, etc. The utility function is quasilinear and given by $u(w, e)=w-c(e)$. The function $c(e)=e^{\eta}$ describes the cost of learning effort, with a constant elasticity $\eta>1$.

Students differ in their ability to transform effort into examination results, as expressed by a student's learning productivity $\gamma$. At all schools, $\gamma$ is distributed according to a 
uniform distribution over the interval $[0, \bar{\gamma}]$, with density $f=1 / \bar{\gamma}$ and c.d.f. $F(\gamma)=f \gamma$ for $0 \leq \gamma \leq \bar{\gamma}$. The performance of a student at the examination is $\gamma e$, and the standard set by the school is denoted by $s \geq 0$. A student with learning productivity $\gamma$ who expands effort $e$ graduates if and only if $\gamma e \geq s$.

Employers only observe whether a student graduates or not, whereas the actual examination performance $\gamma e$, the learning productivity $\gamma$, and the effort $e$ are private information of the student. By consequence, wages for graduates and non-graduates may differ, but wages cannot be conditioned on $\gamma, e$, or $\gamma e$. In such a situation there is no reward to a student for exceeding the standard required for graduation. By consequence, a student with learning productivity $\gamma$ will either expand just enough effort to satisfy the standard, $e=s / \gamma$, or he will dispense no effort at all, $e=0$, and fail at the examination.

The wage $w_{o}$ received by non-graduates is normalized to zero. Denoting by $\tilde{w}$ the wage which a graduate from a given school may expect in the labor market, for a student of this school graduation is worthwhile if $\tilde{w}-c(s / \gamma) \geq w_{o}-c(0)=0$. For any standard $s$ and expected wage $\tilde{w}$, the graduation threshold $\gamma(s, \tilde{w})$ is defined to be the solution $\gamma$ to the equation

$$
\tilde{w}-c\left(\frac{s}{\gamma}\right)=0
$$

All students whose learning productivity is at least as high as the graduation threshold, $\gamma \geq \gamma(s, \tilde{w})$, will graduate, and all those with $\gamma<\gamma(s, \tilde{w})$ will not. For $0 \leq \gamma(s, \tilde{w}) \leq \bar{\gamma}$, the number of graduates from this school is then $1-F(\gamma(s, \tilde{w}))=1-f \gamma(s, \tilde{w})$. From (1) and the identity $\tilde{w}=c(s / \gamma(s, \tilde{w}))$, we find the elasticities

$$
\begin{aligned}
& \frac{\partial \gamma(s, \tilde{w})}{\partial s} \frac{s}{\gamma(s, \tilde{w})}=1 \\
& \frac{\partial \gamma(s, \tilde{w})}{\partial \tilde{w}} \frac{\tilde{w}}{\gamma(s, \tilde{w})}=-\frac{\gamma(s, \tilde{w}) c(s / \gamma(s, \tilde{w}))}{s c^{\prime}(s / \gamma(s, \tilde{w}))}=-\frac{1}{\eta}>-1 .
\end{aligned}
$$

That is, the graduation threshold rises proportionately with the standard, and decreases less than proportionately if the expected graduate wage increases.

Each school has an equal number of students, normalized to unity. There are two sets of schools $C=L, H$, where we denote also the numbers of the schools in both sets by $L$ and $H$. The set $L(H)$ contains schools with a student body originating from a disadvantaged 
(favored) social background. As a convenient, if over-simplifying, label we call the former the "lower-class schools" and the latter the "higher-class schools". For example, such social segregation in schools may be the result of Tiebout sorting in the local property market combined with substantial costs of commuting to schools located far away from the student's residence. The sets $L$ and $H$ are interpreted as containing all schools with a given social background which supply graduates to the same regional labor market. As an interesting and plausible case, we specifically consider the possibility that lower class workers are less mobile than higher class workers. Then the relevant labor market is smaller for lower class schools than for higher class schools, i.e., $L<H$.

Conditional on the standard $s_{i}$ required by a school $i \in C, C=L, H$, employers' willingness to pay for a graduate from school $i$ is $\lambda_{C} s_{i}$. This formulation expresses the idea that the examination performance $s_{i}$ determines productivity at work, which for simplicity is measured in the same units. Moreover, social origin affects the wages according to the parameters $\lambda_{C}$, where we assume $0<\lambda_{L} \leq \lambda_{H}=1$. That is, the wage paid to graduates from lower class schools is lower by the exogenous factor $\lambda_{L} \leq 1$. This parameter may reflect properties of disadvantaged students which are relevant for their productivity at the workplace but not tested in the examination, for example good manners, rhetorical abilities, stable families, belonging to social networks, or all sorts of "soft skills". As an alternative interpretation, $\lambda_{L}$ might be identified with outright discrimination against disadvantaged workers in the sense that they are being paid less than workers from favorable origins in spite of identical productivity. ${ }^{3}$

There might be other reasons why social origin could be relevant for schooling outcomes. Specifically, disadvantaged students might enter school with an inherently lower ability, or might be less willing to exert effort so as to succeed in school. While it would be easy to integrate such differences in the model ${ }^{4}$ we focus on labor market prospects so as to emphasize that class specific standards need not be the consequence of lower ability or a

\footnotetext{
${ }^{3}$ Discrimination is difficult to rationalize when firms maximize profits. Since we do not explicitly describe firms' hiring choices, our model does not rule it out, however. Kee (1995) and Zorlu (2002) present empirical evidence that wage discrimination against ethnic minorities is present in the Netherlands, van Ours and Veenman (2002) find that second generation immigrants in the Netherlands are less likely to be employed, conditional on education.

${ }^{4}$ These variants could be modeled by compressing the ability distribution, and by inflating the effort cost function, for lower class schools by factors analogous to $\lambda_{L}$. From (1), it is clear that these modifications affect the learning decision of lower class students essentially in the same way as a depressed wage.
} 
lack of willingness to learn on the part of the lower class students.

Employers do not observe the standard $s_{i}$ required by an individual school but they observe the social origin of the school's students. Such an informational scenario will occur, for example, if the residences of disadvantaged students are clustered in space so that the location of a school contains information about the social background of the school's students. In the same time, it may be too costly for firms to monitor the grading standards of individual schools. Consequently, wages may differ between higher-class and lower-class schools but not according to the graduation standards of the individuals schools.

Denoting, for the schools $i \in C$, by $s_{i}$ the standards set by these schools and by $\tilde{w}_{i}$ the wages expected for their graduates, the wage paid to graduates from any school $i \in C, C=L, H$, is given by

$$
w_{C}=\sum_{i \in C} \lambda_{C} s_{i} \frac{1-F\left(\gamma\left(s_{i}, \tilde{w}_{i}\right)\right)}{\sum_{j \in C}\left[1-F\left(\gamma\left(s_{j}, \tilde{w}_{j}\right)\right)\right]} .
$$

That is, the wage is given by a weighted average of the wages which would, under full information, be paid to the graduates from the schools in the relevant labor market, where the weights are given by the shares of the individual schools in the total number of graduates. In an equilibrium the wage is correctly anticipated by students when they choose their effort levels. Thus, for any vector of standards $\left(s_{i}\right)_{i \in C}$, an equilibrium wage is a fixed point of (4) satisfying $w_{C}=\tilde{w}_{i}$, for all $i \in C$. Since for all expected wages $\left(\tilde{w}_{i}\right)_{i \in C}$, the right hand side of (4) is just a weighted average of the values $\lambda_{C} s_{i}$ for all schools, for all vectors of standards such a fixed point exists in the interval $\left[\lambda_{C} \min _{i \in C}\left\{s_{i}\right\}, \lambda_{C} \max _{i \in C}\left\{s_{i}\right\}\right]$.

To see how a school's choice of standard affects the equilibrium wage in class $C=L, H$, insert $w_{C}=\tilde{w}_{i}$ for all $i \in C$ in (4) so as to find

$$
\sum_{i \in C}\left[w_{C}-\lambda_{C} s_{i}\right]\left[1-F\left(\gamma\left(s_{i}, w_{C}\right)\right)\right]=0
$$

Differentiating the equilibrium condition (5) implicitly, one obtains

$$
\frac{\mathrm{d} w_{C}}{\mathrm{~d} s_{i}}=-\frac{f\left[\lambda_{C} s_{i}-w_{C}\right] \frac{\partial \gamma\left(s_{i}, w_{C}\right)}{\partial s}-\lambda_{C}\left[1-F\left(\gamma\left(s_{i}, w_{C}\right)\right)\right]}{\sum_{j \in C}\left[1-F\left(\gamma\left(s_{j}, w_{C}\right)\right)\right]+f \sum_{j \in C}\left[\lambda_{C} s_{j}-w_{C}\right] \frac{\partial \gamma\left(s_{j}, w_{C}\right)}{\partial \tilde{w}}} .
$$


In the following, we focus specifically on symmetric situations where all schools $i, j \in C$ of one class choose identical standards $s_{i}=s_{j}=s_{C}$, implying an identical graduation threshold $\gamma_{C}=\gamma\left(s_{C}, w_{C}\right)$. Then the equilibrium wage is uniquely determined and equal to $w_{C}=\lambda_{C} s_{C}$ for all schools in $C$. Moreover, starting from symmetric standards, the comparative static equation (6) reduces to $\mathrm{d} w_{C} / \mathrm{d} s_{i}=\lambda_{C} / C$. This equation will be used in the analysis of the standards set by schools, to which we now turn.

\subsection{Optimal Standards}

We assume that each school maximizes the sum of the wages earned by its students. Schools thus care for their students, without however taking effort costs into account. ${ }^{5}$ When deciding about the standards they require for graduation, schools anticipate the optimal choices by students and the equilibrium wage. If school $i \in C$ sets standard $s_{i}$, it thus expects that the wage for graduates from class $C$ will be $w_{C}$ according to (5), taking the standards $\left(s_{j}\right)_{j \in C, j \neq i}$ chosen by all other schools in the market as given. School $i$ 's maximization problem can thus be stated as

$$
\max _{s_{i} \geq 0} \quad W_{i}\left(s_{i}\right)=F\left(\gamma\left(s_{i}, w_{C}\right)\right) w_{o}+\left[1-F\left(\gamma\left(s_{i}, w_{C}\right)\right)\right] w_{C}
$$

With $w_{o}=0$ we obtain the necessary condition for an interior solution:

$$
\frac{\partial W_{i}}{\partial s_{i}}=-f w_{C}\left[\frac{\partial \gamma\left(s_{i}, w_{C}\right)}{\partial s}+\frac{\partial \gamma\left(s_{i}, w_{C}\right)}{\partial \tilde{w}} \frac{\mathrm{d} w_{C}}{\mathrm{~d} s_{i}}\right]+\left[1-F\left(\gamma\left(s_{i}, w_{C}\right)\right)\right] \frac{\mathrm{d} w_{C}}{\mathrm{~d} s_{i}}=0
$$

Condition (7) shows the trade-off faced by a school. On the one hand, as expressed by the first term in square brackets in (7), a more demanding standard decreases welfare by reducing the number of graduates. On the other hand, a higher standard raises the wage for graduates. This enhances welfare both directly, as measured by the last term in (7), and indirectly by increasing the number of graduates. This effect, which is formalized by the second term in the square brackets in (7), counteracts the decline in the graduation rate triggered by the higher standard.

\footnotetext{
${ }^{5}$ This omission reflects current debates in education policy which do not seem to be very concerned about students enjoying insufficient leisure.
} 
In order to characterize the equilibrium, we write $\gamma_{i}=\gamma\left(s_{i}, w_{C}\right)$ and use (2), (3), and $F\left(\gamma_{i}\right)=\gamma_{i} / \bar{\gamma}$ so as to restate $(7)$ as

$$
\frac{\partial W_{i}}{\partial s_{i}}=-\frac{\gamma_{i} w_{C}}{\bar{\gamma} s_{i}}+\frac{\mathrm{d} w_{C}}{\mathrm{~d} s_{i}}\left[1-\frac{\gamma_{i}}{\bar{\gamma}}\left(1-\frac{1}{\eta}\right)\right]=0
$$

By inserting $s_{i}=s_{C}, \gamma_{i}=\gamma_{C}, w_{C}=\lambda_{C} s_{C}$ and $\mathrm{d} w_{C} / \mathrm{d} s_{i}=\lambda_{C} / C$ in (8), ${ }^{6}$ we find the graduation threshold and, implicitly, the standard in a symmetric equilibrium:

$$
\gamma_{C}^{*}=\frac{\bar{\gamma}}{C+1-(1 / \eta)} \quad \text { and } \quad \lambda_{C} s_{C}^{*}-c\left(\frac{s_{C}^{*}}{\gamma_{C}^{*}}\right)=0 \quad \text { for } C=L, H .
$$

In (9), the limiting case $C=1$ represents a market consisting of only one school. Since in this special case each school effectively determines its own graduate wage, this is equivalent to a scenario where the employers have full information about the standards applied by each individual school.

From the first equation in (9) we note that $H>L$ implies $\gamma_{H}^{*}<\gamma_{L}^{*}$. Thus, if the market for graduates from higher class schools is larger than the market for disadvantaged graduates, then the graduation rate will be larger among the higher class students than among the lower class students. Higher graduation rates among better off students therefore need not be the result of superior abilities. Quite the contrary, a higher learning productivity $\bar{\gamma}$ will raise the graduation threshold $\gamma_{H}^{*}$ and hence reduce graduation rates.

In order to obtain comparative static results for the equilibrium standard, we differentiate the second equation in (9), observing that $\gamma_{C}^{*}$ depends on $\bar{\gamma}$ as given in the first equation in (9). Using $c\left(s_{C}^{*} / \gamma_{C}^{*}\right)=\left(s_{C}^{*} / \gamma_{C}^{*}\right)^{\eta}=\lambda_{C} s_{C}^{*}$ we arrive at:

$$
\frac{\mathrm{d} s_{C}^{*}}{\mathrm{~d} \lambda_{C}}=\frac{s_{C}^{*}}{\lambda_{C}(\eta-1)}>0 \quad \text { and } \quad \frac{\mathrm{d} s_{C}^{*}}{\mathrm{~d} \bar{\gamma}}=\frac{\eta s_{C}^{*}}{\bar{\gamma}(\eta-1)}>0 \quad \text { for } C=L, H
$$

Specifically, for the grading policy of lower class schools this implies:

Proposition 1 The larger the wage discount for graduates from disadvantaged social backgrounds, and the lower the learning productivity of such students, the lower is the standard chosen by a school with students from lower social classes.

\footnotetext{
${ }^{6}$ In the appendix it is shown that at a symmetric solution to (8), the second order condition for a maximum is satisfied.
} 
This result shows that a school which cares about the incomes of their students will grade more leniently if its students are socially disadvantaged. As one may expect, such behavior may simply be the consequence of lower abilities on the part of students from lower social classes. Proposition 1, however, shows that more lenient grading may just as well be the rational reaction of a school to the unfavorable job prospects of its graduates.

Figure 3-1 illustrates the students' choices of learning effort in the full information case $L=H=1$. The steeper (flatter) straight line gives the wage obtained by graduates of the higher (lower) class school as a function of the standard. The convex curves describe the effort cost for students of various learning productivities. As the learning productivity increases from $\gamma_{o}$ towards $\gamma_{1}$, these curves bend downwards. The maximal standard a student is willing to satisfy is determined by the intersection of the class-specific wage line with the effort cost curve corresponding to the student's learning productivity. A student with learning productivity $\gamma^{*}$ will graduate ${ }^{7}$ if the standard does not exceed the value $s_{C}^{*}$ derived by the intersection of $c\left(s, \gamma^{*}\right)$ and the wage line corresponding to his social origin, $w_{L}$ or $w_{H}$. As a consequence of the lower wage, this standard must be lower for a lower class student.

As a next result, we find from (9):

$$
\frac{\mathrm{d} s_{C}^{*}}{\mathrm{~d} C}=\frac{\eta s_{C}^{*}}{(1-\eta)[C+1-(1 / \eta)]}<0 .
$$

Proposition 2 A smaller market size $C$ raises the standard $s_{C}^{*}$.

This result illustrates the well-known grading externality among schools sharing a common labor market. If a lower class school $i \in L$ marginally lowers its standard the willingness to pay for a graduate from this school decreases by $\lambda_{L}$. Since school $i$ has only weight $1 / L$ in the group of lower class schools this translates only into a wage decrease of $\lambda_{L} / L$. Schools therefore have an incentive to free ride on the high wages brought about by the tough standards of other schools, by grading leniently themselves. The result is a general devaluation of standards which is the more pronounced the larger the market is.

\footnotetext{
${ }^{7}$ Note that from (9), the graduation thresholds are equal, $\gamma_{L}^{*}=\gamma_{H}^{*}=\gamma^{*}$, if $L=H$.
} 


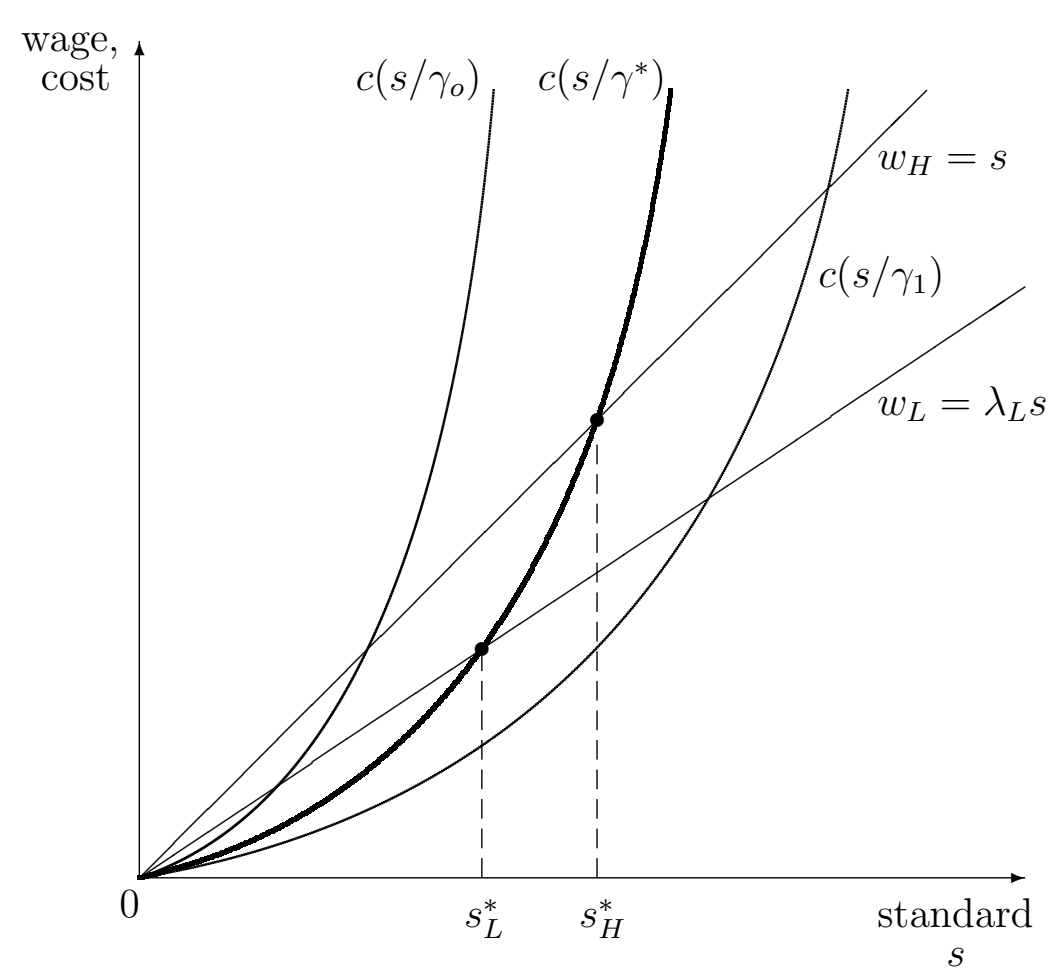

Figure 3-1: GRAdUATION STANDARDS AND GRADUATION THRESHOLD OF SCHOOLS WITH STUDENTS FROM DIFFERENT SOCIAL BACKGROUNDS.

As a consequence of Proposition 2, one conjectures that the equilibrium standard of lower class schools may be tougher than the one required by higher class schools if the market size for lower class graduates is sufficiently small. Making this intuition precise, we observe that $s_{L}^{*} \geq s_{H}^{*}$, from $\eta>1$, is equivalent to $s_{L}^{*}(\eta-1) \geq s_{H}^{*}{ }^{(\eta-1)}$. Using the second equation from (9), $\lambda_{H}=1$, and the definition of the cost function $c\left(s_{C}^{*} / \gamma_{C}^{*}\right)=\left(s_{C}^{*} / \gamma_{C}^{*}\right)^{\eta}$, this inequality can be transformed into $\lambda_{L} \gamma_{L}^{*} \geq \gamma_{H}^{*}$. Replacing the graduation thresholds with the help of the first equation in (9), we find

Proposition 3 The standard chosen by lower class schools is higher than or equal to the standard chosen by higher class schools if and only if

$$
\lambda_{L} \geq\left(\frac{L+1-\frac{1}{\eta}}{H+1-\frac{1}{\eta}}\right)^{\eta}
$$


According to Proposition 3, lower class schools demand a tougher standard than higher class schools if the wage discount for disadvantaged students is moderate compared to the difference in market sizes between the two kinds of schools.

We now turn to the empirical analysis of the interaction of standards and the social composition of schools. As an introduction, we give a brief account of the education system in the Netherlands.

\subsection{Data and estimation approach}

\subsubsection{The Dutch education system}

Dutch compulsory education encompasses twelve school years. At age five it starts with primary education (Basisschool) which lasts eight years. Today, parents may choose among three types (opleidingen) of institutions in secondary education (Voortgezet Onderwijs, $V O):^{8}$

(i) Pre-vocational or middle level secondary education (Voorbereidend middelbaar beroepsonderwijs, VMBO) lasts four school years and comprises four main branches: The Kaderberoepsgerichte leerweg (KB), the Basisberoepsgerichte leerweg (BB), the Theoretische leerweg (TL) and the Gemengde leerweg (GL). The latter two (VMBO-GT) are focussed on a more theoretical approach, whereas students in the former two branches $(V M B O-B K)$ must partake in a practical central examination that replaces one theoretical subject. Most $V M B O$ students move on to vocational training after graduation, but it is also possible to proceed to 4th grade of HAVO education (see below). The $V M B O$ branch was established in 1999, replacing the Middelbaar algemeen voortgezet onderwijs (MAVO) (equivalent to VMBO-GT) and Voorbereidend beroepsonderwijs, $V B O$ (equivalent to $V M B O-B K$ ) branches. As we will be using data from the classes of 2002 and 2003, in our analysis the branches are still referred

\footnotetext{
${ }^{8}$ Most Dutch schools offer more than one of these opleidingen, and often one school will provide access to all three branches of secondary education.
} 
to as $M A V O$ and $V B O$, where the $2003 V M B O-G T$ graduates are counted as $M A V O$ graduates.

(ii) Senior or higher general secondary education (Hoger Algemeen Voortgezet Onderwijs, $H A V O)$ amounts to five years of schooling and is aimed at providing students with a general education and preparing them for entry into higher professional education $(H B O)$, which leads to a bachelor's degree. Here as well, graduates can enroll in fifth grade $V W O$ (see below) upon graduation rather than proceeding to $H B O$. Alternatively, they might opt for vocational training.

(iii) Pre-university education (Voorbereidend Wetenschappelijk Onderwijs, VWO) encompasses six years of schooling. Its goal is to enable students to take up a university education; it is thus the highest form of secondary education in the Netherlands.

To the casual observer, Dutch secondary education appears to be characterized by central standards, as students end their scholastic careers with central examinations. However, central exams (centraal examen) account for only half the final grade. The other half is determined via decentralized testing (schoolexamen), ${ }^{9}$ leaving grading and standard-setting to a large extent at the individual school's discretion. ${ }^{10}$

The centraal examen are centrally arranged and graded by the testing agency CITO (Central Institute for Test Development). ${ }^{11}$ All students of the same opleiding are faced with identical questions and grading is done by CITO within 4 weeks' time. An official body, appointed by the Ministry of Education, CEVO (Centrale examencommissie vaststelling opgaven) establishes the norms for the central exams. ${ }^{12}$ The school exams on the other hand are conducted and -more importantly- devised and graded by the local schools. There are, however, guidelines set by the department of education (Ministerie van $O C W$ ) concerning the subject matter covered in school exams, to which schools must abide. To this end, the local schools set up "exam rules" (examenreglement), which establish the

\footnotetext{
${ }^{9}$ In the basic vocational programme $V M B O-B B$ the school exam accounts for two thirds of the final grade.

${ }^{10}$ An early study by Dronkers (1999) is also concerned with the school and central exams and discusses a variety of possible causes for discrepancies between the two grades.

${ }^{11}$ For further information, go to: http://www.cito.nl/com_assess_ex/nat_final_ex/eind_fr.html

${ }^{12}$ In some subjects, no centralized testing occurs (e.g. physical education and arts). The analysis in this book is limited to subjects where both types of testing are employed and schoolexamen grades can thus be compared to centraal examen grades.
} 
curriculum and required reading for the local exams. The examenreglement needs to be accredited by the central authorities and is accessible to the respective school's students. Nonetheless, it is obvious that in essence it is the individual school which sets the standard, at least within a certain range.

\subsubsection{Estimation approach}

Our empirical approach uses the co-existence of central and school-specific grades in order to detect differences in local standards. Let $G_{i}^{c}$ denote the average centraal examen grade and $G_{i}^{s}$ the average schoolexamen grade in school $i$. Under coinciding central and school specific standards, we would expect $G_{i}^{s}=G_{i}^{c}$. An upward deviation of $G_{i}^{s}$ from $G_{i}^{c}$ then constitutes a local standard that falls short of the central standard and vice versa. Our (inverse) operationalization for the standard $s_{i}$ applied by school $i$ is therefore the difference $\Delta G_{i}=G_{i}^{s}-G_{i}^{c}$ between the average grades obtained at this school in the school specific and in the central examination.

On a formal level, the continuous variable $\Delta G_{i}$ departs from the binary pass-fail standard $s_{i}$ featuring in the theoretical model. Since it is likely that a school which grades leniently also awards degrees more easily, it is, however, plausible that the factors determining graduation standards affect average grades in a similar way. Moreover, it is plausible that many employers and universities require a certain minimum grade from applicants whom they are willing to consider seriously. In such a case, this is the standard a student must meet, and the grading scale effectively determines a binary standard.

The difference $\Delta G_{i}$ cannot in itself be interpreted normatively. It does not say whether the school specific or the central standard is correct in the sense of measuring the "true" skill level of students. A positive $\Delta G_{i}$ might be a correction for an overambitious central standard rather than grade inflation by school $i .^{13}$ In this book we will not, however, question the appropriateness of the central grading scheme and therefore accept it as the benchmark against which double standards are to be detected. This is justified by the main focus of our investigation. We are not primarily interested in grade inflation in

\footnotetext{
${ }^{13}$ It can be ruled out, however, that school grading is conditional on central grades, as the centraal examen is the last exam of the entire school career.
} 
itself. It may well be that on a local level teachers tend to award higher or lower grades in general, say because school exams tend to be standardized in a different manner than central exams. We would then expect $\Delta G_{i}$ to be different from zero but constant across schools. Our focus, instead, is on double standards depending on social status. If standards are socially differentiated, $\Delta G_{i}$ will be systematically affected by the social composition of the schools' student body, whatever the average deviation between school specific and central grades.

Such a systematic effect, if it is found, may be the consequence of diverging grading schemes or of a different choice of examination topics. If the first is the case, all schools ask essentially the same questions at the school specific examination but those with disadvantaged students then grant higher marks for any given answer. Alternatively, $\Delta G_{i}$ may be higher in schools with disadvantaged students because teachers ask questions which are tailored to the students' knowledge. Also in this case, however, we consider the label "double standards" to be appropriate since it does not really matter whether grades are better because expectations are lower, or because difficult topics are avoided.

Another property of $\Delta G_{i}$ is that it is unaffected by peer and sorting effects that may emerge in a system of school choice. ${ }^{14}$ While sorting by ability will evidently have a massive influence on average central grades in a given school, the grade difference should not be affected, as we would expect school grades to change at the same rate. The same is true for possible peer effects that arise from sorting. Peer effects should impact both grades and thus leave $\Delta G_{i}$ unchanged.

In order to explain the grade difference $\Delta G_{i}$, we use the estimation equation:

$$
\Delta G_{i}=\beta_{0}+\beta_{1} \cdot y_{i}+\beta_{2} \cdot x_{i}+\epsilon_{i}
$$

where $i$ denotes the individual school, $y_{i}$ are variables describing the student body's social composition, $x_{i}$ is a vector of control variables, and $\epsilon_{i}$ is the error term. We will focus on two variables which capture the school-level social composition $y_{i}$ :

\footnotetext{
${ }^{14}$ There is a vast literature both theoretical and empirical on peer effects, see e.g. Epple and Romano (1998). Hsieh and Urquiola (2006) discuss the problems that arise in disentangling sorting, peer and competition effects when measuring changes in school quality.
} 
(i) The percentage of students considered cultural minority students.

(ii) The percentage of students receiving federal study cost allowance (Tegemoetkoming studiekosten), eligibility for which implies that parents have a low disposable income.

In accordance with Proposition 1, we expect to find decreasing local standards with increasing school-level percentages (i) and (ii). That is, if double standards are employed, we expect $\beta_{1}$ to be positive. According to Proposition 2, an increase in market size leads schools to set lower educational standards. While we cannot provide a direct test of this hypothesis, studying the different branches of secondary education will shed some light on this effect. It is reasonable to think of the market size to be increasing in the level of education. That is, the relevant labor market is smallest in geographical terms for students who have earned a diploma in $V B O$ and largest for those who hold a $V W O$-diploma. Hence, the above estimation will be conducted for all school branches separately. The cutting of standards as measured by $\beta_{1}$ is suspected to be largest in $V W O$, smallest for those with a diploma in $V B O$, and in between for the other two branches.

\subsubsection{Data sources}

The data employed in this analysis stems from four different sources. School-level data concerning students' performance and social affiliation as well as schools' characteristics is taken from the Kwaliteitskaart Voortgezet Onderwijs (Quality Cards for Secondary Education), issues 1998 - 2004. The Kwaliteitskaarten are published on a yearly basis by the Netherlands Inspectorate of Education for all Dutch secondary schools. The dataset provides information on number of students, administrative form of the school (private/denominational/public), the school branches that can be attended at the school, average class sizes, subject-level average grades attained in school and central exams, the recommended type of secondary school based on students' performance in primary education (i.e. students' entrance levels of performance), the percentage of ethnic minority students, the percentage of students with a study cost allowance etc.

The dependent variable $\Delta G_{i}$ is constructed from the performance data of the 2003 and 2004 Kwaliteitskaarten. As the original Kwaliteitskaarten file contains interdisciplinary average grades only as a mean of school and central grades, we calculated the average 
school specific $\left(G_{i}^{s}\right)$ and central $\left(G_{i}^{c}\right)$ grades covering all subjects by weighing the average school and central grades in each subject with the number of students that had actually taken part in the exams in that particular subject.

The percentage of cultural minority ( $C U M I)$ students is defined as the share of students in a given school branch who have a non-Dutch background. ${ }^{15}$ Along with the percentage of students receiving study cost allowance we use this variable as a proxy for low social status, as neither the Inspectorate nor the individual schools collect detailed data on parents' socioeconomic status. At the end of basisschool each student is given a non-binding advice by his teachers as to which school branch is deemed appropriate in secondary education. We add this advice as control variable for the incoming students' skill level. "Above advice" ("below advice") denotes a student attending a more (less) demanding branch than the one recommended. We also use the percentage of students in ability-tracked classes in the second year of secondary education and the average class size from the Kwaliteitskaarten. ${ }^{16}$

In addition to school level data, we use some variables which are available on a postcode level only. Specifically, the Statusscores postcodegebieden are postcode level data proxying for the students' social background. They are supplied by The Social and Cultural Planning Office of the Netherlands (SCP), a Dutch government agency. The status scores are calculated in 4 year intervals, taking into account variables such as mean education, mean income, average rents etc. Postcode areas that have a low social status are denoted with values greater than zero, areas of higher status receive negative values. We match these scores with the schools' 4-digit postcodes taken from the Kwaliteitskaarten. More data on a postcode level comes from the Kerncijfers postcodegebieden 2003 as well as the Kerncijfers wijken en Buurten 2001-2005, published by the Dutch Office of Statistics $(C B S)$. The percentage of school-aged children is calculated from the dataset Bevolking per 4-cijferige postcode 2004, published by the $C B S$.

\footnotetext{
${ }^{15} \mathrm{~A}$ student is considered part of a cultural minority if he satisfies one of the following criteria: both parents were born in (or have nationality of): one of the republics of former Yugoslavia, Greece; Italy; Cape Verde, Morocco, Portugal, Spain, Tunisia or Turkey; Moluccan background; Surinamese, Antillean or Aruban background; Roma background; caravan dwellers; other non-European background and not having completed full primary education in the Netherlands; Eastern European background and not having completed two years of Dutch schooling.

${ }^{16}$ Ability-tracked in this context means that students attend classes with students from their chosen branch only, whereas non-tracked students attend classes together with students from other branches. After the second year of secondary education there are no mixed classes.
} 
Since school-level financial endowment as well as characteristics of the teaching staff might influence average grades and standard setting, data from the series Onderwijs in Cijfers $(O I C)$ is used in the estimation, too. Onderwijs in Cijfers is published annually by the Dutch Ministry of Education and is intended to provide school managers with information on the above mentioned matters for all Dutch secondary schools.

Table 3-1 displays descriptive statistics for the explanatory variables used in the estimation.

TABle 3-1: DesCRIPTIVE STATISTICS.

\begin{tabular}{lrrrrr}
\hline Variable & N & Mean & Std. Dev. & Min & Max \\
\hline Above advice \% VWO & 801 & 21.363 & 16.394 & 0 & 96 \\
Above advice \% HAVO & 754 & 12.773 & 12.362 & 0 & 88 \\
Above advice \% MAVO & 991 & 7.167 & 13.473 & 0 & 96 \\
Above advice\% VBO & 578 & 13.155 & 16.217 & 0 & 100 \\
Below advice \% HAVO & 754 & 5.244 & 5.128 & 0 & 30 \\
Below advice \% MAVO & 991 & 14.670 & 11.504 & 0 & 82 \\
Below advice\% VBO & 578 & 17.313 & 15.444 & 0 & 100 \\
Minority students \% VWO & 834 & 4.246 & 7.146 & 0 & 78.947 \\
Minority students \% HAVO & 783 & 6.092 & 9.446 & 0 & 72.222 \\
Minority students \% MAVO & 1093 & 8.414 & 12.629 & 0 & 100 \\
Minority students \% VBO & 634 & 14.687 & 16.194 & 0 & 94.117 \\
Study cost \% VWO & 834 & 26.033 & 10.244 & 8.673 & 100 \\
Study cost \% HAVO & 783 & 35.254 & 12.755 & 11.659 & 100 \\
Study cost \% MAVO & 1089 & 38.565 & 20.558 & 4.854 & 100 \\
Study cost \% VBO & 632 & 67.553 & 22.188 & 9.473 & 100 \\
Tracked \% & 1493 & 63.273 & 37.261 & 0 & 100 \\
Class size & 1491 & 23.271 & 4.270 & 6 & 31.666 \\
No. Students (x1000) & 1517 & 0.898 & 0.514 & 0.01 & 2.949 \\
Short term debt (share of balance) & 708 & 0.307 & 0.111 & 0 & 0.811 \\
Long term debt (share of balance) & 708 & 0.029 & 0.064 & 0 & 0.596 \\
Staff growth & 1392 & 0.006 & 0.059 & -0.705 & 0.368 \\
No. students growth & 1408 & 0.012 & 0.070 & -0.516 & 1.768 \\
Part time staff (share) & 1392 & 0.356 & 0.090 & 0.057 & 0.897 \\
Status postcode & 1514 & 0.181 & 1.039 & -2.744 & 3.888 \\
Avg. income postcode (x1000) & 1486 & 13.422 & 2.366 & 8.777 & 27.676 \\
School aged postcode \% & 1518 & 17.106 & 3.634 & 2.564 & 37.5 \\
Population postcode (x1000) & 1498 & 8.4348 & 4.239 & 0.04 & 42.78 \\
\hline
\end{tabular}

\subsection{Empirical Results}

\subsubsection{Determinants of standards in Dutch schools}

Descriptive statistics for the difference between school specific and central grades, $\Delta G_{i}$, are shown in table 3-2 for the pooled classes of 2002 and 2003. On average, grades awarded 
in school exams are higher than those awarded in central exams in all branches but VBO. Thus, the local school standards in these branches seem to be - on average - lower than the centrally devised standard. The difference is highest for pre-university education and lowest for $V B O$ schools. The minimum values also indicate that on a school-level, $V W O$ and HAVO schoolexamen grades drop only slightly below the central grades, at most. In $M A V O$ and $V B O$ education, however, some schools underscore more heavily in the school exams. Altogether, it seems that the schools in the higher branches of secondary education reduce the standards by more than those at the lower end. This is consistent with the idea of geographically larger job markets causing lenient grading, presented in Proposition 2.

TABle 3-2: Summary Statistics $\Delta G_{i} 2002 / 2003$.

\begin{tabular}{lrrrrc}
\hline Variable & $\mathbf{N}$ & Mean & Std. Dev. & Min & Max \\
\hline VWO & 835 & 4.667 & 2.535 & -2.093 & 16.446 \\
HAVO & 786 & 2.549 & 2.309 & -4.985 & 12.422 \\
MAVO & 1101 & 1.602 & 2.768 & -6.737 & 17.079 \\
VBO & 646 & -0.115 & 3.396 & -9.222 & 14.500 \\
\hline
\end{tabular}

We carried out OLS regressions for all four branches of secondary education separately, with the branch-specific difference $\Delta G_{i}$ as the dependent variable. We will first describe the results for pre-university education $V W O$ (Table 3-3). Specification (1) includes typical school-level variables only, (2) adds Onderwijs in Cijfers variables and (3) includes postcode-level data as well. In accordance with the theoretical predictions, in specifications (1) to (3) we find that an increasing percentage of cultural minority students leads to lower standards in local exams. The share of students eligible for study cost allowance does not seem to be linked to lenient grading. One reason is that a large percentage of minority students also qualify for study cost allowance, resulting in overlapping effects for the two variables. This becomes obvious when we interchangeably employ only one of these two proxies for social status. Omitting the percentage of minority students from the estimation in specification (4) results in a considerably larger and significant effect of the share of study cost recipients on standard depreciation. Dropping the study cost allowance recipients in specification (5) yields similar effects on the minority share coefficient, strengthening the idea that these variables are to some extent congruent.

The third variable accounting for social status (Status postcode) also somewhat supports our hypothesis. Lower status on a postcode level also leads to higher grading differences (remember, the status variable is coded inversely), although this effect is not significant 


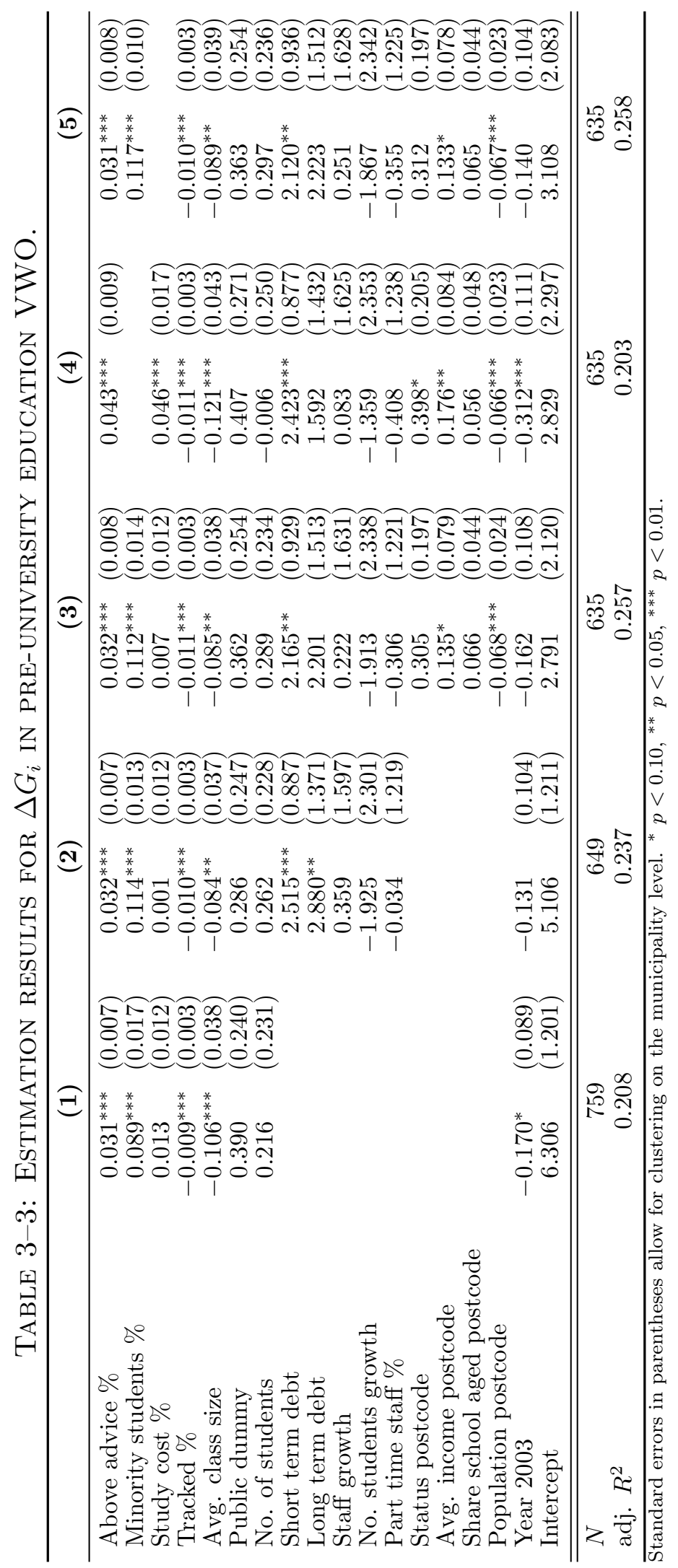


in most specifications. Somewhat surprising is the fact that higher postcode-level incomes also lead to larger gaps in grading standards. This is difficult to explain, but it suggests that status and income do not measure the same thing.

The coefficient on the public school dummy indicates that public schools tend to inflate grades more than private schools, possibly due to competitive pressure. ${ }^{17}$, though the coefficient is again insignificant. In addition, we observe that indebted schools tend to grade more leniently. Setting lower standards may be an attempt of these schools at attracting more students and exploiting economies of scale. ${ }^{18}$ A higher percentage of students attending a school branch deemed too demanding for them in their advice after basisschool also leads to a decline in standards. Here, a high share may be an indicator of competitive pressure leading schools to admit students above their initial advice. ${ }^{19}$ A low percentage of ability-tracked students is also linked with the deterioration of standards.

Table 3-4 extends the analysis to the other three school branches, where column (1) describes HAVO, column (2) MAVO, and column (3) VBO education. The main result holds for $H A V O$ as well as MAVO: A lower class student body, if measured by the share of cultural minority students, causes a depreciation in standards. The coefficient for study cost allowance recipients, however, is not significant. It becomes so upon omission of the cultural minority variable for $H A V O$ and MAVO. ${ }^{20}$ Interestingly, the coefficients of the share of cultural minority students in $H A V O$ and $M A V O$ are only about half as large as the one found for $V W O$ (see specification (3) in table 3-3). Moreover, the grade gap in $V B O$ education does not at all seem to be related to social composition of the student body. In fact, the explanatory power of the $V B O$ model is almost entirely driven by the year dummy. Together, we take these results as tentative evidence in favor of the hypothesis that schools supplying graduates to smaller job markets tend to inflate disadvantaged students' grades by less.

Contrary to pre-university education $V W O$, financial variables do not appear to drive the

\footnotetext{
${ }^{17}$ School choice leads to approximately $70 \%$ of Dutch students actually attending private schools, many of which are denominational.

${ }^{18}$ Dutch schools receive a fixed federal transfer for every student.

${ }^{19}$ If there were only the central examination, such admission practices would not make much sense, as the students might just fail to attain the diploma.

${ }^{20}$ We do not report the regressions for these specifications. They are available upon request.
} 
TABle 3-4: Estimation Results for $\Delta G_{i}$ : HAVO (1), MAVO (2), VBO (3).

\begin{tabular}{|c|c|c|c|c|c|c|}
\hline \multirow[b]{2}{*}{ Above advice $\%$} & \multicolumn{2}{|c|}{ (1) } & \multicolumn{2}{|c|}{ (2) } & \multicolumn{2}{|c|}{ (3) } \\
\hline & $0.045^{* * *}$ & $(0.010)$ & $0.045^{* * *}$ & $(0.010)$ & 0.010 & $(0.010)$ \\
\hline Below advice \% & -0.003 & $(0.020)$ & $-0.034^{* * *}$ & $(0.008)$ & $-0.020^{*}$ & $(0.011)$ \\
\hline Minority students $\%$ & $0.058^{* * *}$ & $(0.019)$ & $0.043^{* * *}$ & $(0.007)$ & 0.012 & $(0.008)$ \\
\hline Study cost $\%$ & 0.007 & $(0.010)$ & 0.002 & $(0.005)$ & 0.008 & $(0.007)$ \\
\hline Tracked & $-0.004^{*}$ & $(0.002)$ & $-0.005^{* *}$ & $(0.002)$ & -0.004 & $(0.004)$ \\
\hline Avg. class size & 0.032 & $(0.037)$ & $-0.119^{* * *}$ & $(0.028)$ & -0.075 & $(0.055)$ \\
\hline Public dummy & $0.374^{*}$ & $(0.219)$ & -0.132 & $(0.209)$ & -0.435 & $(0.269)$ \\
\hline No. of students & 0.286 & $(0.239)$ & 0.030 & $(0.181)$ & 0.234 & $(0.334)$ \\
\hline Short term debt & 0.484 & $(0.944)$ & 0.262 & $(0.748)$ & $-2.503^{* *}$ & $(1.076)$ \\
\hline Long term debt & 1.303 & $(1.427)$ & -2.133 & $(1.474)$ & -2.805 & $(2.364)$ \\
\hline Staff growth & -1.729 & $(1.446)$ & 1.366 & $(1.317)$ & -1.796 & $(2.728)$ \\
\hline No. students growth & -0.776 & $(2.116)$ & -0.047 & $(1.940)$ & -3.654 & $(3.113)$ \\
\hline Part time staff $\%$ & 0.635 & $(1.494)$ & -0.887 & $(1.294)$ & 2.386 & $(2.455)$ \\
\hline Status postcode & $0.573^{* * *}$ & $(0.204)$ & $0.292^{*}$ & $(0.172)$ & 0.057 & $(0.320)$ \\
\hline Avg. income postcode & $0.276^{* * *}$ & $(0.089)$ & $0.236^{* * *}$ & $(0.069)$ & 0.251 & $(0.215)$ \\
\hline Share school aged postcode & $0.078^{* *}$ & $(0.036)$ & 0.010 & $(0.036)$ & 0.022 & $(0.083)$ \\
\hline Population postcode & -0.023 & $(0.023)$ & 0.010 & $(0.020)$ & 0.050 & $(0.033)$ \\
\hline Year 2003 & 0.130 & $(0.114)$ & $-1.010^{* * *}$ & $(0.119)$ & $3.527^{* * *}$ & $(0.240)$ \\
\hline Intercept & -5.004 & $(1.993)$ & 1.740 & $(1.525)$ & -4.505 & $(4.557)$ \\
\hline & \multirow{2}{*}{\multicolumn{2}{|c|}{$\begin{array}{c}597 \\
0.215\end{array}$}} & \multirow{2}{*}{\multicolumn{2}{|c|}{$\begin{array}{c}802 \\
0.280\end{array}$}} & \multirow{2}{*}{\multicolumn{2}{|c|}{$\begin{array}{c}454 \\
0.315\end{array}$}} \\
\hline adj. $R^{2}$ & & & & & & \\
\hline
\end{tabular}

cutting of standards in either $H A V O$ or $M A V O$. An explanation for this difference may be that competition among schools for $V W O$ students is more intense than in the case of $H A V O$ or $M A V O$, because prospective $V W O$ students make more use of their right to choose, or choose among a larger set of schools. Furthermore, if educating $V W O$ students is less expensive, schools that offer more than one branch may resort to attracting $V W O$ students rather than $H A V O$ or $M A V O$ students. Most of the other control variables do not differ much across school branches.

In essence, even though some of the control variables' coefficient signs are not as expected, the empirical results for $V W O, H A V O$ and $M A V O$ clearly reject the hypothesis that social composition does not influence the magnitude of standard cutting. Not only do we find significant effects of social composition on grading standards, we also can dismiss concerns that students of low status might, on top of their low status, be discriminated when it comes to grading. The opposite is true. Moreover, the size of the coefficients for the different branches and the fact that the explanatory power for $V B O$ is mainly driven by a time or cohort effect seem consistent with the hypothesis that standard cutting increases in relevant labor market size. 


\subsubsection{Endogeneity issues}

In this section we address the possibility that the share of minority students itself may be a function of the grade difference $\Delta G_{i}$ or that both variables are driven by another variable not included in the estimation. Reverse causality problems would arise if minority students were to choose schools with more lenient grading while non-minority students do not behave in this manner. Given the absence of catchment areas in the Netherlands, this problem could even be aggravated since students and their parents do not have to move to the vicinity of the desired school.

Intuitively, we have no reason to believe that parents of lower social status care more about their children's grades than their well-off counterparts. Quite the contrary, one would probably expect parents of higher social status to be rather more career-oriented. On top of that, it should be noted that even in the absence of catchment areas, sending an offspring to farther away schools which award better grades entails travel costs and is thus more easily feasible for well-off families.

On a technical level, we carried out instrumental variable (IV) regressions in order to account for possible endogeneity of social status. As a measure of status in these regressions we restrict attention to the minority share as the stronger predictor of grade differences, dropping the study cost variable. We do not report full regression results for the IV estimations. Rather, table $3-5$ shows the coefficients of the instrumented explanatory variable "minority share" for all four school branches and all instruments.

The first instrument we employ is the population density in the schools' respective municipalities, the reasoning being that immigrants and subsequent minority generations tend to live in the larger cities and thus in densely populated areas. On the other hand, we do not expect population density to be linked to grade difference other than through the higher minority share. ${ }^{21}$ The F-values for instrument significance in the first stage regressions insinuate that population density is a relevant instrument for all branches. In all four branches, the results are in line with the OLS results and suggest that OLS underestimates

\footnotetext{
${ }^{21}$ Higher grade differences do not cause a change in population density in the absence of catchment areas as there is no need for relocation. See Karsten et al. (2006) for evidence that place of residence and location of attended school often differ.
} 
the effect of the minority share.

The next instrument is also related to geography: the Dutch postcodes. These are arranged so that the west of the country, where the larger cities are located, is assigned low postcode numbers which increase as one moves north-west. The intuition for the instrument is that minorities historically cluster in the regions with lower postal codes and at the same time exogeneity can be assumed as grade differences are not suspected to be influenced by postal code characteristics other than the ones we control for. ${ }^{22}$ The first stage F-values however indicate that there is a problem with instrument relevance in the $V W O$ and the $V B O$ branches. The coefficients for these two branches should thus be interpreted with caution. Generally speaking, the coefficients are larger than those obtained from OLS - with the exception of $V B O$. This again suggests that by using OLS, we rather underestimate the true effect of the minority student share on standards.

Our final instrument is the share of minority students in a different school branch at the same school. Most schools offer more than one branch, and we expect minority shares to be highly correlated across branches within the same school. Grade differences in one school branch should be independent of the minority share in another branch unless the school applies a school-specific grading policy, regardless of branch. If this was true, however, we would expect to find lenient grading also in $V B O$ when a large share of minority students is present. As this is not the case - at least not to the same extent as in the other branches - such common grading policies do not seem to be present. We employed as instruments the minority share in all school branches but the one under consideration, rendering us with three instruments per school branch (e.g. the minority share in $V W O$ schools is instrumented by the minority shares in $H A V O, M A V O$, and $V B O)$. As displayed in table 3-5, the coefficients for all school branches are close to the OLS results, regardless of the instrument used. ${ }^{23}$ The final column of table $3-5$ presents coefficients when population density and the minority share in the adjacent school branch are used as instruments (the adjacent branch for $V W O$ is $H A V O$ and vice versa. The same is true for $M A V O$ and

\footnotetext{
${ }^{22}$ On ethnical clustering in the Netherlands, see de Graaff, Gorter and Nijkamp (2001).

${ }^{23}$ Whereas population density and postcode are available for all schools, the shares of minority students in other school branches are obviously only available if a certain school offers more than one opleiding. This is not always the case, especially when the instrument is not from an adjacent school branch to the instrumented one, as can be seen in table 3-5. Since results are virtually invariant to the choice of school-branch instrument, there is no reason to suspect selection effects, though.
} 


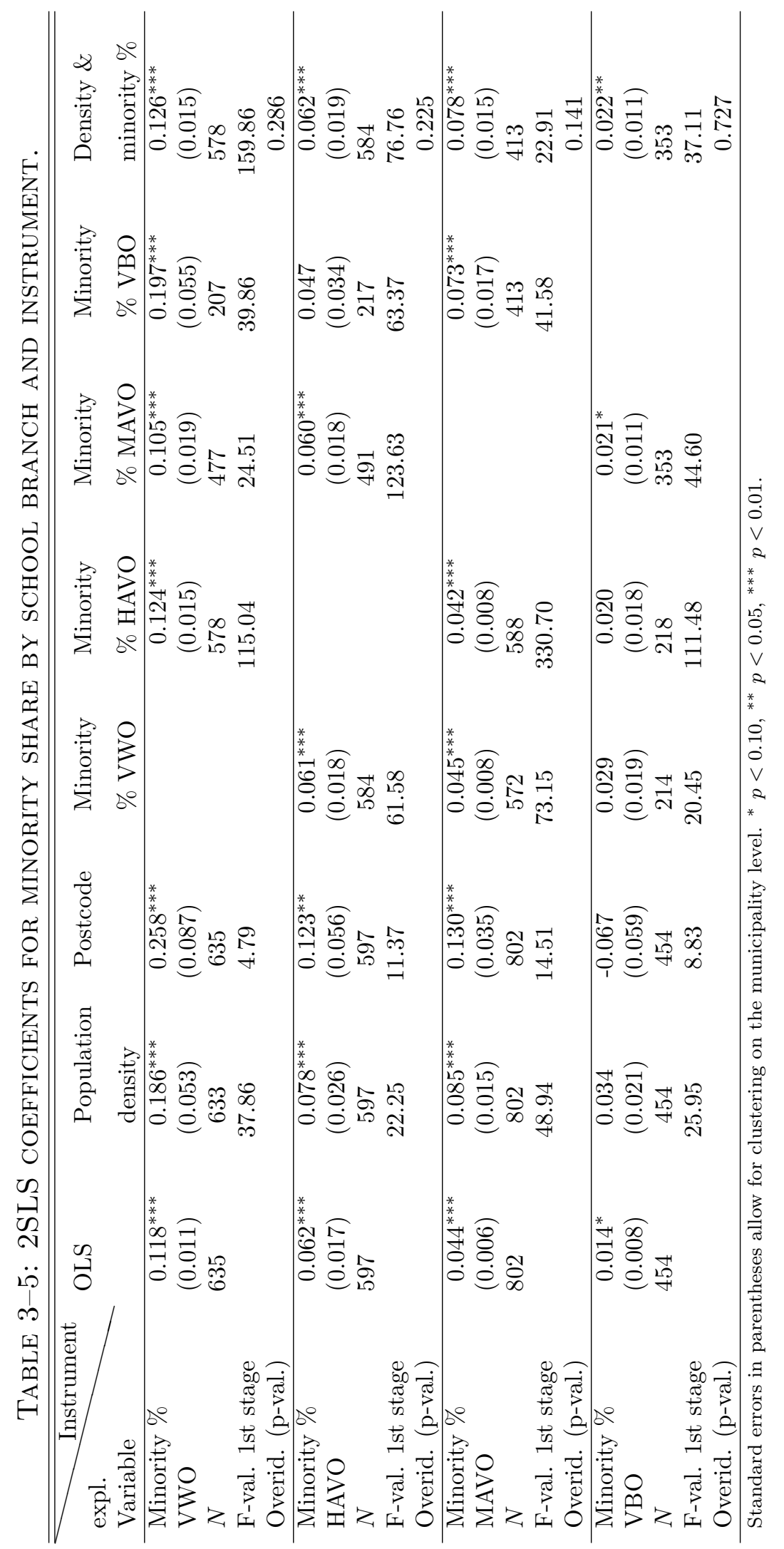


$V B O$ ). Standard overidentification tests (p-values in table $3-5$ ) do not suggest that there is a problem with the orthogonality of the instruments and all coefficients are at least as large as in OLS across the board. Altogether, the instrumental variable regressions confirm the OLS results.

\subsubsection{Longitudinal data}

Lastly, we intend to back up our cross-sectional results with longitudinal evidence. We focus on a specification which includes the minority share and a few of the school level controls. Adding the share of study cost allowance and financial controls does not alter the coefficient on the minority share and at the same time the chosen specification allows us to retain a larger number of observations. The estimations do not include the postcode and municipality level controls as they are only reported biannually. Since we could not find any signs of endogeneity in the status variable (minority share) in the previous subsection, we treat it as exogenous in the longitudinal analysis.

When the minority share is used as the key explanatory variable in fixed effects (FE) estimation, we cannot obtain any significant results. This is not very surprising because the minority share varies little over time, and we do not expect schools to react immediately to a change in the minority students' share. Rather, schools will establish or adjust a lenient grading policy over the course of time. To account for this fact, we calculate a weighted moving average of the minority shares at the year of graduation and the three years prior. The weights are the number of students in the respective years. This makes sense because the minority share is defined as the share of CUMI-students in opleidingpopulation. Hence, the current graduating class influences the $C U M I$-share in all of these four years. Our moving average then describes the school's average minority share while the graduating cohort attended school.

Table 3-6 reports the results for the fixed and random effects (RE) regressions in the university preparatory branch $V W O$ when we use the weighted average $C U M I$-variable. The coefficient for minority share is significant in both FE and RE, yet the magnitude of the coefficient is quite different, with the fixed effects estimate suggesting an even larger effect. A standard Hausman test indicates that the difference between the FE and RE 
TABle 3-6: FiXed AND RANDOM EFFECTS FOR VWO BRANCH.

\begin{tabular}{lcccc}
\hline \hline & \multicolumn{3}{c}{ Fixed effects } & \multicolumn{3}{c}{ Random effects } \\
\hline Minority students \% & $0.2659^{*}$ & $(0.154)$ & $0.0998^{* * *}$ & $(0.035)$ \\
Above advice \% & 0.0104 & $(0.008)$ & $0.0215^{* * *}$ & $(0.006)$ \\
Tracked \% & 0.0045 & $(0.007)$ & $-0.0054^{*}$ & $(0.003)$ \\
Avg. class size & $-0.1090^{* *}$ & $(0.046)$ & $-0.0983^{* * *}$ & $(0.036)$ \\
Public dummy & & & $0.5732^{* *}$ & $(0.252)$ \\
No. of students & 0.9680 & $(0.749)$ & 0.3146 & $(0.226)$ \\
Year 2003 & -0.0757 & $(0.105)$ & $-0.1685^{*}$ & $(0.096)$ \\
N & 714 & & 718 & \\
\hline
\end{tabular}

Two schools that reported implausible values for minority share were excluded from the estimation. The significant coefficient in the fixed effects estimation hinges on the exclusion of these schools. Standard errors in parentheses allow for clustering on the panel variable (school). ${ }^{*} p<0.10,{ }^{* *} p<0.05,{ }^{* * *} p<0.01$.

coefficients is statistically significant.

Given the short time-series, one should obviously not overstress the results of the longitudinal analysis. Nevertheless, the results from this subsection suggest that there is a positive within-school influence of minority share on the difference between school exam and central exam grades, supporting the results from the cross-sectional estimation presented in the previous subsections.

\subsection{Summary and Outlook}

In this chapter, we analyzed the impact of social class on the choice of grading standards by schools. We showed in a theoretical model that schools with a disadvantaged student body tend to apply less demanding standards if graduates from such backgrounds face less appealing job market conditions than others. The predictions of the model were then tested on data from the Netherlands since the Dutch educational setup provides the rare opportunity of measuring decentralized grades awarded by the individual schools against the benchmark of central test results. The empirical results show that schools with many students from cultural minorities, or receiving financial aid, award better grades.

This result is strikingly different from the result of the PISA study reported by Prenzel et al. (2005). Whereas this study suggests that students from lower classes get a rough deal from the grading and examination system which holds them back from enjoying more rewarding types of education, our results rather show that such students are held to less 
demanding standards than students from average backgrounds. While we refrain from drawing any more general conclusions from these results at this stage, it seems safe to point out that, in order to explain the treatment of lower class students by the schooling system, more than a simple appeal to discrimination is needed.

This observation suggests that much more research is required in order to enhance the understanding of how standards are set. For example, it should be fruitful to integrate other motives for the choice of standards. As some of our empirical results suggest, competition for students may be an important driver of grade inflation. This will be analyzed empirically and treated in more detail in the following parts of the book. Chapter 4 gives a short survey of the literature on school competition, and chapter 5 deals with the impact of school choice on academic achievement and the setting of standards. 


\section{Appendix to Chapter 3: Second order condition.}

Differentiating (8) once more with respect to $s_{i}$, we find, with $f=1 / \bar{\gamma}$

$$
\begin{aligned}
\frac{\partial^{2} W_{i}}{\partial s_{i}^{2}} & =-f \frac{\gamma_{i}}{s_{i}} \frac{\mathrm{d} w_{C}}{\mathrm{~d} s_{i}}-f w_{C}\left[\frac{\partial\left(\frac{\gamma_{i}}{s_{i}}\right)}{\partial s_{i}}+\frac{\partial\left(\frac{\gamma_{i}}{s_{i}}\right)}{\partial \tilde{w}} \frac{\mathrm{d} w_{C}}{\mathrm{~d} s_{i}}\right] \\
& -f\left(1-\frac{1}{\eta}\right)\left[\frac{\partial \gamma_{i}}{\partial s_{i}}+\frac{\partial \gamma_{i}}{\partial \tilde{w}} \frac{\mathrm{d} w_{C}}{\mathrm{~d} s_{i}}\right] \frac{\mathrm{d} w_{C}}{\mathrm{~d} s_{i}}+\left[1-f \gamma_{i}\left(1-\frac{1}{\eta}\right)\right] \frac{\mathrm{d}^{2} w_{C}}{\mathrm{~d} s_{i}^{2}}
\end{aligned}
$$

From (2) and (3) one has $\partial \gamma_{i} / \partial s_{i}=\gamma_{i} / s_{i}$, hence $\partial\left(\gamma_{i} / s_{i}\right) / \partial s_{i}=0$, and $\partial \gamma_{i} / \partial \tilde{w}=$ $-(1 / \eta) \gamma_{i} / w_{C}$. Inserting this and rearranging, one arrives at

$$
\frac{\partial^{2} W_{i}}{\partial s_{i}^{2}}=-f\left(1-\frac{1}{\eta}\right) \frac{\gamma_{i}}{s_{i}}\left(2-\frac{1}{\eta} \frac{s_{i}}{w_{C}} \frac{\mathrm{d} w_{C}}{\mathrm{~d} s_{i}}\right) \frac{\mathrm{d} w_{C}}{\mathrm{~d} s_{i}}+\left[1-f \gamma_{i}\left(1-\frac{1}{\eta}\right)\right] \frac{\mathrm{d}^{2} w_{C}}{\mathrm{~d} s_{i}^{2}}
$$

At a symmetric situation with $w_{C}=\lambda_{C} s_{C}=\lambda_{C} s_{i}, \gamma_{i}=\gamma_{C}$, and $\mathrm{d} w_{C} / \mathrm{d} s_{i}=\lambda_{C} / C,(\mathrm{~A} .14)$ reduces to

$$
\frac{\partial^{2} W_{i}}{\partial s_{i}^{2}}=-f\left(1-\frac{1}{\eta}\right) \frac{\lambda_{C}}{C} \frac{\gamma_{C}}{s_{C}}\left(2-\frac{1}{\eta C}\right)+\left[1-f \gamma_{C}\left(1-\frac{1}{\eta}\right)\right] \frac{\mathrm{d}^{2} w_{C}}{\mathrm{~d} s_{i}^{2}} .
$$

From $\eta>1$ and $C \geq 1$, it follows that the first term in (A.15) is strictly negative. Moreover, $\eta>0$ and $f \gamma_{C}<1$ imply $1-f \gamma_{C}[1-(1 / \eta)]>0$. Thus, $\mathrm{d}^{2} w_{C} / \mathrm{d} s_{i}^{2} \leq 0$ is sufficient for $\partial^{2} W_{i} / \partial s_{i}^{2}<0$ at a symmetric situation.

Defining $A\left(s_{i}\right)=f\left(\lambda_{C} s_{i}-w_{C}\right)\left(\partial \gamma_{i} / \partial s_{i}\right)-\lambda_{C}\left[1-F\left(\gamma_{i}\right)\right]$ and $B\left(s_{i}\right)=\sum_{j \in C}\left[1-F\left(\gamma_{j}\right)\right]+$ $f \sum_{j \in C}\left(\lambda_{C} s_{j}-w_{C}\right)\left(\partial \gamma_{j} / \partial \tilde{w}\right)$, we can write (6) as $\mathrm{d} w_{C} / \mathrm{d} s_{i}=-A\left(s_{i}\right) / B\left(s_{i}\right)$. We have

$$
\begin{aligned}
\frac{\mathrm{d} A}{\mathrm{~d} s_{i}}=f & \left(\lambda_{C}-\frac{\mathrm{d} w_{C}}{\mathrm{~d} s_{i}}\right) \frac{\partial \gamma_{i}}{\partial s_{i}} \\
& +f\left(\lambda_{C} s_{i}-w_{C}\right)\left(\frac{\partial^{2} \gamma_{i}}{\partial s_{i}^{2}}+\frac{\partial^{2} \gamma_{i}}{\partial s_{i} \partial \tilde{w}} \frac{\mathrm{d} w_{C}}{\mathrm{~d} s_{i}}\right)+f \lambda_{C}\left(\frac{\partial \gamma_{i}}{\partial s_{i}}+\frac{\partial \gamma_{i}}{\partial \tilde{w}} \frac{\mathrm{d} w_{C}}{\mathrm{~d} s_{i}}\right) .
\end{aligned}
$$

From symmetry, $\lambda_{C} s_{i}-w_{C}=0$, and hence the second term in (A.16) drops out. Using, 
in addition, $s_{i}=s_{C}, \gamma_{i}=\gamma_{C}, \mathrm{~d} w_{C} / \mathrm{d} s_{i}=\lambda_{C} / C,(2)$, and (3), (A.16) reduces to

$$
\frac{\mathrm{d} A}{\mathrm{~d} s_{i}}=f \lambda_{C} \frac{\gamma_{C}}{s_{C}}\left(2-\frac{1}{C}-\frac{1}{\eta C}\right)
$$

Similarly, one finds

$$
\frac{\mathrm{d} B}{\mathrm{~d} s_{i}}=f\left(\lambda_{C} \frac{\partial \gamma_{i}}{\partial \tilde{w}}-\frac{\partial \gamma_{i}}{\partial s_{i}}\right)-2 \sum_{j \in C} f \frac{\partial \gamma_{j}}{\partial \tilde{w}} \frac{\mathrm{d} w_{C}}{\mathrm{~d} s_{i}}+\sum_{j \in C} f\left(\lambda_{C} s_{j}-w_{C}\right)\left(\frac{\partial^{2} \gamma_{j}}{\partial \tilde{w} \partial s_{i}}+\frac{\partial^{2} \gamma_{j}}{\partial \tilde{w}^{2}} \frac{\mathrm{d} w_{C}}{\mathrm{~d} s_{i}}\right)
$$

which, with symmetric standards and using (2) and (3), reduces to

$$
\frac{\mathrm{d} B}{\mathrm{~d} s_{i}}=-f \frac{\gamma_{C}}{s_{C}}\left(1-\frac{1}{\eta}\right)
$$

Moreover, symmetry yields $A=-\lambda_{C}\left(1-f \gamma_{C}\right)$ and $B=C\left(1-f \gamma_{C}\right)$. Together with (A.17) and (A.18), one so finds

$$
\frac{\mathrm{d}^{2} w_{C}}{\mathrm{~d} s_{i}^{2}}=-\frac{\frac{\mathrm{d} A}{\mathrm{~d} s_{i}} B-\frac{\mathrm{d} B}{\mathrm{~d} s_{i}} A}{B^{2}}=-\frac{2 f \lambda_{C}}{C\left(1-f \gamma_{C}\right)} \frac{\gamma_{C}}{s_{C}}\left(1-\frac{1}{C}\right) \leq 0,
$$

where the sign follows on $C \geq 1$. 

CHAPTER 4

\section{Institutions in Education (II) - Competition}

Competition is the second major institution in the economics of education that is considered in this book. Many people are reluctant to believe that education markets may benefit from institutionalizing competition. This lack of faith possibly stems from a mindset that education is somehow a good that is "above" the profane realm of market mechanisms. However, from an economics perspective there is little to theoretically justify why competition should not be a force that works here just as well as in other markets.

To economists, the possibly beneficial effects of competition in the market for education are by no means a new discovery. Friedman (1955) argued that school choice in the form of vouchers would exert competitive pressure on school authorities which in turn would lead them to provide higher school quality. On the downside, increased choice can lead to increased sorting by ability. This cream-skimming by the better schools is often thought to leave the least able students amongst themselves. In addition to being stuck in a bad school, they may thus be robbed of any positive peer effects ${ }^{24}$ they may have experienced in a mixed-ability school.

\footnotetext{
${ }^{24}$ It is often argued that the presence of high-ability students in a classroom has a positive effect on the academic achievement of lower-ability students in the same classroom. This has been termed "peer effect".
} 


\section{The Link between School Quality and Competition}

In the United States, a considerable percentage of the population relocates each year and secondary education is traditionally funded to a considerable degree by means of local property taxes. This makes educational policies and their effects on households' location decisions a standard example of Tiebout's (1956) idea of voting with the feet. A large part of the literature on competition in education relies heavily on this idea which implies higher school quality being capitalized in house prices. Indeed, there has been a whole strand of literature that has shown that households do take school quality into account when choosing their place of residence and are willing to pay a premium for it. Aside from the empirical evidence, the fact that many realtors provide their customers with information on local schools' test scores confirms the importance of school quality. ${ }^{25}$

Whether school quality reacts to parents exercising the exit-option (or the threat thereof) has been at the center of another strand of research. Predominantly, school quality is measured in terms of academic achievement, i.e. test scores and graduation rates, mostly due to the quantitative nature of these measures. ${ }^{26}$ The main exogenous variable is the intensity of competition in the relevant market. A reasonable indicator of competition seems to be the number of schools or school districts that make up the choice set within a particular market. Alternatively, the Herfindahl index of concentration, which is closely related to the number of schools or districts (Martinez-Vazquez and Seaman 1985, Hoxby 2000) can be used. The percentage of students attending private schools (Hoxby 1994) or the number of private schools is also often employed, as these schools provide the real outside option to public schools, which may be too similar to actually impose competitive pressure upon one another. Evidently, these measures are all the more powerful when education markets are clearly defined geographically, determining a household's choice set.

When employing competition measures, endogeneity issues need to be taken into account.

\footnotetext{
${ }^{25}$ Obviously, in a larger geographical context, there are many other variables such as job availability which influence residential patterns. Within a metro area, however, school quality has been shown to be closely linked to house prices. See Black (1999), Weimer and Wolkoff (2001), Barrow (2002) and Bayer, Ferreira and McMillan (2005). For evidence that these effects can also be found outside the United States, see Cheshire and Sheppard (2003).

${ }^{26}$ Whether grades and the like are a good measure of school quality is disputable. While certainly an intriguing issue, the discussion is beyond the focus of this book.
} 
Picture a school district whose schools perform poorly. This district will be especially prone to the initiation of private schooling, as there are more students who are unhappy with the school they presently attend and this will add to the demand for alternatives. Failure to acknowledge this mechanism may lead to an underestimation of the impact of choice on achievement, as one may concurrently observe high degrees of competition and low public school quality. In a similar fashion, the number of school districts may be a function of school quality. Even though the endogeneity of competition has recently been contested by Brasington (2005) and Rothstein (2007), at least testing for the possible endogeneity through use of instrumental variables seems in order.

Empirical Evidence for the United States. Even though school choice continues to be promoted as a means of ensuring that students receive a better education and voucher programs are introduced or extended in the United States, the scientific evidence on the effects of competition are far from being unambiguous. Using data from the UTD Texas School Project, Hanushek and Rivkin (2003) define metropolitan areas as education markets. Competition is measured by a Herfindahl index, which shows no significant connection to school quality. Marlow (1999) on the other hand finds a positive impact on achievement in many of his specifications, when competition is operationalized through the use of a county-wide Herfindahl index. Earlier, Marlow (1997) had already stated positive effects of the number of available schools per student on SAT scores using state-level data. ${ }^{27}$ Studies by Borland and Howsen (1993) and Zanzig (1997) only find effects up to a certain threshold level of competition. Geller, Sjoquist and Walker (2006) cannot identify a significant positive influence of competition by private schools on test scores in Georgia at all.

Most prominent in the public discourse are probably two studies by Hoxby (1994, 2000). In the more recent paper she develops an index of competition based on the number of school districts in a metropolitan area. While she cannot identify a significant positive effect with OLS, the use of streams as an instrumental variable for the number of districts leads her to the conclusion of a positive influence of choice on achievement. ${ }^{28}$ The earlier study

\footnotetext{
${ }^{27}$ Schools per student or per capita is not a reasonable concept of competition when local education markets are studied. Simply imagine a local education market which harbors few students or is sparsely populated but has only one school. This would imply high levels of competition when in fact the school is a local monopolist.

${ }^{28}$ The use of rivers as an instrument has recently been challenged by Rothstein (2007), who claims that Hoxby's results cannot be replicated.
} 
also finds a positive effect, measuring competition as the percentage of students in the market attending private schools. Here, the instruments are the shares of the population associated with various religious denominations. An approach similar to Hoxby (1994) is used by Dee (1998), Jepsen (1999) and Sander (1999). Even though all three studies allow for endogeneity of competition, only Dee finds a significant positive link to levels of achievement. This lack of consensus in the literature is best summarized in an extensive survey of studies on school choice by Belfield and Levin (2002), who state that a mere third of the empirical studies undertaken with US data find significantly positive effects of levels of competition on academic achievement.

Empirical Evidence for Other Countries. Possibly due to the assumption that Tiebout-sorting is less prevalent in Europe, a large portion of the literature is concerned with North America. Moreover, in a European context, education isn't typically funded via local taxes, pointing to lower levels of Tiebout-style competition. However, there are countries which allow for school choice without changing residential location, i.e. these countries do not set up mandatory catchment areas. When the institutional feature of nationwide school choice is combined with fixed per-student governmental funding, the setup corresponds to an unrestricted nationwide system of school vouchers. A voucher system compares favorably to traditional Tiebout competition, as it enables low-income families who otherwise wouldn't be able to afford living in a good school district to exercise the exit-option. It provides a level playing field when it comes to making educational choices, at least on a financial level.

Outside Europe, Hsieh and Urquiola (2006) study the Chilean experience in the wake of the introduction of nationwide school vouchers in 1981. They find that not only did the voucher system fail in ameliorating educational outcomes but on top of that it led to increased sorting and cream-skimming, leaving the least able students behind in the public school system. Åhlin (2003) as well as Sandström and Bergström (2005) state that the abolition of catchment areas in Sweden and the installation of a voucher scheme in 1992 led to positive effects on achievement. Beneficial effects are also found by Bradley, Johnes and Millington (1999) for the United Kingdom and by Herczyñski and Herbst (2005) for Poland. Both these studies define competition as the number of schools in the education market. Using urban density as a proxy for school competition, Gibbons and Silva (2008) find that students in densely populated areas in the UK fare better academically. 
It should have become obvious by now that there is a vast literature on school competition that uses educational achievement as an outcome, yet evidence on positive effects is shaky at best. The following part of the book contributes to this discussion in that it adds to the picture evidence on the effects of competition on achievement in the unique subject that is the Netherlands. Not only are the Netherlands unique in allowing nationwide school choice - which clearly distinguishes it from the US setup - but the fact that we are able to measure grading standards allows us to tackle a second question, which has rarely been the subject of scrutiny so far: Does competition have an impact on local grading standards? 

CHAPTER 5

\section{Choice in Local Education Markets: A Driver of High Academic Achievement or of Low Grading Standards?}

This part of the book picks up where chapter 3 left off: It adds the dimension of competition to the agenda. There have been indications that competition may play a role in determining educational standards in chapter 3. Whereas these hints came from control variables that may to some extent also proxy for competition, the current part of the book develops explicit measures of the intensity of competition in local education markets and investigates their impact on educational standards and student achievement.

Recalling the literature survey from the previous chapter, the impact of school competition has been explored to a much lesser degree in Europe than in North America. Given the substantial institutional differences between the US and many European countries, further research is in order. This chapter fills this gap by considering the Dutch education system which is characterized by centrally devised and graded school exit examinations and fixed per-student funding through the central government. In combination with unrestricted school choice which has been in place ever since the early 20th century, this constitutes a system of nationwide quasi-vouchers. Even though Walford (2000) criticizes increasing interventions of the central government when it comes to curricula and the size of teaching staff, it is still obvious that this education system complies with conceptions of a competitive school system harbored by proponents of school choice. Hence, it makes for an interesting subject of studying the implications of school competition. 
So far, the research on Dutch school choice has been largely descriptive (Patrinos (2002), De Vijlder (2000), Ritzen, van Dommelen and de Vijlder (1997), and Dronkers (1995)). Empirical studies by Levin (2004) and Dronkers (2004) examine the effect of attending a catholic school on academic performance. Both conclude that catholic schools generate superior educational outcomes. Clearly, this does not say anything about the impact of levels of competition on achievement. We should, however, take these results as ample evidence that the real outside option to attending a non-catholic school in the Netherlands is transferring to a catholic school rather than choosing another non-catholic one. This is acknowledged in the following sections, where mainly the impact of competition by catholic schools on non-catholic schools is considered.

The remainder of the chapter is organized as follows: part 5.1 gives a brief overview of the Dutch education system. Data sources are described in section 5.2, along with the general empirical strategy. Various competition indices and the measure for grading standards are discussed. Section 5.3 contains the main empirical results. Beneficial effects of competition on academic achievement are found and neither various robustness checks nor the 2SLS estimations suggest any differently. Chapter 5.4 uses quantile regression (QR) and inverse/instrumental variable quantile regression methods (IVQR) in order to determine whether school competition harms schools at the lower tail of the achievement distribution, despite the positive effects that mean regression suggests. Section 5.5 concludes.

\subsection{School Choice, Centralized Funding and Exams}

In this section, a short summary of the institutional setup of school choice in the Netherlands, the organization of school leaving examinations and centralized funding is given.

Dutch compulsory education encompasses twelve school years and starts with primary education (Basisschool) at age five. Primary education lasts eight years and is in most cases completed with the taking of the CITO (Central Institute for Test Development) End of Primary School Test, a standardized test supposed to help parents determine the type of secondary education most suitable for their child. There are three types (opleidingen) of institutions in secondary education among which parents may choose, ranging from pre-vocational to pre-university education. The analysis in this chapter is restricted to 
the pre-university branch VWO, because it is assumed that parents and students in higher branches make more use of the freedom to choose and thus the effects of competition should be more distinct in VWO. ${ }^{29}$ For a more detailed description of VWO and the other school branches, please refer to chapter 3.3.1.

The demand side of Dutch secondary education so far has briefly been touched upon in chapter 3. In a nutshell, it is characterized by parents enjoying unrestricted nationwide school choice. There are no catchment areas whatsoever and schools can neither charge tuition nor easily decline students based on criteria such as ability, thus leaving (at least theoretically) little room for cream-skimming.

Market entry barriers on the supply side are also low, as everyone in the Netherlands is granted the right to set up a school, if he or she so desires. The Dutch government is obliged to take care of school funding as soon as the number of enrolled students rises above a certain number, regardless of denomination or other philosophies and views held by the founders. A fixed annual transfer from the central government is then being triggered by every student enrolled in a particular institution of secondary education. Furthermore, if a school's enrolment drops below a certain level, it can be shut down. As a consequence of this institutional setup, $70 \%$ of Dutch secondary schools are non-public schools.

As has already been mentioned earlier, Dutch students end their secondary schooling careers with the taking of central examinations. These central exams (centraal examen) account for half the final grade. The other half is determined via decentralized school-level exams (schoolexamen). The centraal examen are centrally arranged and graded by the testing agency CITO. ${ }^{30}$

As a whole, this setup seems very fitting for an investigation into the existence of market mechanisms in local education markets.

\footnotetext{
${ }^{29}$ Denessen, Sleegers and Smit (2001) find that with higher socioeconomic status, proximity as a reason for a particular school choice becomes less important. Since the share of students from a lower status background is lower in VWO than in other branches, this implies that in VWO more so than in other branches parents will not just pick the school that is geographically most convenient.

${ }^{30}$ The analysis in this chapter is again limited to subjects where standardized central exams are given. Please refer to chapter 3 for more details.
} 


\subsection{Empirical Strategy and Data Sources}

This section describes the general estimation approach used in testing the idea that schools which are exposed to higher levels of competition respond by providing superior school quality. It discusses various measures of school quality as well as competition. Furthermore, the possible endogeneity of the competition variable is addressed.

\subsubsection{Estimation approach}

The data used in this chapter comprises information on the graduating classes of 2002 and 2003. ${ }^{31}$ While section 5.3 presents estimates obtained from a model that includes school and year fixed effects, the fact that the competition variable hardly varies from one year to another means that even though chapter 5.3.2 reports some longitudinal estimates, the main focus of this chapter is on cross-sectional analysis of the data. The impact of competition on educational achievement is estimated using the following baseline estimation equation:

$$
G_{i j}=\alpha C_{i j}+\mathbf{X}_{\mathbf{i}} \boldsymbol{\beta}+\mathbf{Z}_{\mathbf{j}} \boldsymbol{\delta}+\varepsilon_{i j}
$$

where $i$ denotes the individual $V W O$-school and $j$ education markets (in the context of this book, this will typically be a municipality), $G_{i j}$ is the average centraal examen grade at school-level, $C_{i j}$ is the level of competition faced by school $i$ in market $j, \mathbf{X}_{\mathbf{i}}$ is a vector of control variables at the school level and $\mathbf{Z}_{\mathbf{j}}$ is a vector of control variables at the local geographic (municipality) level. To allow for the possible correlation of $\varepsilon_{i j}$ within geographic areas considered, the model allows for clustering of the standard errors at the municipality level.

\footnotetext{
${ }^{31}$ Even though data on grades and some controls are available prior to 2001, due to a different system of standardization, these exam outcomes cannot be compared to post-2000 grades. For the class of 2001, some of the school level controls could not be obtained.
} 


\subsubsection{Measuring Competition and Achievement}

Two important questions have to be addressed before estimating the baseline equation:

(i) Which outcome measure is to be employed?

(ii) How should competition be measured?

Many measures come to mind when (i) is considered. This work uses school-level average grades in the central exit examinations. Even though quality of education involves so many more components than grades, they may well constitute one of the best available measures of educational output as they are considerably easier to grasp and measure than other aspects. These grades are determined by means of a central exam and central grading, administered by an independent institute (CITO). This practice renders them as close as one can get to an impartial measure of school quality, as long as one is willing to accept that the central exam tests the skills that should be conveyed by a Dutch secondary school. Since exams are mandatory, there is no worry about selection-bias, either, as would be the case with voluntary tests such as the American SAT (Scholastic Aptitude Test). Another variable that has often been used as an outcome are graduation rates. While this variable is available, in the Dutch setting it seems inappropriate, as half of the final grade and thus the graduation rate is determined via decentralized testing. In essence, this makes graduation rates (and standards) a choice variable for the individual school.

There are also numerous ways to capture the intensity of competition (ii). Probably most common is the use of a Herfindahl index of student enrollment, which measures the fragmentation of the student population within a given education market. The Herfindahl index that applies to a certain market $j$ is calculated as:

$$
H_{j}=\sum_{i=1}^{n} s_{i j}^{2},
$$

where $s_{i j}$ is the share of $V W O$-school $i$ 's students in the total number of $V W O$ students in market $j$. 
An even more straightforward measure is the number of $V W O$-schools within an education market, as choice ultimately is a question of the number of alternatives that are on offer.

Even in the presence of school districts, the problem with the above measures is that it is a priori unclear what the geographical boundaries of an education market are. When Tiebout-sorting within a metropolitan area is present, it is insufficient to consider only those institutions within the same school district as a schools's competition. Hence, it makes more sense to count all schools within the metro area as competitors. The Dutch system of school choice without the need to relocate aggravates the problem, as parents can theoretically reside in Amsterdam and send their offspring to a school in a place as far away as Maastricht. As attending a farther away school entails travel cost, it is reasonable to assume that there are limits in terms of distance when it comes to the choice of school. ${ }^{32}$ Following Levin (2004), in this analysis it is assumed that the Dutch gemeenten constitute the boundaries to an education market and the Herfindahl index as well as the number of $V W O$-schools are calculated at the gemeente level. It seems reasonable to assume that people have some sort of attachment to the municipality where they reside and thus are likely to choose among schools located in the same municipality. Since it is, however, not necessary to attend a school within one's municipality of residence, the number of $V W O$ schools within a $15 \mathrm{~km}$ radius around the school in question is also used as a robustness check.

One measure that does not carry with it the need to define education markets is the distance in kilometers to the nearest $V W O$-school. Here, the argument is that competition increases in proximity as it becomes more feasible for students to transfer from one school to another. Any positive (or negative, for that matter) effects of competition should then be more pronounced when proximity is high.

In all of the above measures but the Herfindahl index, only catholic schools will be treated as competitors for the non-catholic schools. As Levin (2004) and Dronkers (2004) have stated, catholic schools outperform other forms of schooling, even after controlling for selection effects, making these schools all the more attractive. The reasoning then is that

\footnotetext{
${ }^{32}$ Denessen, Driessena and Sleegers (2005) find that among 17 reasons Dutch parents cited contributing to the choice of their school, proximity ranked 5th. School quality was found to be the most important reason for a particular choice.
} 
when parents choose a school, the real outside option to public/protestant schooling is a catholic school rather than another public or protestant school. It is also important to notice that about $30 \%$ of all schools are catholic schools. This is a substantially higher share than in most other countries, making opting into the catholic school sector a possibility that is widely available.

Additionally, the effects of competition on the local grading standard are considered. It is often argued that an undesirable effect of competition may be that schools facing competitive pressure will try to attract students by inflating grades, that is, they will apply a lower grading standard. Just as in chapter 3 , the measure of grade inflation is $\Delta G_{i j}=G_{i j}^{s}-G_{i j}^{c}$. Recall from section 3.3.2 that $G_{i j}^{c}$ denotes the average centraal examen grade and $G_{i j}^{s}$ the average schoolexamen grade in school $i$ in district $j$. The setting of average grades $G_{i j}^{c}$ is governed by the central standard defined by a committee of experts. The setting of school grades $G_{i j}^{s}$ on the other hand is governed by locally defined standards. Under coinciding central and school specific standards, one would expect $G_{i j}^{s}=G_{i j}^{c}$, because grading scales are identical in central and school exams. An upward deviation of $G_{i j}^{s}$ from $G_{i j}^{c}$ then constitutes a local standard that falls short of the central standard. If one is willing to accept that the centrally devised standard is the "true" standard, this may be interpreted as grade inflation.

The final outcome variable considered is per-student spending, which is expected to drop under competitive pressure as schools are forced to operate more efficiently. ${ }^{33}$

\subsubsection{Data Sources}

Six different sources provide the data employed in this analysis. With the exception of the data on catholics in the population and the geographical information on school location, these have been used and described in chapter 3. The reader should refer to section 3.3.3 for more details.

\footnotetext{
${ }^{33}$ If parents take per student spending as an indicator of school quality, there may also be a counteracting effect such that schools try to attract students by building a reputation of spending more money per student.
} 
Data on catholic population was provided by the Institute for Applied Research on Religion (KASKI) of the Radboud University Nijmegen. School-level data concerning students' present and past performance along with personal characteristics is again taken from the Kwaliteitskaart Voortgezet Onderwijs (Quality Cards for Secondary Education), issues 2002 - 2004. The school location information given in the Quality Cards are geocoded at the actual street address level and a matrix of distances between all schools is calculated.

The Kwaliteitskaarten dataset provides the school-level control variables and the dependent variables $G_{i j}$ for the central exam and $\Delta G_{i j}$ for the grading standard. Apart from some 'placebo regressions', the empirical analysis will be restricted to the effect of catholic competition on the grades in non-catholic schools. Controls are added for other possible determinants of academic performance. The percentage of cultural minority (CUMI) students is defined as the share of students in a given school branch who have a non-Dutch background. ${ }^{34}$ Along with the percentage of students receiving study cost allowance it proxies for low social status. We add the advice given to students at the end of primary school as a control variable for the incoming students' skill level. Above advice denotes the share of students attending a more demanding branch than the one recommended, i.e. these students are in VWO, yet the given advice was for HAVO - which is the lower school branch adjacent to VWO - at the most. Departing from the variable definitions in chapter 3, we add the variable half above advice. Half above advice denotes the percentage of students who did not get a clear VWO recommendation but rather were ranked in between HAVO and VWO. The percentage of students in ability-tracked classes in the first and second year of secondary education and the average class size are also included.

Finally, postcode level controls are mostly the same as in chapter 3 . They include the quality of life index for a given area, which proxies for the students' social background and is supplied by The Social and Cultural Planning Office of the Netherlands (SCP). The status scores take into account variables such as mean education, mean income, average rents and others. Areas with low social status receive values greater than zero, areas of higher status receive negative values. Data on per capita income, the share of school aged children in the population, population density and the land area at the gemeente level

\footnotetext{
${ }^{34}$ While 'cumi' is an official term in the Netherlands and there is a law that specifies the requirements to be considered part of a cultural minority, essentially these are students who themselves or whose parents were born in Eastern Europe or Third World countries.
} 
comes from Nederland regionaal, published by the Dutch Office of Statistics $(C B S)$.

Again, data from the series Onderwijs in Cijfers (OIC) is used in some of the estimations because financial endowment and characteristics of the teaching staff may affect average grades and standard setting as well as per-student spending. Variables included in the estimations are the share of short and long term debt in the total annual balance, the rate of student body growth or shrinkage, the rate of staff growth or shrinkage and the share of the staff that are part-timers with less than $80 \%$ of a full teaching position. However, data availability is a bit of a problem, as many variables are missing for a large number of schools. Another problem is that the data is not reported at the school level but rather for groups of schools.

Tables A5-1 and A5-2 in the appendix display descriptive statistics for the variables used in the estimation.

\subsection{Estimation Results}

As stated above, this work is concerned with the effect of catholic competition on noncatholic schools. ${ }^{35}$ In all of what follows, a further distinction is made between fully roman-catholic schools and schools that are only in part operated by the catholic church. These partly catholic schools include all kinds of cooperations of the catholic church with other organizations, such as catholic schools cooperating with private/public/protestant schools. If not stated otherwise the competition variable is the number of catholic schools according to one of these two definitions of catholic schools in the municipality. ${ }^{36}$

Descriptive statistics for the dependent variables $G_{i j}, \Delta G_{i j}$ and per student spending are

\footnotetext{
${ }^{35}$ non-catholic schools evidently include non-public schools which are not affiliated with the catholic church, such as protestant or private schools. These schools, neither operated by the catholic church nor public, make up about half of the non-catholic schools.

${ }^{36}$ There is one exception: The towns of Hoek van Holland and Hoogvliet are administered by the municipality of Rotterdam, yet they are located rather far away from the actual city. The town Hoek van Holland is $30 \mathrm{~km}$ away, while Hoogvliet is approximately $15 \mathrm{~km}$ from Rotterdam. Both towns do not directly border Rotterdam and other municipalities have to be traversed in order to reach Rotterdam. This can be seen in figure A5-1 in the appendix. For these reasons, Hoek van Holland and Hoogvliet are treated as education markets separate from Rotterdam.
} 
shown in tables 5-1 for the pooled classes of 2002 and 2003, split up by catholic schools and non-catholic schools. On average, grades awarded in central exams are slightly higher in catholic schools. Even though the difference is statistically significant, it does not seem to be very large, even for school-level averages. ${ }^{37}$

Grade inflation on the other hand seems to be more prevalent in non-catholic schools, the difference in means is again statistically significant. Average spending per student is also higher in non-catholic schools. As schools can gain additional funds from the government when they have a large share of minority students enrolled, no statements on efficiency can be made from this data without controlling for student body composition.

The means of central exam grades and grade differences are significantly different across the groups for both definitions of catholic schools. In the end, however, it doesn't even matter whether or not these differences are significant but rather it matters whether students and their parents perceive catholic schools to be superior. From the data it also seems that the pure roman-catholic schools outperform even the partly catholic schools, yet parents may perceive the partly catholic schools mainly as 'catholic' and thus as an alternative to the non-catholic schools. The competition variable which includes these partly catholic schools may thus be the more appropriate one.

When it comes to the competition variables, table 5-2 shows that the average non-romancatholic school faces about one roman-catholic competitor, whereas the average noncatholic school faces about 1.4 competitors. The maximum amount of competitors is five. As can be expected from the fact that Dutch municipalities are rather small in land area, the number of competitors within $15 \mathrm{~km}$ is much higher than when the education market is defined at the municipality level. The larger competitor set of non-catholic schools also goes with a shorter distance to the nearest catholic school; the Herfindahl index ranges from 0.06 which is indicative of a pretty competitive market to 1 for those municipalities harboring one school only.

Estimation results when the central grade is used as the outcome variable are presented

\footnotetext{
${ }^{37}$ Keep in mind, though, that while individual grades range from 0 to 100, most school-level averages range from 60 to 70 .
} 
TABle 5-1: Summary Statistics, Dependent VARiables.

\begin{tabular}{|c|c|c|c|c|c|c|c|}
\hline \multirow[b]{2}{*}{ Variable } & \multicolumn{3}{|c|}{ (partly) catholic schools } & \multicolumn{3}{|c|}{ non (partly) catholic schools } & \multirow[b]{2}{*}{$\operatorname{diff} \neq 0$} \\
\hline & $\mathbf{N}$ & Mean & $\mathrm{SD}$ & $\mathbf{N}$ & Mean & $\mathrm{SD}$ & \\
\hline Central grade & 369 & 64.40 & 2.59 & 639 & 63.91 & 3.08 & $* *$ \\
\hline Grade inflation & 369 & 4.39 & 2.17 & 639 & 5.08 & 2.81 & $* * *$ \\
\hline \multirow[t]{2}{*}{ Per student spending } & 176 & 5880 & 1257 & 308 & 6032 & 1175 & no \\
\hline & \multicolumn{3}{|c|}{ Roman-catholic schools } & \multicolumn{3}{|c|}{ non Roman-catholic schools } & \\
\hline Variable & $\mathbf{N}$ & Mean & SD & $\mathbf{N}$ & Mean & SD & $\operatorname{diff} \neq 0$ \\
\hline Central grade & 275 & 64.63 & 2.41 & 733 & 63.89 & 3.07 & $* * *$ \\
\hline Grade inflation & 275 & 4.16 & 2.04 & 733 & 5.08 & 2.76 & $* * *$ \\
\hline Per student spending & 129 & 5827 & 1305 & 355 & 6032 & 1166 & * \\
\hline
\end{tabular}

The upper part considers all schools that are in part catholic as competition, whereas the bottom part considers only fully Roman-Catholic schools as competition. ${ }^{*} p<0.10,{ }^{* *} p<0.05,{ }^{* * *} p<0.01$.

TABle 5-2: SUMmary STATistics, COMPETITION VARIABLES.

\begin{tabular}{lrrrrr}
\hline & \multicolumn{5}{c}{ non (partly) catholic schools } \\
\cline { 2 - 6 } Variable & $\mathbf{N}$ & Mean & SD & Min & Max \\
\hline No. cath. schools gemeente & 639 & 1.41 & 1.67 & 0 & 5 \\
No. cath. schools 15km radius & 639 & 4.96 & 4.11 & 0 & 15 \\
km to (partly) cath. school & 639 & 6.16 & 7.29 & 0.08 & 42.55 \\
Herfindahl gemeente & 631 & 0.40 & 0.31 & 0.06 & 1 \\
\hline & \multicolumn{7}{c}{ non Roman-catholic schools } \\
\hline \multicolumn{1}{c}{ Variable } & \multicolumn{7}{c}{ Max } \\
\hline No. cath. schools gemeente & 733 & 0.97 & 1.33 & 0 & 5 \\
No. cath. schools 15km radius & 733 & 3.44 & 3.03 & 0 & 12 \\
km to Roman-cath. school & 733 & 12.23 & 17.41 & 0.15 & 86.66 \\
Herfindahl gemeente & 725 & 0.42 & 0.32 & 0.06 & 1 \\
\hline
\end{tabular}

The upper part considers all schools that are not even in part catholic schools, whereas the bottom part considers those schools that are not Roman-Catholic schools. 
in table 5-3 for non-catholic schools ${ }^{38}$ and in table 5-4 for non-roman-catholic schools. ${ }^{39}$ Specification (1) includes the number of competitors and a year dummy only. Whenever municipality characteristics are added in column (2), the coefficient on competition actually becomes positive and in the case of non-catholic schools significant. Including school level control variables in column (3) further increases the effect of competition. It can be seen that the school level variables now pick up the effects from the municipality level controls, all of which now turn insignificant. The control variables mostly point in the theoretically expected direction. A high share of minority students and students whose advice after basisschool deemed $V W O$ too demanding lead to lower average grades. The same goes for a high percentage of untracked students. Somewhat surprising is the highly significant positive coefficient of class size. This could be due to the fact that Dutch schools receive extra funding for low ability students. These funds are often used to lower class size. In the end this means that smaller classes are a proxy of sorts for a high number of underachieving students. The non-religious school dummy has a negative coefficient, indicating that among the non-catholic schools, those schools not affiliated with any religion perform even worse. ${ }^{40}$ Including school finance measures in column (4) does not alter the results from column (3) much. The financial variables do not add much in terms of explanatory value, as only short term debt is even marginally significant. This is not too surprising, as these variables are reported at an aggregated level of groups of schools. On the downside, many observations are lost due to the limited availability of the financial variables. To put the coefficients into perspective, a one standard deviation change in competition increases central exam grades by 0.15 (non-catholic schools) and 0.1 (non-roman-catholic schools) standard deviations, respectively. This is not a huge effect, but according to Belfield and Levin (2002) in the range of what other studies find. Overall, it seems that competition has a small but significant positive impact on central exam grades.

In order to retain as many observations as possible, from here on only specification (3) is

\footnotetext{
${ }^{38}$ Non-catholic schools are not even partly operated by the catholic church. The competition variable thus includes schools that are only in part operated by the catholic church.

${ }^{39}$ Non-roman-catholic schools may be partly operated by the catholic church, yet they are not fully romancatholic. The competition variable thus includes only those schools that are fully operated by the catholic church.

${ }^{40}$ Alternatively, dummies for the specific denominations can be included. This leaves the results unchanged, the only two significant dummies are those for the non-catholic religious schools. The non-religious school dummy thus captures the same effect. Similarly, including dummies for the Dutch dioceses (bisdommen) does not significantly reduce the estimated effect of competition.
} 
used, as the additional controls do not add much in terms of explanatory value yet they significantly reduce the sample size. In addition, we were unable to obtain information from the Dutch authorities with regards to why so many observations are missing. It is thus not clear on what criteria the smaller sample would be selected, i.e. whether schools report their financial data voluntarily. In that case, a selection model would have to be estimated to obtain unbiased results.

\subsubsection{Endogeneity of Competition}

Another issue that has to be dealt with is the possible endogeneity of competition to local school quality. That is, in an area where public school quality is low, demand for alternative forms of schooling may be especially high, causing a downward bias in the competition coefficients estimated by OLS. To overcome this problem, 2SLS estimation is employed, where the estimation equations are

$$
C_{i j}=\gamma_{0}+\mathbf{I}_{\mathbf{j}} \gamma_{1}+\mathbf{X}_{\mathbf{i}} \gamma_{2}+\mathbf{Z}_{\mathbf{j}} \gamma_{3}+u_{i j}
$$

and

$$
G_{i j}=\beta_{0}+\beta_{1} C_{i j}+\mathbf{X}_{\mathbf{i}} \boldsymbol{\beta}_{2}+\mathbf{Z}_{\mathbf{j}} \boldsymbol{\beta}_{3}+\varepsilon_{i j}
$$

The first stage is given by (21) and the second stage by (22), where the definitions are as in $(19)$ and $I_{j}$ is the set of instruments.

The instruments proposed are the number of catholics living in the education market and its square. As catholics tend to found and attend catholic schools, their number is obviously closely related to the number of catholic schools in the education market. Exogeneity can be assumed because there is no reason to believe that catholics fare better on standardized tests. Moreover, geographical areas where catholics dominate are largely historically predetermined.

The first stage results (table 5-5) indicate that both instruments are highly significant and that there is no problem with weak instruments. The second stage coefficients (table 5-6) are scaled down a bit compared with the OLS results and as is always the case with 2SLS the standard errors increase significantly, rendering the effect of competition insignificant 


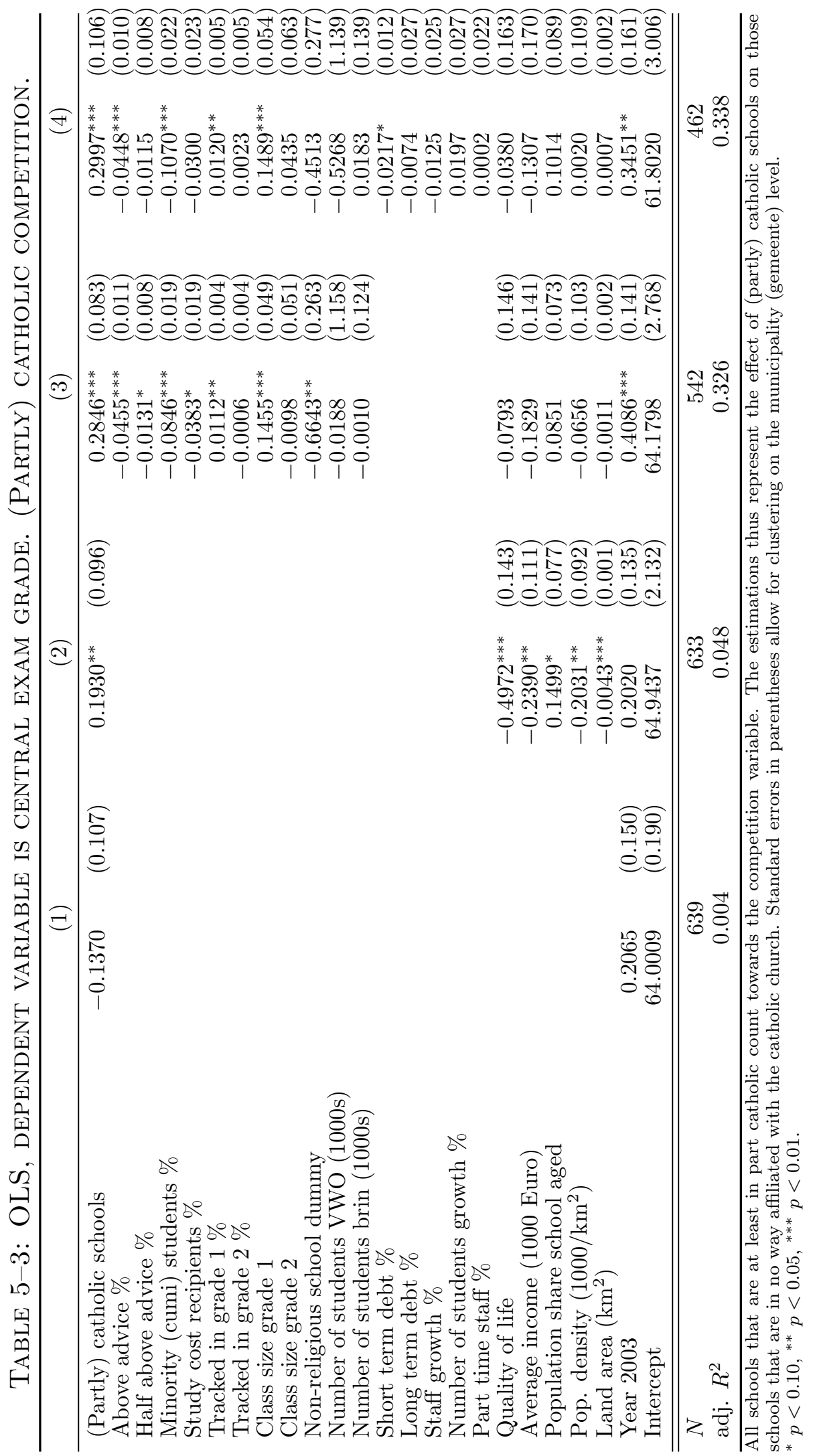




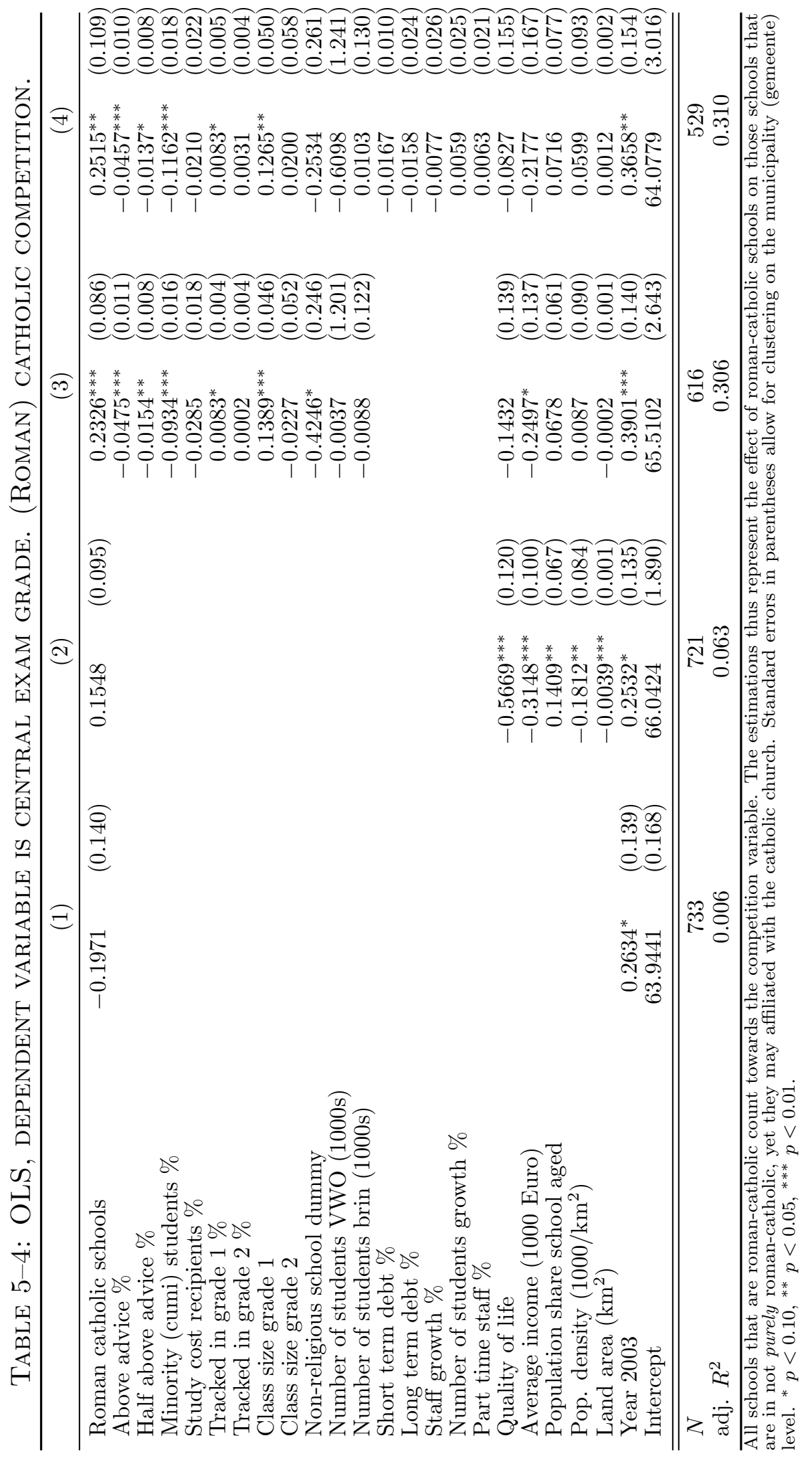


for non-roman-catholic schools. Hausman tests of statistical differences in the OLS and 2SLS estimates, however, fail to reject exogeneity of the competition variable in both cases. When it comes to instrument exogeneity, standard overidentification tests fail to reject the exogeneity of the instruments at any reasonable level.

It should be noted however, that the overidentification tests do not carry much informative value here, as both instruments are derived from the same reasoning. Thus, in an alternative specification shown in tables A5-3 and A5-4 in the appendix, the total length of the road network within a municipality is used as an additional instrument. This instrument is closely related to population size, which is used as an instrument for competition by Geller, Sjoquist and Walker (2006) as well as Hsieh and Urquiola (2006), yet it also takes into account the accessibility of schools. ${ }^{41}$ Any urban/rural differences in achievement are tried to capture by controlling for population density and land area at the market level. Population density should also not react to school quality, as it is not necessary to physically move to the vicinity of the school of choice. The results from these alternative 2SLS estimations are virtually identical and the overidentification statistic is even smaller.

In the end, the 2 SLS results indicate that we can have some confidence in the validity of the baseline OLS results.

TABle 5-5: First Stage Statistics.

$(1)$

(Partly) catholic
$(2)$

Roman-catholic

\begin{tabular}{|c|c|c|c|c|}
\hline $\begin{array}{l}\text { Catholics in municip. (1000s) } \\
\text { Cath in municip. squared }\end{array}$ & $\begin{array}{r}0.1071^{* * *} \\
-0.0007^{* * *}\end{array}$ & $\begin{array}{l}(0.0112) \\
(0.0001)\end{array}$ & $\begin{array}{l}0.0643^{* * *} \\
-0.0003^{*}\end{array}$ & $\begin{array}{l}(0.0166) \\
(0.0002)\end{array}$ \\
\hline F-test excluded instr. & \multicolumn{2}{|c|}{$\begin{array}{c}\mathrm{F}(2,140)=58.36 \\
\mathrm{p}=0.000\end{array}$} & \multicolumn{2}{|c|}{$\begin{array}{c}\mathrm{F}(2,153)=15.63 \\
\mathrm{p}=0.000\end{array}$} \\
\hline partial $R^{2}$ excluded instr. & \multicolumn{2}{|c|}{0.61} & \multicolumn{2}{|c|}{0.41} \\
\hline$R^{2}$ & \multicolumn{2}{|c|}{$\begin{array}{l}0.83 \\
542\end{array}$} & \multicolumn{2}{|c|}{0.66} \\
\hline
\end{tabular}

Estimates are for 1st stage of 2SLS. Number of schools is the dependent variable of 1st stage. Estimates shown for the excluded instruments only. Control variables are as in column (3) of the baseline OLS tables 5-3 and 5-4. Standard errors in parentheses allow for clustering by municipality. ${ }^{*} p<0.10,{ }^{* *} p<0.05,{ }^{* * *} p<0.01$.

\footnotetext{
${ }^{41}$ Gibbons and Silva (2008) find that academic achievement is higher in urban areas of the UK. This could cast doubt on the assumption of exogeneity. However, they expressly attribute this effect to higher levels of competition.
} 
TABle 5-6: 2SLS, DEPENDENT VARIABLE IS CENTRAL EXAM GRADE.

\begin{tabular}{|c|c|c|c|c|}
\hline \multirow[b]{2}{*}{ (Partly) catholic schools } & \multicolumn{2}{|c|}{$\begin{array}{c}(1) \\
(\text { Partly) catholic }\end{array}$} & \multicolumn{2}{|c|}{$\begin{array}{c}(2) \\
\text { Roman-catholic }\end{array}$} \\
\hline & $0.2434^{*}$ & $(0.127)$ & & \\
\hline Roman catholic schools & & & 0.1700 & $(0.155)$ \\
\hline Above advice $\%$ & $-0.0456^{* * *}$ & $(0.011)$ & $-0.0473^{* * *}$ & $(0.010)$ \\
\hline Half above advice \% & $-0.0136^{*}$ & $(0.008)$ & $-0.0157^{* *}$ & $(0.008)$ \\
\hline Minority (cumi) students \% & $-0.0831^{* * *}$ & $(0.020)$ & $-0.0915^{* * *}$ & $(0.017)$ \\
\hline Study cost recipients $\%$ & $-0.0384^{* *}$ & $(0.019)$ & -0.0289 & $(0.018)$ \\
\hline Tracked in grade $1 \%$ & $0.0111^{* *}$ & $(0.004)$ & $0.0083^{*}$ & $(0.004)$ \\
\hline Tracked in grade $2 \%$ & -0.0007 & $(0.004)$ & 0.0002 & $(0.004)$ \\
\hline Class size grade 1 & $0.1466^{* * *}$ & $(0.048)$ & $0.1413^{* * *}$ & $(0.045)$ \\
\hline Class size grade 2 & -0.0101 & $(0.050)$ & -0.0233 & $(0.052)$ \\
\hline Non-religious school dummy & $-0.6707^{* *}$ & $(0.264)$ & $-0.4278^{*}$ & $(0.244)$ \\
\hline Number of students VWO (1000s) & 0.0414 & $(1.182)$ & 0.0869 & $(1.247)$ \\
\hline Number of students brin $(1000 \mathrm{~s})$ & -0.0055 & $(0.121)$ & -0.0147 & $(0.119)$ \\
\hline Quality of life & -0.0757 & $(0.146)$ & -0.1381 & $(0.140)$ \\
\hline Average income (1000 Euro) & -0.1818 & $(0.138)$ & $-0.2497^{*}$ & $(0.135)$ \\
\hline Population share school aged & 0.0748 & $(0.075)$ & 0.0557 & $(0.063)$ \\
\hline Pop. density $\left(1000 / \mathrm{km}^{2}\right)$ & -0.0507 & $(0.097)$ & 0.0221 & $(0.087)$ \\
\hline Land area $\left(\mathrm{km}^{2}\right)$ & -0.0008 & $(0.001)$ & 0.0000 & $(0.001)$ \\
\hline Year 2003 & $0.4060^{* * *}$ & $(0.137)$ & $0.3859^{* * *}$ & $(0.137)$ \\
\hline Intercept & 64.3534 & $(2.741)$ & 65.6897 & $(2.627)$ \\
\hline$N$ & \multirow{2}{*}{\multicolumn{2}{|c|}{$\begin{array}{c}542 \\
0.325\end{array}$}} & \multirow{2}{*}{\multicolumn{2}{|c|}{$\begin{array}{c}616 \\
0.306\end{array}$}} \\
\hline adj. $R^{2}$ & & & & \\
\hline test of overid. restr. $\chi^{2}(1)$ & 0.010 & $=0.920)$ & 0.145 & $=0.703)$ \\
\hline
\end{tabular}

\subsubsection{Robustness checks}

Table 5-7 displays results for some alternative specifications. In all of these, the dependent variable is the central exam grade. The top part (a) of the table shows that the effect of catholic competition on public schools is somewhat larger than for all non-catholic schools. This is intuitively consistent with the finding that non-religious schools are the worst schools among the non-catholic schools.

Because there may be urban/rural differences in the effects of competition and because catholic competition might not have as much of an effect in predominantly catholic dioceses, part (b) of the table shows how sensitive the results are to dropping these schools from 
the sample. ${ }^{42}$ While dropping the grote 4 (big 4) cities Amsterdam, Utrecht, Rotterdam and Den Haag slightly reduces the competition effects, the impact of catholic alternatives seems to be especially large in those dioceses that are not predominantly catholic. The effect of catholic competition seems to be largest in non-catholic areas outside the grote 4 .

An important question is whether the effect of competition is truly an effect that can only be found when catholic schools are treated as the competitors. The bottom part (c) of table 5-7 shows that the number of other schools than the catholic ones does not have an impact on exam grades and that catholic competition does not improve the outcome for other catholic schools. These estimates are in line with the assumption of this chapter that competition in the Netherlands is mainly inter-denominational and affects the non-catholic schools

Other proxies for competition are employed in table 5-8. The number of schools within a $15 \mathrm{~km}$ radius is significant at the ten percent level. If it is in fact true that households mostly choose schools that are located within their own gemeente, then the $15 \mathrm{~km}$ radius is an inappropriate specification as it will almost inevitably contain schools in other municipalities. The same argument is true for distance to the nearest catholic school (not significant), as this will sometimes be the distance to a school outside the municipality. In addition, a drawback of the data used is that all distances are calculated 'as the crow flies', thus neglecting geographical obstacles such as rivers or bad connecting roads between places. The Herfindahl measure of competition does not solely depend on catholic school competition. Higher concentration is associated with lower average grades, yet the coefficient is significant only in one of the 2SLS estimations. Even though the Herfindahl index comprises the shares of all schools in a market, it is still heavily influenced by the number of catholic schools in the market. Thus, the significant coefficient does not stand against the hypothesis that catholic schools are the real competition. Quite the contrary, the effect should be reduced in comparison to a competition measure that considers only catholic schools. Taken together, the rather weak results for the alternative competition measures provide some support for treating the municipalities as separate education markets.

Finally, table 5-9 reports estimates when school and year fixed effects are included. As can be seen in part (a), the coefficient on the number of competitors has the expected sign

\footnotetext{
${ }^{42}$ The dioceses of Roermond, Breda and Den Bosch are classified as predominantly catholic dioceses because the share of catholics in the population is above $40 \%$ in all three.
} 
TABle 5-7: Robustness CHECKS, DePendent VARIABle EXAM GRADE.

(1)

(Partly) catholic
(2)

Roman-catholic

(a) catholic competition, effect on public schools

Number of catholic schools in muni.

$0.3723^{* * *}$

$(0.129)$

Number of rom.-cath. schools in muni.

$0.3353^{* *}$

$(0.137)$

(b) catholic competition (\# cat schools), sub-samples

Catholic, w/out big 4 cities

Rom.-cath., w/out big 4 cities

Catholic, w/out cath. dioceses

$0.2494^{* *}$

$0.3409^{* * *}$

Catholic, w/out big 4 and cath. dioc.

$0.3711^{* * *}$

Rom.-cath., w/out big 4 and cath. dioc.

\section{(c) other forms of competition, placebo regressions}

All competitors on all schools

$\begin{array}{rr}0.0293 & (0.036) \\ 0.0461 & (0.047) \\ 0.0380 & (0.043) \\ -0.0034 & (0.118) \\ 0.0119 & (0.146) \\ -0.0049 & (0.046) \\ 0.0080 & (0.041) \\ 0.0174 & (0.059) \\ 0.0192 & (0.050) \\ -0.0835 & (0.077) \\ -0.0245 & (0.095)\end{array}$

All competitors on non-cat. schools

All competitors on non-rom.-cat. schools

Cat. competitors on cat. schools

R.-cat. competitors on rom.-cat. schools

Non-cat. competitors on all schools

Non-rom.-cat. comp. on all schools

Non-cat. competitors on non-cath schools

Non-rom.-cat. comp. on non-rom.-cath. sch.

Non-cat. competitors on cath. schools

$-0.0245$

$0.2020^{*}$

$0.3027^{* * *}$

$0.3595^{* *}$

Non-rom.-cat. comp. on rom.-cath. schools

Part (a) shows the effect of 'number of catholic/roman-catholic schools in municipality' on central exam grades in public schools. Part (b) shows the coefficients of the variable 'number of catholic/ roman-catholic schools in municipality'. The bottom part (c) shows coefficients for other forms of competition that are not believed to have an effect on academic achievment. Where applicable, all schools that are at least in part catholic schools count towards the competition variable in column (1), whereas only roman-catholic schools are considered in column (2). Only coefficients of the competition variable are displayed. Control variables are as in column (3) of the baseline OLS tables 5-3 and 5-4. Standard errors in parentheses allow for clustering on the municipality (gemeente) level. ${ }^{*} p<0.10,{ }^{* *} p<0.05,{ }^{* * *} p<0.01$.

but is nowhere near statistical significance. Part (b) shows rather inconsistent estimates when the Herfindahl index is employed as the competition measure. While the effect on non-catholic schools is highly significant and in the expected direction, there is no effect to be found on non-roman-catholic schools. Upon excluding changes in the Herfindahl index greater than 0.1 points, the effects of student fragmentation on non-catholic schools are significant in both cases. The magnitude of the coefficient - which would imply an increase in grades by 20 to 30 points when going from a monopoly to perfect competition - is, however, rather implausible. Since the data comprise only two years and especially the number of schools hardly changes, not too much should be read into these results. 
TABle 5-8: Other MeAsuRes OF COMPETITION.

\begin{tabular}{|c|c|c|c|c|}
\hline \multirow[b]{2}{*}{ OLS estimates } & \multicolumn{2}{|c|}{$\begin{array}{c}(1) \\
\text { (Partly) catholic }\end{array}$} & \multicolumn{2}{|c|}{$\begin{array}{c}(2) \\
\text { Roman-catholic }\end{array}$} \\
\hline & & & & \\
\hline $\begin{array}{l}\text { Cath. schools w/in } 15 \mathrm{~km} \\
\mathrm{~km} \text { to nearest catholic school } \\
\text { Roman-cath. schools w/in } 15 \mathrm{~km} \\
\text { km to nearest rom.-cath. school } \\
\text { Herfindahl enrolment }\end{array}$ & $\begin{array}{l}0.075^{* *} \\
0.004\end{array}$ & $\begin{array}{l}(0.037) \\
(0.021)\end{array}$ & $\begin{array}{r}0.075 \\
-0.007 \\
-0.385\end{array}$ & $\begin{array}{r}(0.047) \\
(0.008) \\
(0.535)\end{array}$ \\
\hline \multicolumn{5}{|l|}{ 2SLS estimates } \\
\hline $\begin{array}{l}\text { Cath. schools w/in } 15 \mathrm{~km} \\
\mathrm{~km} \text { to nearest catholic school } \\
\text { Roman-cath. schools w/in } 15 \mathrm{~km} \\
\text { km to nearest rom.-cath. school } \\
\text { Herfindahl enrolment }\end{array}$ & $\begin{array}{r}0.137^{*} \\
-0.057\end{array}$ & $\begin{array}{l}(0.075) \\
(0.038)\end{array}$ & $\begin{array}{r}0.079 \\
-0.011 \\
-0.774\end{array}$ & $\begin{array}{r}(0.082) \\
(0.015) \\
(1.068)\end{array}$ \\
\hline
\end{tabular}

TABle 5-9: Fixed EFFECts ESTIMATES, DEP. VAR. IS CENTRAL EXAM GRADE.

(1)

(Partly) catholic
(2)

Roman-catholic

\section{(a) catholic competition}

Number catholic schools muni.
0.1990
$(0.477)$

0.1503

Number rom.-cath. sch. muni.

(b) competition measured by Herfindahl-index (HI)

HI, eff. on all schools

HI, eff. on non-cat. schools

HI, eff. on non-rom.-cat. sch.
$-0.789$

$-19.012^{* * *}$

$-1.404$

\section{(c) competition, Herfindahl-index (HI) robustness}

HI, eff. on all schools

HI, eff. on non-cat. schools

HI, eff. on non-rom.-cat. sch.

$$
\begin{aligned}
& -13.983 \\
& -30.971^{\text {*** }} \\
& -22.838^{\text {** }}
\end{aligned}
$$

$(10.377)$

Fixed effects estimates of the effect of 'number of catholic/roman-catholic schools in municipality' on central exam grades in non (roman-)catholic schools are displayed in the top part of the table. The bottom part shows the effect of changes in the Herfindahl index of enrolment within a municipality on central exam grades in all schools/ non-catholic/ non- (roman)catholic schools. Herfindahl-index robustness excludes municipalities where the change in the Herfindahl index was greater than 0.1 (this applies to 10 out of 868 schools). Only coefficients of the competition variable are displayed. Control variables are as in column (3) of the baseline OLS tables 5-3 and 5-4. Standard errors in parentheses allow for clustering on the municipality (gemeente) level. There are no 2SLS estimates, because the data on catholics are supplied for one year only, hence the instrument doesn't vary over time. ${ }^{*} p<0.10,{ }^{* *} p<0.05,{ }^{* * *} p<0.01$. 
TABle 5-10: Alternative outcome measures.

(1)

(Partly) catholic
(2)

Roman-catholic

catholic competition, effect on grade inflation

Number of catholic schools in muni.

Number of rom.-cath. schools in muni. $N$
$-0.1695^{*}$

$(0.0899)$

542
$-0.1601^{*}$ 616

\section{catholic competition, effect on per student spending}

Number of catholic schools in muni. $-1.8138$ $(46.3016)$

Number of rom.-cath. schools in muni.

$$
252
$$

estimates of the effect of 'number of catholic/roman-catholic schools in municipality' on grade inflation and per student spending. Control variables are as in column (3) of the baseline OLS tables 5-3 and 5-4. Standard errors in parentheses allow for clustering by municipality. ${ }^{*} p<0.10,{ }^{* *} p<0.05,{ }^{* * *} p<0.01$.

\subsubsection{Alternative outcome variables}

Two alternative outcomes of competition are considered in this section. When it comes to per-student spending, there is clearly no effect to be found. ${ }^{43}$ More interesting results are obtained for the effect of competition on grade inflation. As stated above, theory suggests that under competitive pressure, schools will tend to award higher schoolexamen-grades in order to attract students. Somewhat puzzling is the fact that OLS results show that higher levels of competition actually induce lower levels of grade inflation. ${ }^{44}$ The magnitude of the effect is similar to the effect on central grades: a one standard deviation shift in competition lowers grade inflation by 0.1 standard deviations. In light of the finding that competition increases the central exam grades, this means that obviously schools do not react to competition by inflating local school grades by the same amount.

Whenever school and year fixed effects are included in table 5-11, the coefficient on the

\footnotetext{
${ }^{43}$ The only significant effect is found for the distance measure. The farther the nearest catholic school is away, the more money non-catholic schools spend per student. Since the distance measure did not have an effect on exam grades, an interpretation of this result is hard to come up with. In addition, the per student spending data is available for only roughly half of the schools.

${ }^{44} 2$ SLS results are not reported, since Hausman tests again fail to reject exogeneity of the competition variable.
} 
number of competitors has the expected sign but is not statistically significant, as was the case for central exam grades. Similarly, part (b) shows inconsistent estimates when the Herfindahl index is employed as the competition measure. While the effect on non-catholic schools is highly significant and in the expected direction, there is no effect to be found on non-roman-catholic schools. Upon excluding changes in the Herfindahl index greater than 0.1 points, the effects of student fragmentation on non-catholic schools are much larger for the non-roman-catholic schools, too. The estimates imply an increase in grade inflation by 15 to 20 point when going from perfect competition to a monopoly. As stated earlier in the context of central grades, this seems rather implausible and one should rather stress the cross-sectional results which also point to a slightly beneficial effect of competition, leading to higher local school grading standards.

This section so far has provided some tentative evidence that competition may not be so detrimental after all, not even when it comes to grade inflation.

TABle 5-11: Fixed EFFECTS ESTIMATES, DEPENDENT VARIABLE IS GRADE INFLATION.

$(1)$

(Partly) catholic
(2)

Roman-catholic

\section{(a) catholic competition}

Number catholic schools muni. Number rom.-cath. sch. muni.

$$
-0.2073 \quad(0.415)
$$

0.0659

(b) competition measured by Herfindahl-index (HI)
HI, eff. on all schools
$-0.305$
HI, eff. on non-cat. schools
HI, eff. on non-rom.-cat. sch.
$11.244^{* * *}$

\section{(c) competition, Herfindahl-index (HI) robustness}

$\begin{array}{lll}\text { HI, eff. on all schools } & 6.359 & (9.155) \\ \text { HI, eff. on non-cat. schools } & 18.901^{* *} & (9.080) \\ \text { HI, eff. on non-rom.-cat. sch. } & 14.724 & (9.405)\end{array}$

Fixed effects estimates of the effect of 'number of catholic/roman-catholic schools in municipality' on grade inflation in non (roman-)catholic schools are displayed in the top part of the table. The bottom part shows the effect of changes in the Herfindahl index of enrolment within a municipality on grade inflation in all schools/non-catholic/non-(roman-)catholic schools. Herfindahl-index robustness excludes municipalities where the change in the Herfindahl index was greater than 0.1 (this applies to 10 out of 868 schools). Only coefficients of the competition variable are displayed. Control variables are as in column (3) of the baseline OLS tables 5-3 and 5-4. Standard errors in parentheses allow for clustering on the municipality (gemeente) level. There are no 2SLS estimates, because the data on catholics are supplied for one year only, hence the instrument doesn't vary over time. ${ }^{*} p<0.10,{ }^{* *} p<0.05,{ }^{* * *} p<0.01$. 


\subsection{Distributional Analysis - QR and IVQR}

Whenever competition in the education sector is discussed, a major concern is that the consequences of choice may be very different at different points of the achievement distribution. Specifically, it is often argued that the best schools will be able to lure the most able students away from the badly performing schools. When this is the case, positive effects of competition on the mean school may still be observed, that is, the average effect of competition may be beneficial. At the same time, it may be the case that the effects of competition are actually negative for the underachieving schools because they lose their most able students to the 'elite' schools at the upper tail of the achievement distribution for whom the effects of competition would then be positive. Thus, the results presented in the previous chapter are misleading, whenever the effect varies across the distribution. A tool that is very useful in this context is quantile regression (QR), as proposed by Koenker and Bassett (1978). In general notation, it allows the calculation of the $\tau$-th quantile of a dependent variable $Y$ given the independent variables $X$ by solving:

$$
\boldsymbol{\beta}(\tau)=\arg \min _{\boldsymbol{\beta}} E\left[\rho_{\tau}(Y-\mathbf{X} \boldsymbol{\beta})\right]
$$

where $\rho_{\tau}$ is the 'check function' or 'loss function' given by:

$$
\rho_{\tau}(\varepsilon)=[\tau-1(\varepsilon<0)] \varepsilon,
$$

and $\varepsilon=(Y-\mathbf{X} \boldsymbol{\beta})$. The check function thus generates asymmetrically weighted absolute residuals. The $\boldsymbol{\beta}$ that minimizes equation (23) contains the parameters of interest for quantile $\tau$.

A quantile regression in the context of this chapter can be written in the form of a random coefficients model. The effect of competition on academic achievement in the presence of heterogenous effects across the distribution of the outcome variable can then be represented by the following estimation equation: 


$$
G_{i j}=\alpha(U) C_{i j}+\mathbf{X}_{\mathbf{i}} \boldsymbol{\beta}(\boldsymbol{U})+\mathbf{Z}_{\mathbf{j}} \boldsymbol{\delta}(\boldsymbol{U})+\varepsilon_{i j}(U)
$$

where - as defined earlier in the chapter $-G_{i j}$ are academic outcomes, $C_{i j}$ is the measure of competition and $\mathbf{X}_{\mathbf{i}}$ as well as $\mathbf{Z}_{\mathbf{j}}$ are vectors of control variables. ${ }^{45}$ In the spirit of Doksum (1974), the rank term $U$ can be interpreted as unobserved, innate ability or proneness (in this context, e.g. proneness to learn). Unobserved ability is normalized to be uniformly distributed and thus represents the rank of the individuals when it comes to ability: $U \mid C, \mathbf{X}_{\mathbf{i}}, \mathbf{Z}_{\mathbf{j}} \sim$ Uniform $(0,1)$. Individuals with the same observable characteristics will exhibit heterogenous outcomes whenever their rank in $U$ differs. The use of QR can thus be interpreted as accounting for unobserved heterogeneity.

While QR has become increasingly popular in the recent past (perhaps due to its now wide availability in commonly used statistics packages), conventional QR suffers from the same problems as OLS whenever endogeneity is present. That is, equation (25) gives unbiased results only if competition is not determined together with $U$. As has been laid out earlier, it is not unlikely that $C_{i j}$ may be statistically dependent on $U$. This means that even though in the previous sections of this chapter, 2SLS estimates did not point to any endogeneity issues at the mean, things may be different at other quantiles. As endogeneity problems can be countered through the use of instrumental variables in regular OLS situations, intuitively the question of whether IV methods can be applied to $\mathrm{QR}$ comes to mind. Indeed, a method of coping with endogeneity in the context of QR has been suggested and further developed by Chernozhukov and Hansen (2005, 2006, 2007 and 2008) and has been dubbed instrumental variable quantile regression or inverse quantile regression (IVQR). ${ }^{46}$

Again using the random coefficients model from equation (25), the assumptions underlying the IVQR model are:

\footnotetext{
${ }^{45}$ The corresponding fixed coefficients model with additive disturbances can be written as: $G_{i j}=\alpha C_{i j}+$ $\mathbf{X}_{\mathbf{i}} \boldsymbol{\beta}+\mathbf{Z}_{\mathbf{j}} \boldsymbol{\delta}+\varepsilon_{i j}(U)$.

${ }^{46}$ IVQR so far has not been implemented in any statistics packages, yet the MATLAB code is kindly provided by Chris Hansen on his website.
} 
(a1) $\alpha(U) C_{i j}+\mathbf{X}_{\mathbf{i}} \boldsymbol{\beta}(\boldsymbol{U})+\mathbf{Z}_{\mathbf{j}} \boldsymbol{\delta}(\boldsymbol{U})$ is strictly increasing in $U$.

(a2) $U \mid \mathbf{X}_{\mathbf{i}}, \mathbf{Z}_{\mathbf{j}}, \mathbf{I}_{\mathbf{i j}} \sim \operatorname{Uniform}(0,1)$. $U$ is independent of $\mathbf{X}_{\mathbf{i}}, \mathbf{Z}_{\mathbf{j}}$ and the instruments $\mathbf{I}_{\mathbf{i j}}$ which are excluded from the structural equation (25) (where $\mathbf{I}$ consists of at least as many instruments as there are endogenous variables, $\operatorname{dim}(\mathbf{I}) \geq \operatorname{dim}(C))$. In what follows, it is possible to plug in the instruments themselves into the regressions. Alternatively, one can run a 'first stage', where similar to 2SLS, the endogenous variable is linearly projected onto the exogenous variables plus the excluded instruments. The predicted values of the endogenous variable then make up $\mathbf{I}_{\mathbf{i j}}$. The latter approach is chosen for the estimations in this chapter.

(a3) Rank invariance or rank similarity: Under each realization of the endogenous variable $C_{i j}$, an observation's rank would stay the same or change only in terms of random slippages.

From the structural equation (25) and the monotonicity assumption (a1) it can be seen that $G_{i j} \leq \alpha(\tau) C_{i j}+\mathbf{X}_{\mathbf{i}} \boldsymbol{\beta}(\boldsymbol{\tau})+\mathbf{Z}_{\mathbf{j}} \boldsymbol{\delta}(\boldsymbol{\tau})$ is equivalent to $U \leq \tau$ where $\tau$ denotes the quantile of interest. Denoting by $Q_{G}(\cdot)$ the conditional quantiles of $G$ and Considering (a1) and (a2), it then follows that

$$
P\left[G_{i j} \leq Q_{G}\left(\tau \mid C_{i j}, \mathbf{X}_{\mathbf{i}}, \mathbf{Z}_{\mathbf{j}}\right) \mid \mathbf{X}_{\mathbf{i}}, \mathbf{Z}_{\mathbf{j}}, \mathbf{I}_{\mathbf{i j}}\right]=\tau,{ }^{47}
$$

which is equivalent to

$$
P\left[G_{i j} \leq \alpha(\tau) C_{i j}+\mathbf{X}_{\mathbf{i}} \boldsymbol{\beta}(\boldsymbol{\tau})+\mathbf{Z}_{\mathbf{j}} \boldsymbol{\delta}(\boldsymbol{\tau}) \mid \mathbf{X}_{\mathbf{i}}, \mathbf{Z}_{\mathbf{j}}, \mathbf{I}_{\mathbf{i j}}\right]=\tau .
$$

This moment condition is what Chernozhukov and Hansen $(2005,2006)$ call the main

\footnotetext{
${ }^{47}$ The conditional quantiles $Q_{G}\left(\tau \mid C_{i j}, \mathbf{X}_{\mathbf{i}}, \mathbf{Z}_{\mathbf{j}}\right)=\alpha(\tau) C_{i j}+\mathbf{X}_{\mathbf{i}} \boldsymbol{\beta}(\boldsymbol{\tau})+\mathbf{Z}_{\mathbf{j}} \boldsymbol{\delta}(\boldsymbol{\tau})$ of the structural QR equation suffer from endogeneity bias. Thus, Chernozhukov and Hansen (2008) define the structural quantile function (SQF) as $S_{G}\left(\tau \mid c_{i j}, \mathbf{x}_{\mathbf{i}}, \mathbf{z}_{\mathbf{j}}\right)=\alpha(\tau) c_{i j}+\mathbf{x}_{\mathbf{i}} \boldsymbol{\beta}(\boldsymbol{\tau})+\mathbf{z}_{\mathbf{j}} \boldsymbol{\delta}(\boldsymbol{\tau})$, where the lowercase variables denote realizations of the random variables defined above. The SQF gives the latent outcome $G_{i j}$ when the endogenous variable $C_{i j}$ is fixed at a certain level and the disturbance is sampled independent of $C_{i j}$. Because of the endogeneity of competition, the SQF is a different function than the regular conditional quantile function $Q_{G}\left(\tau \mid C_{i j}, \mathbf{X}_{\mathbf{i}}, \mathbf{Z}_{\mathbf{j}}\right)$ that can be derived analogous to equation (23). In the presence of endogeneity however, $S_{G}\left(\tau \mid c_{i j}, \mathbf{x}_{\mathbf{i}}, \mathbf{z}_{\mathbf{j}}\right)$ cannot be directly estimated via a $\mathrm{QR}$ because the outcomes are latent. However, the use of suitable instruments can overcome this limitation. In order to keep the notation simple, this book will not discriminate between $Q_{G}$ and $S_{G}$.
} 
implication of the model. Equation (27) essentially states that the $\tau$-th quantile of the random variable $G_{i j}-\alpha(\tau) C_{i j}-\mathbf{X}_{\mathbf{i}} \boldsymbol{\beta}(\boldsymbol{\tau})-\mathbf{Z}_{\mathbf{j}} \boldsymbol{\delta}(\boldsymbol{\tau})$ given $\mathbf{X}_{\mathbf{i}}, \mathbf{Z}_{\mathbf{j}}, \mathbf{I}_{\mathbf{i j}}$ is equal to zero. ${ }^{48}$

The coefficients $\boldsymbol{\beta}^{*}, \boldsymbol{\delta}^{*}$ and most importantly $\boldsymbol{\gamma}$ should then equal zero in the following quantile regression:

$$
G_{i j}-\alpha(\tau) C_{i j}-\mathbf{X}_{\mathbf{i}} \boldsymbol{\beta}(\boldsymbol{\tau})-\mathbf{Z}_{\mathbf{j}} \boldsymbol{\delta}(\boldsymbol{\tau})=\mathbf{X}_{\mathbf{i}} \boldsymbol{\beta}^{*}(\tau)+\mathbf{Z}_{\mathbf{j}} \boldsymbol{\delta}^{*}(\tau)+\mathbf{I}_{\mathbf{i j}} \boldsymbol{\gamma}(\tau)
$$

Since $\alpha(\tau)$ in equation (28) is unknown, an $\widehat{\alpha}(\tau)$ must be chosen so that it minimizes the distance of $\gamma$ from zero. For a finite sample size $n$ this can be evaluated using a Wald statistic $W_{n}(\alpha)$ and the coefficient $\widehat{\alpha}(\tau)$ can be chosen accordingly:

$$
\widehat{\alpha}(\tau)=\arg \inf _{\alpha \in \mathcal{A}} W_{n}(\alpha)
$$

where

$$
(\widehat{\boldsymbol{\beta}}(\alpha, \tau), \widehat{\boldsymbol{\delta}}(\alpha, \tau), \widehat{\boldsymbol{\gamma}}(\alpha, \tau))=\arg \inf _{(\boldsymbol{\beta}, \boldsymbol{\delta}, \boldsymbol{\gamma})} Q_{G, n}(\tau, \alpha, \boldsymbol{\beta}, \boldsymbol{\delta}, \boldsymbol{\gamma})
$$

and $\mathcal{A}$ is a grid of potential values for $\alpha, W_{n}(\alpha)=n(\widehat{\gamma}(\alpha, \tau))^{\prime} \widehat{M}(\alpha)(\widehat{\gamma}(\alpha, \tau))$ and $M(\alpha)$ is the inverse of the asymptotic variance $\sqrt{n}(\widehat{\gamma}(\tau)-\gamma(\tau))$. $W_{n}(\alpha)$ then becomes the Wald statistic for testing $\gamma(\alpha, \tau)=0$. Estimates for the parameters can then be written as $(\widehat{\alpha}(\tau), \widehat{\boldsymbol{\beta}}(\tau), \widehat{\boldsymbol{\delta}}(\tau))=(\widehat{\alpha}(\tau), \widehat{\boldsymbol{\beta}}(\widehat{\alpha}(\tau), \tau), \widehat{\boldsymbol{\delta}}(\widehat{\alpha}(\tau), \tau))$.

To find a practical way of estimating the IVQR model, consider that equation (28) can be stated as:

$$
G_{i j}-\alpha(\tau) C_{i j}=\mathbf{X}_{\mathbf{i}}\left(\boldsymbol{\beta}(\boldsymbol{\tau})+\boldsymbol{\beta}^{*}(\tau)\right)+\mathbf{Z}_{\mathbf{j}}\left(\boldsymbol{\delta}(\boldsymbol{\tau})+\boldsymbol{\delta}^{*}(\boldsymbol{\tau})\right)+\mathbf{I}_{\mathbf{i j}} \gamma(\boldsymbol{\tau})
$$

${ }^{48}$ Consider for example the moment condition for the 0.1 quantile: $P\left[G_{i j} \leq Q_{G}\left(0.1 \mid C_{i j}, \mathbf{X}_{\mathbf{i}}, \mathbf{Z}_{\mathbf{j}}\right) \mid \mathbf{X}_{\mathbf{i}}, \mathbf{Z}_{\mathbf{j}}, \mathbf{I}_{\mathbf{i j}}\right]=$ 0.1 , which is equivalent to $P\left[G_{i j}-\alpha(0.1) C_{i j}-\mathbf{X}_{\mathbf{i}} \boldsymbol{\beta}(\mathbf{0 . 1})-\mathbf{Z}_{\mathbf{j}} \boldsymbol{\delta}(\mathbf{0 . 1}) \leq 0 \mid \mathbf{X}_{\mathbf{i}}, \mathbf{Z}_{\mathbf{j}}, \mathbf{I}_{\mathbf{i j}}\right]=0.1$. This is the case because only $10 \%$ of the observations of $G_{i j}$ are below $Q_{G}\left(0.1 \mid C_{i j}, \mathbf{X}_{\mathbf{i}}, \mathbf{Z}_{\mathbf{j}}\right)$. From this it can be seen that 0 must be the 0.1 quantile of $G_{i j}-\alpha(0.1) C_{i j}-\mathbf{X}_{\mathbf{i}} \boldsymbol{\beta}(\mathbf{0 . 1})-\mathbf{Z}_{\mathbf{j}} \boldsymbol{\delta}(\mathbf{0 . 1})$, because 0 is the value below which $10 \%$ of the observations of $G_{i j}-\alpha(0.1) C_{i j}-\mathbf{X}_{\mathbf{i}} \boldsymbol{\beta}(\mathbf{0 . 1})-\mathbf{Z}_{\mathbf{j}} \boldsymbol{\delta}(\mathbf{0 . 1})$ lie (this is the definition of the 0.1 quantile). The same is true for every $\tau$. 
with $\left(\boldsymbol{\beta}(\boldsymbol{\tau})+\boldsymbol{\beta}^{*}(\tau)\right)=\boldsymbol{\beta}(\boldsymbol{\tau})$ and $\left(\boldsymbol{\delta}(\tau)+\boldsymbol{\delta}^{*}(\tau)\right)=\boldsymbol{\delta}(\tau)$. In practice, the first step of IVQR consists of running the $\tau$-quantile regression of $G_{i j}-\alpha C_{i j}$ on $\mathbf{X}_{\mathbf{i}}, \mathbf{Z}_{\mathbf{j}}$ and $\mathbf{I}_{\mathbf{i j}}$ for a given grid of values of $\alpha$, thus obtaining the coefficients $\boldsymbol{\beta}(\alpha, \tau), \boldsymbol{\delta}(\alpha, \tau)$ and $\boldsymbol{\gamma}(\alpha, \tau)$. In a second step, the $\widehat{\alpha}(\tau)$ is chosen which minimizes $W_{n}(\alpha)$. The coefficients of $\widehat{\beta}(\tau), \widehat{\delta}(\tau)$ are then implied by $\widehat{\beta}(\widehat{\alpha}(\tau), \tau), \widehat{\delta}(\widehat{\alpha}(\tau), \tau)$.

In what follows, estimates for the effect of competition on educational achievement and grade inflation are presented for the 5th to the 95th quantile (in steps of 5) using both QR and IVQR.

\subsubsection{QR and IVQR estimates}

The main results of both QR and IVQR results are contained in table 5-12 while figures 5-1 and 5-2 visualize the results.

The conventional QR results suggest that the effects of competition are positive for all schools except for those at the top of the grade distribution. These estimates are statistically significant for all but the 5th quantile and the top two deciles. Thus, contrary to what one might expect, it does not seem that the schools at the bottom of the grade distribution suffer from cream skimming by the schools at the top of the grade distribution and the IVQR results do nothing to change this impression. The IVQR estimates are mostly in the range of what QR suggests and - as is to be expected - standard errors are somewhat inflated.

From the QR results, competition seems to have the smallest restraining effect on grade inflation in the bottom part of the distribution of grade inflation. That is, schools which already practice little grade inflation ${ }^{49}$ do not react to competition by raising their local grading standards. It is the middle part of the distribution, starting at the 35 th quantile that seems to react to competition by actually increasing their local grading standards. Obviously, one would have hoped for schools at the top of the grade inflation distribution to raise their standards the most as a reaction to competition. Still, the result clearly

\footnotetext{
${ }^{49}$ While there are a few schools that award lower school grades than central exam grades, the 5 th percentile already practices grade inflation.
} 
points out that schools that already practice heavy grade inflation do not try and attract students by further inflating their grades in response to competitive pressure. Once again, the IVQR results confirm the QR results.

\subsection{Summary and Outlook}

This chapter analyzed the effect of competition among secondary schools on achievement and grading standards in a setting that satisfies most of the criteria that are stipulated by school choice proponents. The Dutch empirical evidence is in line with theoretical predictions. Most of the empirical results support the notion of competition in the educational sector yielding beneficial results, i.e. leading to higher central exam scores while at the same time exerting a restraining effect on grade inflation. Competition in the Netherlands appears to be driven by catholic schools, while the availability of non-catholic alternatives doesn't seem to induce markedly higher educational achievement or lower levels of grade inflation. ${ }^{50}$ No evidence of endogeneity of competition could be found and quantile regression results clear concerns that competition may be detrimental to schools at the bottom of the grade distribution.

The placebo regressions suggest that sorting by ability and consequently peer effects is not what's driving these results. Suppose that school choice leads to perfect segregation by ability, i.e. all high-ability students leave for a catholic competitor. Those students remaining in the public sector would then attain considerably lower grades than the former mixed-ability student population. Then, using only non-catholic grades as the outcome variable could lead to the assumption that competition leads to lower achievement when this market is compared to one where no segregation occurs for lack of alternatives. Even when a rich set of controls is used, one couldn't completely disentangle the effect of sorting from the impact of competition. From the OLS results one could then hypothesize that in the Netherlands, the less able students leave for catholic schools. From the placebo regression results it seems, however, that catholic schools are not affected by competition at all. Competition does not seem to affect catholic grades, thus the competition effect net

\footnotetext{
${ }^{50}$ Placebo regressions for the dependent variable grade inflation are not reported. Just as in the case of exam grades, they show no significant effects.
} 


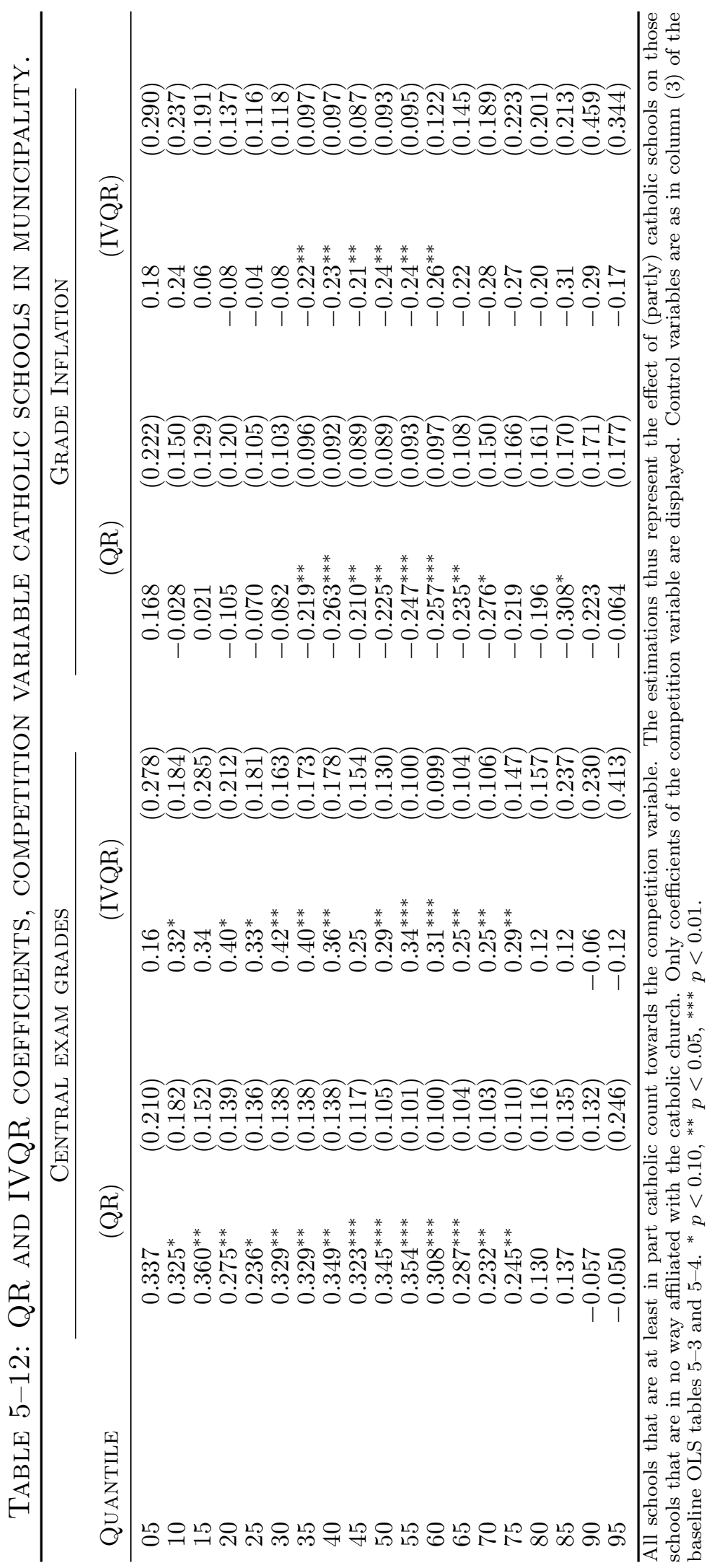



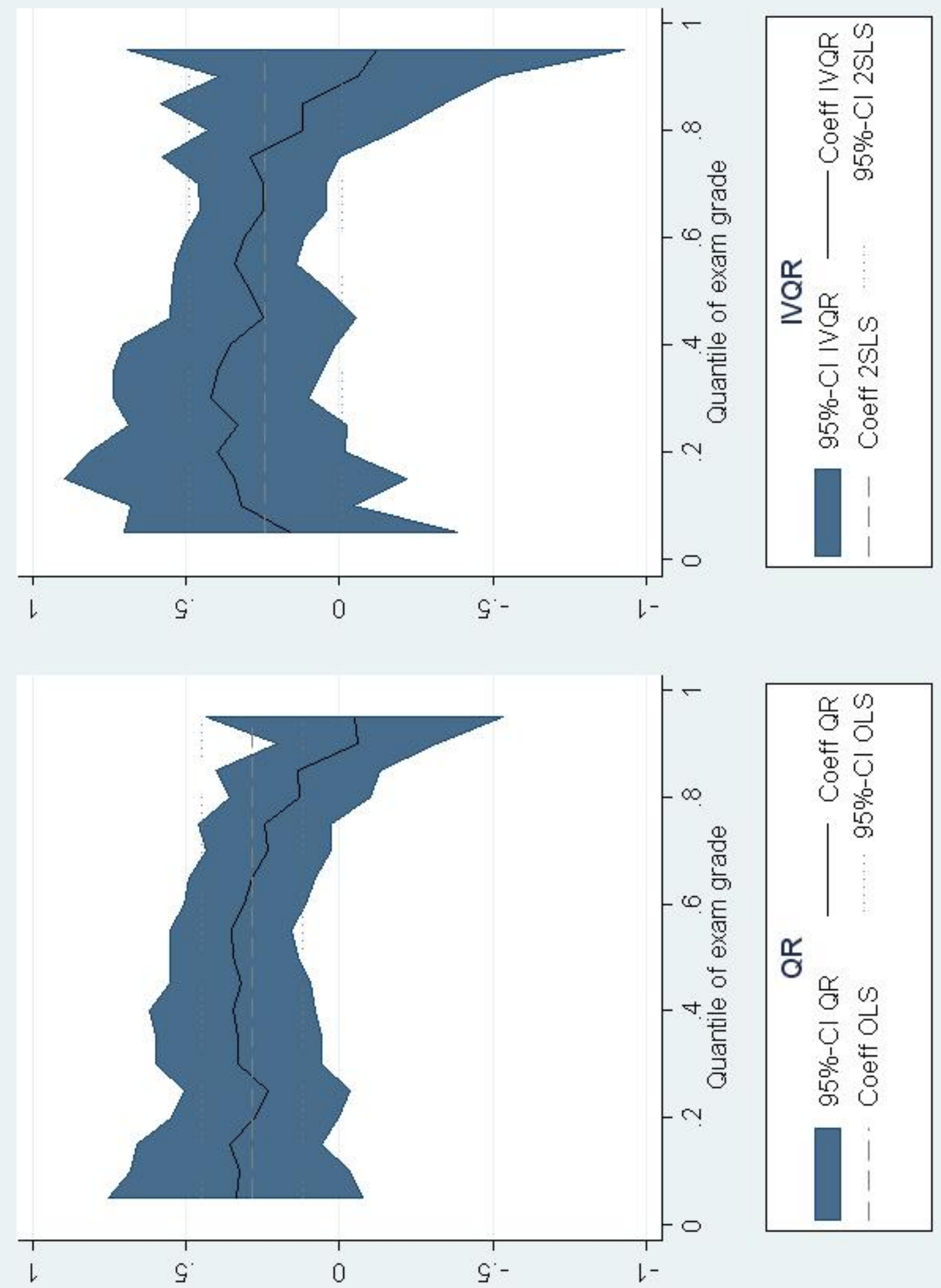

Figure 5-1: QR AND IVQR estimates, CEnTRAl Exam GRAdes. 

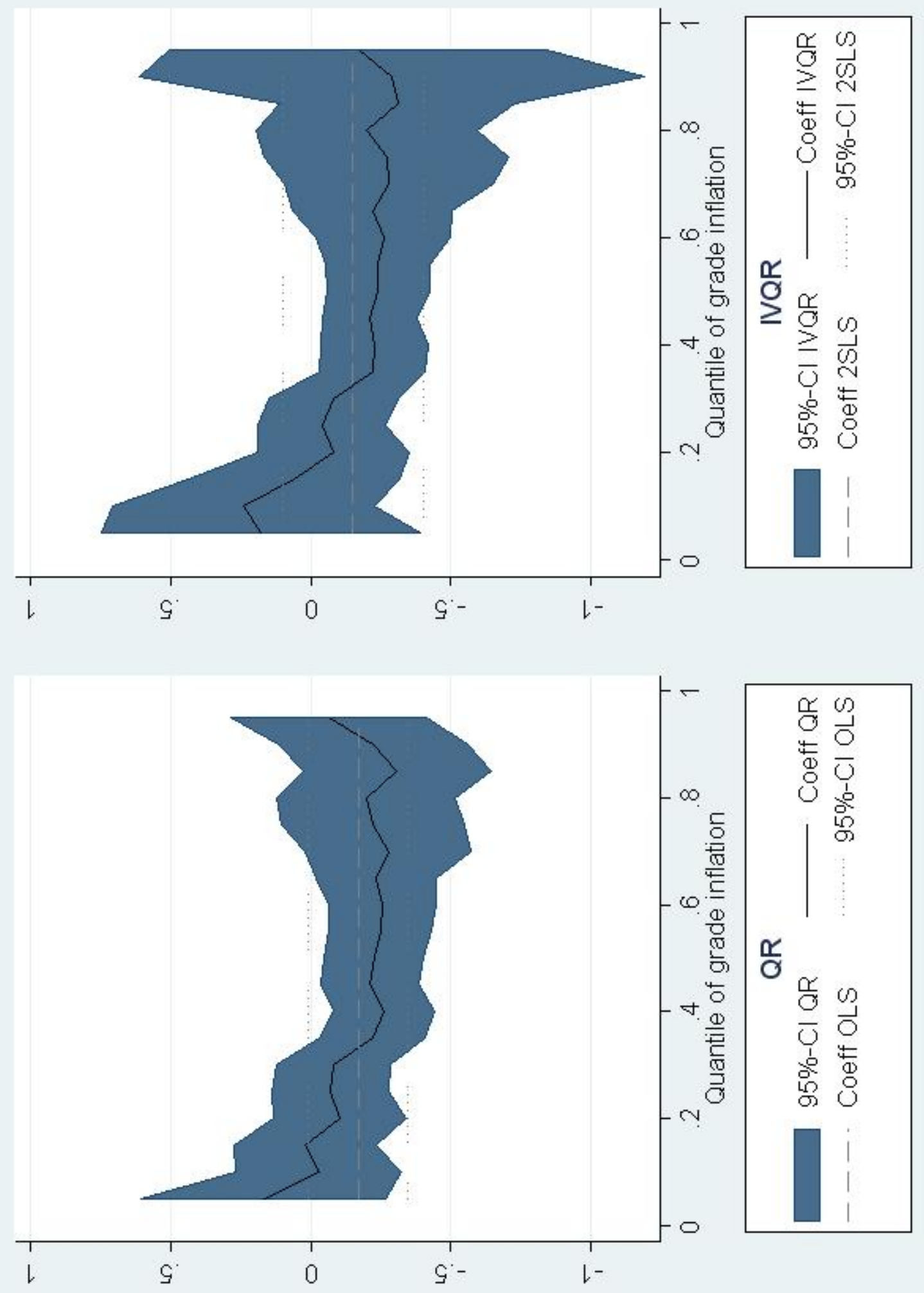

Figure 5-2: QR AND IVQR Estimates, GRAde inflation. 
of sorting is supposedly still positive.

To answer the question that has been posed rather blatantly in the title of this chapter: competition as measured by the availability of catholic schools in close proximity seems to have positive effects on educational achievement as well as on the setting of standards. The latter is a bit surprising in light of the fact that earlier on it had seemed tempting to assume that competition leads to a deterioration of standards - a claim that we can now clearly discard, at least in the Dutch context. There is, however, a need to look deeper into the mechanisms that drive the setting of standards at the local level. Also, so far only competition in the pre-university branch of education has been considered. Hence, it will be interesting to see whether these effects carry over to the lower school branches.

This concludes the first part of the book, which can be called the "education part" only on a rather superficial level. Instead, before moving on to the "media part", it should be pointed out once again that the common denominator of all the research presented in this book is that it revolves around the importance of institutions for local public policy. Media and education markets are chosen because they make for an interesting subject of studying this. Apart from that, another connection to the following chapters is easily made: Just as in the school competition chapter and - albeit passingly in the context of geographical size of labor markets - the standards chapter, proximity and spatial considerations will be an important issue in the subsequent chapters of this book. Specifically, chapter 7 deals with the effect of proximity of media outlets on the ability of jurisdictions to attract government funds, and chapter 8 investigates whether the geographical congruence of media markets and jurisdictions has an effect on local government efficiency. 


\section{Appendix to Chapter 5}

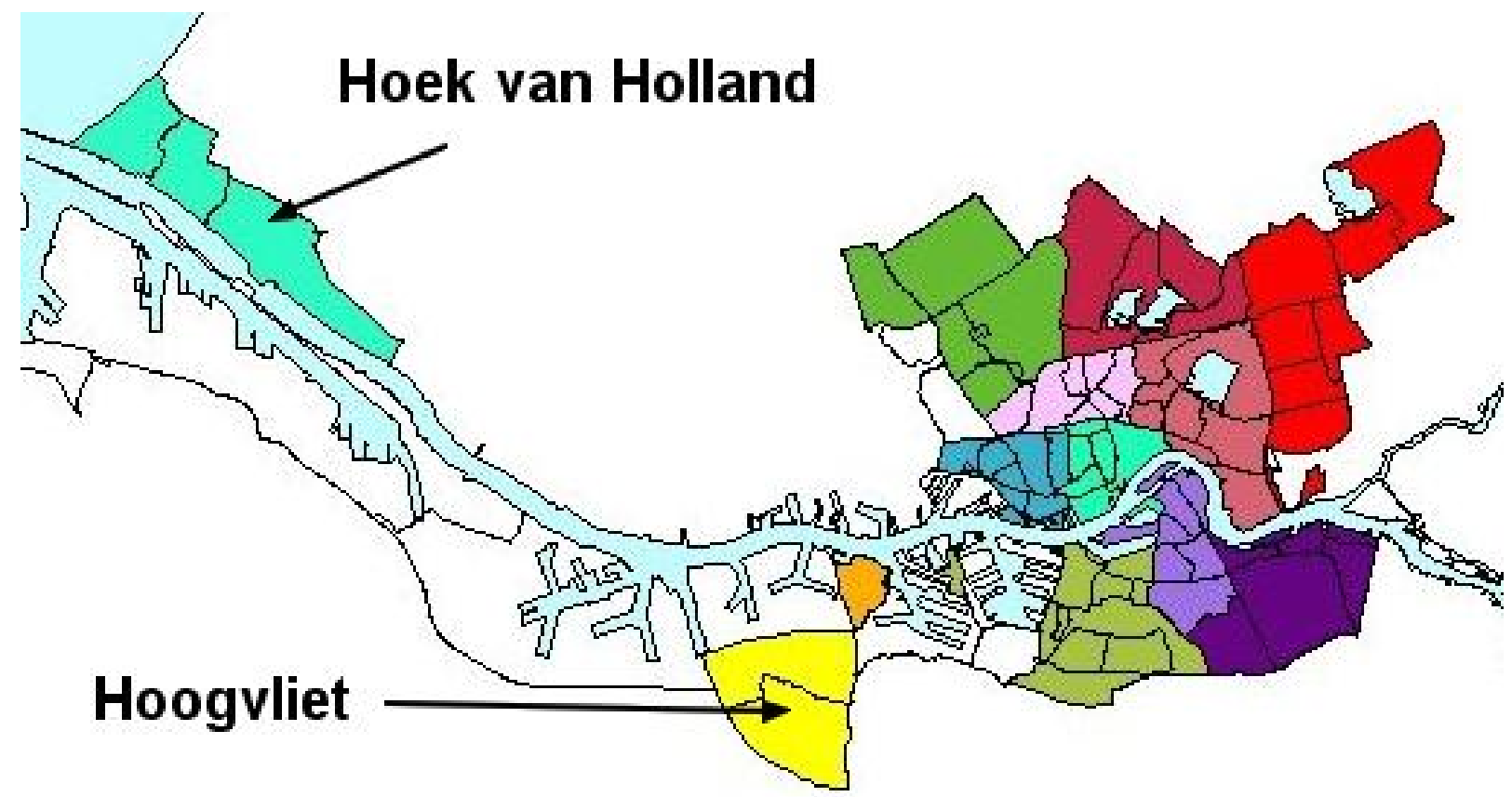

Figure A5-1: Rotterdam, DeElgemeenten. Shaded areas are the RotterDAM BOROughs. Source: Centrum voor Onderzoek en Statistiek, Rotterdam 
TABle A5-1: Summary STATistics, NON-CATHOLIC SCHOOLS.

\begin{tabular}{|c|c|c|c|c|c|}
\hline & $N$ & Mean & Std. Dev. & Min & $\operatorname{Max}$ \\
\hline Above advice $\%$ & 575 & 22.22 & 17.95 & 0 & 100.00 \\
\hline Half above advice $\%$ & 575 & 37.98 & 24.11 & 0 & 100.00 \\
\hline Minority (cumi) students $\%$ & 616 & 5.44 & 9.82 & 0 & 78.94 \\
\hline Study cost recipients $\%$ & 615 & 28.07 & 11.33 & 8.67 & 100.00 \\
\hline Tracked in grade $1 \%$ & 591 & 34.32 & 34.59 & 0 & 100.00 \\
\hline Tracked in grade $2 \%$ & 584 & 61.14 & 36.21 & 0 & 100.00 \\
\hline Class size grade 1 & 597 & 25.28 & 2.64 & 16.00 & 32.00 \\
\hline Class size grade 2 & 587 & 25.22 & 2.65 & 11.00 & 31.00 \\
\hline Non-religious school dummy & 639 & 0.65 & 0.47 & 0 & 1.00 \\
\hline Number of students VWO (1000s) & 620 & 241.05 & 117.10 & 6.00 & 785.00 \\
\hline Number of students brin (1000s) & 614 & 1849.83 & 1104.02 & 97.00 & 5697.00 \\
\hline Short term debt \% & 538 & 32.23 & 11.18 & 0 & 86.80 \\
\hline Long term debt $\%$ & 538 & 3.36 & 7.20 & 0 & 54.30 \\
\hline Staff growth \% & 608 & 2.84 & 5.70 & -25.50 & 30.50 \\
\hline Number of students growth $\%$ & 608 & 1.88 & 5.02 & -16.20 & 27.60 \\
\hline Part time staff $\%$ & 608 & 37.59 & 9.73 & 15.90 & 69.00 \\
\hline Quality of life & 639 & 0.03 & 1.07 & -2.74 & 3.52 \\
\hline Average income (1000 Euro) & 633 & 12.99 & 1.12 & 10.80 & 19.20 \\
\hline Population share school aged & 638 & 17.67 & 1.82 & 13.90 & 24.00 \\
\hline Pop. density $\left(1000 / \mathrm{km}^{2}\right)$ & 638 & 2.04 & 1.59 & 0.05 & 5.67 \\
\hline Land area $\left(\mathrm{km}^{2}\right)$ & 638 & 117.96 & 118.00 & 6.62 & 765.39 \\
\hline Number of catholics (1000s) & 638 & 22.59 & 25.76 & 0.22 & 108.48 \\
\hline
\end{tabular}

TABle A5-2: Summary STATISTICS, NON ROMAN-CATHOLIC SCHOOLS.

\begin{tabular}{|c|c|c|c|c|c|}
\hline & $N$ & Mean & Std. Dev. & Min & Max \\
\hline Above advice $\%$ & 659 & 22.49 & 17.70 & 0 & 100.00 \\
\hline Half above advice $\%$ & 659 & 38.16 & 24.03 & 0 & 100.00 \\
\hline Minority (cumi) students $\%$ & 710 & 5.47 & 9.95 & 0 & 78.94 \\
\hline Study cost recipients $\%$ & 708 & 28.18 & 11.77 & 8.67 & 100.00 \\
\hline Tracked in grade $1 \%$ & 683 & 33.74 & 34.13 & 0 & 100.00 \\
\hline Tracked in grade $2 \%$ & 675 & 61.31 & 35.90 & 0 & 100.00 \\
\hline Class size grade 1 & 689 & 25.24 & 2.66 & 16.00 & 32.00 \\
\hline Class size grade 2 & 678 & 25.20 & 2.62 & 11.00 & 301.00 \\
\hline Non-religious school dummy & 733 & 0.57 & 0.49 & 0 & 1.00 \\
\hline Number of students VWO (1000s) & 709 & 241.21 & 114.97 & 6.00 & 785.00 \\
\hline Number of students brin (1000s) & 708 & 1857.34 & 1070.33 & 97.00 & 5697.00 \\
\hline Short term debt $\%$ & 625 & 32.35 & 11.04 & 0 & 86.80 \\
\hline Long term debt \% & 625 & 3.49 & 7.50 & 0 & 54.30 \\
\hline Staff growth $\%$ & 696 & 2.87 & 5.78 & -25.50 & 30.50 \\
\hline Number of students growth $\%$ & 700 & 1.86 & 5.14 & -16.20 & 35.50 \\
\hline Part time staff $\%$ & 696 & 37.31 & 9.55 & 15.90 & 69.00 \\
\hline Quality of life & 733 & 0.06 & 1.08 & -2.74 & 3.52 \\
\hline Average income (1000 Euro) & 721 & 12.98 & 1.12 & 10.80 & 19.20 \\
\hline Population share school aged & 729 & 17.72 & 1.87 & 13.90 & 24.10 \\
\hline Pop. density $\left(1000 / \mathrm{km}^{2}\right)$ & 729 & 1.99 & 1.58 & 0.05 & 5.67 \\
\hline Land area $\left(\mathrm{km}^{2}\right)$ & 729 & 118.78 & 119.92 & 6.62 & 765.39 \\
\hline Number of catholics (1000s) & 729 & 22.85 & 25.20 & 0.22 & 108.48 \\
\hline
\end{tabular}


TABle A5-3: First stage Statistics, AdDitional instrument.

\begin{tabular}{|c|c|c|c|c|}
\hline \multirow[b]{2}{*}{ Catholics in municip. (1000s) } & \multicolumn{2}{|c|}{$\begin{array}{c}(1) \\
(\text { Partly) catholic }\end{array}$} & \multicolumn{2}{|c|}{$\begin{array}{c}(2) \\
\text { Roman-catholic }\end{array}$} \\
\hline & $0.0921^{* * *}$ & $(0.0101)$ & $0.0513^{* * *}$ & $(0.0170)$ \\
\hline Cath in municip. squared & $-0.0006^{* * *}$ & $(0.0001)$ & -0.0003 & $(0.0002)$ \\
\hline Road network $(\mathrm{km})$ & $0.0007^{* * *}$ & $(0.0002)$ & $0.0008^{*}$ & $(0.0004)$ \\
\hline F-test excluded instr. & \multicolumn{2}{|c|}{$\begin{array}{c}\mathrm{F}(3,140)=47.84 \\
\mathrm{p}=0.000\end{array}$} & \multicolumn{2}{|c|}{$\begin{array}{c}\mathrm{F}(3,153)=14.96 \\
\mathrm{p}=0.000\end{array}$} \\
\hline partial $R^{2}$ excluded instr. & \multicolumn{2}{|c|}{0.63} & \multicolumn{2}{|c|}{0.43} \\
\hline$R^{2}$ & \multicolumn{2}{|c|}{0.83} & \multicolumn{2}{|c|}{0.66} \\
\hline$N$ & \multicolumn{2}{|c|}{542} & \multicolumn{2}{|c|}{616} \\
\hline
\end{tabular}

Estimates are for 1st stage of 2SLS. Number of schools is the dependent variable of 1st stage. Estimates shown for the excluded instruments only. Control variables are as in column (3) of the baseline OLS tables 5-3 and 5-4. Standard errors in parentheses allow for clustering by municipality. ${ }^{*} p<0.10,{ }^{* *} p<0.05,{ }^{* * *} p<0.01$.

TABLE A5-4: 2SLS CENTRAL EXAM, ADD'L INSTRUMENT

(1)

(Partly) catholic

(Partly) catholic schools

Roman catholic schools

Above advice \%

Half above advice \%

Minority (cumi) students \%

Study cost recipients \%

Tracked in grade $1 \%$

Tracked in grade $2 \%$

Class size grade 1

Class size grade 2

Non-religious school dummy

Number of students VWO (1000s)

Number of students brin (1000s)

Quality of life

Average income (1000 Euro)

Population share school aged

Pop. density $\left(1000 / \mathrm{km}^{2}\right)$

Land area $\left(\mathrm{km}^{2}\right)$

Year 2003

Intercept
(2)

Roman-catholic

\begin{tabular}{lcc}
\hline$N$ & 542 & 616 \\
adj. $R^{2}$ & 0.325 & 0.306 \\
\hline
\end{tabular}

test of overid. restr. $\chi^{2}(2) \quad 0.016 \quad(p=0.992) \quad 0.548 \quad(p=0.760)$

Second stage estimates, instruments are the number of catholics in the municipality and its square and the length of the road network in the municipality. All schools that are at least in part catholic schools count towards the competition variable in column (1), whereas only roman-catholic schools are considered in column (2). Control variables are as in column (3) of the baseline OLS tables 5-3 and 5-4. Standard errors in parentheses allow for clustering on the municipality (gemeente) level. * $p<0.10,{ }^{* *} p<0.05,{ }^{* * *} p<0.01$. 



\section{CHAPTER 6}

\section{An Introduction to the Links between Information, Media and Political Economics}

As has just been stated, the common ground for the research in this book is that it revolves around the importance of institutions for public policy. The following three chapters are concerned with the institution of mass media and its connection to political economy. This is a rather new branch of research that has emerged in the past decade or so and is by no means as visible as the economics of education is these days. In order to illustrate the significance of mass media, however, let us briefly return to the economics of education for an example.

Education economics as well as labor economics never tire of stressing the significance of accumulating human capital for a society and especially in Germany, the media have played a major role in reminding people of this fact. The disappointing PISA performances created a sheer media frenzy that in the end led to many changes in educational policy such as the introduction of central exit examinations across Germany. This of course is merely an example for the influence of mass media that comes in handy in light of the previous chapters. Yet, more generally speaking, if it is the media that seems to play a major part in getting the information out to citizens and this has an impact on policies, doesn't this beg the following question:

What role does the media play for public policy in a democracy? 
The above example of the PISA coverage aside, everywhere in the mass media, from local newspapers and radio shows to national television programs and the internet, coverage of politics and politicians abounds. The media thus transmits political information to their audiences, which in part consist of potential voters. Assuming that voters base their decision on which candidate to cast their ballot for on rational reasoning, the political information that they obtain from mass media may influence voting decisions.

Whenever information affects voting, a feedback loop from the electorate's state of being informed to politician behavior can be suspected. Whether the information status of the electorate shapes the incentives of incumbent politicians is an issue that clearly stems from a political economy perspective on government. If incumbents were benevolent agents who solely seek to work in a well-defined public interest as in the traditional public finance approach, the above question would be redundant. In contrast to the notion of such ideal Weberian politicians, however, political economy, i.e. the economic analysis of politics, has long stressed that politicians should rather be viewed as self-interested individuals who strive to maximize their own well-being. As a consequence, an elected politician may be tempted to pursue goals which are not in the best interest of voters.

An elected politician who primarily pursues his own agenda constitutes a principal-agent problem. Once elected into office, an incumbent can take advantage of his position for his own purposes. Politicians may exploit disposable resources, accept bribes from interest groups, implement policies according to their own preferences or simply enjoy their status instead of working hard. In principle, voters can punish bad behavior by throwing politicians out of office in the next election. However, voters commonly are uncertain about relevant features of politics and, as a consequence, rent-seeking behavior often cannot be verified. This uncertainty allows rent-seeking incumbents to still stand a chance of being reelected. In the end, the extent of rent-seeking depends on the incentives of politicians induced by voting behavior, which in turn may hinge on the electorate's level of being informed.

Ever since Downs (1957), political economics has stressed the importance of information for the establishment of politicians' incentives through electoral competition. Political information of interest to voters comes in many flavors: personal characteristics of politicians such as their competence, motives and ideological position, responsibility for policy areas, implemented policies and their consequences if outcomes cannot be observed immediately, 
as well as information about rules and procedures that shape policy decisions. Surveys of the political economy literature as provided by Persson and Tabellini (2000), Besley (2006) and Mueller (2003) show that the information level prevalent in the electorate affects outcomes in many public finance issues. Generally speaking, the critical questions to be answered are:

(1) What is the nature of the information that voters have?

(2) How do voters obtain this information?

(3) And how does the distribution of information in the electorate affect the incentives of incumbent politicians?

The role of mass media in providing information to voters has only recently gained the attention of economists despite the fact that mass media commonly are the primary source of political information for voters. In a 2004 survey, American voters were asked about their dominant source of political news and information. Television came out on top with $74 \%$ of respondents calling it a primary source, followed by radio (54\%) and newspapers (51\%) (Horrigan, Garrett and Resnick 2004). These figures suggests that studying the impact of mass media on voting behavior is in order. Over the past few years, a small but growing political economy literature has emerged that strives to theoretically identify the channels through which mass media affect policy-making and, accordingly, to find empirical evidence. Published papers in this area of research deal with media capture by politicians or interest groups, media effects on voter turnout and reasons for media bias. This book, however, mainly contributes to the question of how the mass media affects policy-making and the subsequent two chapters deal with the impact of media markets on policy outcomes.

Chapter 7 examines whether the geography of television markets in the United States affects the allocation of federal funds. An illustrative model shows that news programs may be biased towards regions close to media outlets because reporting from these locations is less expensive. As a consequence, citizens who live near media outlets may be better informed about the spending decisions by an incumbent politician than citizens living in more distant areas. Such a distribution of information induces the incumbent to allocate more funds to regions where media activity is higher because the effect of an extra dollar 
spent on expected votes is larger there. This prediction is tested empirically using US data on county-level grant spending, Designated Market Areas (DMAs) and location of licensed television stations. ${ }^{51}$ It is shown that the proposed media variables significantly affect the geographical distribution of grant spending, as predicted by the theoretical model. Counties that are closer to cities where many television stations are located receive significantly larger amounts of funds per capita. These results are robust to allowing for endogeneity and spatial correlation.

Whether a more informed electorate makes an incumbent politician work harder is at the core of chapter 8. A formal model outlines the argument how the share of informed voters affects the incentives of an incumbent politician to behave well. All voters agree that the incumbent is supposed to use funds at his disposal efficiently, i.e., he is expected to generate the maximum quantity of a public good with a given budget. Newspapers provide a share of voters with information about a random shock which affects public good production. Thus, informed voters are better able to observe the incumbent's performance. The model predicts that a larger share of informed voters induces the incumbent to invest more effort in public good production. This prediction is tested using panel data on newspaper circulation and government efficiency in Norwegian municipalities. The results support the model's prediction that a more informed electorate induces higher efficiency.

Both chapters contribute to the branch of political economy which deals with media market effects on public policy. The theoretical analysis in chapter 7 is closely related to Strömberg (2004a). In this paper, Strömberg adapts the location model by Lindbeck and Weibull (1987) to study both competition between media companies and political competition. ${ }^{52}$ Strömberg states that news programming must ensure attracting an audience which is relevant to advertisers because for most TV stations the bulk of revenues is generated by selling airtime to advertisers. According to Strömberg (2004a), another feature of news production are high costs of setting up a newscast or the first copy of a newspaper, wheras the costs incurred by additional copies or viewers are relatively small. As a consequence, Strömberg's model predicts that mass media bias their programs in favor of large

\footnotetext{
${ }^{51}$ DMAs are the current industry standard for defining television markets in the United States.

${ }^{52}$ Strömberg (2001) uses a modified version of the media model to explain the formation of informed and uniformed voters in various existing political economy models. The analysis deals with diverse issues such as redistribution, the size of the government sector, rents and corruption, the effectiveness of lobby groups and political business cycles.
} 
groups, groups that are more valuable to advertisers, groups that attach a higher value to information and groups which are easier to reach in terms of distributing news. Strömberg argues that politicians spread their campaign pledges via mass media taking the above mentioned biased reporting into account. Thus, pledged spending is higher in areas that are subject to higher levels of media attention, because a larger share of those voters who benefit are actually aware of the campaign pledges and consider them when they go to the polls. The gist of the model is that voters who are more valuable to commercial media receive favorable policies.

In a closely related paper, Strömberg (2004b) empirically tests whether politicians cater to informed voters in their policy-making. He uses data on the allocation of funds provided by a major New Deal program in the United States. In a formal model he outlines his theory that incumbent governors use radio programs as a means of advising voters of what they have done for them. This is assumed to affect voting behavior because voters only take benefits into account when they can attach them to a particular candidate. In line with his theoretical prediction, in a cross-section analysis Strömberg finds that per capita spending is higher in counties with a more informed electorate, i.e., counties with large shares of households owning radio receivers. However, the share of households with access to radio broadcasts constitutes merely an indirect measure of voter information. Snyder and Strömberg (2008) pick up on this problem and provide a more detailed analysis of the relation between media, information and politics. They present an empirical analysis identifying three substantial effects from mass media on politics, i.e. the knowledge voters possess, incumbent behavior and resulting policies. At the heart of their analysis is the geographical fit between newspaper markets and congressional districts in the United States. They find that a poor fit leads to voters being less informed about their congressmen because newspapers hardly report about them. Another result is that congressmen from districts that are highly congruent with newspaper markets work harder for their constituency as measured by their participation in congressional hearings and committee work as well as incidences of voting against the party line. Finally, Strömberg and Snyder present evidence that the reduced accountability of politicians leads to lower federal spending in poor-fit districts. In a somewhat different context, Revelli (2008) examines the relation between local media markets and jurisdictions. He shows that local media serve as a vehicle for yardstick competition. His findings suggest that yardstick competition affects tax policies of British district governments belonging to the same local media market. 
Besley and Burgess (2002) study whether a more informed electorate is more successful in holding incumbent politicians accountable. They apply an agency model in order to demonstrate that more information in the electorate provides incentives for opportunistic politicians to behave well. They test this prediction using a panel data set from India. Newspaper circulation in Indian states serves as a proxy for the share of informed voters and the analysis goes on to show that in hard times state governments provide more food and spend more money on relief purposes in those areas where newspaper circulation is higher. A related paper by Reinikka and Svensson (2005) shows that in Uganda, less corruption occurs in a government program on school improvement in areas where local newspapers actively report about the project. Further evidence that more transparency disciplines incumbents comes from Svaleryd and Vlachos (2008). They find that political rents are smaller in Swedish municipalities when voters are better informed about politics.

So far, all studies mentioned have adopted the rather optimistic view that the media report facts sincerely and biased reporting only consists of choosing a (possibly slanted) subset of all available stories, e.g. news programs may cater to relevant audiences and choose the facts they report accordingly. However, another substantial source of bias may be that media do not transmit all of their collected information truthfully. Journalists can omit important facts, emphasize only selected facts or slant stories in various other ways. Several factors can lead to media bias, e.g. private interest groups or politicians may control or bribe media outlets, an issue that led Besley and Prat (2006) to examine features of media markets and politics which affect the freedom of the press. In an agency framework, media outlets can inform voters about an incumbent politician, yet whenever the politician is successful in bribing the media, they suppress bad signals. The authors show that the number of independent news outlets and transaction costs for bribing substantially influence the freedom of the press. Public ownership of news media is assumed to imply lower transaction costs, thus making media capture more likely and media capture in turn is shown to reduce accountability. Djankov et al. (2003) support this prediction in finding that countries with a large share of state owned media exhibit poor government performance. In Petrova (2008) media capture is an issue in that rich voters can bribe the media to manipulate the coverage of redistribution issues. Her formal analysis predicts that lower income inequality and the availability of diverse information sources lead to a lower probability of media capture. The examination of cross-country panel data supports these predictions. Similarly, Corneo (2006) develops a model where mass media inform voters about the consequences of alternative policies. However, interest groups can bribe 
the media in order to manipulate coverage. Corneo shows that media bias is more likely when firm ownership is more concentrated.

Media capture is not the only source of distorted news. Rather, biased reporting may also be brought about from the demand side. Mullainathan and Shleifer (2005) show that media bias can result from a confirmatory cognitive bias of media consumers. Readers who hold beliefs, e.g. about the competence of a politician, which they would like to see confirmed in the news can induce commercial media to slant the information contained in the respective publications. The authors show that with heterogenously biased beliefs, competition may not reduce but even strengthen media bias because this allows media companies avoid price competition. Gentzkow and Shapiro (2006) formally demonstrate that biased coverage can also stem from a media firm's desire to build a reputation for accurate reporting. Assuming that customers perceive information to be more accurate whenever it is close to their prior beliefs, commercial mass media are willing to distort their reporting in the direction to these beliefs. Baron (2006) introduces the career concerns of journalists as another source of media bias. Journalists may use slanting in order to have their stories make the front page because this pushes their careers, and profit-maximizing media companies may allow for slanting if journalists in turn accept lower wages. Moreover, Baron shows that even rational media consumers who are fully aware of slanting may be influenced by media bias. Gabszewicz, Laussel and Sonnac (2001) construct a model that demonstrates how the advertising market has an effect on the political orientation of media outlets. Commercial media organizations that largely rely on advertising revenue are shown to adopt rather neutral instead of extreme political positions.

There is also quite a bit of empirical evidence of biased media. DellaVigna and Kaplan (2007) argue that biased media affect voting behavior. They show that the entry of the Fox News channel into US cable television markets significantly increased the share of votes for the Republicans party in these regions as opposed to those areas where Fox News was not yet available. Groseclose and Milyo (2005) on the other hand find a tendency among US media outlets to slant their stories towards liberal political positions. They suspect various factors leading to a liberal bias such as corresponding political preferences of journalists or, as Hamilton (2006) argues, that some groups with more liberal attitudes are more valuable to advertisers and thus receive more media attention.

Other empirical work finds effects of television on voter turnout. Gentzkow (2006) shows 
that the introduction of television in the United States significantly lowered voter turnout. In addition, he demonstrates that the consumption of information-heavy media such as radio and newspapers was substituted by television consumption leading lower levels of political knowledge in voters. Althaus and Trautman (2008) study the impact of television market size on voter turnout in the United States. They find that turnout in local elections is lower in large television markets. Local elections are assumed to be less newsworthy in larger markets so that residents in these markets are provided with less political information, which in the literature is presumed to push down voter turnout. Prior (2006) finds that the rise of television in the United States contributed to the incumbency advantage of US House representatives in the 1960s. He suggests that television allowed incumbent politicians to accumulate more media appearances than potential challengers and therefore the incumbents were better able to make an impression on voters. Prior's study finds the television effect to be particularly large among less educated people.

This introductory chapter has shed some light on the existing literature that deals with the impact of mass media on politics. Notwithstanding that theoretical and empirical studies obviously already have identified various facets of the relation between media markets and the political sphere, this branch of the literature still is in its infancy and the following chapters attempt to make a contribution to this still often overlooked field of economics. As has been laid out above, chapter 7 deals with how the distribution of government spending may be distorted by the (non-)existence of local media outlets. Chapter 8 is positioned at the crossroads of the media literature and a branch of public economics that is concerned with the determinants of local government efficiency - specifically, the relationship between newspaper readership in a municipality and the potential effect it may have on government efficiency is contemplated. A large part of the literature that is of great relevance to the following two chapters has already been surveyed here. Unless specific aspects are of vital relevance to the respective chapter, from here on we will only passingly refer to these papers and the reader is encouraged to return to this section for a more detailed description. 

CHAPTER 7

\section{Local Television Markets and the Distribution of Public Spending}

Given that one of the unifying themes of this book is the connection between institutions and local policies, an introductory remark to this chapter is in order: this research considers the media's effect on policies that may not seem to be decidedly local and in illustrating our point, in this chapter we will often allude to a Governor deciding on how to spread grants among the counties in his constituency. Even though we believe this can already be considered a local or undoubtedly a regional policy, there are clearly political levels that cover smaller geographical areas (e.g. congressional districts) and the reader may be more inclined to apply the "local" label to these levels. In this context, it is important to note that the arguments put forward in this chapter describe just as well the incentives faced by a congressman who decides on how to distribute spending among the constituencies in his district.

When it comes to government spending, grants account for a non-trivial share of the federal budget. Each year US politics channels hundreds of billions of these federal grant dollars to states and local jurisdictions. Political economics suggests that the distribution of grants is affected by incumbent politicians' behavior which in turn is driven by the aim of winning reelection. Indeed, a recent quote from Senator Clinton points out that politicians believe one of their primary tasks to be bringing money to their districts: "I'm very proud of my earmarks [grants]. It's one of the reasons I won 67 percent of the vote, because I took care 
of my people." 53 But will they care equally for all voters in the electorate or do incentives exist which may induce them to bias their effort in favor of certain groups of voters?

The quote from Senator Clinton indicates that politicians assume voters to follow a retrospective voting strategy asking "What have you done for me lately?" when casting their ballot, as argued by Popkin (1991). Consequently, information plays an important role because only voters who know that an incumbent is responsible for some benefit consider this when going to the polls. If politicians know that some voters are better informed, these voters may receive favorable policies. This leads to the crucial questions of how voters obtain their information and why some voters are informed whereas others are not. There are many ways in which people may obtain information. For example, information may be conveyed in daily life by talking to neighbors and friends. Today, however, the main sources of information are media like the internet, newspapers and television. As they are considered to be the primary source of information for most US citizens (Napoli and Yan, 2007), this chapter examines local TV news. TV stations which broadcast local news for a given market tend to cluster together in few places (media cities). As to that, Adams (1980) finds that local news coverage is biased in favor of regions close to the media cities, leaving large areas of a market with only little attention. This finding is in line with recent work by sociologists indicating that the proximity of events to media outlets makes coverage more likely (Kaniss, 1997; Oliver and Myers, 1999). In this chapter, we examine whether this stylized fact of US television markets affects public policies.

In a simple model we show that news programs may be biased in favor of places close to media cities because reporting from these locations is less expensive. Thus, the model predicts that voters in counties close to media cities are better informed about public policies and receive more money. We test this prediction empirically using US data on county-level grant spending, Designated Market Areas (DMAs) and location of licensed television stations. DMAs are the current industry standard for defining television markets in the United States. We show that the proposed media variables significantly affect the geographical distribution of grant spending, as predicted by the theoretical model. These results are robust to correcting for endogeneity and spatial correlation.

\footnotetext{
${ }^{53}$ Mike Wereschagin, David Brown and Salena Zito, "Clinton: Wright 'would not have been my pastor", Pittsburgh Tribune-Review, March 25, 2008, http://www.pittsburghlive.com/x/pittsburghtrib/s_ $558930 . \mathrm{html}$.
} 
In terms of related research, the closest connection is to the work by Strömberg $(2004 a, b)$ which analyzes the influence of media on fiscal policy and has already been summarized in chapter 6. To recap, Strömberg (2004a) examines competition between media outlets and identifies incentives leading mass media to bias programs in favor of certain groups. His theoretical model predicts media to report more on issues concerning large groups, groups that are more attractive to advertisers, groups that attach a higher value to information and groups which are easier to reach in terms of distributing news. These groups are thus better informed and this leads to favorable policies towards them. Strömberg (2004b) approximates the share of informed voters by the share of households owning a radio and tests empirically whether these voters receive favorable policies. He uses US data on county-level spending by the Federal Emergency Relief Administration (FERA), a major New Deal program in the 1930s, and finds that counties with a larger share of these households received more funds.

In both papers, Strömberg argues that the rise of broadcast media should have enabled more distant regions to better attract grants. Once the reception technology, e.g. radios, becomes widely spread in a region the cost of delivering news via the airwaves are significantly reduced as compared to delivering newspapers. Whenever the entire population in a media market is equipped with the reception technology, the discriminating effect of delivery costs on the information level in remote parts of the market should have vanished as should the subsequent effect on grant allocation.

Since in today's US television markets almost every household owns at least one television set, the cost of delivering television programs to consumers should be equalized, regardless of the viewer's geographical location. This chapter asks whether in the absence of delivery cost, there is still a tendency to bias the news programming in favor of certain regions. We focus on the cost of newscast production. In order to create coverage, news media must gather costly information. These production costs are very high for the first consumer, yet once the program is produced, the public good nature (i.e. non-rivalry in consumption) of broadcasts means essentially zero marginal costs of delivering the newscast to one more household. Finding the optimal "first copy costs" is therefore a crucial task for commercial TV stations. If the cost of collecting information differs among potentially newsworthy events, this may divert resources to less costly reporting and thus introduce a bias in coverage driven by the cost side. We argue that the cost of gathering information increases with distance to media cities. This introduces an effect on news coverage that counteracts 
Strömberg's argument regarding distribution cost. He argues that broadcast media face significantly lower costs of distributing news to distant regions than newspapers. Thus, the rise of radio and television may result in paying more attention to remote areas. Yet, whenever information from these jurisdictions comes at a higher price, this creates a bias against remote areas that cannot be eradicated even by equipping everyone in the market with the reception technology. This bias will always run opposite to Strömberg's predicted positive effect of increased diffusion of the reception technology on public spending.

We proceed with a theoretical model in section 7.1, section 7.2 gives a description of the data and estimation approach. The empirical results are presented in section 7.3 and section 7.4 concludes.

\section{1 $\quad$ Model}

In order to study equilibrium spending levels in a retrospective voting model, we explain the formation of two classes of voters, the informed and the uninformed. An incumbent politician seeking reelection decides about the allocation of public funds among different groups in the electorate. Let the politician be an incumbent US state governor and let each group comprise the residents of a county within the state. We further assume that the state area is congruent with a television market and that there are two television stations broadcasting news. These newscasts are the single source of information about politics available to the individuals. We adapt the framework presented in Strömberg (2004a) to study how the costs of producing news affect news coverage of the TV stations. Unlike Strömberg's paper we allow the costs of producing a unit of news to vary across counties. Consequently, the costs of a broadcast program essentially depend on the allocation of air time across counties.

To keep the model simple, we assume that coverage of the governor's policies is ensured, implying that all voters watching the news are informed about spending levels. However, as an individual vote has virtually no influence on the electoral outcome, citizens consume news for entertainment value only and learning about the governor is a by-product, i.e. people care about what is going on in their community rather than about politics per se. In the next section, we analyze air time allocation by two competing television stations, 
given that on the demand side, viewers desire information on their county of residence. The resulting number of viewers that encounter some news will then constitute the respective groups of informed voters in the analysis of gubernatorial spending decisions.

\subsubsection{Local TV News}

In a television market, two commercial TV stations $A$ and $B$ compete for audience by broadcasting local news. Each station allocates total air time $N$ across counties $c=$ $1,2, \ldots, C$ such that $\sum_{c} n_{c}^{s}=N$ with $n_{c}^{s}$ being news time devoted to a county $c$ by station $s=A, B$. Voters care about what is going on in their community, i.e. they are interested only in news on their resident county. $\phi$ denotes the probability that a voter comes across county-related news on TV - this probability increases in news time devoted to a county $\phi^{\prime}\left(n_{c}\right)>0$, with decreasing marginal effect $\phi^{\prime \prime}\left(n_{c}\right)<0$ and $\phi^{\prime}(0)=\infty$. Thus, the expected utility of watching news for a voter in county $c$ is defined as $u_{c}\left(n_{c}\right)=\phi\left(n_{c}\right) \cdot \bar{u}$, where $\bar{u}$ denotes the exogenous utility derived from an interesting newscast. For simplicity, we assume that all voters equally care for news on their home county implying that differences in expected utility are due only to allocated news time. Finally, a voter $i$ chooses station $A$ if

$$
u_{c}\left(n_{c}^{A}\right)-u_{c}\left(n_{c}^{B}\right) \geq \xi_{i}
$$

and station $B$ otherwise. $\xi_{i}$ denotes how voter $i$ evaluates fixed characteristics of station $A$ relative to station $B$, e.g. sympathy for anchormen and the style of presenting news or the ideological bias of a station. A positive value of $\xi_{i}$ implies that voter $i$ favors station $B$ whereas negative values indicate a bias in favor of station $A$, leaving news levels out of consideration. This individual evaluation is given by the county-specific distribution function $F_{c}$. For simplicity, we assume that $F_{c}$ is the uniform distribution with support $\left[-\frac{1}{2 f_{c}}, \frac{1}{2 f_{c}}\right]$ and density $f_{c}$. Consequently, a voter watches station $A$ 's newscasts with probability $F_{c}\left[u_{c}\left(n_{c}^{A}\right)-u_{c}\left(n_{c}^{B}\right)\right]$.

Now we turn to the cost of news production. Broadcast media like television face high costs when it comes to producing programs for the first consumer whereas the marginal costs of the following consumers are approximately zero. Once a signal is broadcast, no additional 
costs are incurred when more people consume the program. The main task of journalists is gathering information to produce coverage. Being confronted with a larger number of events taking place all over the market area, TV stations face higher costs of collecting information in remote counties not only because it takes time and money to get there but journalists located in close proximity to the TV station are also usually better connected within networks generating easier access to contact persons and better information about institutions (Kaniss, 1997). Hence, with both stations being situated at the same place we presume marginal reporting costs $k_{c}$ to vary across counties equally for stations $A$ and $B$. Counties located far away from the media city feature high values of $k_{c}$ whereas $k_{c}$ is lower for counties near the two stations.

Both stations maximize expected profits. As advertisers on local television usually are less concerned with aiming at specific socio-demographic groups than advertisers in newspapers (Kaniss, 1997) both stations simply strive to maximize their audience shares regardless of audience composition. With revenues per viewer from advertising normalized to one, station $A$ maximizes expected profit

$$
E\left[\pi^{A}\right]=\sum_{c}\left[p_{c} \cdot F_{c}\left[u_{c}\left(n_{c}^{A}\right)-u_{c}\left(n_{c}^{B}\right)\right]-k_{c} \cdot n_{c}^{A}\right]
$$

subject to the air time constraint. $p_{c}$ denotes population in county $c$. Both stations decide simultaneously and non-cooperatively about allocating news time across counties. As the two stations face exactly the same optimization problem the unique Nash-Equilibrium ${ }^{54}$ has both stations broadcasting the same news on each county in the market. Thus, equilibrium news allocation is given by a pair of strategies $\left(\mathbf{n}^{\mathbf{A}}, \mathbf{n}^{\mathbf{B}}\right)$ satisfying $n_{c}^{A}=n_{c}^{B}=n_{c}^{*}$, the air time constraint and

$$
p_{c} f_{c} \phi_{c}^{\prime}\left(n_{c}^{*}\right) \bar{u}-k_{c}=\lambda, \quad \lambda>0
$$

for all counties. Equation (34) summarizes the message of the model regarding news time

\footnotetext{
${ }^{54}$ Basically, the model of competition between the two television stations is analogous to models of redistributive politics as introduced by Lindbeck and Weibull (1987) and extended by Dixit and Londregan (1996). As the basic model has already attained textbook status (see, e.g., Persson and Tabellini, 2000) we abstain from extensively proving uniqueness and existence of the Nash-Equilibrium in this simple setting. Lindbeck and Weibull (1987) or Strömberg (2004a) clearly characterize equilibrium strategies and give proof. With $u$ strictly concave and assuming $F_{c}[\cdot]$ to be the uniform distribution, the objective functions of both stations satisfy the concavity condition for existence of equilibrium.
} 
allocation in equilibrium $n_{c}^{*}=n^{*}\left(k_{c}, f_{c}, p_{c}, \bar{u}\right)$ and implies that the marginal effect of a news unit on expected profit must be equal across all counties. Assuming that the distribution function $F_{c}$ is the same for all counties, the model predicts that both stations broadcast more news on counties where collecting information is less expensive and on counties with larger population. As we argue that gathering information is less expensive in places close to the location of the two stations this results in more coverage of counties close to the stations whereas more distant counties are left with only little media attention.

Equilibrium news also define the share of informed voters $\phi_{c}\left(n_{c}^{*}\right)$ in each county. Recalling what the model predicts on equilibrium news allocation, the share of informed voters decreases in counties' distance from the TV stations and increases in a county's population.

Note that this describes the allocation of coverage in general. In the following, we assume that there is always coverage of the activities of persons as prominent as governors, but, due to the calculus of television, the share of citizens who are aware of this differs among counties. Thus, in the next subsection, there are informed voters who know how much money was allocated to their county by the governor whereas uninformed voters do not attribute spending to the governor.

\subsubsection{Strategic Allocation of Grants}

In this section, we use a simple probabilistic voting model as in Strömberg (2004b) to show how an incumbent spreads a given budget strategically across counties to maximize the probability of reelection. The incumbent wins the election if he gets more than half of all votes cast. He allocates total grants $G$ across the counties in his state such that

$$
\sum_{c} p_{c} \cdot g_{c}=G
$$

where $g_{c}$ denotes grants per capita in county $c$. Since each voter $i$ in county $c$ derives utility $W_{c}=W_{c}\left(g_{c}\right)$ from grants and cares about ideological features of the incumbent his total utility is

$$
W_{c}\left(g_{c}\right)-\sigma_{i}-\delta
$$


where $\sigma_{i}$ is an individual ideological component and $\delta$ is the incumbent's general popularity in the electorate as a whole; both components are random variables and may be positive or negative.

Now we can take our result on informed voters from the last subsection and put pieces together. Only an informed voter $i$ in county $c$ knows that the incumbent is responsible for the grant allocation and takes this into account when casting the ballot. Then, voter $i$ votes for the incumbent if his total utility under the incumbent's regime has met some minimum standard $\overline{W_{i}}$ :

$$
\alpha_{i} \cdot W_{c}\left(g_{c}\right)-\sigma_{i}-\delta \geq \overline{W_{i}}
$$

and for the challenger otherwise. The dummy variable $\alpha_{i}$ equals one if citizen $i$ is informed and zero if he is not informed. Hence, the probability that $\alpha_{i}=1$ is given by the share of informed voters $\phi_{c}$.

We assume a special form of the utility function :

$$
W_{c}(g)=s_{c} \cdot \frac{1}{1-\varepsilon} \cdot g^{1-\varepsilon},
$$

where $\varepsilon>0$ captures the concavity of the utility function and the parameter $s_{c}$ affects the marginal utility of an extra dollar of grants. Note that $W_{c}$ is strictly concave with marginal utility falling from $\infty$ toward 0 when $g$ is increased from 0 toward $\infty$. Evidently, since a higher $s_{c}$ raises $W_{c}^{\prime}$ for a given $g$, the voters in a county with a higher $s_{c}$ are more responsive to grant money regarding their voting decision. Thus, $s_{c}$ measures how important grants are in relation to ideology.

To keep things simple we assume that $\sigma_{i}+\overline{W_{i}}$ has a county-specific uniform distribution with mean $m_{c}$ and density $\psi_{c}$. The higher $\psi_{c}$, the larger is the number of swing voters in the county. The number of votes for the incumbent in that county $c$ is

$$
V_{c}=p_{c}\left(\frac{1}{2}+\psi_{c}\left(\phi_{c} \cdot W_{c}-m_{c}-\delta\right)\right)
$$


Consequently, the incumbent wins the election if

$$
\sum_{c} V_{c}=\sum_{c} p_{c}\left(\frac{1}{2}+\psi_{c}\left(\phi_{c} \cdot W_{c}-m_{c}-\delta\right)\right) \geq \frac{1}{2} \sum_{c} p_{c} .
$$

Rearranging, we obtain the equivalent expression

$$
\frac{1}{\sum_{c} p_{c} \psi_{c}} \sum_{c} p_{c} \psi_{c}\left(\phi_{c} \cdot W_{c}-m_{c}\right) \geq \delta
$$

Apparently, for any allocation of grants it depends on the realization of the general popularity shock, $\delta$, whether (41) is satisfied and the incumbent wins the election. Contingent on grant allocation the probability of reelection, $P$, is given by

$$
P=\Omega\left[\frac{1}{\sum_{c} p_{c} \psi_{c}} \sum_{c} p_{c} \psi_{c}\left(\phi_{c} \cdot W_{c}-m_{c}\right)\right]
$$

where $\Omega$ denotes the distribution function of $\delta$.

The incumbent strives to maximize the probability of being reelected by allocating grants strategically across counties. In equilibrium, the optimal allocation of grants $\mathbf{g}^{*}$ satisfies the first-order condition

$$
\psi_{c} \cdot \phi_{c} \cdot W^{\prime}\left(g_{c}^{*}\right)=\mu, \quad \mu>0
$$

and the budget constraint. ${ }^{55}$ Equation (42) summarizes the central message of the model regarding the incumbent's incentives to allocate grants strategically: In equilibrium, the number of votes gained by an extra dollar is equal across counties. Assume that the governor allocates his budget equally across counties. Then, the marginal effect on expected votes is larger in counties with higher values of $\psi_{c}$ and $\phi_{c}$. The only way to satisfy the equilibrium condition is to raise spending levels in counties where the marginal effect is

\footnotetext{
${ }^{55}$ Due to the concavity of $W(g)$, the Hessian of the incumbent's payoff function is a diagonal matrix with all elements on the diagonal being negative. Thus, the Hessian is negative definite and the incumbent's payoff function is concave. Finally, as the constraint set is convex, $\mathbf{g}^{*}$ constitutes a unique global constrained maximum.
} 
large. With $W\left(g_{c}\right)$ strictly concave, raising spending levels pushes down the marginal effect on expected votes in the respective counties. Simultaneously, raising the amount of grants in some counties implies lower spending levels in other counties due to the budget constraint. Thus, $W^{\prime}\left(g_{c}\right)$ increases in the latter counties leading to equilibrium. Finally, larger shares of informed voters $\left(\phi_{c}\right)$ and more swing voters $\left(\psi_{c}\right)$ give rise to allocating more grants to counties.

The share of informed voters, $\phi_{c}$, results from the competition in the television market. As $\phi_{c}^{*}=\phi\left(n_{c}^{*}\right)$ and $n_{c}^{*}=n^{*}\left(k_{c}, f_{c}, p_{c}, \bar{u}\right)$, the model predicts grant spending to be higher in counties where media find it less cumbersome to gather information (low $k_{c}$ ). This is the main message of the model. Furthermore, the model predicts that equilibrium spending is higher in counties with many swing voters $\left(\psi_{c}\right)$, in counties with large populations $\left(p_{c}\right)$ and where the relative importance of grants as against ideology is higher $\left(s_{c}\right)$.

Despite the fact that every household has access to television, the model predicts that commercial TV stations still face incentives to bias the program in favor of counties close to the station's headquarters. This leads to a less informed electorate in more distant counties, which makes it less attractive for politicians to channel funds to these counties. This effect runs counter Strömberg's (2004b) result that the rise of broadcast media may eliminate the disadvantages of distant regions concerning grant allocation. The information level in distant regions may be lower, even if all households in these regions have access to TV news and thus a high penetration with TV sets may not suffice to eliminate the media-induced disadvantages remote areas face.

In the next chapter, we outline our strategy of identifying effects on county spending levels driven by television market geography. Analyzing data on US television markets and the allocation of federal grants across counties, we empirically check the theoretical predictions.

\subsection{Data and estimation approach}

Having laid out the theoretical hypotheses, the remainder of the chapter is concerned with the empirical analysis of media impact on public spending. First, we give an outline of the empirical specification and data sources used in the estimation. The results section then 
discusses our findings.

\subsubsection{Empirical Strategy}

In the estimation we will be using a cross-section of counties across the 48 contiguous states of the United States of America. ${ }^{56}$

The dependent variable chosen is the per capita amount of federal grants awarded to the respective counties in 2000. Since we set out to discover how the intensity of media activity shapes the spending decisions of politicians, we would ideally want to use spending the geographical distribution of which is completely at the politician's discretion as our left-hand-side variable. Even though governors enjoy quite a bit of budgetary power, such monies are hardly ever available to politicians. Quite the contrary, most grants are not freely distributed across counties but are rather distributed according to formulas that have been decided upon in the political process. Thus, one could easily arrive at the conclusion that funds are being distributed in some sort of 'just' manner because there is a formula that exactly determines the amount each jurisdiction is to receive. Such reasoning does not take into account that before being channeled to final recipients many formula grants typically pass through intermediary government levels or institutions. Here, political actors may put pressure on bureaucrats to divert spending according to the politician's preferences. Among these political actors are senators and governors. We assume that senators as well as governors are interested in maximizing the amount of federal dollars awarded to their state and then distribute them so as to maximize the probability of reelection. It is important, though, to realize that in addition to bureaucrats being influenced by politicians when it comes to the distribution of formula grants, not all grants are awarded via formulas and sometimes the formula merely marks the upper bound for the amount of grants that a county can receive. This leaves at least part of the federal grants at the discretion of politicians to distribute among their constituencies.

\footnotetext{
${ }^{56}$ Grants to New York City counties are attributed to New York County (Manhattan) because the dependent variable was not available for all five boroughs. Washington, D.C. is excluded from the estimations as are counties that cannot be unambiguously assigned to a single media market. A number of counties is omitted because of missing values, leaving us with 2934 observations (approximately $94 \%$ of US counties) for the estimations.
} 
It can be argued that aside from Governors and Senators influencing the distribution of grants, there are are many other political actors who follow their own political agenda, most notably members of Congress. From a theoretical view, it is expected that the governor will favor media cities. The same rationale goes for members of Congress who distribute monies, as their districts span more than a single county. For our purposes, however, it does not even matter whether it is the governor/congressman who distributes the money or Congress members who pull funds into their district. An explanation for the latter mechanism would be if Congressmen hailing from media counties generate more funds because they are subject to heavier media scrutiny and thus put more effort into their political actions than their counterparts from non-media places. Both mechanisms will favor media counties.

An argument backing our choice of outcome measure comes from Levitt and Snyder (1997), who distinguish between low-variation and high-variation federal expenditure and state that high-variation spending is more prone to manipulations by politicians and easier to claim credit for. High-variation spending is in essence defined as federal expenditure net of direct transfers to individuals and government procurement contracts, leaving federal programs often administered by state and local governments for examination. This definition is not far from the federal grants variable we are using, yet we choose to stick with the more clear-cut definition of federal grants. Thus, in order to explain the differences in federal grants per capita across communities, we use the following OLS baseline specification where we enter all left- and right-hand side variables but those defined as shares and the population variables in natural logarithms:

$$
g_{c}=\gamma \phi_{c}+\beta^{\prime} x_{c}+\varepsilon_{c}
$$

where $g_{c}$ is the (log of) dollar amount of federal grants per capita awarded to county $c$.

The share of informed voters in a county, $\phi_{c}$, is accounted for by either the county's distance to the next media city or the number of TV stations in the respective county. These are the key variables in determining whether there is a connection between the intensity of media coverage, voter information and the geographical distribution of federal grant awards. As 
we have shown in the theoretical model, the politician will direct grants towards counties that are closer to the media cities, as they generate more media coverage than grants awarded to farther away counties. This is due to the fact that the TV station reporting on projects financed through grant awards can do so at a lower cost if the project is realized in the proximity of the station's headquarters. Hence, the first variable proxying for voter information is the (log of) distance from the county's population centroid to the nearest media center. Our definition of media centers is based on the Designated Market Areas (DMAs) stipulated by Nielsen Media Research. The United States is split up into 210 DMAs 7-1), which are made up of those counties that tend to watch the same TV stations. ${ }^{57}$ DMAs can cross state borders and are named after the city or cities where most TV stations are located. Whenever there are multiple cities of importance to the media market, they enter the DMA name (e.g. the San Francisco DMA is called San FranciscoOakland-San Jose). When this is the case, our distance variable measures distance to the nearest city appearing in the DMA name. The intuition behind this is that even though they may not constitute the largest agglomeration in the DMA, these places are classified as media cities and a politician's activity in these places will probably generate more attention than it would in other places. As these distances vary a great deal across states and even DMAs, we use a relative distance measure calculated as county $c$ 's distance to media center divided by the average distance of all counties included in the same DMA to their nearest media city. This seems reasonable, as TV stations divide their news time among events occuring within their own DMA. ${ }^{58}$ We hypothesize the coefficient on the distance variable to bear a negative sign, implying decreasing effects of distance on the amount of grants received (see the results section for further discussion).

Though not explicitly modeled as a distance measure, the second variable in $\phi_{c}$ essentially accounts for physical distance and thus transaction cost on behalf of media organizations, too. It is the (log of) the number of full-service TV stations licensed in the county under consideration. Aside from capturing zero distance to the nearest media outlet, it accounts for effects of having multiple outlets at one's disposal. ${ }^{59}$ These full-service stations are

\footnotetext{
${ }^{57}$ Thus changes in DMA affiliation actually do occur from time to time, whenever viewing habits in a given county change.

${ }^{58}$ We do not believe media coverage to be exclusive to within-DMA counties as there are outside-DMA events that warrant coverage. Yet these are of such importance that coverage is not a choice and thus the choice set is still made up of within-DMA counties only.

${ }^{59}$ This variable is calculated as $\log ($ number of TV stations +1$)$ in order to avoid generating many missing
} 


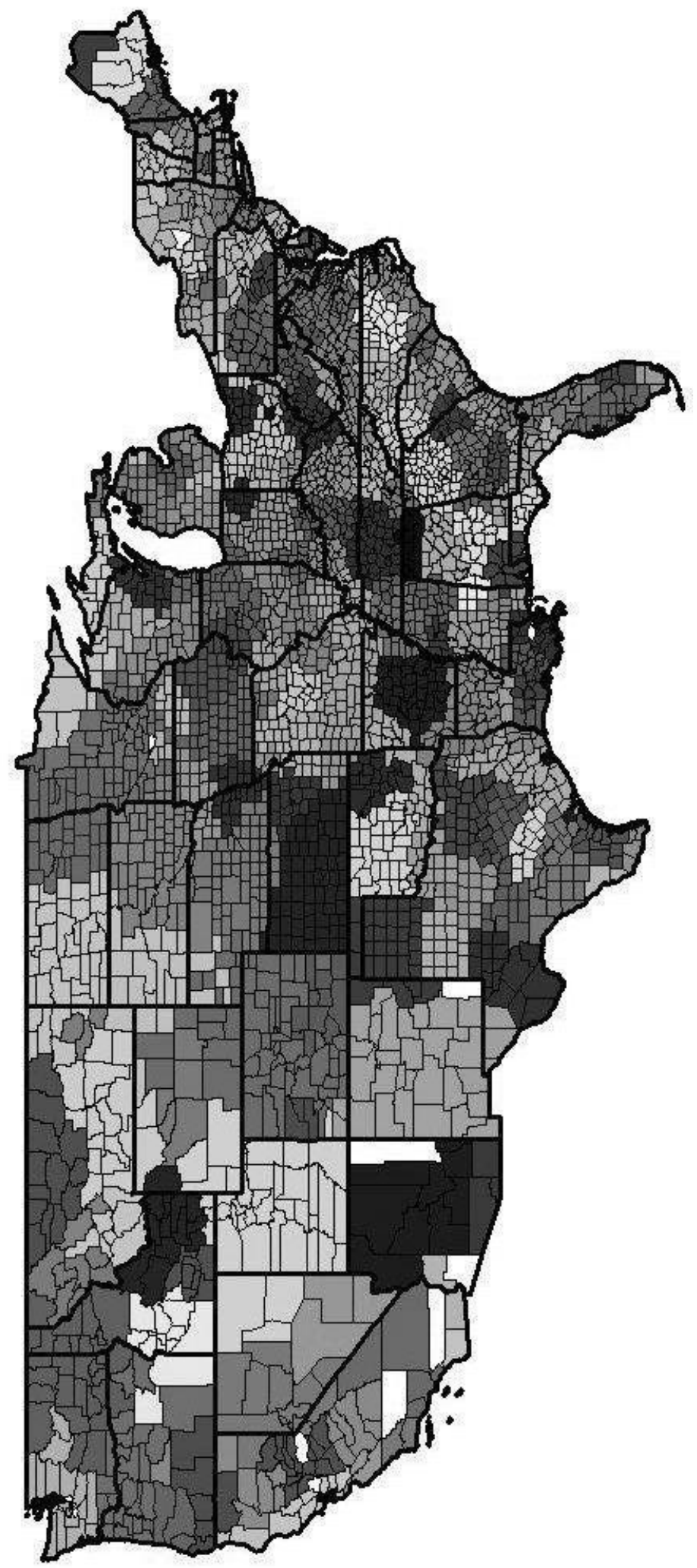

Figure 7-1: DMAs And STATE Borders. DMAs In GRAY SHADings, STATE BorDERS ARE BOLD, THIN LINES ARE COUNTY BORDERS. 
made up in large part of affiliates of the four big networks ABC, CBS, NBC, FOX plus the PBS stations. There are a little over 700 entities which contain at least one fully licensed station, compared to about 340 media cities. We expect this variable to be a predictor of federal grant spending, because having at least one media outlet in the immediate vicinity will greatly increase chances of news being picked up on, even without being a Nielsen media city. Obviously, all media center counties are host to at least one TV station and so the log of distance and the log of the number of TV stations are to some extent two measures for the same concept. Accordingly, we use the two variables interchangeably as indicators of the availability of media outlets.

As quite a few DMAs cross state borders, we add the share of DMA population living in the same state that county $c$ belongs to and a dummy variable taking on value 1 if all media cities in the DMA are located in another state than county $c$. The latter variable (out-of-state) accounts for counties possibly being marginalized within their own DMA information-wise, because they are not an important enough target group for TV stations. ${ }^{60}$ The share of DMA population living in the same state as county $c$ could also measure marginalization such that a smaller share means less media attention. It may, however, also be a measure for yardstick competition, as will be discussed later. In addition, if county $c$ is not out-of-state (i.e. there is a media city that caters to county $c$ 's needs) a smaller share of DMA population living in the same state as $c$ might lead to higher grants, as media attention may be more "on the spot". In an attempt to disentangle these effects, we add an interaction of the two variables. Finally, the percentage of residents with at least a bachelor's degree is added as a control for informed voters.

As data on the number of persons registered to vote could not be obtained at county-level, we calculate relative voter turnout as the number of democratic and republican votes cast in the 1996 presidential election divided by population of that year. We then divide this number by the average turnout in the state county $c$ is located in. The assumption inherent to this transformation is that the governor's choice set is made up of all counties in the state. A high voter density $\psi_{c}$ is believed to induce higher levels of funding as well. We

values. The estimated coefficient $\gamma$ will therefore not represent an elasticity. $\gamma$ can be transformed into an elasticity as follows: $\gamma \cdot[j /(j+1)]$, where $\mathrm{j}$ is the number of TV stations.

${ }^{60}$ In addition to having no media city in their state, only $16 \%$ of these counties have a TV station as opposed to $24 \%$ of the in-state-counties. 
measure voter mobility as the number of times the majority in presidential elections in county $c$ has shifted from 1980 to $1996 .^{61}$

Controls for financial needs of a county and its population as well as politico-economic variables are also included. They measure the relative importance of federal grants to different groups in the population, as well as the relative success of different groups in acquiring federal grants through activities such as lobbying. The political variables we include are distance to the state capital relative to all other counties in the same state, the percentage of residents employed by the federal government and the percentage of residents employed by state and local government. While distance from the capital is believed to be negatively related to the ability to generate funds, e.g. due to higher lobbying costs (Borck and Owings 2003), a high percentage of federal and other government employees supposedly leads to higher grants per capita. The latter variables also account for "politician density". What we mean by that is that there are differences in how well counties are represented in the political process, leading to the well-represented jurisdictions receiving more money. As we do not have data on the number of politicians hailing from the respective counties, we assume that the percentage of residents employed by federal, state and local governments in county $c$ is highly correlated with the number of political agents operating on behalf of county $c$.

We also include a number of controls to account for the distribution of grants on the basis of formulas. ${ }^{62}$ In addition to income, poverty rate, unemployment rate, share of females, percentage of high school dropouts, county expenditure per capita, percentage of population under 24 and bank deposits per capita, we also add the Herfindahl index of ethnic fragmentation, ${ }^{63}$ the ratio of mean to median income and the white percentage of the population. ${ }^{64}$ All OLS and 2SLS estimations allow for clustering of standard errors by state and include population density and population as well as state dummies. Full sample estimations also

\footnotetext{
${ }^{61}$ The $\log$ of mobility is calculated as $\log$ (majority shifts +1 ) for the same reasons stated earlier.

${ }^{62}$ For a list of variables these formulas may contain, see Randsell (2004). Most of them are highly collinear with income, so we choose not to include all of them.

${ }^{63}$ The index takes on values between 0 (if there were an infinite number of population groups) and 1, where 0 indicates total ethnic heterogeneity and 1 indicates a completely homogenous population. Alesina, Baqir and Easterly (1999) find that fragmentation leads to higher intergovernmental spending.

${ }^{64}$ Differing ethnic compositions can result in the same Herfindahl index, so the white percentage accounts for the relative importance of the white population in the calculation of the index.
} 
include an indicator for whether the county is classified as a metropolitan/micropolitan area.

\subsubsection{Omitted Variables and Endogeneity of TV Station Location}

Even though in most settings one would like to make use of panel data for empirical estimations in order to minimize omitted variable bias, there is one important reason why we do not believe we would be able to identify the effects outlined in the model using this kind of data. The problem lies in the absolute and relative stationarity of our two key variables, respectively. Whereas the number of major TV stations licensed in a given county shows at least some, however limited, variation over time, the distance a county is located from the nearest media city is fixed. The only possible reasons for this distance to actually change would be (a) if a new media city emerges or a former one is not granted that status any longer or (b) if the DMA a county belongs to changes. Although (b) sometimes happens, we believe the variation in the data will be insufficient to identify any effects. ${ }^{65}$ We are well aware of the limitations inherent to cross-sectional data, yet try to counter these problems through the use of state effects and 2SLS.

An obvious candidate to be concerned about when it comes to endogeneity is the number of TV stations. OLS estimates may be biased due to omitted variables that affect both the number of TV stations and the amount of grants a county receives per capita. This bias may go either way, depending on the direction of correlation of the omitted variable with the endogenous regressor as well as with the dependent variable. A possible omitted factor would be the presence of interest groups and lobbying activity, or to be more precise, the presence of industries or groups of people that are well represented by interest groups. One could think of the agricultural sector or heavy industry as branches that have traditionally been successful in acquiring grants. Agricultural heavy counties tend to be rural, so often they aren't home to a TV station. Counties with heavy industry are located both in rural areas as well as in urban surroundings. For rural industrial counties the same reasoning as for agriculture applies. Urban counties with a higher share of heavy industry on the

\footnotetext{
${ }^{65}$ Gentzkow (2006) assumes current DMA borders to be a valid approximation to those in the 1960 s.
} 
other hand are probably not the kind of urban counties where TV stations tend to locate, as they would rather emerge in a more service-industry oriented county in the same metro area. Hence, the omission of lobbying activity would introduce a downward bias in the OLS estimates.

A second issue we would like to address is measurement error in the number of TV stations. Data on TV stations is obtained from the FCC and TV stations are assigned to the county where the station is licensed or where the main transmitter is located. In most cases this will be identical with the county where the actual TV studio is located but sometimes the two locations do not coincide, causing the TV stations variable to be measured with error. As is well known from the literature, measurement error biases OLS estimates towards zero.

Finally, the location of TV stations may be endogenous to government spending, as they include PBS affiliates, which are funded by the Corporation for Public Broadcasting (CPB, which in turn is funded by the US federal government), federal and state governments. ${ }^{66}$ Because these stations may tend to emerge or be placed for political reasons where spending is high, the use of OLS might lead us to overestimate the effect of having a TV station in the home county. The same is true if network TV stations emerge where a large amount of grants is spent. This may happen, either because there is more to report on in these places or because politicians influence the licensing process in some way. ${ }^{67}$

Hence, we instrument the number of TV stations and the first stage equation estimated is:

$$
\phi_{c}=\pi^{\prime} z_{c}+\theta^{\prime} x_{c}+v_{c}
$$

where $z_{c}$ denotes the vector of instruments and the second stage is as in equation (43). We instrument the log TV station variable with two exogenous variables. The first is the

\footnotetext{
${ }^{66} \mathrm{CPB}$ grants to local jurisdictions are excluded from our dependent variable. Around 2000, PBS received about $\$ 250$ million per year from the CPB, \$300 million from state governments, whereas federal grants and contracts accounted for $\$ 70$ million. See http://www.cpb.org or http://www. newenglandfilm. com/news/archives/00december/pbs.htm

${ }^{67}$ Prior (2006) argues that politicians have only rarely tried to influence the licensing process, though.
} 
log of the number of TV sets in a given county in 1960. This should capture whether the audience was large enough for a station to be interested in locating there or for the FCC to grant a license to that city. The number of TV sets in 1960 is unlikely to be correlated with either grants in 2000 or some underlying variable measuring inherent political interest, as television did not serve as a major channel of distributing political information until the mid 1960s (Roper 1985). This may be especially true for local news, as film or video equipment, if at all available, was nowhere near as affordable as nowadays. The number of TV sets is also unlikely to be related to lobbying activity. The second instrument is the log of the number of low power (LP) TV stations that are not classified as Class-A (CA) and have a broadcasting power of less than 10kw. ${ }^{68}$ We argue that many of these are local public access stations or other stations so low in reach and information content (hence they are neither classified CA nor have significant broadcasting power) that they cannot serve the governor in promoting his actions. ${ }^{69}$ Thus, their location cannot be contingent on public spending in county $c$ or local voters' interest in county $c$ 's current affairs. Their number is at the same time positively correlated with the number of full service TV stations. One reason is that even small stations will employ people who are trained in broadcasting and these people can be found in the media counties. In addition, these small TV stations are no more or less likely to be located in a successful lobbying county than in any other county.

\subsubsection{Spatial Autocorrelation}

There are good reasons to check for spatial dependencies in our data. Spatial autocorrelation induced by strategic interaction could be responsible for possible (dis-)similarities between grants awarded to neighboring counties. One reason for suspecting such effects is yardstick competition. We would then expect spending between neighbors to be positively correlated. As yardstick competition essentially requires two governments that strategically interact, this may not be all that relevant in our setting, where the governor decides

\footnotetext{
${ }^{68} \mathrm{CA}$ stations are low power TV stations which are given protected status by the FCC because they convey local information. We exclude stations above $10 \mathrm{kw}$, because they might have a reach large enough to make them an attractive outlet for politicians. The log is again calculated as (log of TV stations +1$)$.

${ }^{69}$ Indeed, according to the National Association of Broadcasters, the total audience of low power stations including Class A is 800,000 nationwide http://www.nab.org.
} 
on how to distribute grants across his state. Thus, when focusing on the governor's actions, grant spending in, say county A and B of the same state cannot be the outcome of strategic interaction. It will rather be decided upon by a single person in order to maximize the number of votes, taking into account voters' reactions to a variation in the allocation of grants. This implies that the Governor's decisions are quite likely to be driven to a large extent by measurable population characteristics rather than policy interdependence. ${ }^{70}$

However, there may be other political agents such as the aforementioned congressmen or elected county officials that make strategic interaction seem rather conceivable. In addition, such strategic interaction can of course occur in counties bordering another state. We already try to account for this fact by including the variable DMA home share in our estimations. This variable measures the percentage of the population in a county's DMA living in the same state the county under consideration belongs to. The higher the share living outside the home state, the more information about what is going on in the other state we expect TV stations to convey, thus creating yardstick competition among Governors. Even though we include this control and we do not feel the spatial dependence in our setting to be an exclusively strategic one, in order to account for the above mentioned effects, we estimate a spatial lag regression model which can be displayed in matrix form as follows:

$$
g=\rho W g+X \beta+\varepsilon,
$$

where $\varepsilon$ is a vector of i.i.d. error terms, $g$ is a vector representing grant spending, $W$ is a spatial weight matrix, $\beta$ is a vector of coefficients to be estimated and $W g$ gives the measure of grant spending in neighboring counties. The interaction between own and neighbors' spending is captured in the coefficient to be estimated, $\rho$, which we would then expect to have a positive sign. Another reason for the choice of the spatial lag model could be spillovers which we may not be able to capture in the baseline specification. In this case, the spatial correlation, as expressed in $\rho$ may point in either direction.

\footnotetext{
${ }^{70}$ If people are envious of the amount of grants their neighboring counties receive, a sort of interdependence would be introduced in that the Governor cannot distribute his funds unequally but must rather follow up on a grant award to county A with an award to county B, thus creating positive spatial autocorrelation.
} 
Another rationale for spatial correlation in our context would be locally correlated shocks or the existence of spatially correlated omitted variables which drive the governor's choice of local spending. In both cases the spatial interdependence is relegated to the error term, yielding the following spatial error model appropriate:

$$
\begin{aligned}
& g=X \beta+\varepsilon \\
& \varepsilon=\lambda W \varepsilon+u,
\end{aligned}
$$

where the notation differs from above in that $\varepsilon$ is a vector of spatially autocorrelated error terms, $u$ is a vector of i.i.d. error terms and $\lambda$ is the parameter measuring the extent of spatial autocorrelation. We also estimate a specification that allows for the simultaneous presence of spatial lag and error. Essentially this means estimating equation (45), where the error term is as in equation (47), via a three step procedure that takes into account the endogeneity of the spatially lagged variable. ${ }^{71}$

It must be pointed out that these models will be estimated as a robustness check rather than as a means of determining what mechanism is responsible for possible spatial dependencies. Our interest is mainly in determining whether the main media related variables distance to media city and log number of TV stations pick up some of the spatial effects and whether standard errors may be biased downwards in the OLS specification due to the neglect of spatial effects.

\subsubsection{Data Sources}

The data mentioned above is gathered from a variety of sources. While the dependent variable federal grants per capita is taken from the Consolidated Federal Funds Report 2000

\footnotetext{
${ }^{71}$ Lag and error specification are estimated using maximum likelihood (ML), the combined spatial lag and error model via the GS2SLS estimator proposed by Kelejian and Prucha (1998). The weighting matrix $W$ is row standardized based on rook contiguity, i.e. counties sharing a common border are treated as neighbors.
} 
(CFFR), many sociodemographic controls stem from the County Databook 2000, published by the US Census Bureau. More sociodemographic controls are taken from the database County Profiles published by the US Department of Agriculture. ${ }^{72}$ The county distances to the nearest media city are calculated based on the county population centroids provided by the Census Bureau and the geographic location of media cities obtained by using geocoding software. The names of DMAs and the media cities are those defined by Nielsen Media Research for the year 2002. Counties are assigned to DMAs based on the Nielsen definitions of the same year. The number of fully-licensed as well as low-power TV stations by county is calculated using the Federal Bureau of Communications' Wireless Telecommunications Bureau Database as of July 2006. Unfortunately, we were unable to obtain data for the actual time period under consideration, yet we believe that given the little variation in the data over time mentioned above, this does not hurt our results too much. The number of votes cast for the Republican and Democratic parties in the presidential elections from 1980 to 1996 is taken from the USA Counties 1998 CD published by the US Census Bureau. This data was combined with the intercensal population estimates (provided by the same source) in order to calculate vote shares of the Republican and Democrat parties in the presidential elections as well as voter turnout and voter mobility (density). Finally, the number of television sets by county in 1960 is taken from the ICPSR County and City Data Book Consolidated File: County Data 1947-197\%. Micropolitan areas are as of 2003, because this classification did not yet exist in 2000. Summary statistics are displayed in table $7-1$

\subsection{Empirical Results}

\subsubsection{The Link between media activity and spending}

We employ two samples in estimating our model: a full sample of counties, containing 2934 observations and a subset containing all 1652 micropolitan and metropolitan counties in the dataset (Figure 7-2 shows counties by sample, where Metro/Micro counties are nested

\footnotetext{
72 available online at http://maps.ers.usda.gov/profiles/webcensusdownload.aspx.
} 


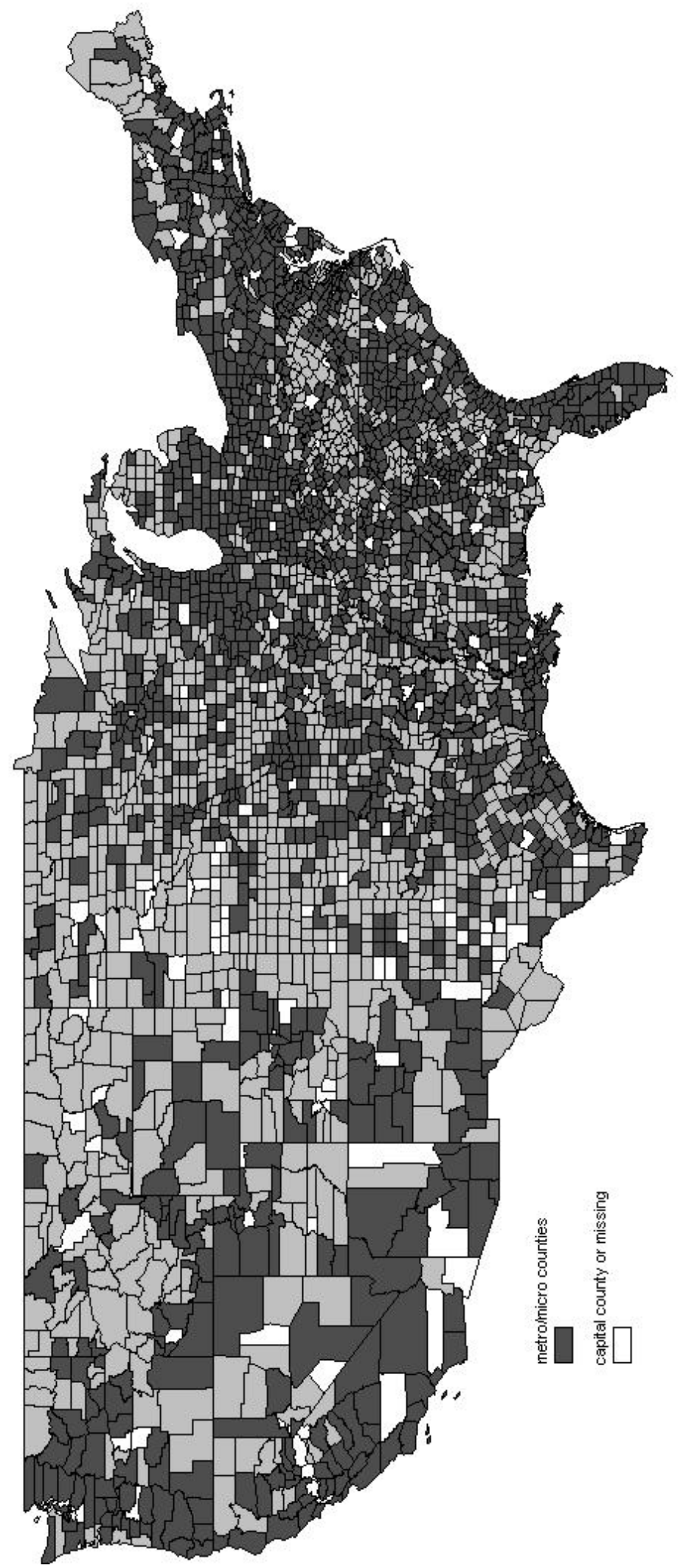

Figure 7-2: Counties BY SAMPle, DARKER SHADING MARKS METRO/MICRO COUNTIES 
TABle 7-1: Summary STATistics.

\begin{tabular}{|c|c|c|c|c|c|}
\hline & $N$ & Mean & Std. Dev. & Min & Max \\
\hline grants per capita $(\$)$ & 2934 & 1053 & 729 & 96 & 10937 \\
\hline grants per cap w/o Medicaid $(\$)$ & 2933 & 529 & 582 & -224 & 9986 \\
\hline full service tv stations & 2934 & 0.51 & 1.43 & 0 & 21 \\
\hline distance to media city ratio & 2934 & 100.98 & 56.69 & 0.66 & 336 \\
\hline Median income $1997(\$)$ & 2934 & 32461 & 7900 & 14178 & 77513 \\
\hline bachelor or higher pct & 2934 & 13.19 & 6.28 & 3.7 & 53.4 \\
\hline out of state county & 2934 & 0.146 & 0.353 & 0 & 1 \\
\hline DMA share in home state & 2934 & 78.25 & 30.38 & 0.07 & 100 \\
\hline native american pct & 2934 & 1.49 & 5.42 & 0 & 86 \\
\hline poverty pct & 2934 & 15.00 & 6.22 & 1.9 & 46.7 \\
\hline high school dropout pct & 2934 & 30.69 & 10.23 & 4.5 & 68.4 \\
\hline under 24 yrs pct & 2934 & 34.33 & 4.28 & 20.2 & 66 \\
\hline unemployed pct & 2934 & 4.75 & 2.52 & 0.7 & 27.6 \\
\hline bank deposits per cap $(1000 \$)$ & 2934 & 11.40 & 5.90 & 0.84 & 108.63 \\
\hline female pct & 2934 & 50.47 & 1.85 & 32.74 & 57.43 \\
\hline expenditure per cap $(1000 \$)$ & 2934 & 2.24 & 0.864 & 0.017 & 10.47 \\
\hline mean to median income & 2934 & 1.67 & 0.27 & 0.79 & 10.12 \\
\hline white pct & 2934 & 85.16 & 15.59 & 12.60 & 99.50 \\
\hline ethnic fragmentation & 2934 & 0.75 & 0.18 & 0.26 & 0.99 \\
\hline distance to capital ratio & 2934 & 100.01 & 54.0 & 4 & 362 \\
\hline fed gov employed pct & 2934 & 0.69 & 1.22 & 0.04 & 37.24 \\
\hline other gov employed pct & 2934 & 6.56 & 2.83 & 2.24 & 52.52 \\
\hline turnout ratio 1996 & 2934 & 0.99 & 0.13 & 0.16 & 1.85 \\
\hline voter density & 2934 & 0.72 & 0.83 & 0 & 3 \\
\hline metro/micro indicator & 2934 & 0.56 & 0.49 & 0 & 1 \\
\hline population density (1000/sqm) & 2934 & 0.165 & 0.639 & 0.0002 & 16.398 \\
\hline land area (1000 sqm) & 2934 & 0.955 & 1.290 & 0.015 & 20.053 \\
\hline population $(100,000 \mathrm{~s})$ & 2934 & 0.838 & 2.819 & 0.005 & 95.193 \\
\hline low power tv stations & 2934 & 1.69 & 5.23 & 0 & 70 \\
\hline tv sets 1960 & 2930 & 13618 & 55457 & 139 & 1816565 \\
\hline
\end{tabular}

within the full sample. $\left.{ }^{73}\right)$ Note that all counties containing the state capitals $(n=48)$ have been excluded from the analysis as some grants that cannot be attributed to a single county are assigned to the state capital and including these counties would likely lead us to overestimate the effect of the media on grant spending.

The main reason for splitting up our sample is that rural and nonrural counties may not be comparable because rural counties receive more grants per capita due to effects we may not be able to control for. These include scale effects, minimum grants per county leading to higher per capita grants in less populous counties, overrepresentation in the political process or flat rate grants per county. Even though we control for a number of urbanity measures such as metro/micro classification, ethnic fractionalization, population density and population, we want to rule out the possibility of measuring urban-rural differences in grant spending in our media variables. Descriptive statistics in tables 7-2, 7-3 and 7-4

\footnotetext{
${ }^{73}$ Metro areas are defined by the Bureau of the Census as areas containing a core urban area of 50,000 or more population. Micropolitan areas contain an urban core of at least 10,000 population. Metro or micro areas include one or more counties, specifically the core urban area, as well as many adjacent counties. Around $80 \%$ of the US population resides in metropolitan areas.
} 
show that:

(a) distance ratios are largest in the full sample, implying large distance ratios on rural counties,

(b) the raw correlation between grants and distance is higher in the full sample than in the Metro/Micro sample (this holds if we exclude Medicaid grants. We will exclude Medicaid later on as a robustness check) and

(c) rural counties indeed receive larger amounts of grants per capita. We take this as a hint that the relationship probably differs across samples.

TABle 7-2: Mean Distance Ratio to neARest Media City.

\begin{tabular}{lccccc}
\hline & $N$ & Mean & Std. Dev & Min & Max \\
\hline Full sample & 2934 & 100.98 & 56.69 & 0.66 & 336.08 \\
Metro/Micro & 1652 & 79.94 & 53.72 & 0.66 & 336.08 \\
\hline
\end{tabular}

TABLE 7-3: RAW CORRELATIONS GRANTS/DistANCE, GRANTS/TV STATIONS.

\begin{tabular}{lrrrr}
\hline & \multicolumn{2}{c}{ incl. Medicaid } & \multicolumn{2}{c}{ excl. Medicaid } \\
& Full sample & Metro micro & Full sample & Metro micro \\
\hline Grants/Distance & 0.156 & 0.053 & 0.058 & -0.032 \\
Grants/TV stations & -0.024 & 0.074 & 0.021 & 0.112 \\
\hline$N$ & 2934 & 1652 & 2933 & 1651 \\
\hline
\end{tabular}

TABLE 7-4: MEAN GRANTS PER CAPITA.

\begin{tabular}{lrrrrr}
\hline & $N$ & Mean & Std. Dev & \multicolumn{1}{c}{ Min } & Max \\
\hline Full sample Medicaid & 2934 & 1053.03 & 729.09 & 96.27 & 10937.44 \\
Metro/Micro Medicaid & 1652 & 896.28 & 523.34 & 96.27 & 7404.66 \\
Full sample no Medicaid & 2933 & 529.64 & 582.07 & -224.37 & 9986.81 \\
Metro/Micro no Medicaid & 1651 & 470.17 & 386.37 & -224.37 & 7210.87 \\
\hline
\end{tabular}

Counties with negative values of grants per capita without Medicaid $(n=5)$ are excluded from the following estimations. All results remain unaltered when a transformation is applied that allows logs to be taken (and the counties are included).

One reason as to why a log-log model could be in order is that the effect of distance may diminish with increasing distance (i.e. expenses are incurred whenever news happens farther away, whether the production team travels 50 or 100 miles doesn't really matter). In this specification, a negative coefficient on distance indicates a negative but leveling off relationship. In a similar vein, increases in the number of TV stations may yield decreasing 
gains in grants, as the effect of the first and second (i.e. introduction of competition) TV station certainly differs from the influence of the tenth station.

Full sample results of the OLS regressions using the number of TV stations as our measure of media coverage are shown in table 7-5. Column (1) displays coefficients using population controls only. Column (2) adds income, Column (3) uses the full set of controls and Column (4) adds an interaction between DMA home share and the out-of-state indicator.

Having TV stations in the county leads to higher grant awards, yet the effect decreases in the number of stations. As mentioned above, the elasticity can be calculated as $\gamma \cdot[j /(j+$ $1)$ ], accordingly the loss of the only TV station in a county incurs a drop in grants per capita of approximately $1.9 \%$ whereas an increase from 10 to 11 stations only generates $[10 \cdot 10 / 11] \cdot 0.038=0.35 \%$ more grants per capita. Somewhat surprising is, that a higher home state share in county $i$ 's DMA leads to lower grant awards, yet it is consistent with the idea of yardstick competition. The sign on out-of-state counties is as expected, yet insignificant. When the interaction is introduced, the effect of being out-of-state is $-12 \%$. Keep in mind, though, that this is evaluated at a DMA home share of zero. For out of state counties, an increase in the home share is associated with a gain in grants, whereas in-state counties lose money when their DMA home share increases. Considering that the average DMA home share for out-of-state counties is $20 \%$ as opposed to $88 \%$ for the in-state counties, this could mean that a county that has no media city in its home state can make up for this disadvantage by its state's DMA home share being larger (i.e. being relatively more important). As for the in-state counties the negative coefficient on home share implies that given that there is a media city in your state it is best shared with as few people as possible, which would also mean a positive media effect on grants.

Finally, most of the political and socio-economic variables are significant and have the expected signs.

The results obtained when distance to the nearest media city is employed as our measure of media activity are displayed in table 7-6. Again, the estimation results are consistent with our theoretical predictions. The coefficient on distance is highly significant and predicts that a county located twice as far away from the nearest media city as the average county in the DMA receives $3.4 \%$ less in grants per capita. All the other variables' coefficients resemble those in table $7-5$. 


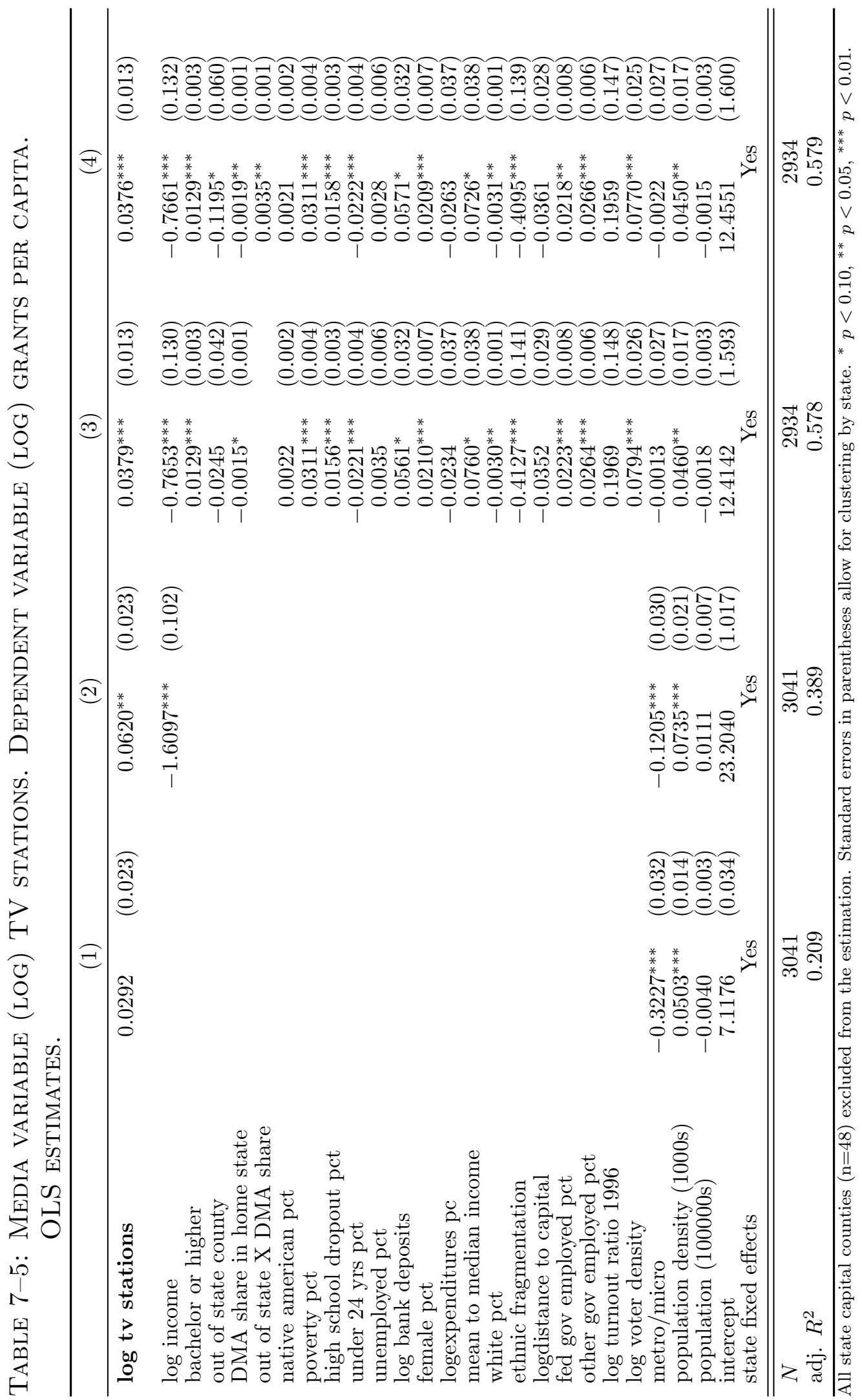




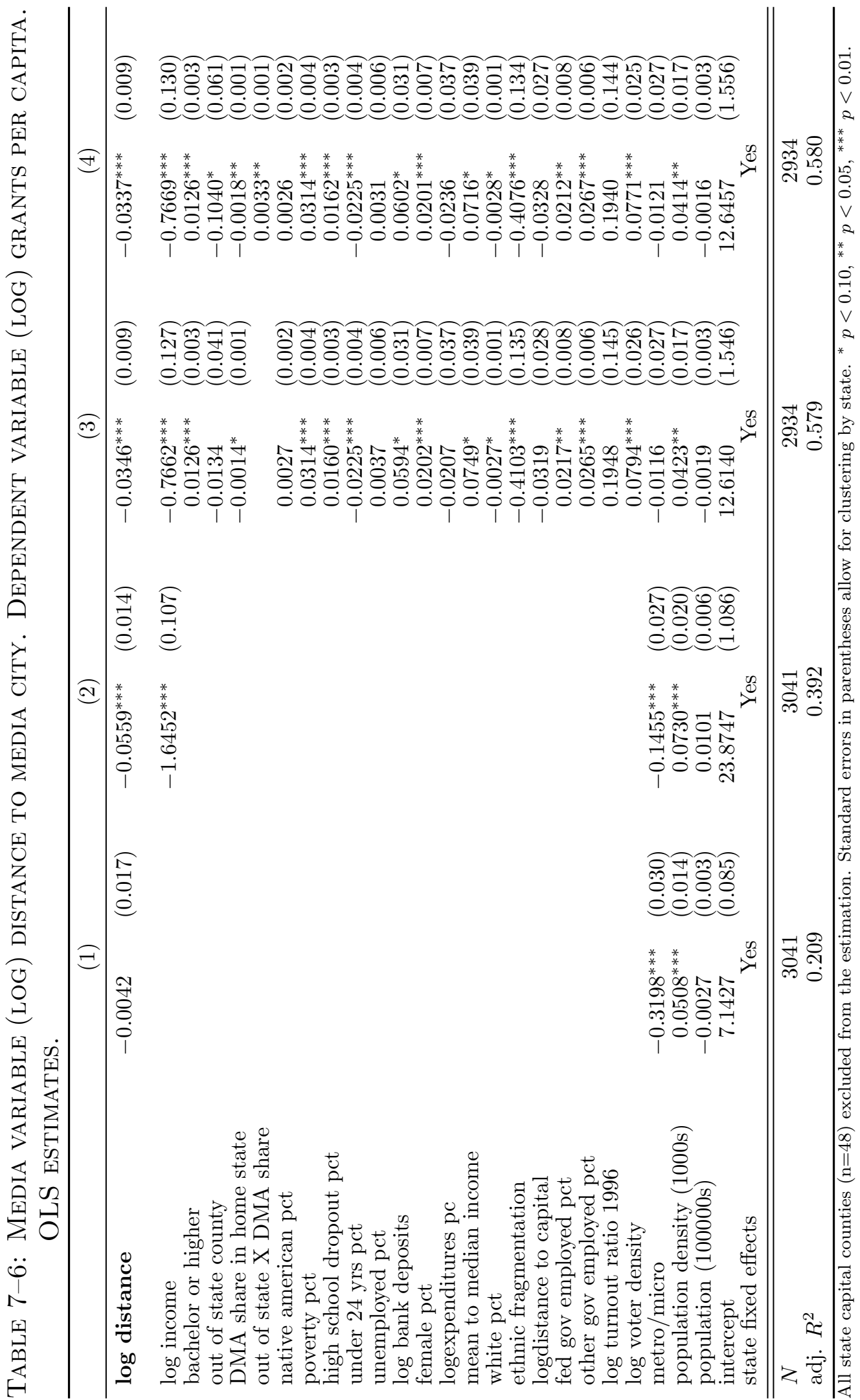


Next, we consider the Metro/Micro subsamples (Table $7-7$ reports the coefficients on the media variables, where columns (1)-(4) indicate the same specifications as in tables 7-5 and 7-6. The full specifications can be found in the appendix, tables A7-2 and A7-3). Once more, there is a highly significant effect of number of media activity on grants received. Within this urban sample, the effects of distance and harboring a TV station roughly match the results we found before. The magnitude of the coefficients differs only by around $10 \%$ between the samples

In sum, we find the hypothesized effect of our key variables in both samples, leading us to conclude that counties less exposed to media coverage receive less attention when grants are distributed. We take this as evidence that a vote-maximizing politicians' rationale does favor counties where media activity is high.

TABle 7-7: Dependent VARIABle (LOG) GRANTS PER CAPitA. OLS, METRO/MICRO SAMPLE.

\begin{tabular}{lcccc}
\hline & $(1)$ & $(2)$ & $(3)$ & $(4)$ \\
\hline log distance & -0.0188 & $-0.0716^{* * *}$ & $-0.0333^{* * *}$ & $-0.0319^{* * *}$ \\
$N$ & $(0.017)$ & $(0.014)$ & $(0.011)$ & $(0.011)$ \\
log tv stations & 1691 & 1691 & 1652 & 1652 \\
$N$ & $0.0514^{*}$ & $0.0832^{* * *}$ & $0.0405^{* * *}$ & $0.0403^{* * *}$ \\
$N$ & $(0.027)$ & $(0.026)$ & $(0.014)$ & $(0.014)$ \\
\end{tabular}

Specifications (1) to (4) are as in the full sample estimations. Only counties that belong to a metropolitan or micropolitan area are included. All state capital counties $(\mathrm{n}=48)$ excluded from the estimation. Standard errors in parentheses allow for clustering by state. ${ }^{*} p<0.10,{ }^{* *} p<0.05,{ }^{* * *} p<0.01$.

\subsubsection{SLS results}

In this section we address the possibility that TV station location is a function of grant spending or that TV station location as well as grant spending are influenced by some underlying variable in the error term. The reasoning for our instruments has been laid out in 7.2.2, table 7-8 shows some first stage statistics. Both instruments are highly correlated with the number of full service TV stations, standard overidentification tests fail to reject instrument exogeneity at conventional levels.

Table 7-9 displays the two stage least squares (2SLS) estimation results. In the full sample (1), the coefficient of having a TV station is much higher than in the OLS estimations and 
thus suggests that we largely underestimated the effect of having one or more television stations at virtually zero distance. The coefficient of 0.33 means that the loss of the only TV station leads to a cut in grants by around 16\% while an increase from 10 to 11 stations leads to a gain of $3 \%$ in federal funding. Things are similar in the Metro/Micro sample (2), where the coefficient on TV stations is of the expected sign, yet smaller than in the full sample.

A few words on the magnitude of the coefficients are in order. The effect of TV stations is several times larger in 2SLS than in OLS. This in itself does not mean we cannot trust these results. After all, as the earlier examples show, the losses generated by a shutdown of a county's sole TV station would then be below twenty percent. We do not consider this to be an implausible effect. In any event, the instrumental variables corroborate the OLS results and suggest that the OLS estimates may be considered as a lower bound of the media effect.

\subsubsection{Robustness checks}

Having established a positive influence of media activity on grant spending, this section is concerned with how robust these results are to changes in specification and sample. As we have mentioned before, all estimations so far have excluded the 48 state capital counties because some grant monies are attributed to them when the actual distribution across the state is unknown. As table A7-4 in the Appendix shows, with capital counties included, the effects are far stronger, in some specifications even twice as large as without capital counties, thus excluding these jurisdictions seems reasonable.

In a second test, we excluded Medicaid spending from the grants variable. Medicaid accounts for roughly half the federal grant money in our data and is also considered to be rather "fixed" (Levitt and Snyder 1997). Excluding these payments is an implicit test of whether our media variables pick up health status in the population or some other characteristic we have not controlled for. In three of our four OLS specifications the estimated media effects are now at least $20 \%$ larger than before (Table A7-5 in the appendix), whereas the effect of TV stations is about $10 \%$ lower in the full sample when Medicaid is excluded. The larger effects are in line with what we would expect if Medicaid cannot be influenced 
Table 7-8: First stage statistics. Dependent variable (log) tV Stations.

\begin{tabular}{lrrrr}
\hline & \multicolumn{2}{c}{ Full sample } & \multicolumn{2}{c}{ Metro Micro sample } \\
\hline log low power tv stations & $0.075^{* * *}$ & $(0.015)$ & $0.138^{* * *}$ & $(0.024)$ \\
log tv sets 1960 & $0.180^{* * *}$ & $(0.015)$ & $0.229^{* * *}$ & $(0.019)$ \\
\hline $\mathrm{F}(2,47)$ & 80.59 & $(p=0.000)$ & 98.61 & $(p=0.000)$ \\
\hline adj. $R^{2}$ & \multicolumn{3}{c}{0.288} & 0.285 \\
partial adj. $R^{2}$ & \multicolumn{2}{c}{0.088} & 0.119 \\
$N$ & \multicolumn{2}{c}{2930} & 1650 \\
\hline
\end{tabular}

$\overline{\text { Estimates are for 2nd stage dependent variable (log of) grants per capita. Results when (log of) grants per capita excluding }}$ Medicaid is employed are not reported as the samples only differ by two observations and results are virtually the same. All state capital counties $(n=48)$ excluded from the estimation. Standard errors in parentheses allow for clustering by state. $*$ $p<0.10,{ }^{* *} p<0.05,{ }^{* * *} p<0.01$.

by political agents as much as other grant schemes. The fact that the coefficient actually decreases in the TV full sample weakens this argument somewhat, yet the hypothesized effects put forward in the earlier sections of this chapter are still very much present and in three out of four cases even strengthened.

\subsubsection{Spatial regression results}

Checking whether our results are contaminated by spatial effects, we find that they do not change as much as one might expect, even though we do find highly significant spatial correlation. Most importantly, both our media variables remain virtually unaltered in comparison to the OLS results. Table 7-10 displays the coefficients on the media variables, spatial error $(\lambda)$ and spatial lag $(\rho)$ estimates as well as test statistics. Estimations are carried out on the full sample only.

The number of TV stations remains highly significant in both the lag and the error specification. The robust LM multipliers however favor the lag model. ${ }^{74}$ We find highly significant positive spatial correlation in both models, yet the inclusion of the spatial parameters leaves the effect of TV stations unchanged in the lag and the error model. Because the presence of spatial error cannot be rejected in the lag model and vice versa (see the robust LM tests), estimation of a combined spatial lag and error model is in order. As mentioned

\footnotetext{
${ }^{74}$ The robust multipliers test for significance of the spatial error parameter in the presence of a spatial lag
} parameter (Robust LM (error)) and vice versa (Robust LM (lag)). 
Table 7-9: Dependent variable (log of) GRAnts Per Capita. 2SLS estimates.

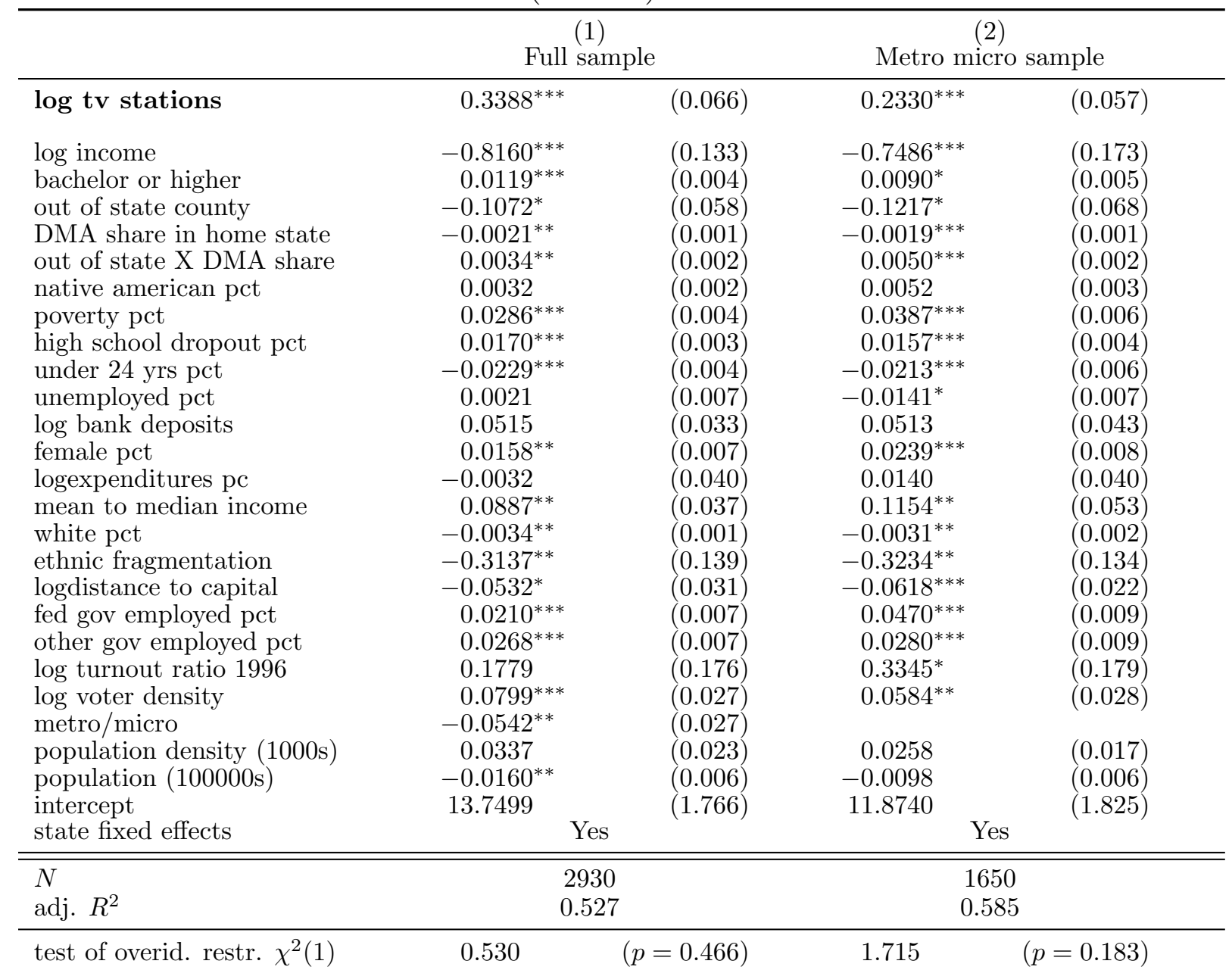

All state capital counties $(\mathrm{n}=48)$ excluded from the estimation. Standard errors in parentheses allow for clustering by state. ${ }^{*} p<0.10,{ }^{* *} p<0.05,{ }^{* * *} p<0.01$.

earlier, we apply the three step spatial-IV estimator (GS2SLS) suggested by Kelejian and Prucha (1998). The results for this GS2SLS estimator once again indicate that the media effect does not pick up spatial autocorrelation. ${ }^{75}$

Things are not very different in the case of the distance to media center variable. Again, the lag specification is preferred over the spatial error model. The robust LM multipliers indicate significant lag effects in the presence of spatially correlated error terms and vice

\footnotetext{
${ }^{75}$ As suggested by Kelejian and Prucha (1998), we use the full set of spatially-first-lagged exogenous variables
} as instruments to account for the endogeneity of the spatial lag. 
Table 7-10: Spatial ML And GS2SLS Estimations.

\begin{tabular}{|c|c|c|c|c|c|c|}
\hline & \multicolumn{3}{|c|}{$\log$ tv stations } & \multicolumn{3}{|c|}{ log distance } \\
\hline & ML-lag & ML-error & GS2SLS & ML-lag & ML-error & GS2SLS \\
\hline $\log$ tv stations & \multirow[t]{2}{*}{$\begin{array}{c}0.036^{* *} \\
(0.016)\end{array}$} & \multirow[t]{2}{*}{$\begin{array}{l}0.036^{* *} \\
(0.015)\end{array}$} & \multirow[t]{2}{*}{$\begin{array}{l}0.036^{* * *} \\
(0.014)\end{array}$} & & & \\
\hline log distance & & & & $\begin{array}{c}-0.034^{* * *} \\
(0.009)\end{array}$ & $\begin{array}{c}-0.035^{* * *} \\
(0.009) \\
\end{array}$ & $\begin{array}{c}-0.034^{* * *} \\
(0.008)\end{array}$ \\
\hline$\rho$ & \multirow[t]{2}{*}{$\begin{array}{l}0.157^{* * *} \\
(0.022)\end{array}$} & & $\begin{array}{l}0.130^{* * *} \\
(0.031)\end{array}$ & \multirow[t]{2}{*}{$\begin{array}{l}0.159^{* * *} \\
(0.022)\end{array}$} & & $\begin{array}{l}0.135^{* * *} \\
(0.032)\end{array}$ \\
\hline$\lambda$ & & $\begin{array}{l}0.205^{* * *} \\
(0.027) \\
\end{array}$ & 0.053 & & $\begin{array}{l}0.206^{* * *} \\
(0.027) \\
\end{array}$ & 0.050 \\
\hline robust LM (error) & \multicolumn{2}{|c|}{$\begin{array}{l}03.81^{*} \\
09.53^{* * *}\end{array}$} & & \multicolumn{2}{|c|}{$\begin{array}{l}03.65^{*} \\
10.10^{* * *}\end{array}$} & \\
\hline $\begin{array}{l}\text { robust LM (lag) } \\
\text { LR test }\end{array}$ & $51.06^{* * *}$ & $49.09^{* * *}$ & & $52.20^{* * *}$ & $49.44^{* * *}$ & \\
\hline$N$ & 2934 & 2934 & 2934 & 2934 & 2934 & 2934 \\
\hline
\end{tabular}

versa, so the GS2SLS procedure again seems to be the best fit for our data. The negative effect of distance is about the same as in OLS in all three models.

As was explained earlier, the discussion as to what the factors underlying the spatial correlation are is beyond the scope of this research. We thus stick with the rather blunt statement that apart from spatially correlated shocks or omitted variables that take on similar values in neighboring counties, the rationale for suspecting such effects could be either yardstick competition or spillovers in the provision of public goods.

In the end, we are content with being able to state that the significance in both media activity variables cannot be an artefact of spatial dependencies.

\subsection{Summary and Outlook}

This chapter set out to analyze the effects of geographical distance from media outlets on federal grant spending. We found strong support for our theoretical predictions in the measure of distance to media outlets and media density combined, the number of TV stations. The effect of distance to the nearest media city is in the hypothesized direction in both samples as well. Neither of these effects is confounded with spatial dependencies. Endogeneity on the other hand seems to be a problem when it comes to estimating the effect of the number of TV stations on grants received. We massively underestimate the coefficient in the OLS specifications. Even if one were to doubt the validity of our 
instruments, the direction of the effect is in the hypothesized direction in OLS, albeit of smaller magnitude. Still, at a rate of approximately $\$ 1,000$ per capita even a gain or loss of around $2 \%$ in grants per capita amounts to a large sum for a county harboring, say, 100,000 inhabitants, not to speak of the effects estimated via 2SLS. Being located far away from the media center leads to lower grants as well, yet the effect seems to be somewhat smaller, considering that most counties aren't located farther than twice the average distance from the nearest media center. It doesn't matter, however, which effect is stronger, as both measure distance to media outlets (with the number of TV stations measuring an additional effect of media density). In terms of robustness and magnitude our results strongly suggest that the intensity of media activity matters to politicians and influences the geographical distribution of federal grants.

Whether media activity matters is also an issue in the following part of the book. In order to measure media activity, we will use various indicators of how actively events in local jurisdictions are covered by local newspapers. However, the next chapter does not deal with the the geographical distribution of spending across jurisdictions but rather it is concerned with the media's role in influencing how efficient public funds are used within local jurisdictions. 


\section{Appendix to Chapter 7}

Table A7-1: Counties by \# of full power TV stations (Incl. Class A).

\begin{tabular}{lrrrr}
\hline & \multicolumn{2}{c}{ Full sample } & \multicolumn{2}{c}{ Metro micro sample } \\
number of TV stations & Frequency & pct & Frequency & pct \\
\hline 0 & 2,284 & 77.85 & 1,123 & 67.98 \\
1 & 359 & 12.24 & 258 & 15.62 \\
2 & 115 & 3.92 & 102 & 6.17 \\
3 & 51 & 1.74 & 46 & 2.78 \\
4 & 45 & 1.53 & 43 & 2.60 \\
5 & 31 & 1.06 & 31 & 0.88 \\
6 & 13 & 0.44 & 13 & 0.73 \\
7 & 12 & 0.41 & 12 & 0.30 \\
8 & 5 & 0.17 & 5 & 0.36 \\
9 & 6 & 0.20 & 6 & 0.24 \\
10 & 4 & 0.14 & 4 & 0.12 \\
11 & 2 & 0.07 & 2 & 0.24 \\
12 & 1 & 0.03 & 1 & 0.06 \\
13 & 4 & 0.14 & 4 & 0.06 \\
16 & 1 & 0.03 & 1 & 100.00 \\
\hline Total & 1 & 0.03 & 1 & \\
\hline
\end{tabular}




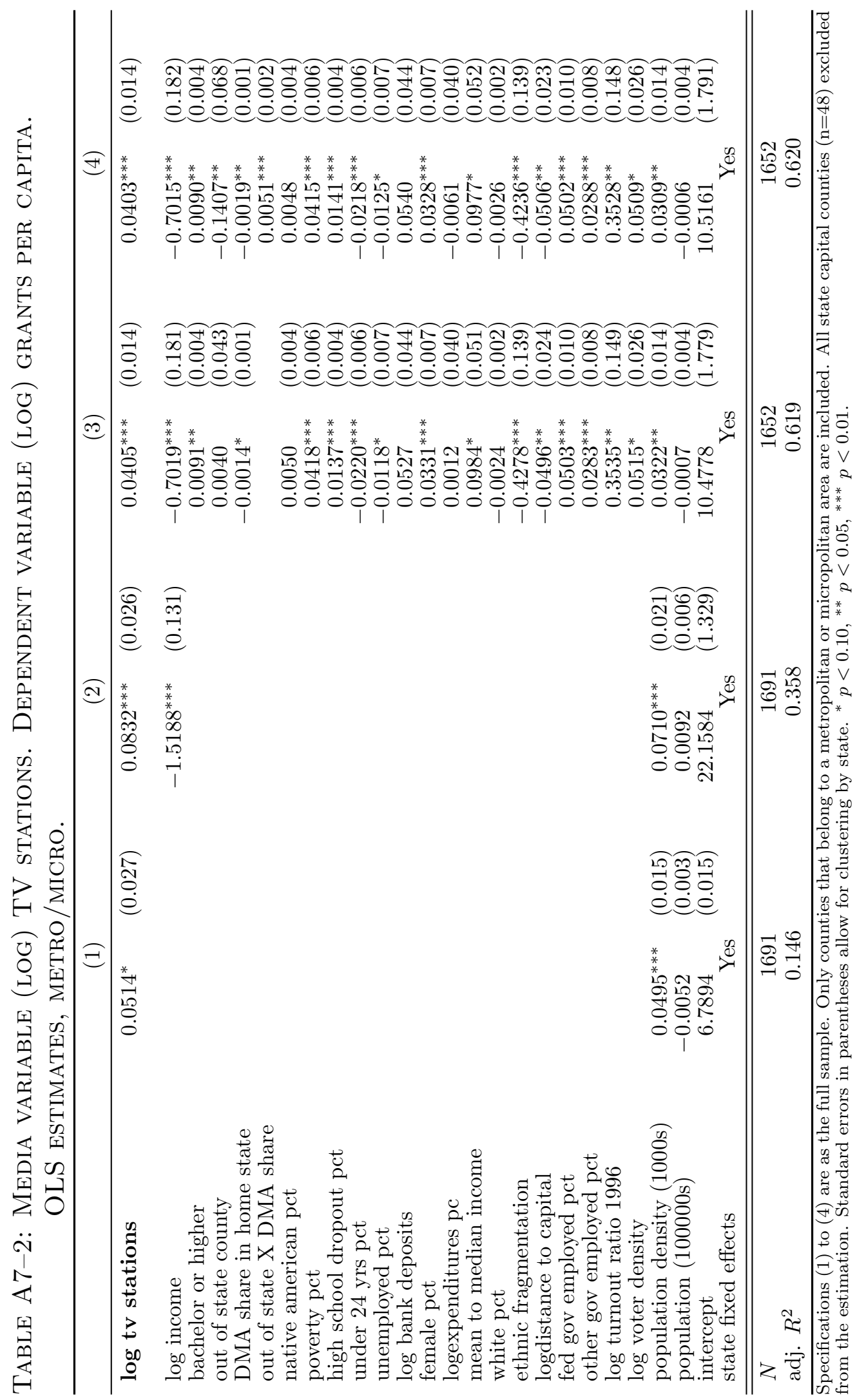




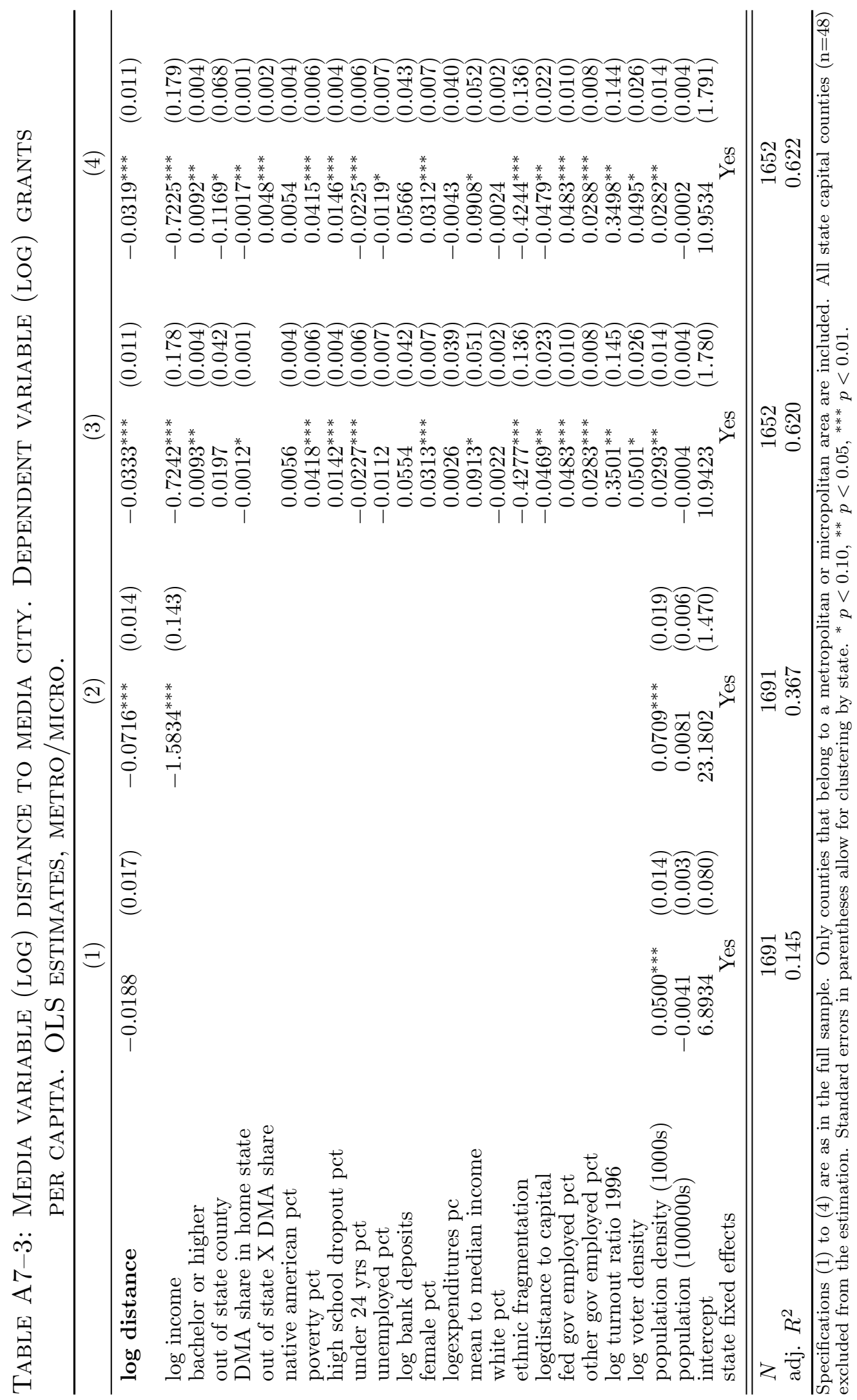


Table A7-4: Sample including state capitals. Dependent variable (log) GRANTS PER CAPITA.

\begin{tabular}{ccccc}
\hline & \multicolumn{2}{c}{ Medicaid included } & \multicolumn{2}{c}{ Medicaid excluded } \\
& Distance & $\mathrm{TV}$ & Distance & $\mathrm{TV}$ \\
\hline OLS full sample & $-0.044^{* * *}$ & $0.067^{* * *}$ & $-0.058^{* * *}$ & $0.075^{* * *}$ \\
2SLS full sample & $(0.009)$ & $(0.012)$ & $(0.011)$ & $(0.018)$ \\
& & $0.389^{* * *}$ & & $0.451^{* * *}$ \\
\hline OLS metro/micro & $-0.040^{* * *}$ & $0.058)$ & & $(0.087)$ \\
2SLS metro/micro & $(0.010)$ & $(0.013)$ & $(0.012)$ & $0.084^{* * *}$ \\
& & $0.275^{* * *}$ & & $0.017)^{* * *}$ \\
\end{tabular}

All state capital counties $(\mathrm{n}=48)$ included in the estimation. Standard errors in parentheses allow for clustering by state. ${ }^{*} p<0.10,{ }^{* *} p<0.05,{ }^{* * *} p<0.01$.

Table A7-5: Sample excluding Medicaid. Dependent variable (log) grants PER CAPITA.

\begin{tabular}{|c|c|c|c|c|}
\hline & $\begin{array}{c}(1) \\
\text { Distance }\end{array}$ & $\begin{array}{l}(2) \\
\mathrm{TV}\end{array}$ & $\begin{array}{c}(3) \\
\text { Overid }\end{array}$ & First $\stackrel{(4)}{\mathrm{F}}(2,47)$ \\
\hline $\begin{array}{l}\text { OLS full sample } \\
\text { 2SLS full sample }\end{array}$ & $\begin{array}{c}-0.043^{* * *} \\
(0.010)\end{array}$ & $\begin{array}{l}0.034^{*} \\
(0.017) \\
0.369^{* * *} \\
(0.097)\end{array}$ & $(p=0.755)$ & $\begin{array}{c}78.01 \\
(p=0.000)\end{array}$ \\
\hline $\begin{array}{l}\text { OLS metro/micro } \\
\text { 2SLS metro/micro }\end{array}$ & $\begin{array}{c}-0.041^{* * *} \\
(0.013)\end{array}$ & $\begin{array}{l}0.054^{* *} \\
(0.017) \\
0.312^{* * *} \\
(0.080)\end{array}$ & $\left(p=\begin{array}{l}1.550 \\
0.213)\end{array}\right.$ & $\begin{array}{c}95.35 \\
(p=0.000)\end{array}$ \\
\hline
\end{tabular}



CHAPTER 8

\section{How Newspaper Circulation Enhances Local Government Efficiency}

While in the United States local television news is the primary conveyor of local information to most people, the hierarchy of the different kinds of mass media is very different in most other parts of the world. Typically, local newspapers are the first choice if one wants to dip into what is going on at the local level, and so this portion of the book explores whether local newspaper circulation affects public sector efficiency in Norwegian municipalities. Norway is chosen for its very diverse newspaper landscape and because more than 400 municipalities make it an excellent subject for analyzing the effects of local media on local policies.

In Norway, the central government aims to ensure equal living conditions throughout the country. This includes the provision of welfare services like health care, education and social services in high quality across all municipalities. To this end, central government allocates a budget to each jurisdiction, but municipalities autonomously decide on how these services can be implemented to best match local preferences. Within the municipalities, a locally elected government is responsible for the provision of public services. As this is the most prominent task of local government, voters should mainly consider public service performance when deciding on the reelection of local officials. Thus, elections provide incentives for the latter to perform well because a more efficient use of disposable funds implying a higher level of services, given the fixed budget - should increase the chances of reelection. 
At the municipal level, individuals usually know who is in charge of local services and they can at the same time observe service provision in their day-to-day life. It is, however, likely that they are not perfectly informed about all factors that determine public service provision. In particular, when they cast their ballot, it is essential to know whether factors that are not in control of local government have influenced service provision. If such local or country-wide shocks have been a factor in public service production, voters who are aware of this can judge government performance more accurately.

As local newspapers play an important role in informing voters in Norway, this study strives to examine whether certain newspaper market characteristics can explain differences across municipalities in public service efficiency. We present a stylized model to illustrate how the degree of information in the electorate shapes an incumbent's incentives to behave well. The central prediction of the model is that a larger share of informed voters in the electorate makes the incumbent work harder because external factors are not confounded with incumbent's effort. This prediction is tested using panel data on Norwegian municipalities for the years 2001-2005. Our main variables are an index of public sector efficiency in Norwegian municipalities as introduced by Borge, Falch and Tovmo (2008) and three measures of voter information that are based on newspaper circulation at the municipality level. The results support the model's prediction that a more informed electorate induces higher efficiency.

Recalling chapter 6, this research is evidently positioned within the political economy literature that deals with the impact of mass media on policy outcomes. It is very closely related to Snyder and Strömberg (2008) who show that a poor fit between newspaper markets and political districts in the US leads to less coverage of politics and that voters in districts with such a poor fit are thus less informed about politics. This leads to their being less successful in holding their representatives accountable and accordingly federal spending is lower in these districts. The ground-breaking work by Strömberg $(2004 a, b)$ that identified the positive effects of being informed on the ability to attract funds merits mention once again in this chapter. The same goes for Besley and Burgess (2002) and their finding that higher newspaper circulation induces higher levels of calamity relief provided by the government - implying that better informed voters should be more successful in holding governments accountable. In a Scandinavian setting, Svaleryd and Vlachos (2007) find that increased political competition as well as local media coverage reduce political rents in Sweden. 
Additionally, this investigation is related to the literature on efficiency in public service provision. Theoretical contributions in this field go back to the work of Niskanen (1971, 1975) as well as Migué and Bélanger (1974). The central aspect of these studies is that bureaucracies strive to allocate funds from a given budget to expenditures that do not raise public service production, thus leading to less efficiency. Hence the interests of bureaucrats collide with the interests of politicians and voters and policy outcomes depend on the interaction of these players.

There is a vast empirical literature on local efficiency, for a survey see De Borger and Kerstens (2000). Many of these studies deal with efficiency in specific parts of the public sector or programs rather than with overall efficiency. In contrast, the index of local public sector efficiency in Norwegian municipalities that we use in this chapter provides a measure of global public sector efficiency and was first used by Borge, Falch and Tovmo (2008). The authors find that high fiscal capacity and a high degree of party fragmentation lead to low efficiency, whereas increased democratic participation brings along higher efficiency in Norwegian municipalities. The Norwegian efficiency index has also been employed by Revelli and Tovmo (2007), who suggest that local government efficiency in Norway shows a spatial pattern due to yardstick competition.

\subsection{Media and Efficiency: Theoretical Links}

In this section, we theoretically establish how mass media, in our case newspapers, serve as an institution that enhances the accountability of incumbent politicians. As it is essentially the voting behavior of the electorate that determines incumbents' incentives we have to analyze the impact of newspapers on voters. It is quite reasonable to assume that newspapers influence voting decisions because they play a key role in providing voters with information about politicians.

We develop a stylized political economy model of a single constituency with a continuum of voters normalized to unity. There are two periods of time. 


\section{Production of a public good}

In the first period, an incumbent government provides the public good $y$ according to the production technology

$$
y_{1}=a_{1}+\theta^{I}+\varepsilon_{1}
$$

The level of the public good in period 1 results from the incumbent's effort $\left(a_{1} \in[0, \infty)\right)$, his competence $\left(\theta^{I}\right)$ and a temporary shock $\left(\varepsilon_{1}\right)$. Subscripts denote the time period and superscript $I$ refers to the incumbent. We assume that competence, $\theta^{I}$, is a permanent feature of the incumbent. With regard to Norway, one can think of $y$ as the services that a municipality provides to its citizens. To provide these services, municipal governments are endowed with a fixed budget by the central government. Hence, incumbent politicians cannot raise $y$ by increasing revenues, but effort they exert may affect the level of public services in the following ways:

- Bargaining between politicians and local public administration. Administration competes with service production for money from the municipal budget. Local government does have the final say on the allocation of funds, yet the public administration heavily takes part in budgeting (Kalseth and Rattso 1998). Thus, the politicians' bargaining power affects the allocation of funds. If, for example, politicians invested effort to raise their expertise this could increase their bargaining power and, finally, lead to a higher level of services due to resource allocation.

- Monitoring the administration. The administration not only takes part in budgeting but also implements political decisions. Once funds are allocated to public service provision, the level of services is higher if these funds are used in an efficient manner. If politicians try harder to monitor the implementation this will raise efficiency and, consequently, the level of services.

The effect of the incumbent's competence $\theta^{I}$ on public good production resembles the effect of effort. $\theta$ denotes the exogenously given talent of a politician to influence public good provision. At a given effort level, a more competent politician will provide a higher level of public services. Finally, the shock component $\varepsilon$ can be either a local shock or a country-wide shock which affects the level of $y$. 


\section{Information}

$\theta^{I}$ and $\varepsilon_{1}$ are random variables. At the time when the incumbent decides about his effort level, neither he nor the electorate know the realizations of $\theta^{I}$ and $\varepsilon_{1}$. Common knowledge are the distributions $\theta \sim N\left(\bar{\theta}, \sigma_{\theta}^{2}\right)$ and $\varepsilon \sim N\left(0, \sigma_{\varepsilon}^{2}\right)$.

After the incumbent has chosen effort and the values of $\theta^{I}$ and $\varepsilon_{1}$ have been realized, all voters observe the level of the public good, $y_{1}$. An exogenously defined share of voters $\lambda$ reads local newspapers for reasons that are independent of politics, e.g., because they care about news on sports, weddings, obituaries, clubs and the like. We assume that newspapers have perfect information about $\varepsilon_{1}$ and report it. ${ }^{76}$ The probability $q$ that a voter $i$ finds the information about $\varepsilon_{1}$ in the newspaper depends on how much news space $s$ the editors assign to local politics. Thus, $q=q(s)$ and we presume $q(0)=0, q^{\prime}>0$ and $q^{\prime \prime}<0$. So the probability that a voter $i$ is informed about $\varepsilon_{1}$ is $\lambda \cdot q(s)$. Given the large electorate, the share of informed voters is also defined by $\alpha:=\lambda \cdot q(s)$.

Let us briefly illustrate this argument about informed voters by an example. Suppose that there is no newspaper published in a municipality but citizens read newspapers that come from contiguous municipalities. If these newspapers bias local coverage in favor of their home municipalities only little space will be allocated to news about our municipality of interest. Still, there can be many readers in this municipality but it is unlikely that they are well informed about local politics. On the other hand, we would expect a more informed electorate if a newspaper market and a municipality coincide geographically.

So we have two groups of voters in the electorate. A share of $\alpha$ voters are perfectly informed about the shock component $\varepsilon_{1}$. Observing $y_{1}$, these voters can clearly distinguish between the shock and the sum of the two components attributed to the incumbent. A share of $1-\alpha$ voters only know the distribution of $\varepsilon_{1}$ and may confound the effect of the shock on $y_{1}$ with the impact of $a_{1}$ and $\theta^{I}$.

\footnotetext{
${ }^{76}$ The extreme assumption that newspapers perfectly observe $\varepsilon_{1}$ serves to simplify the analysis. Alternatively, we could assume that newspapers only receive a less noisy signal than voters. This would not substantially change our results.
} 


\section{Timing}

Now we have determined what voters know when casting the ballot. Before we examine the incumbent's incentives and the optimal voting behavior, we briefly summarize the game between the incumbent and the electorate. The timing is as follows:

Period 1:

- The incumbent politician chooses effort $a$ without knowing his own competence.

- The values of both the incumbent's competence, $\theta^{I}$, and the shock, $\varepsilon_{1}$, are realized.

- All voters observe $y_{1}$. Additionally, a share $\alpha$ of voters learn the value of $\varepsilon_{1}$ from the newspaper.

- Elections are held. The incumbent faces a challenger whose competence is drawn from a normal distribution with mean $\bar{\theta}$ and variance $\sigma_{\theta}^{2}$.

Period 2:

- The winner of the election chooses effort.

- $y_{2}^{I}$ is realized if the incumbent of period 1 still is in office or $y_{2}^{C}$ is realized if the challenger has won the election.

\section{The incumbent's incentives}

The incumbent knows that the level of $y_{1}$ will affect his chances of reelection. He can influence the level of $y_{1}$ by choosing $a_{1}$. Effort brings along cost $C(a)$ with $C^{\prime}>0$ and $C^{\prime \prime}>0$. At the end of period 1 , there is an election where the incumbent faces a randomly drawn challenger. If the incumbent wins, he will receive an exogenous rent $R>0$ from staying in office. Thus, the incumbent chooses $a_{1}$ to maximize

$$
p^{I}\left(a_{1}\right) \cdot R-C\left(a_{1}\right)
$$


where $p^{I}$ denotes the probability that the incumbent is reelected. There is no discounting. The first-order condition is

$$
\frac{\partial p^{I}}{\partial a_{1}} \cdot R=C^{\prime}\left(a_{1}\right)
$$

The first-order condition shows that the incumbent weighs the expected rent against present cost when he chooses $a_{1}$. He will increase effort as long as the marginal effect on the expected payoff in period 2 is larger than the marginal cost of effort in period 1. In order to analyze how effort affects the probability of reelection, $p^{I}$, we have to examine the voting decisions in the electorate.

\section{Optimal voting behavior}

All voters receive utility $u=u(y)=y$ from the public good. Each voter cares about $y_{2}$, the level of $y$ in period 2, and about his own ideological position in relation to the incumbent, $\beta_{i}$. $\beta_{i}$ is drawn from a uniform distribution with support $\left[-\beta_{0}, \beta_{0}\right]$. Negative values of $\beta_{i}$ imply an ideological bias of voter $i$ in favor of the incumbent, whereas positive values mean a bias in favor of the challenger. Voter $i$ prefers the incumbent if

$$
\tilde{y}_{2 i}^{I} \geq \tilde{y}_{2 i}^{C}+\beta_{i}
$$

where $\tilde{y}_{2 i}^{I}$ and $\tilde{y}_{2 i}^{C}$ denote the expected level of $y$ in period 2 under the incumbent and under the challenger respectively. Voters are rational and expect the competence of the randomly drawn challenger to be $\bar{\theta}$. Furthermore, as there is no incentive to invest effort in period 2 for any politician in office, all voters correctly expect that $a_{2}^{I}=a_{2}^{C}=0$. Hence, the expected level of $y_{2}$ depends only on the competence of the incumbent politician in period 2 so that

$$
\tilde{y}_{2 i}^{I}=\tilde{\theta}_{i}^{I} \quad \text { and } \quad \tilde{y}_{2 i}^{C}=\tilde{\theta}_{i}^{C}=\bar{\theta}
$$

Consequently, (51) reduces to

$$
\tilde{\theta}_{i}^{I} \geq \bar{\theta}+\beta_{i}
$$

The expected competence of the incumbent depends on the information a voter possesses. Voters are rational and update their prior beliefs about competence using Bayes' rule. We 
have to distinguish informed voters from uninformed voters. In each group, $\tilde{\theta}_{i}^{I}$ is the same for every single voter. From now on, $\tilde{\theta}_{m}^{I}$ denotes the competence as estimated by informed voters and $\tilde{\theta}_{n}^{I}$ labels the competence as estimated by uninformed voters.

As informed voters observe $y_{1}$ and, additionally, $\varepsilon_{1}$, they expect the incumbent's competence to be

$$
\tilde{\theta}_{m}^{I}=y_{1}-\tilde{a}_{1}-\varepsilon_{1}=\theta^{I}+a_{1}-\tilde{a}_{1}
$$

where $\tilde{a}_{1}$ denotes effort in period 1 as expected by the voters. Uninformed voters only observe the value of $y_{1}$ and form the expectation ${ }^{77}$

$$
\tilde{\theta}_{n}^{I}=\frac{\sigma_{\varepsilon}^{2} \bar{\theta}+\sigma_{\theta}^{2}\left(y_{1}-\tilde{a}_{1}\right)}{\sigma_{\varepsilon}^{2}+\sigma_{\theta}^{2}}
$$

The incumbent wins the election if he gets more than half of all votes cast which we can write as

$$
\alpha \cdot \frac{\tilde{\theta}_{m}^{I}-\bar{\theta}+\beta_{0}}{2 \beta_{0}}+(1-\alpha) \cdot \frac{\tilde{\theta}_{n}^{I}-\bar{\theta}+\beta_{0}}{2 \beta_{0}} \geq \frac{1}{2}
$$

Inserting (53), (54) and (48) and rearranging, we obtain

$$
\left[\alpha+(1-\alpha) \frac{\sigma_{\theta}^{2}}{\sigma_{\varepsilon}^{2}+\sigma_{\theta}^{2}}\right] \cdot\left(a_{1}-\tilde{a}_{1}+\theta-\bar{\theta}\right)+(1-\alpha) \frac{\sigma_{\theta}^{2}}{\sigma_{\varepsilon}^{2}+\sigma_{\theta}^{2}} \cdot \varepsilon_{1} \geq 0 .
$$

The probability of reelection, $p^{I}$, is given by the probability that (56) is met. ${ }^{78}$ The lefthand side of (56) is a normal random variable with mean

$$
\mu=\left[\frac{\alpha \cdot \sigma_{\varepsilon}^{2}+\sigma_{\theta}^{2}}{\sigma_{\varepsilon}^{2}+\sigma_{\theta}^{2}}\right] \cdot\left(a_{1}-\tilde{a}_{1}\right)
$$

\footnotetext{
${ }^{77}$ In Appendix A1 it is shown how uninformed voters update their expectations.

${ }^{78}$ To be precise, this condition only holds true for $\bar{\theta}-\beta_{0}<\tilde{\theta}_{m}^{I}, \tilde{\theta}_{n}^{I}<\bar{\theta}+\beta_{0}$. However, for large values of $\beta_{0}$ the approximation error is very small and, in equilibrium, $p^{I}$ is the probability of reelection for all $\tilde{\theta}_{m}^{I}, \tilde{\theta}_{n}^{I}$.
} 
and variance

$$
\sigma^{2}=\frac{\alpha^{2} \cdot \sigma_{\varepsilon}^{2} \sigma_{\theta}^{2}+\sigma_{\theta}^{4}}{\sigma_{\varepsilon}^{2}+\sigma_{\theta}^{2}}
$$

Now we can compute the probability of reelection as $p^{I}=1-F\left(0 ; \mu, \sigma^{2}\right)$, where $F$ is the distribution function of the left-hand side of (56).

\section{Equilibrium}

The incumbent maximizes his objective function, (49), taking the voters' expectations about effort, $\tilde{a}_{1}$, as given. Taking $p^{I}=1-F\left(0 ; \mu, \sigma^{2}\right)$ into account, the first-order condition turns into

$$
-\frac{\partial F\left(0 ; \mu, \sigma^{2}\right)}{\partial \mu} \frac{\partial \mu}{\partial a_{1}} \cdot R=f\left(0 ; \mu, \sigma^{2}\right) \frac{\partial \mu}{\partial a_{1}} \cdot R=C^{\prime}\left(a_{1}\right)
$$

An equilibrium with rational expectations requires $a_{1}=\tilde{a}_{1}$. Thus, in equilibrium, $\mu=0$ and the first-order condition is

$$
\frac{1}{\sqrt{2 \pi} \cdot \sigma} \cdot\left[\frac{\alpha \cdot \sigma_{\varepsilon}^{2}+\sigma_{\theta}^{2}}{\sigma_{\varepsilon}^{2}+\sigma_{\theta}^{2}}\right] \cdot R-C^{\prime}\left(a_{1}\right)=0,
$$

with $1 /(\sqrt{2 \pi} \cdot \sigma)=f(0 ; 0, \sigma)$. From (60) one arrives promptly at the following result.

Proposition 1 In equilibrium, the incumbent's effort level in period 1, a $a_{1}^{*}$, is uniquely defined by

$$
a_{1}^{*}=\left(C^{\prime}\right)^{-1}\left(\frac{1}{\sqrt{2 \pi}} \cdot \frac{1}{\sqrt{\sigma_{\varepsilon}^{2}+\sigma_{\theta}^{2}}} \cdot \frac{\alpha \cdot \sigma_{\varepsilon}^{2}+\sigma_{\theta}^{2}}{\sqrt{\alpha^{2} \cdot \sigma_{\varepsilon}^{2} \sigma_{\theta}^{2}+\sigma_{\theta}^{4}}} \cdot R\right) \text {. }
$$

Proof. See Appendix A2.

Proposition 1 shows that equilibrium effort hinges on the variance of the shock, $\sigma_{\varepsilon}^{2}$, the variance of competence, $\sigma_{\theta}^{2}$, the rent, $R$, and the share of informed voters, $\alpha=\lambda \cdot q(s)$. As we strive to study how the information in the electorate affects the incentives of the incumbent, we are mainly interested in the impact of $\lambda$ and $s$ on the effort level. Proposition 1 leads to the main message of the model. 
Proposition 2 The incumbent's effort increases in the share of informed voters.

\section{Proof. See Appendix A3.}

So the central prediction of the model is that a larger share of informed voters makes the incumbent work harder. Consequently, for given $\theta^{I}$ and $\varepsilon_{1}$, the level of the public good, $y_{1}$, is higher when many voters read newspapers and when newspapers devote more news space, $s$, to information about the shock, $\varepsilon_{1}$.

\subsection{The Norwegian Situation}

In the following sections, Norwegian data serve to check, whether the theoretical predictions derived above hold in a real world setting. There are two main reasons why we chose Norway as the subject of examination. First, the federal structure of Norway with a total of more than 400 municipalities makes for an excellent subject for studying the effects of newspapers on relatively comparable small government units. These municipalities are responsible for a vast array of services where they can decide autonomously on how their budget is spent. Even though local government revenues are rather fixed, this leaves a lot of leeway for municipal officials in shaping the public service structure in their municipality. ${ }^{79}$ Services provided by the municipality include primary and lower secondary education, daycare, care for the elderly, welfare benefits, primary health care and child custody. These services enter into the calculation of the efficiency index (Borge, Falch and Tovmo 2008) which we use to evaluate the performance of local governments. The availability of such an index is another reason for choosing Norway, as it mitigates the problem of having to come up with an appropriate measure public sector accomplishments.

The most important reason for picking Norway, however, is the very diverse newspaper landscape. Data on more than 150 newspapers are used in this study. This is a large number considering that Norway had a population of only roughly 4.8 million in 2008 and

\footnotetext{
${ }^{79}$ There is also another tier between the local and the national level. These fylke districts are sizewise somewhat akin to the US counties. Their main responsibilities include secondary education, dental services and public transportation. Since municipalities provide a broader range of services and people tend to identify with their municipality rather than the fylke, we only consider the municipality level.
} 
it also implies that many of these newspapers have a rather local focus. Thus, in a sense the newspaper market reflects the decentralization of the government sector. This is not the only feature of the Norwegian newspaper sector that makes it particular. Until 2004, Norway had the highest per (adult) capita newspaper reach worldwide. As of today it is only surpassed by Japan in that respect (according to World Press Trends, approximately 600 newspapers per 1000 adults were sold in Norway in 2007 on a daily basis). Seven in ten Norwegian households had one or more newspaper subscriptions in 2007. In the large cities, 64 per cent had a newspaper subscription, while the percentage was 75 in more scarcely populated areas. ${ }^{80}$ It seems entirely possible that this ubiquity of newspapers leads to newspapers being especially able to serve the purpose of informing citizens and thus helping to hold local government accountable. The reach of newspapers in Norway is actually even higher than that of television, as can be seen from the top portion of table 8-1. This may seem particularly puzzling to an observer from the American perspective, where in addition to newspaper circulation being rather low, people often cite local television news as their main source of information. In contrast, while local television does exist in Norway, it is not thought of as being in the neighborhood of newspapers when it comes to serving as a means of information on local issues.

Table 8-1 also demonstrates that newspaper use does not depend on educational level as much as one may expect. Differences in readership (defined as the percentage of residents that read a newspaper on a given day) between the university educated and lower secondary school educated are rather small and have actually decreased in the years 2001-2005, the years that we will be using in the estimations. This is particularly important because it means that the possible confounding of newspaper readership with general interest in politics (as measured by education) is not as big an issue as in other countries. While the gap between educational levels shrunk, the total reach of newspapers is slowly declining, a trend that Norway has in common with other western countries. Finally, the bottom section of table 8-1 establishes that the municipalities for which the efficiency index is available are comparable to all Norwegian communities when it comes to the reach of regional newspapers (defined as storby dagsaviser including Aften, lokale dagsaviser and andre lokalaviser as shown in table A8-2). Here regional reach is defined as the number of newspapers sold per household. All reach variables in the remainder of this chapter will

\footnotetext{
${ }^{80}$ http: //www.ssb.no/medie_en/
} 
have the number of households in the municipality as the denominator. We will also use the terms reach and penetration synonymously.

TABle 8-1: Media REACH In NORWAY.

\begin{tabular}{llllll}
\hline TV reach & $\mathbf{2 0 0 1}$ & $\mathbf{2 0 0 2}$ & $\mathbf{2 0 0 3}$ & $\mathbf{2 0 0 4}$ & $\mathbf{2 0 0 5}$ \\
\hline age 12+ & 71 & 71 & 71 & 71 & 71 \\
\hline Newspaper reach, population & $\mathbf{2 0 0 1}$ & $\mathbf{2 0 0 2}$ & $\mathbf{2 0 0 3}$ & $\mathbf{2 0 0 4}$ & $\mathbf{2 0 0 5}$ \\
\hline Lower secondary school & 70 & 77 & 78 & 74 & 76 \\
Upper secondary school & 83 & 78 & 80 & 78 & 77 \\
University/college low & 85 & 81 & 81 & 81 & 79 \\
University/college high & 86 & 86 & 84 & 87 & 82 \\
All (9-79 years) & 78 & 77 & 77 & 75 & 74 \\
\hline Newspaper reach, households & $\mathbf{2 0 0 1}$ & $\mathbf{2 0 0 2}$ & $\mathbf{2 0 0 3}$ & $\mathbf{2 0 0 4}$ & $\mathbf{2 0 0 5}$ \\
\hline regional papers, all & 1.037 & 0.996 & 0.985 & 0.978 & 0.969 \\
N & 431 & 431 & 431 & 431 & 431 \\
\hline regional papers, efficiency available & 1.042 & 0.996 & 0.982 & 0.987 & 0.968 \\
N & 359 & 379 & 370 & 361 & 374 \\
\hline \hline
\end{tabular}

Sources: Statistics Norway, MBA.

In what follows, we describe the newspaper data which provides information on the circulation of newspapers in Norwegian municipalities. The efficiency index and its components as well as the controls used in the estimation are also explained in brief.

\subsubsection{Data Sources and media measures}

The data we use was gathered from various sources. While the efficiency indicator and its components were provided by Borge, control variables at the municipality level were obtained from Statistics Norway and the Norwegian Social Science Data Services (NSD). The newspaper data stems mainly from the Norwegian Media Businesses' Association (Mediebedriftenes Landsforening, MBL), whose members include most of the Norwegian newspapers. We add data from the Local Newspaper Association (Landslaget for lokalaviser, LLA) for one specification, as a few newspapers are organised solely in LLA. ${ }^{81}$ Thus, the data can be broken down to three categories: newspaper data, efficiency data and controls.

Newspaper data. The data on newspaper circulation is provided by Aviskatalogen, a database maintained by MBL which contains annual information on the circulation of

\footnotetext{
${ }^{81}$ While some LLA members are organized in MBL as well, most of the LLA newspapers are weeklies that our primary dataset does not cover.
} 
Norwegian newspaper publications at the community level. We categorize the newspapers in the database as follows:

(a) national newspapers (riksspredte nyhetsaviser)

(b) regional daily newspapers (storby dagsaviser)

(c) local daily newspapers (lokale dagsaviser)

(d) non-daily local newspapers (andre lokalaviser) and

(e) specialty newspapers (nisjeavisen).

We make use of this classification in order to construct various measures of newspaper reach. In general, reach is defined as follows: reach $i=\sum_{n} \frac{\text { circulation }_{n i}}{\text { households }_{i}}$, where $i$ denotes municipalities and $n$ newspapers. First off, only the newspapers Dagbladet and Verdens Gang are classified as tabloids. Hence, the variable tabloid penetration (in a given municipality) will be equal to the sum of the reach of these newspapers. The national newspaper reach includes the tabloids and Aftenposten, but not Aften (the local branch of Aftenposten) which is considered a regional newspaper as it extensively covers issues concerning the Oslo region. Specialty newspapers are mostly weekly newspapers such as Fiskeribladet (Fishery Gazette) and Computerworld that cater to special interests. Even though these are also national newspapers, they are included in a category of their own, due to their highly specialized focus.

The most important definition of newspaper reach for our purposes is regional reach (made up of the above categories (b), (c) and (d)). This variable comprises the reach of all newspapers that mainly convey local/regional information, i.e. in terms of journalistic focus they serve a clearly defined local or regional market (Høst 1999). We believe regional reach to best represent the effect of newspaper penetration on local government efficiency. ${ }^{82}$ As can be seen in table 8-2 and graphically in figure 8-1, reach and regional reach diverge somewhat. ${ }^{83}$ Not all municipalities that have high overall newspaper readership (as in: high reach) display high regional reach as well. On the map, this can be blatantly seen in the center area of southern Norway. Theory predicts that only regional newspapers enhance

\footnotetext{
${ }^{82}$ The data also enables us to calculate a Herfindahl index of circulation within a given municipality. One may believe that a monopoly newspaper can be bribed into reporting favorably more easily. This is an idea that has been put forward by Besley and Prat (2006). We did not find any effects of newspaper concentration on efficiency and results are not reported in order to economize on space.

${ }^{83}$ The extremely high values of 6.56 and 4.90 for overall reach and national reach occur in the community that harbors Oslo airport.
} 
efficiency because the other papers are very limited in the amount of local information they provide, yet checking the maps in the upper portion of figure 8-2 reveals no clear common pattern of efficiency and regional reach.

The bottom half of figure 8-2 displays the geographical distribution of two further measures of voter information: regional content and regional congruence. Regional content is essentially the sum of the regional reaches in a community, where the reaches of the newspapers are weighted by the share of their total circulation sold in that municipality, i.e.: content $_{i}=\sum_{n}$ reach $_{n i} \cdot \frac{\text { circulation }_{n i}}{\sum_{i} \text { circulation }_{n i}}$, where $i$ denotes municipalities and $n$ newspapers. It can be argued that a high reach in itself doesn't mean a lot of information on the community level. It is entirely conceivable that a high percentage of residents in a small community reads the newspaper originating in the nearest city. Yet, if the share of total readers living in that community is small, the newspaper will not devote a whole lot of space to issues concerning that area and thus reach may not appropriately capture the effect we are interested in. The content variable partly solves this problem when one is willing to assume that a newspaper will devote more attention content-wise to those municipalities where it sells most of its circulation. Snyder and Strömberg (2008) provide convincing evidence for this argument. To account for the diverging levels of information contained on the various municipalities (i.e. 'content'), the reach of each and every single newspaper in $i$ is discounted by the readershare ${ }_{n i}=\frac{\text { circulation }_{n i}}{\sum_{i} \text { circulation }_{n i}}$. The content variable thus says how many equivalents of newspapers that are exclusively concerned with the municipality under consideration are sold per household.

The third indicator of media influence, congruence, was proposed by Snyder and Strömberg (2008). It is supposed to help cope with the possible endogeneity of reach and content due to their possibly being correlated with unobserved municipality or politician characteristics. It is calculated as congruence ${ }_{i}=\sum_{n} \frac{\text { circulation }_{n i}}{\sum_{n} \text { circulation }_{n i}} \cdot \frac{\text { circulation }_{n i}}{\sum_{i} \text { circulation }_{n i}}$, where $i$ denotes municipalities and $n$ newspapers, i.e. it is the sum over the reader shares of newspapers in municipality $i$ weighted by their market shares in that municipality. Intuitively, congruence describes how well the municipalities coincide with the newspaper markets. Put differently, it describes how actively the average newspaper sold in municipality $i$ covers $i$. That is, a value of unity for congruence would mean that the average newspaper read in municipality $i$ perfectly covers issues from that municipality. This measure differs from the former information measures in that once one is willing to assume exogenously determined geographical media markets, the variable does not depend on the possibly endogenous 
reach variable (which is perhaps correlated with unobserved interest in local matters).

We will present estimation results for all these measures employing panel data for the period 2001-2005. We are restricted to these years as the dependent variable, efficiency, is available for this time period only.

Efficiency data. Our measure of public sector efficiency is the efficiency index developed by Borge, Falch and Tovmo (2008). It relates public service production to disposable revenues. Thus, efficiency increases when higher levels of production are extracted from given revenues.

Production is quantified by an aggregate output measure that was developed by Borge, Falch and Tovmo (2001) for the Norwegian authorities (Produksjonsindeks). Output comprises 17 indicators of production in the six main municipal service sectors: care for the elderly, primary and lower secondary education (1st to 10th grade), day care, welfare benefits, child custody, and primary health care. The measure then relates output in a municipality to the country-wide population-weighted mean of aggregate output which is set equal to 100. The production index accounts for both quantity and quality aspects of public good provision. Quality of public services is obviously very hard to capture, yet the production index includes indicators such as the share of single rooms in nursing homes in an attempt to do so. ${ }^{84}$

Then, the aggregate output measure is divided by local government revenues. Revenues comprise own tax revenues per capita and block grants per capita from the central government. These revenues are adjusted by an index that describes varying costs of service production across municipalities. This index includes factors such as population size, settlement pattern, the age composition of the population and social factors. Additionally, since the production of public services is labor-intensive, regional differences in the pay roll tax are taken into account to capture labor costs.

In dividing production by revenues, the efficiency index then measures the efficiency of a municipality as a percentage of the country-wide mean efficiency.

\footnotetext{
${ }^{84}$ The 17 sub-indices and their exact weighting are explained in detail in Borge, Falch and Tovmo (2008).
} 

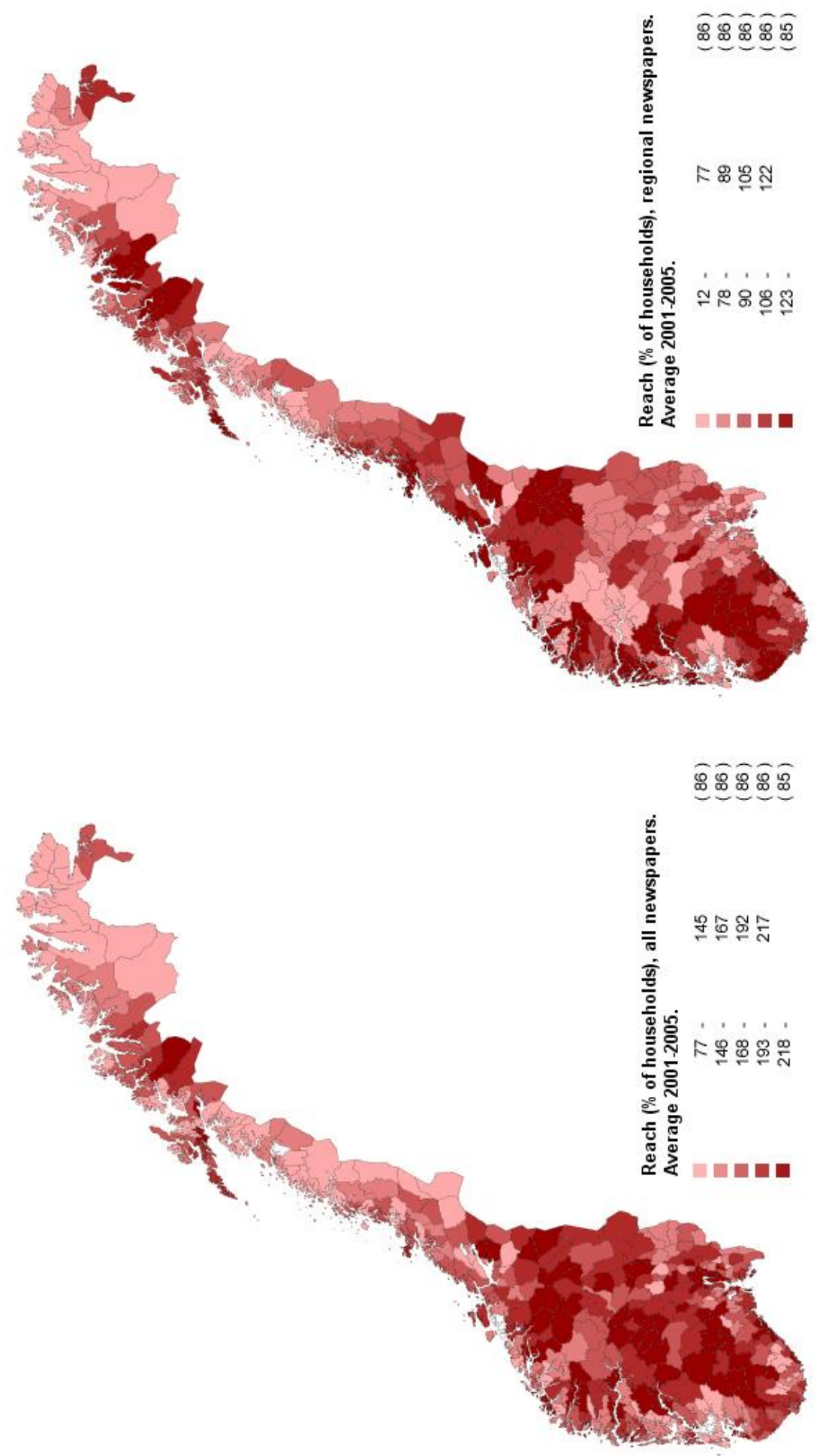

Figure 8-1: ReACH, ALL/REgional neWspapers (*100). 


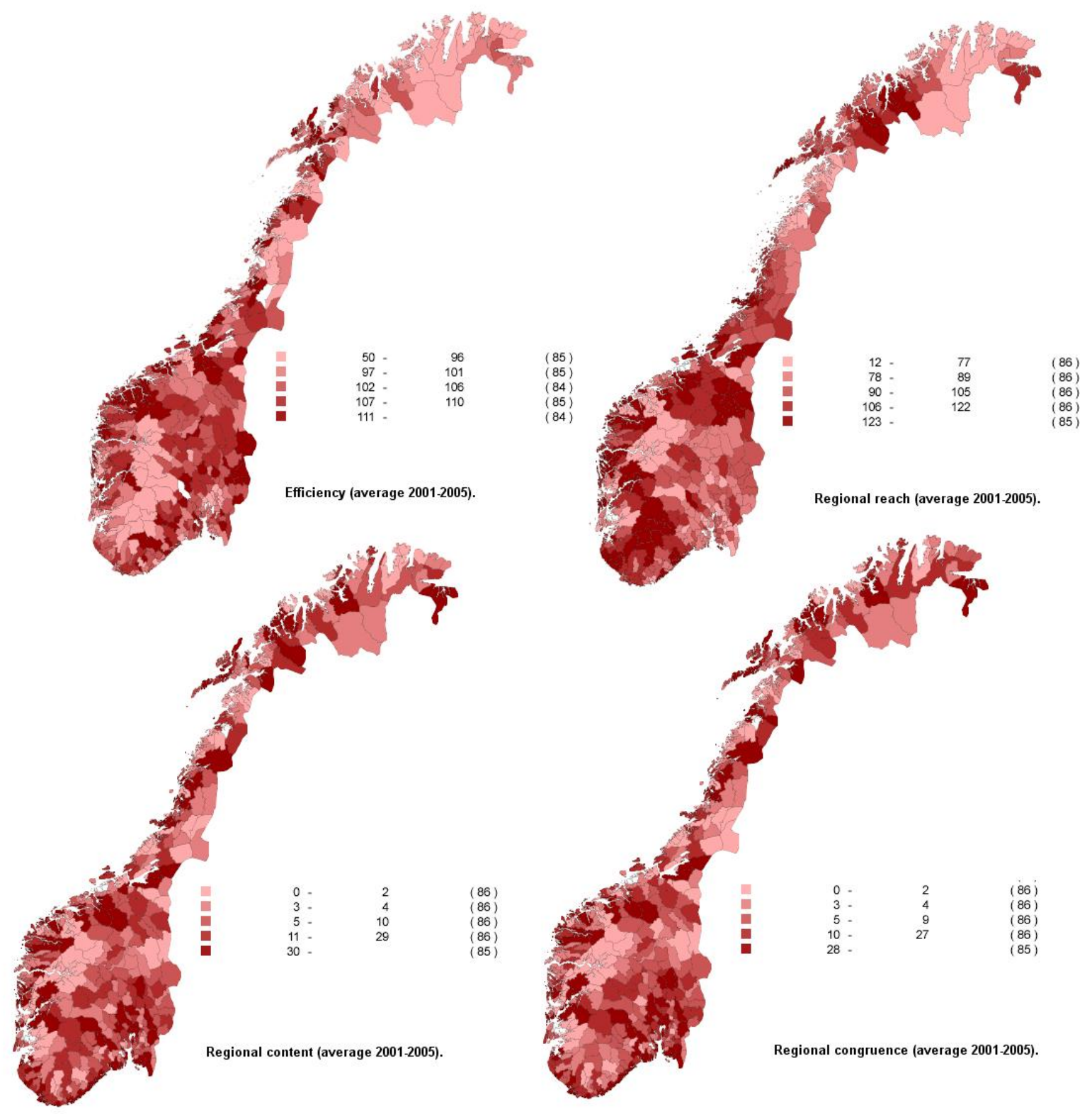

Figure 8-2: EfFiciency, REGional REACH/CONTENT/CONGRUEnCE (*100).

In line with Borge, Falch and Tovmo (2008) we use the efficiency measure as the dependent variable. We acknowledge that there may be a problem with 'division bias' when local government revenue appears both as a control variable and as the denominator of the efficiency index (Borjas, 1980). Thus we also estimate an alternative specification which assumes local output to be the dependent variable while controlling for local government revenue. Local output is again defined as the Produksjonsindeks on the community level 
and so this specification merely captures the general idea of efficiency. A positive coefficient on newspaper circulation while holding local government revenue constant then indicates an efficiency enhancing effect of increases in newspaper reach.

Controls. Variables accounting for heterogeneity at the local level are taken from Statistics Norway and the NSD. These various demographic community characteristics include the percentage of the population classified as urban, population, average household size, income level, religious share of the population, the immigrant share and educational level. Political controls are the number of municipality council seats per 1000 inhabitants, the seat share of local lists in the municipal council and the share of votes received by the strongest party in the council. ${ }^{85}$ Finally, the effect of having an election year is captured by year dummies because local elections take place on the same exact date in all Norwegian municipalities.

Table 8-2 shows summary statistics for all variables.

TABle 8-2: Summary Statistics.

\begin{tabular}{|c|c|c|c|c|c|}
\hline & $N$ & Mean & Std. Dev. & Min & Max \\
\hline newspaper penetration (all) & 1843 & 1.89 & 0.54 & 0.34 & 6.56 \\
\hline regional newspaper penetration & 1843 & 0.99 & 0.27 & 0.04 & 1.83 \\
\hline LLA newspaper penetration & 1840 & 0.06 & 0.20 & 0.00 & 1.69 \\
\hline local newspaper penetration & 1843 & 0.86 & 0.31 & 0.03 & 1.82 \\
\hline tabloid newspaper penetration & 1843 & 0.64 & 0.36 & 0.03 & 4.04 \\
\hline national newspaper penetration & 1843 & 0.78 & 0.48 & 0.03 & 4.90 \\
\hline specialty newspaper penetration & 1843 & 0.12 & 0.12 & 0.03 & 1.02 \\
\hline non-regional newspaper penetration & 1843 & 0.90 & 0.50 & 0.09 & 5.50 \\
\hline regional newspaper content & 1843 & 0.17 & 0.19 & $1.6 e-05$ & 0.86 \\
\hline regional newspaper congruence & 1843 & 0.15 & 0.17 & $2.9 e-04$ & 0.85 \\
\hline local public sector efficiency & 1843 & 103.73 & 10.83 & 44.92 & 137.00 \\
\hline local public sector production & 1843 & 109.98 & 15.73 & 78.92 & 188.12 \\
\hline local government revenue & 1843 & 107.46 & 22.90 & 84.68 & 330.22 \\
\hline secondary school pct & 1843 & 57.99 & 3.95 & 39.84 & 67.19 \\
\hline university educated pct & 1843 & 16.50 & 4.98 & 7.93 & 41.97 \\
\hline local list seats in council pct & 1843 & 5.88 & 11.52 & 0.00 & 100.00 \\
\hline local council seats per 1000 inh. & 1840 & 6.12 & 4.32 & 0.10 & 37.57 \\
\hline share largest party & 1843 & 36.10 & 9.96 & 18.52 & 100.00 \\
\hline average gross income (1000 NOK) & 1843 & 211.88 & 23.47 & 146.00 & 299.70 \\
\hline religious population pct & 1840 & 90.65 & 4.89 & 2.21 & 100.00 \\
\hline immigrant population pct & 1840 & 4.08 & 2.42 & 0.23 & 23.01 \\
\hline average household size & 1840 & 2.40 & 0.18 & 1.91 & 3.26 \\
\hline urban population pct & 1840 & 51.42 & 26.86 & 0.00 & 100.00 \\
\hline population $(1000)$ & 1840 & 11.42 & 30.41 & 0.35 & 538.41 \\
\hline
\end{tabular}

Tabloid, national and specialty newspapers overlap, hence they do not add up to non-regional newspaper penetration.

${ }^{85}$ We also tried including voter turnout as an indicator for unobserved interest in local affairs, yet it was eventually left out as it turned out to be insignificant. 


\subsection{Empirical Strategy}

This section describes the general estimation strategy and possible pitfalls in estimating the effect of interest. As we have a panel dataset at our disposal, we estimate OLS with time and municipality fixed effects. The dependent variables used are local public sector efficiency and local public sector production. The main explanatory variables are the measures of voter information discussed in the previous section. Thus, the estimation equation is:

$$
E_{i t}=\delta \cdot i n f o_{i t}+\mathbf{x}_{\mathbf{i t}} \gamma+c_{i}+u_{i t}
$$

where $E_{i t}$ denotes the efficieny (production) level in municipality $i$ in time period $t$, info $o_{i t}$ denotes the level of voter information (as captured in our newspaper variables), $\mathbf{x}_{i t}$ is a vector of municipality level controls and the unobserved effect $c_{i}$ is allowed to be correlated with $\mathbf{x}_{i t}$ and infort.

Exploiting the panel nature of our dataset takes care of the unobserved heterogeneity that is constant over time, yet whenever there are omitted time-varying variables that influence both the newspaper reach in a given municipality and also that municipality's efficiency, $E\left(u_{i t} \mid \mathbf{x}_{i t}\right.$, info $\left._{i t}, c_{i}\right) \neq 0$.

While finding an exogenous variation in newspaper reach (i.e. the use of 2SLS) would be an appropriate strategy, we could not come up with a convincing instrument for reach. In addition to using the arguably exogenous congruence variable in some of the estimations, we believe there are good reasons to have some faith in the results obtained by simple fixed effects estimation:

One time-varying omitted variable driving both readership and local public sector efficiency is newspaper quality. For our purposes this poses no problem as it doesn't matter whether it is newspaper quality or newspaper reach that is ultimately driving efficiency. Suppose readership increases as a result of enhanced newspaper quality. At the same time the increased quality would induce local government to be more efficient, even without increasing reach. Two remarks on this issue are in order: First, increased newspaper quality leads to individuals being more informed for any given level of reach. In a sense, the effect of increased quality is the same as an increase in readership. Second, it may lead us to overestimate the effect of pure readership (the effect if we could hold quality fixed). So 
we may overestimate this effect but in the end we don't have to distinguish between the two because both are effects of newspapers on local public sector efficiency. ${ }^{86}$ In a related argument, unobserved 'political interest' may induce voters to both read more newspapers and at the same time better monitor politicians. As we have stated in section 8.1, we believe that in the short run, a newspaper's reach is mainly driven by its entertainment value (sports news and the like). Hence, we are confident that the fixed effect takes care of unobserved political interest, at least in a very short panel such as the one at hand.

Aside from unobserved heterogeneity, reverse causality may be an issue. One can easily imagine a slack local government or public administration whose actions lead to very low efficiency and this in turn may lead to a spike in the public's interest in obtaining local information via the local newspapers. Since readership may increase with bad management but not when things are going smoothly (i.e. 'good news is no news'), this implies observing low levels of government efficiency simultaneously with high newspaper readership. Because naïve fixed effects estimation then causes an underestimation of the true (positive) effect of newspaper circulation on government efficiency, we are not too concerned about this issue and would rather interpret our estimates as lower bounds of the true effect. ${ }^{87}$ In a similar vein, the presence of measurement error would bias our estimates towards zero, corroborating the interpretation of $\delta$ as a lower bound on the efficiency enhancing effects.

Another issue worth pointing out is the use of $E_{i t}$ and inf $o_{i t}$ in the estimation. One could also think of using infor $o_{i, t-1}$, i.e. the newspaper reach in the previous year affects government efficiency. This might make sense because while newspapers report on mismanagement right away and politicians will be pressed to react as quickly as possible, on the other hand public budgets may be rather fixed and may perhaps only be altered on an annual basis. However, newspapers also report on the decision making process, and so the pros and cons of a project will be debated in the press and this may lead to efficient decisions right away. More importantly, there is leeway for efficiency gains even when budgets are fixed, mainly by employing these fixed funds in a more efficient manner

\footnotetext{
${ }^{86}$ The model in section 8.1 does not allow for varying degrees of being informed. If such an extension were added, newspaper quality would increase an individual's level of information. Of course, we do not have a newspaper quality measure. In a business economics context, however, reach may even be considered a quality measure.

${ }^{87}$ The reverse causality case is essentially just another form of unobserved heterogeneity with the omitted variable being the extent of corruption or mismanagement.
} 
(e.g. by inducing the public administration to become more efficient without altering budgetary decisions). Another argument for not lagging the newspaper reach variable is that it might make more sense for a politician to try and react to mismanagement accusations right away, as people may want to have a 'quick fix' for the problems at hand, while by next year voters may have 'forgotten' or there may be other problems that need urgent attention. Either way, as will be shown in the following sections, the effects on efficiency that we find are rather small, which may well be due to the fact that many government decisions cannot be overturned or reversed in the short run. Thus, our results describe the short-run actions that are actually feasible.

\subsection{Results}

As mentioned above, all estimations include municipality and year fixed effects effects. All standard errors are clustered at the panel level (municipality). The top portion of table 8-3 shows results with media influence measured as the household penetration with regional newspapers. Column (1) displays results when the only variable is household reach. Column (2) adds population and urbanization controls while column (3) adds a variety of other municipality level controls. Finally, column (4) includes local government revenues as a control in order to check whether greater fiscal capacity leads to higher levels of budgetary slack, as suggested by Borge, Falch and Tovmo (2008) and Revelli and Tovmo (2007).

The fixed effects estimations suggest that increasing the reach of regional newspapers by one percentage point increases local public sector efficiency by around .025 points. In other words, going from zero reach of regional papers to the average reach would increase efficiency by 2.5 points. To put these numbers into perspective, a one standard deviation increase in reach (.27 points) raises efficiency by roughly .065 standard deviations, a rather small effect. The controls suggest that an increase in total population and urban population share leads to higher levels of efficiency, a result that may point to large communities being able to better exploit economies of scale. Higher shares of immigrant and religious population on the other hand are associated with lower levels of efficiency, possibly pointing to these groups being less interested in local politics. Having said that, it is not very surprising that many community level controls are of low or no significance at all, since the 
standardization of the efficiency index already accounts for them. When it comes to the political variables, the result that a larger share of seats in the municipal parliament being taken by local lists is associated with higher efficiency is in line with the notion that these parties are not tied to national party politics, that is, they are assumed to exclusively have local issues on their agenda. The share of votes for the strongest party also bears a positive coefficient, which is in line with Borge, Falch and Tovmo (2008) who find that a higher fragmentation of the local council lowers efficiency. This may be due to the fact that a stronger party may accelerate the decision-making processes (and thus save resources) as there is not as much need for negotiations with other parties. ${ }^{88}$ The single largest predictor of efficiency is local revenue. Just as is the case in Borge, Falch and Tovmo (2008) and Revelli and Tovmo (2007) higher revenue decreases efficiency, presumably via budgetary slack (e.g. via exaggerated levels of public employment, low effort, or increased salaries). The magnitude of the effect is also in the ballpark of what these studies find. Part of this negative effect may be induced whenever communities use additional income for improving public service quality. Because improved quality of public services is hard to capture in the index, this may lead to a downward bias in the coefficient.

In the bottom portion of table 8-3 the main explanatory variable is now regional newspaper content. This variable is the sum of household reaches of all newspapers in a community, where the reach is weighted by the respective reader share of the newspaper in the municipality under consideration. Again, the reader share is supposed to approximate the share of articles in the newspaper that is concerned with issues in the respective municipality. The results from the content estimations, too, back the idea of better informed voters being able to force their local politicians to provide them with local services more efficiently. An increase in content by one standard deviation (.19) increases efficiency by around .1 standard deviations.

Because the inclusion of the local government revenue variable on both sides of the equation (as a control variable and as the denominator of the efficiency index) might lead to biased estimates, we also estimate our model with local government production as the dependent variable. Estimation of the model with revenue included on both sides of the equation

\footnotetext{
${ }^{88}$ At the same time, a negative coefficient wouldn't have been too surprising, either, as a larger share may make it easier to extract rents. In this respect, the positive coefficient on seats per capita is also a bit surprising as it may lead to more need for negotiation. On the other hand a larger number of seats may make it harder to form a rent-extracting cartel.
} 


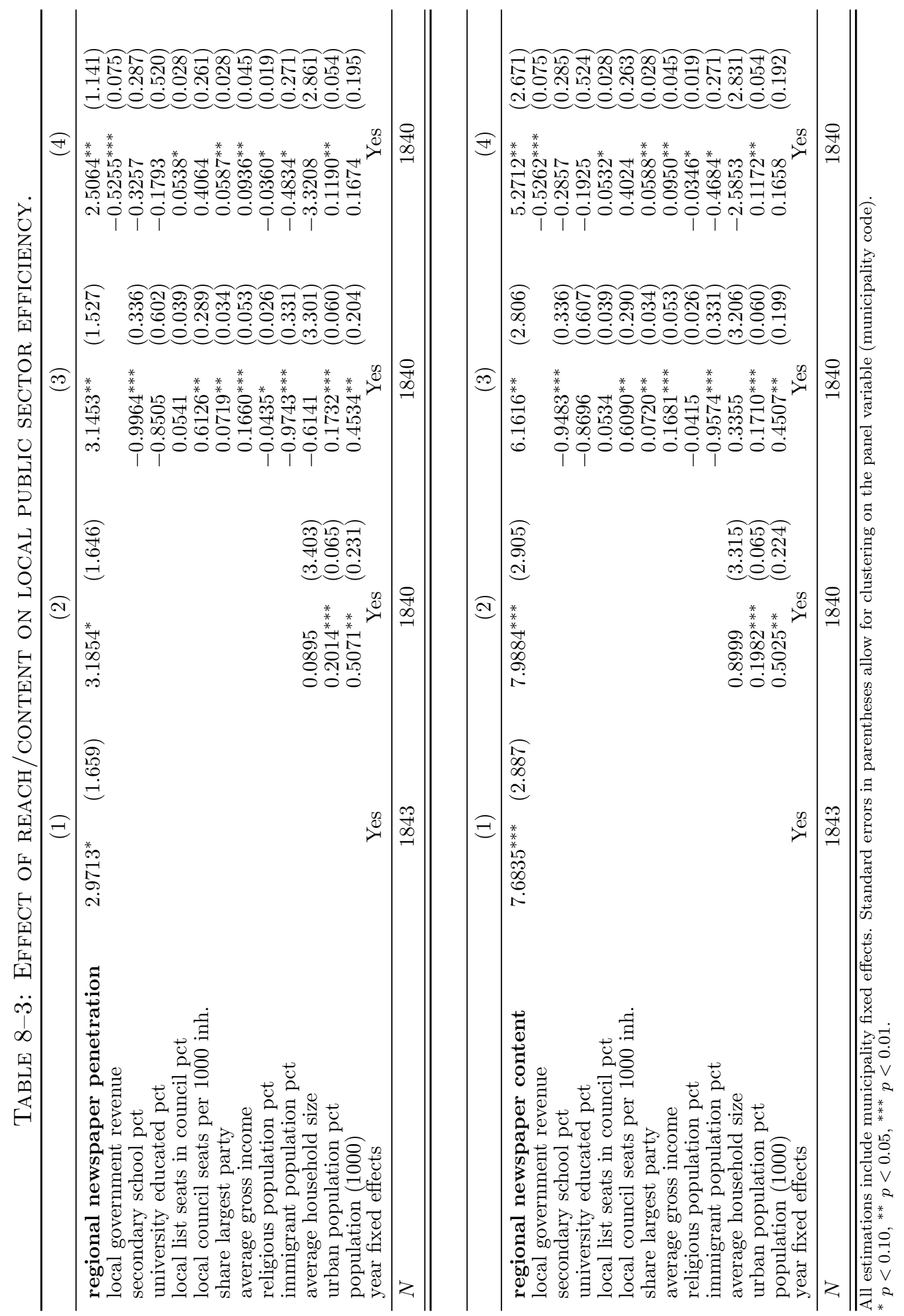




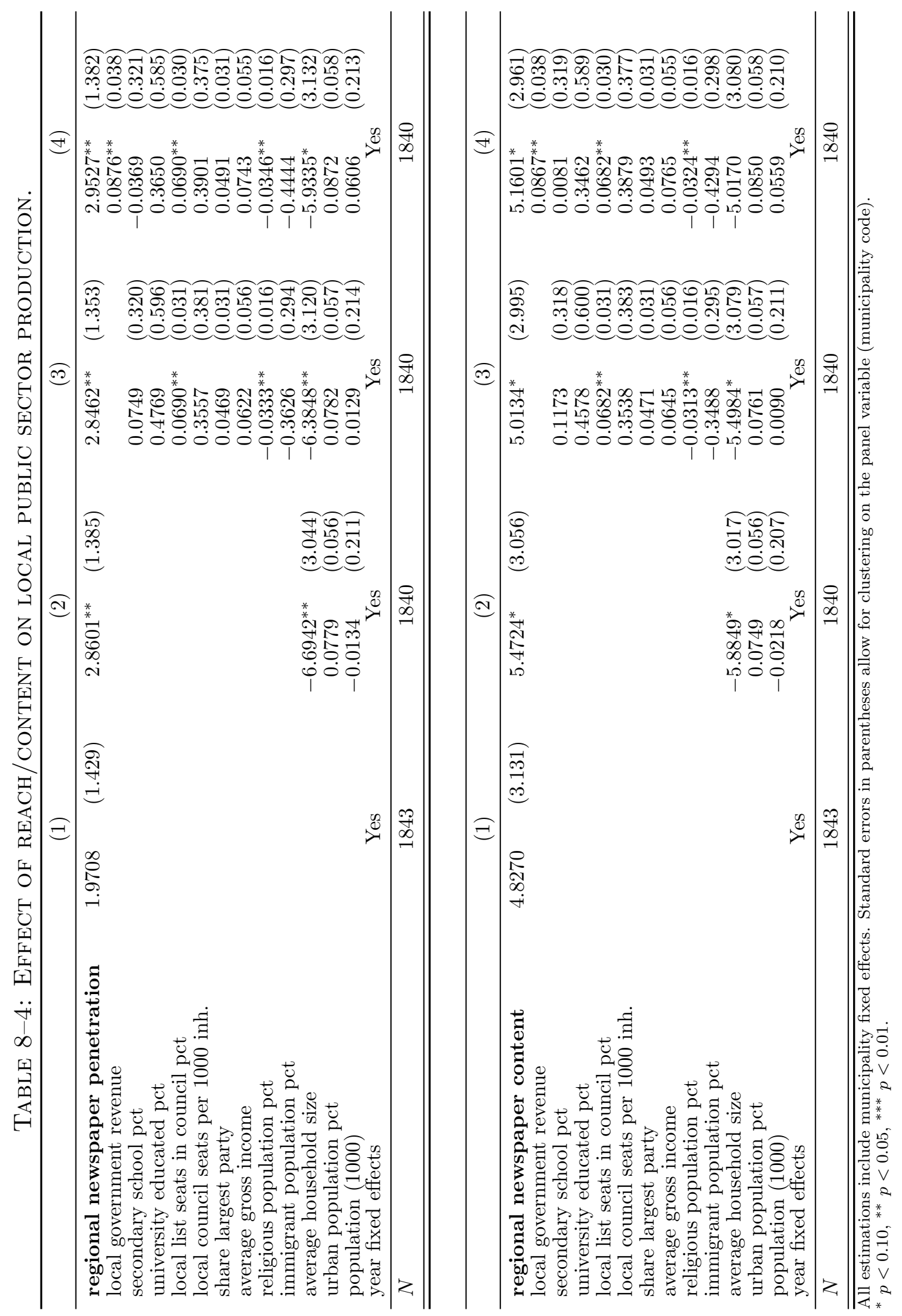


TABle 8-5: Robustness Checks and 'Placebo' tests, DePendent VARiables are PRODUCTION (1) AND EFFICIENCY (2).

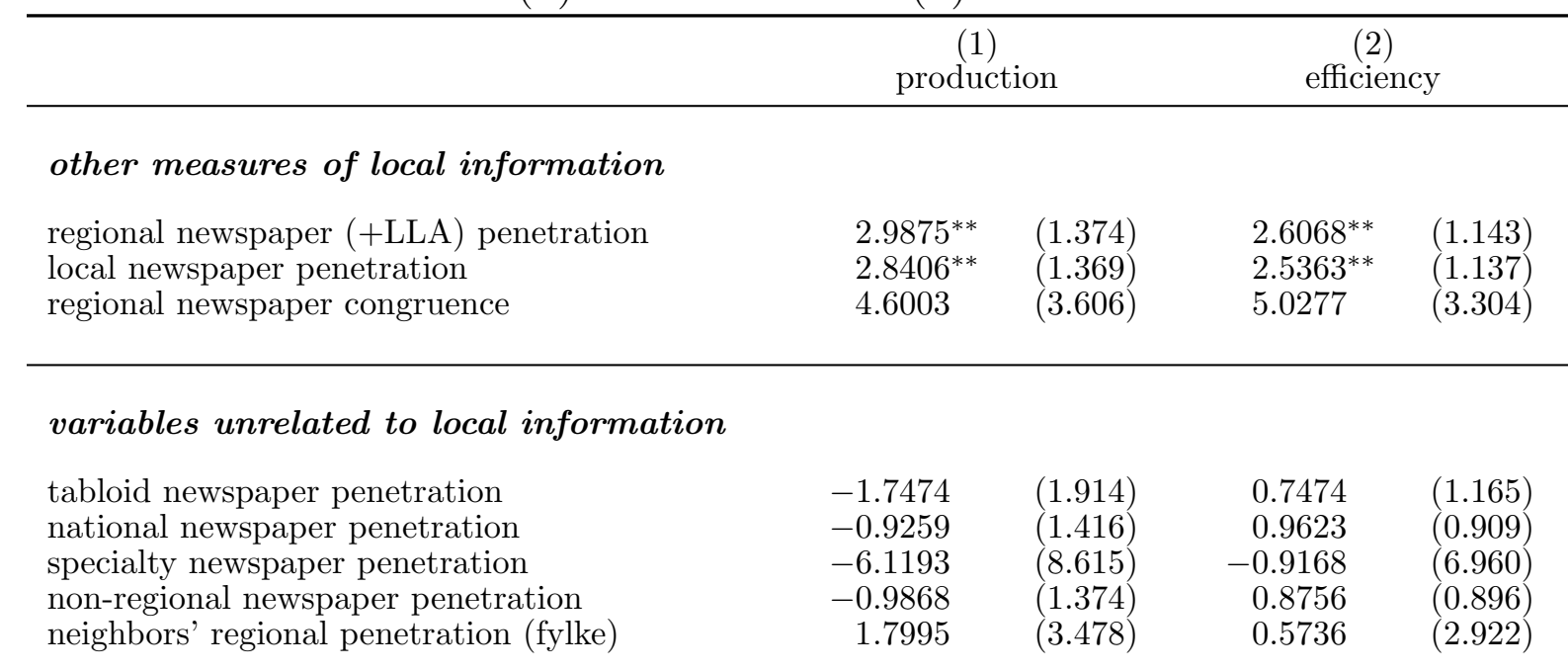

$\overline{\overline{\text { All specifications are as in column (4) of the base regressions. All estimations include municipality fixed effects. Standard }}}$ errors in parentheses allow for clustering on the panel variable (municipality code). ${ }^{*} p<0.10,{ }^{* *} p<0.05,{ }^{* * *} p<0.01$.

only leads to unbiased estimates, as long as there is no measurement error. In the presence of measurement error in the revenue variable, however, the coefficient of revenue will be biased towards -1 (see, e.g. Borjas, 1980). Especially with an index variable such as the revenue index, measurement error is almost certainly an issue. Thus, we put a somewhat larger amount of trust in these estimates, as shown in table 8-4. The top part again displays results for households reach as the main explanatory variable. Regional newspaper content is used in the estimations shown in the bottom part. Here, the results imply that an increase in household reach (penetration) and reach weighted by reader share (content) both lead to higher levels of public sector production. This holds true when local government revenue is controlled for (columns (4)). A one standard deviation increase in content increases production by .065 standard deviations, whereas the effect is .05 standard deviations for household reach. Overall the results are very similar to those presented in table 8-3. 


\subsubsection{Robustness checks and 'placebo' tests}

As a first check of the validity of our results, we use three other measures of local information in table 8-5. The first is regional newspaper reach including small newspapers registered with the LLA. As we could not obtain data on the geographical distribution of the circulation of theses newspapers, all sold newspapers are assigned to the municipality where the newspaper's headquarters is located. This variable also shows a significant positive effect on efficiency and production. As the assignment of the LLA circulation to only one community quite possibly leads to biased estimates (especially in the case of the content and the congruence variable that will be used further on in this section), we refrain from using it in the further estimations. The second media measure is local newspaper reach. These are the newspapers contained in regional reach minus the storby dagsaviser, which have a significantly larger radius of operation (i.e. they are indeed more regional papers than they are local papers). The magnitude and significance of the effect is very similar to the earlier results. The final measure we would expect to exhibit a positive impact on efficiency (production) is regional congruence, as defined in section 8.2.1. As expected, this variable has a positive coefficient that implies going from a situation where the average newspaper sold in municipality $i$ contains virtually no information on $i$ to a situation where the average sold newspaper is completely focused on $i$ increases efficiency by roughly 5 points. The effect is, however, not statistically significant. In other robustness checks we find that the results hold when we exclude all observations where reach or content changed by more than 10 percentage points from one year to the next. Following Borge, Falch and Tovmo (2008) we also excluded all communities with efficiency levels below 80 and above 120. This actually leads to slightly larger coefficients of regional reach, content and congruence as well as slightly higher significance levels.

In five additional specifications ('placebo tests', reported in the bottom part of table 8-5) we use measures of media penetration which we would suspect not to have an influence on either efficiency or production. The first four of these variables are the household reach of tabloid newspapers, national newspapers, specialty newspapers as well as all newspapers excluding those that make up regional reach. As the results in table $8-5$ show, none of these media measures significantly impacts public sector performance. This is in line with the idea that only media that actually carries information on municipal affairs is suited to pressure politicians into using their funds more efficiently and none of the above newspaper 
groups conveying much local content. The final measure is the average reach of regional papers in the other municipalities that are part of municipality $i$ 's fylke (county). Changes in neighboring communities' voter information should not have an effect on efficiency in municipality $i{ }^{89}$ All of these measures combined provide tentative evidence that the media effect is actually very closely related to the local nature of the newspapers being read.

\subsubsection{Municipality size, centrality and media effects}

Three reasons suggest that the effect of newspapers on government efficiency may depend on municipality population or urbanization. First, many smaller or non-urban communities are rather sparsely populated and newspapers might therefore play a more important role in distributing information than in larger communities. Whenever voters in less populous (less urban) places rely more on newspapers for information on the community this implies a larger media effect on efficiency. Second, a larger part of the news may be taken up by local politics in smaller communities, as there is much less going on that the newspapers can actually pick up on (i.e. there is less 'news competition'). ${ }^{90}$ If a larger share of the news is made up of local politics in the less populated or non-urban communities, we would expect the effect of newspapers on efficiency and production to be larger there. A third argument comes from Kalseth and Rattsø (1998) who find that it is the smaller jurisdictions that overspend the most (as in spending more money on public services than the more efficient municipalities). In a similar vein, Sørensen (1984) finds that 'financial stress', measured as the ratio of expenditure growth compared to the growth of tax revenues is positively correlated with centrality. This could mean that the smaller or non-central municipalities have the largest potential for efficiency increases whenever public pressure increases.

Table 8-6 shows estimation results when those municipalities are excluded which have been classified as 'central' by Statistics Norway. This leaves us with about $75 \%$ of the original sample. With the same reasoning we exclude communities with more than 10,000

\footnotetext{
${ }^{89}$ Such effects may actually arise through some sort of yardstick competition. That is, more informed voters in the neighboring municipality receive more efficient politics and yardstick competition may then induce higher levels of efficiency in municipality $i$.

${ }^{90}$ This also means that it takes a much larger scandal to make the news in Oslo or Bergen than it does in some small municipality up north.
} 
TABLE 8-6: CENTRAL MUNICIPALITIES EXCLUDED.

\begin{tabular}{|c|c|c|c|c|}
\hline \multirow[b]{2}{*}{ regional newspaper penetration } & \multicolumn{2}{|c|}{$\begin{array}{c}(1) \\
\text { production }\end{array}$} & \multicolumn{2}{|c|}{$\begin{array}{c}(2) \\
\text { efficiency }\end{array}$} \\
\hline & $4.6923^{* *}$ & $(2.165)$ & $4.0004^{* *}$ & $(1.777)$ \\
\hline regional newspaper content & $15.6465^{* *}$ & $(6.264)$ & $13.5676^{* *}$ & $(5.567)$ \\
\hline regional newspaper congruence & 10.0089 & $(6.793)$ & 9.0051 & $(6.467)$ \\
\hline
\end{tabular}

inhabitants from the estimations in table $8-7$. The cutoff point is chosen as it marks the 75 th percentile of municipality population and 10,000 is at the same time about the average population of a Norwegian municipality (the median population is below 5,000). As both tables show, the effects are in general much larger in the smaller Norwegian communities. In the non-central municipalities the reach effect is more than $50 \%$ larger than in the full sample and the content effect even triples. Also, the coefficient on congruence doubles, yet it is still not statistically significant. When considering municipalities that harbor a population below 10,000, the results are very similar. Now, content and congruence are highly significant and the effects are rather large. Finally, table 8-8 excludes all municipalities that are classified as central and at the same time have a population above 10,000. This leaves more than $85 \%$ of the observations that are in the full sample. Again, all coefficients are statistically significant and of a larger magnitude than in the full sample. ${ }^{91}$ Taken together, the newspaper effect seems to be especially important in these rural communities.

TABLE 8-7: LARGE MUNICIPALITIES EXCLUDED.

\begin{tabular}{lcccc}
\hline & \multicolumn{2}{c}{$(1)$} & \multicolumn{2}{c}{$(2)$} \\
& \multicolumn{2}{c}{ production } & \multicolumn{2}{c}{ efficiency } \\
\hline regional newspaper penetration & $3.9655^{* *}$ & $(1.676)$ & $3.5771^{* *}$ & $(1.393)$ \\
regional newspaper content & $10.9711^{* * *}$ & $(3.825)$ & $9.2288^{* * *}$ & $(2.726)$ \\
regional newspaper congruence & $14.8288^{* * *}$ & $(4.659)$ & $12.9027^{* * *}$ & $(3.551)$ \\
\hline \hline
\end{tabular}

Municipalities with population above 10,000 excluded ( $\mathrm{N}=1354$ remaining). All specifications are as in column (4) of the base regressions. All estimations include municipality and year fixed effects. Standard errors in parentheses allow for clustering on the panel variable (municipality code). ${ }^{*} p<0.10,{ }^{* *} p<0.05,{ }^{* * *} p<0.01$.

\footnotetext{
${ }^{91}$ As a robustness check, we excluded all municipalities with a population below 1,000. This leads to slightly
} higher precision in the estimations. 
TABle 8-8: CENTRAL MUNICIPALITIES ABOVE 10,000 IN POPULATION EXCLUDED.

\begin{tabular}{lcccc}
\hline & \multicolumn{2}{c}{$(1)$} & \multicolumn{2}{c}{$(2)$} \\
production & \multicolumn{2}{c}{ efficiency } \\
\hline regional newspaper penetration & $4.0453^{* *}$ & $(1.576)$ & $3.6142^{* * *}$ & $(1.304)$ \\
regional newspaper content & $11.0027^{* * *}$ & $(3.462)$ & $10.3156^{* * *}$ & $(2.662)$ \\
regional newspaper congruence & $10.5758^{* *}$ & $(4.659)$ & $9.7713^{* *}$ & $(4.108)$ \\
\hline \hline
\end{tabular}

$\overline{\text { Municipalities with population above } 10,000 \text { and at the same time classified as 'central' are excluded (N=1588 remaining). }}$ All specifications are as in column (4) of the base regressions. All estimations include municipality and year fixed effects. Standard errors in parentheses allow for clustering on the panel variable (municipality code).

${ }^{*} p<0.10,{ }^{* *} p<0.05,{ }^{* * *} p<0.01$.

\subsection{Summary and Outlook}

This section set out to explore whether newspaper circulation affects public sector efficiency in Norwegian municipalities. We have developed a model illustrating that a more informed electorate provides incentives for incumbent politicians to behave well. Since newspapers are assumed to serve as a source of information for voters, their circulation in a jurisdiction should have an impact on policy outcomes.

This theoretical prediction has been tested using panel data on Norwegian municipalities, where the main variables are public sector efficiency and various measures of electorate information based on newspaper circulation. The results of the empirical analysis support our theoretical argument that a larger share of informed voters goes with larger efficiency. We find a particularly strong effect of the newspaper variables in small and non-central municipalities.

Regarding the overall rather small effects, we believe that one important reason may be that while voters care about efficiency in general, the weighting in the production index, or its sub-indices even, most likely do not perfectly mirror varying local preferences across municipalities. The production index serves as a monitoring device for the central government, yet, using indicator weights for particular services which rely on country-wide mean values, it cannot perfectly take into account differing preferences across municipalities. An important implication of our results then is that monitoring local politics via newspapers may provide an essential complement to monitoring by the central government. As local newspapers cater to local preferences, they are an important institution when it comes to ensuring the accountability of local governments. 
An important implication of our results is that monitoring politicians and their municipalities by having them report information on all aspects of public service production to upper levels of government may not actually be necessary in the presence of a vibrant newspaper market. Since monitoring efficiency by way of reporting to upper level authorities most likely incurs considerable cost, we are inclined to view the reading of newspapers as a more efficient monitoring or efficiency enhancing device. This is even more true, as newspapers are much more flexible in reporting on issues that people actually care about. The efficiency index on the other hand is a rather inflexible instrument for capturing what may be differing notions of what is efficiency across municipalities. 


\section{Appendix to Chapter 8}

\section{A1 Updating}

For reasons of clarity, we drop all super- and subscripts. The competence variable $\theta$ refers to the incumbent and $a, y$ and $\varepsilon$ denote effort, public good production and the shock respectively in period 1. All voters are rational Bayesians who use all disposable information to form their beliefs. First off, an uninformed voter knows the distributions $\theta \sim N\left(\bar{\theta}, \sigma_{\theta}^{2}\right)$ and $\varepsilon \sim N\left(0, \sigma_{\varepsilon}^{2}\right)$. Thus, his prior belief about the incumbent's competence is $\tilde{\theta}=\bar{\theta}$. Then, he receives the signal $y$ which is informative about $\theta$. The uninformed voter knows that $y=a+\theta+\varepsilon$ but he cannot distinguish between the three terms of the sum on the right-hand side. Expecting the level of effort in period 1 to be $\tilde{a}$, uninformed voters face a signal extraction problem yielding that the density function of $\theta \mid y$ is:

$$
\begin{aligned}
f(\theta \mid y) & =\frac{f(y \mid \theta) \cdot f(\theta)}{f(y)}=\frac{\frac{1}{\sqrt{2 \pi \sigma_{\varepsilon}^{2}}} \cdot \exp ^{-\frac{1}{2 \sigma_{\varepsilon}^{2}}(y-\theta-\tilde{a})^{2}} \cdot \frac{1}{\sqrt{2 \pi \sigma_{\theta}^{2}}} \cdot \exp ^{-\frac{1}{2 \sigma_{\theta}^{2}}(\theta-\bar{\theta})^{2}}}{\frac{1}{\sqrt{2 \pi\left(\sigma_{\theta}^{2}+\sigma_{\varepsilon}^{2}\right)}} \cdot \exp ^{-\frac{1}{2\left(\sigma_{\theta}^{2}+\sigma_{\varepsilon}^{2}\right)}(y-\tilde{a}-\bar{\theta})^{2}}} \\
& =\frac{1}{\sqrt{2 \pi}} \cdot \frac{1}{\sqrt{\frac{\sigma_{\theta}^{2} \cdot \sigma_{\varepsilon}^{2}}{\sigma_{\theta}^{2}+\sigma_{\varepsilon}^{2}}}} \cdot \exp { }^{-\frac{1}{2 \cdot\left(\frac{\sigma_{\theta}^{2} \cdot \sigma_{\varepsilon}^{2}}{\sigma_{\theta}^{2}+\sigma_{\varepsilon}^{2}}\right)}\left(\theta-\frac{\sigma_{\varepsilon}^{2} \bar{\theta}+\sigma_{\theta}^{2}(y-\tilde{a})}{\sigma_{\varepsilon}^{2}+\sigma_{\theta}^{2}}\right)^{2}} \cdot
\end{aligned}
$$

So, for a given level of public good production, the incumbent's competence is drawn from a normal distribution with mean $\frac{\sigma_{\varepsilon}^{2} \bar{\theta}+\sigma_{\theta}^{2}(y-\tilde{a})}{\sigma_{\varepsilon}^{2}+\sigma_{\theta}^{2}}$ and variance $\frac{\sigma_{\theta}^{2} \cdot \sigma_{\varepsilon}^{2}}{\sigma_{\theta}^{2}+\sigma_{\varepsilon}^{2}}$. Consequently, after having received the signal $y$, uninformed voters expect the incumbent's competence to be $\tilde{\theta} \mid y=\frac{\sigma_{\varepsilon}^{2} \bar{\theta}+\sigma_{\theta}^{2}(y-\tilde{a})}{\sigma_{\varepsilon}^{2}+\sigma_{\theta}^{2}}$. The posterior belief, $\tilde{\theta} \mid y$, is a weighted average of the prior and the information contained in $y$. It is intuitive that if the prior is relatively noisy (high $\sigma_{\theta}^{2}$ ), more weight is given to the signal. In contrast, if the signal is not very precise (high $\sigma_{\varepsilon}^{2}$ ), a greater weight is given to the prior.

\section{A2 Proof of Proposition 1}

The incumbent chooses $a$ to maximize his objective function

$$
p^{I}(a) \cdot R-C(a),
$$


taking as given the voters' expectation about effort $\tilde{a}$. This objective function must be concave for the first-order condition to be sufficient for a maximum. To prove concavity, we have to pay attention particularly to $p^{I}$, the probability of reelection for the incumbent. $p^{I}$ is defined by $1-F\left(0 ; \mu, \sigma^{2}\right)$, where $F$ is the distribution function of a normal distribution with mean $\mu$ and variance $\sigma^{2}$. $F$ is both convex and concave on part of its domain. However, we will show that there exists an upper bound for $R$ that ensures the incumbent's objective function to be concave.

First off, to ease the analysis we standardize $F$ so that $p^{I}=\Phi\left(-\frac{\mu}{\sigma}\right)$. Next, we define $x:=-\frac{\mu}{\sigma}$ so that the objective function turns into

$$
[1-\Phi(x)] \cdot R-C(a)
$$

Thus, the first derivative is

$$
-\phi(x) \cdot \frac{\partial x}{\partial a} \cdot R-C^{\prime}(a)
$$

yielding the second derivative

$$
-x \phi(x) \cdot(-1)\left(\frac{\partial x}{\partial a}\right)^{2} \cdot R-C^{\prime \prime}(a) .
$$

The term $-x \phi(x)$ is the slope of the density function $\phi(x)$. At the inflection points $x=-1$ and $x=1$, the slope has its largest absolute values. Thus, $-x \phi(x)$ is bounded between the minimal value $-1 / \sqrt{2 \pi e}$ and the maximal value $1 / \sqrt{2 \pi e}$. In addition, straightforward calculation shows that

$$
\frac{\partial x}{\partial a}=-\frac{1}{\sigma} \cdot \frac{\partial \mu}{\partial a}=-\frac{1}{\sigma} \cdot\left[\frac{\alpha \cdot \sigma_{\varepsilon}^{2}+\sigma_{\theta}^{2}}{\sigma_{\varepsilon}^{2}+\sigma_{\theta}^{2}}\right]=-\frac{1}{\sigma} \cdot \mu^{\prime} .
$$

Now, with the upper bound

$$
R \leq \frac{\sigma^{2}}{\left(\mu^{\prime}\right)^{2}} \cdot \sqrt{2 \pi e} \cdot C^{\prime \prime}(0)
$$

the maximal value of the left-hand term in (A.68) is given by

$$
x \phi(x) \cdot \frac{\left(\mu^{\prime}\right)^{2}}{\sigma^{2}} \cdot R \leq \frac{\sigma^{2}}{\left(\mu^{\prime}\right)^{2}} \cdot \sqrt{2 \pi e} \cdot C^{\prime \prime}(0) \cdot \frac{\left(\mu^{\prime}\right)^{2}}{\sigma^{2}} \cdot \frac{1}{\sqrt{2 \pi e}}=C^{\prime \prime}(0) .
$$


So, finally, with $C^{\prime \prime \prime} \geq 0$, for the second derivative we have that

$$
x \phi(x) \cdot\left(\frac{\partial x}{\partial a}\right)^{2} \cdot R-C^{\prime \prime}(a) \leq 0 .
$$

Consequently, the objective function is concave for $a \geq 0$ and the solution to the first-order condition, $a^{*}$, constitutes a maximum.

In equilibrium, the voters correctly expect $\tilde{a}=a^{*}$ resulting in $\mu=0$ and $p^{I}=1-F\left(0 ; 0, \sigma^{2}\right)$. Then, the first-order condition turns into

$$
\frac{1}{\sqrt{2 \pi} \cdot \sigma} \cdot\left[\frac{\alpha \cdot \sigma_{\varepsilon}^{2}+\sigma_{\theta}^{2}}{\sigma_{\varepsilon}^{2}+\sigma_{\theta}^{2}}\right] \cdot R=C^{\prime}(a)
$$

As $C^{\prime}(a)$ is invertible, the incumbent's effort level in equilibrium is uniquely defined by

$$
a^{*}=\left(C^{\prime}\right)^{-1}\left(\frac{1}{\sqrt{2 \pi}} \cdot \frac{1}{\sqrt{\sigma_{\varepsilon}^{2}+\sigma_{\theta}^{2}}} \cdot \frac{\alpha \cdot \sigma_{\varepsilon}^{2}+\sigma_{\theta}^{2}}{\sqrt{\alpha^{2} \cdot \sigma_{\varepsilon}^{2} \sigma_{\theta}^{2}+\sigma_{\theta}^{4}}} \cdot R\right)
$$

\section{A3 Proof of Proposition 2}

Proposition 1 states that

$$
a^{*}=\left(C^{\prime}\right)^{-1}\left(\frac{1}{\sqrt{2 \pi}} \cdot \frac{1}{\sqrt{\sigma_{\varepsilon}^{2}+\sigma_{\theta}^{2}}} \cdot \frac{\alpha \cdot \sigma_{\varepsilon}^{2}+\sigma_{\theta}^{2}}{\sqrt{\alpha^{2} \cdot \sigma_{\varepsilon}^{2} \sigma_{\theta}^{2}+\sigma_{\theta}^{4}}} \cdot R\right)
$$

To prove that $\frac{\partial a^{*}}{\partial \alpha}>0$, we define

$$
v:=\frac{1}{\sqrt{2 \pi}} \cdot \frac{1}{\sqrt{\sigma_{\varepsilon}^{2}+\sigma_{\theta}^{2}}} \cdot \frac{\alpha \cdot \sigma_{\varepsilon}^{2}+\sigma_{\theta}^{2}}{\sqrt{\alpha^{2} \cdot \sigma_{\varepsilon}^{2} \sigma_{\theta}^{2}+\sigma_{\theta}^{4}}} \cdot R .
$$

Recalling that $C(a)$ is a strictly increasing function, $C^{-1}$ is strictly increasing, too. Thus, the effort level, $a$, is higher for larger values of $v$. So we have to show that $\frac{\partial v}{\partial \alpha}>0$, where $\alpha$ denotes the share of informed voters. The partial derivative yields:

$$
\frac{\partial v}{\partial \alpha}=\frac{1}{\sqrt{2 \pi}} \cdot \frac{1}{\sqrt{\sigma_{\varepsilon}^{2}+\sigma_{\theta}^{2}}} \cdot \frac{1}{\sqrt{\sigma_{\theta}^{2}}} \cdot \frac{\sigma_{\theta}^{2} \sigma_{\varepsilon}^{2}(1-\alpha)}{\left(\alpha^{2} \sigma_{\varepsilon}^{2}+\sigma_{\theta}^{2}\right)^{\frac{3}{2}}}>0
$$

for $0 \leq \alpha<1$. 


\section{TABle A8-1: Description of VARiables.}

Variable

\section{Aviskatalogen data}

newspaper penetration

tabloids

regional newspapers

national newspapers specialty newspapers content

congruence

\section{LLA data}

LLA newspapers

\section{Local gov't data}

local public sector efficiency local public sector production local government revenue

\section{NSD regional data}

secondary school pct university educated pct

\section{KOSTRA variables (ssb.no)}

local list seats in council pct

local council seats per 1000 inh. share largest party average gross income (1000 NOK) religious population pct immigrant population pct average household size urban population pct population (1000)
Description

Percent of households reading a newspaper. values $>100$ denote more than one paper on average.

Dagbladet, Verdens Gang.

Storby dagsaviser (including Aften), lokale dagsaviser, andre lokalaviser as shown in table A8-2. Parentheses after riksspredte nyhetsaviser and storby dagsaviser indicate that these papers are sometimes classified differently.

This alternative classification is not used.

Riksspredte nyhetsaviser as in table A8-2.

Nisjeaviser as shown in table A8-2.

The newspaper penetration in municipality $i$, weighted by the share of newspaper $n$ 's total sales occuring in that municipality.

Content of a newspaper weighted by the newspaper's market share in the municipality.

Local newspapers not included in the Aviskatalogen. Regionally disaggregated circulation data not available, the full circulation is assigned the paper's home municipality

Official efficiency index, developed by Borge et al. (2008) Official production index, developed by Borge et al. (2001) Official revenue index

$\%$ of population over 16 years whose highest degree is secondary $\%$ of population over 16 years whose highest degree is tertiary

Percent of seats in the municipal council taken by non-national parties (only one election in the period under consideration: 2003) Municipalities set the number of seats, as long as lower limit is kept vote share of the largest party in the municipal council

Per taxpayer

Percent of residents registered with the state church none

none

none

none 
TABle A8-2: NeWSPAPERS BY ClASSIFICATION.

\begin{tabular}{|c|c|}
\hline Newspaper & classification \\
\hline DAGBLADET, alm. dager & riksspredte nyhetsaviser \\
\hline DAGBLADET, Fredagsmagasin & riksspredte nyhetsaviser \\
\hline DAGBLADET, lørdag & riksspredte nyhetsaviser \\
\hline DAGBLADET, Magasinet & riksspredte nyhetsaviser \\
\hline DAGBLADET, søndag & riksspredte nyhetsaviser \\
\hline DAGBLADET, Søndagsmagasin & riksspredte nyhetsaviser \\
\hline VG - VERDENS GANG, alm. dager & riksspredte nyhetsaviser \\
\hline VG - VERDENS GANG, lørdag & riksspredte nyhetsaviser \\
\hline VG - VERDENS GANG, søndag & riksspredte nyhetsaviser \\
\hline AFTENPOSTEN, morgenutgaven & riksspredte nyhetsaviser (storby dagsaviser) \\
\hline AFTENPOSTEN, morgenutgaven lørdag & riksspredte nyhetsaviser (storby dagsaviser) \\
\hline AFTENPOSTEN, søndag & riksspredte nyhetsaviser (storby dagsaviser) \\
\hline AFTEN & storby dagsaviser (riksspredte nyhetsaviser) \\
\hline ADRESSEAVISEN & storby dagsaviser \\
\hline BERGENS TIDENDE & storby dagsaviser \\
\hline BERGENSAVISEN & storby dagsaviser \\
\hline DAGSAVISEN & storby dagsaviser \\
\hline ROGALANDS AVIS & storby dagsaviser \\
\hline STAVANGER AFTENBLAD & storby dagsaviser \\
\hline AGDERPOSTEN & lokale dagsaviser \\
\hline AKERSHUS AMTSTIDENDE & lokale dagsaviser \\
\hline ALTAPOSTEN & lokale dagsaviser \\
\hline AURA AVIS & lokale dagsaviser \\
\hline AVISA NORDLAND & lokale dagsaviser \\
\hline BLADET VESTERÅLEN & lokale dagsaviser \\
\hline BRØNNØYSUNDS AVIS & lokale dagsaviser \\
\hline BUDSTIKKA & lokale dagsaviser \\
\hline DRAMMENS TIDENDE & lokale dagsaviser \\
\hline EIDSVOLL ULLENSAKER BLAD & lokale dagsaviser \\
\hline FÆDRELANDSVENNEN & lokale dagsaviser \\
\hline FARSUNDS AVIS & lokale dagsaviser \\
\hline FINNMARK DAGBLAD & lokale dagsaviser \\
\hline FINNMARKEN & lokale dagsaviser \\
\hline FIRDA & lokale dagsaviser \\
\hline FREDRIKSSTAD BLAD & lokale dagsaviser \\
\hline FREMOVER & lokale dagsaviser \\
\hline GJENGANGEREN & lokale dagsaviser \\
\hline GLÅMDALEN & lokale dagsaviser \\
\hline GUDBRANDSD $\varnothing L E N ~ D A G N I N G E N$ & lokale dagsaviser \\
\hline HADELAND & lokale dagsaviser \\
\hline HALDEN ARBEIDERBLAD & lokale dagsaviser \\
\hline HAMAR ARBEIDERBLAD & lokale dagsaviser \\
\hline HARSTAD TIDENDE & lokale dagsaviser \\
\hline HAUGESUNDS AVIS & lokale dagsaviser \\
\hline HELGELAND ARBEIDERBLAD & lokale dagsaviser \\
\hline LAAGENDALSPOSTEN & lokale dagsaviser \\
\hline LINDESNES & lokale dagsaviser \\
\hline LOFOTPOSTEN & lokale dagsaviser \\
\hline MOSS AVIS & lokale dagsaviser \\
\hline NAMDALSAVISA & lokale dagsaviser \\
\hline NORDLYS & lokale dagsaviser \\
\hline OPPLAND ARBEIDERBLAD & lokale dagsaviser \\
\hline ØSTLANDETS BLAD & lokale dagsaviser \\
\hline ØSTLANDS-POSTEN & lokale dagsaviser \\
\hline ØSTLENDINGEN & lokale dagsaviser \\
\hline PORSGRUNNS DAGBLAD & lokale dagsaviser \\
\hline RANA BLAD & lokale dagsaviser \\
\hline RINGERIKES BLAD & lokale dagsaviser \\
\hline RJUKAN ARBEIDERBLAD & lokale dagsaviser \\
\hline ROMERIKES BLAD & lokale dagsaviser \\
\hline
\end{tabular}


TABle A8-2: Newspapers By Classification (CONTINUED).

\begin{tabular}{|c|c|}
\hline Newspaper & classification \\
\hline $\begin{array}{l}\text { ROMSDALS BUDSTIKKE } \\
\text { SANDEFJORDS BLAD } \\
\text { SARPSBORG ARBEIDERBLAD } \\
\text { SMAALENENES AVIS } \\
\text { SØR-TRØNDELAG } \\
\text { SUNNHORDLAND } \\
\text { SUNNMØRSPOSTEN } \\
\text { TELEMARKSAVISA } \\
\text { TELEN } \\
\text { TIDENS KRAV } \\
\text { TØNSBERGS BLAD } \\
\text { TROMS FOLKEBLAD } \\
\text { TROMSØ } \\
\text { TRØNDER-AVISA } \\
\text { VALDRES } \\
\text { VARDEN }\end{array}$ & $\begin{array}{l}\text { lokale dagsaviser } \\
\text { lokale dagsaviser } \\
\text { lokale dagsaviser } \\
\text { lokale dagsaviser } \\
\text { lokale dagsaviser } \\
\text { lokale dagsaviser } \\
\text { lokale dagsaviser } \\
\text { lokale dagsaviser } \\
\text { lokale dagsaviser } \\
\text { lokale dagsaviser } \\
\text { lokale dagsaviser } \\
\text { lokale dagsaviser } \\
\text { lokale dagsaviser } \\
\text { lokale dagsaviser } \\
\text { lokale dagsaviser } \\
\text { lokale dagsaviser }\end{array}$ \\
\hline 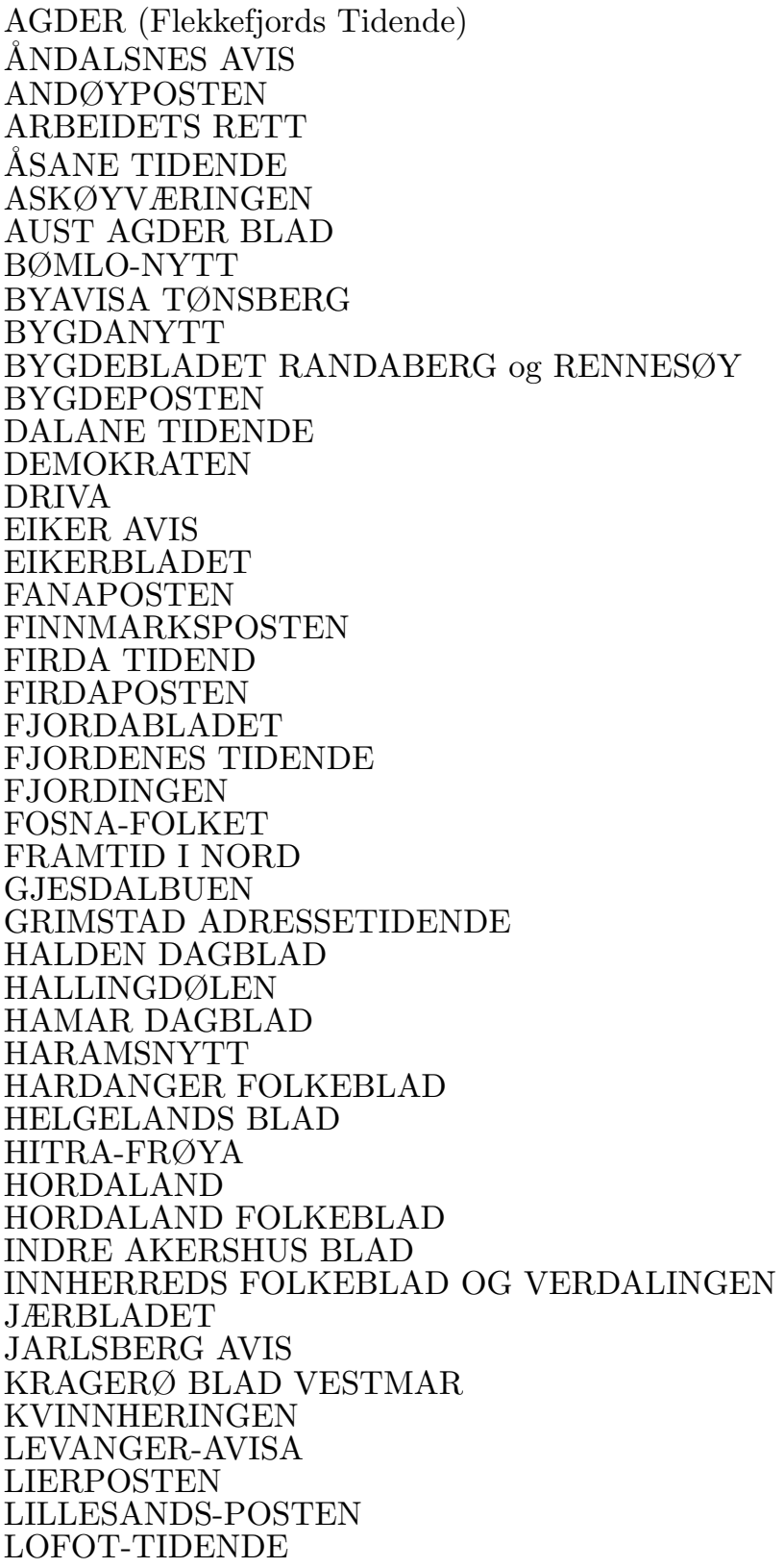 & $\begin{array}{l}\text { andre lokalaviser } \\
\text { andre lokalaviser } \\
\text { andre lokalaviser } \\
\text { andre lokalaviser } \\
\text { andre lokalaviser } \\
\text { andre lokalaviser } \\
\text { andre lokalaviser } \\
\text { andre lokalaviser } \\
\text { andre lokalaviser } \\
\text { andre lokalaviser } \\
\text { andre lokalaviser } \\
\text { andre lokalaviser } \\
\text { andre lokalaviser } \\
\text { andre lokalaviser } \\
\text { andre lokalaviser } \\
\text { andre lokalaviser } \\
\text { andre lokalaviser } \\
\text { andre lokalaviser } \\
\text { andre lokalaviser } \\
\text { andre lokalaviser } \\
\text { andre lokalaviser } \\
\text { andre lokalaviser } \\
\text { andre lokalaviser } \\
\text { andre lokalaviser } \\
\text { andre lokalaviser } \\
\text { andre lokalaviser } \\
\text { andre lokalaviser } \\
\text { andre lokalaviser } \\
\text { andre lokalaviser } \\
\text { andre lokalaviser } \\
\text { andre lokalaviser } \\
\text { andre lokalaviser } \\
\text { andre lokalaviser } \\
\text { andre lokalaviser } \\
\text { andre lokalaviser } \\
\text { andre lokalaviser } \\
\text { andre lokalaviser } \\
\text { andre lokalaviser } \\
\text { andre lokalaviser } \\
\text { andre lokalaviser } \\
\text { andre lokalaviser } \\
\text { andre lokalaviser } \\
\text { andre lokalaviser } \\
\text { andre lokalaviser } \\
\text { andre lokalaviser } \\
\text { andre lokalaviser } \\
\text { andre lokalaviser }\end{array}$ \\
\hline
\end{tabular}


TABle A8-2: Newspapers By Classification (CONTINUED).

\begin{tabular}{|c|c|}
\hline Newspaper & classification \\
\hline LOKALAVISA SØR-ØSTERDAL & andre lokalaviser \\
\hline LOKALAVISEN OPPEGÅD & andre lokalaviser \\
\hline MALVIK-BLADET & andre lokalaviser \\
\hline MØRE-NYTT & andre lokalaviser \\
\hline MOSS DAGBLAD & andre lokalaviser \\
\hline NORDDALEN & andre lokalaviser \\
\hline NORDHORDLAND & andre lokalaviser \\
\hline NORDSTRANDS BLAD & andre lokalaviser \\
\hline NYE TROMS & andre lokalaviser \\
\hline OPDALINGEN & andre lokalaviser \\
\hline ØYENE & andre lokalaviser \\
\hline RAKKESTAD AVIS & andre lokalaviser \\
\hline RAUMNES & andre lokalaviser \\
\hline RINGSAKER BLAD & andre lokalaviser \\
\hline RØYKEN OG HURUMS AVIS & andre lokalaviser \\
\hline SALTENPOSTEN & andre lokalaviser \\
\hline SANDE AVIS & andre lokalaviser \\
\hline SANDNESPOSTEN & andre lokalaviser \\
\hline SETESDØLEN & andre lokalaviser \\
\hline SØGNE OG SOGNDALEN BUDSTIKKE & andre lokalaviser \\
\hline SOLABLADET & andre lokalaviser \\
\hline SØR-VARANGER AVIS & andre lokalaviser \\
\hline STJØRDALENS BLAD & andre lokalaviser \\
\hline STRANDBUEN & andre lokalaviser \\
\hline STRILEN & andre lokalaviser \\
\hline SVELVIKSPOSTEN & andre lokalaviser \\
\hline TRØNDERBLADET & andre lokalaviser \\
\hline TVEDESTRANDSPOSTEN & andre lokalaviser \\
\hline VARINGEN & andre lokalaviser \\
\hline VENNESLA TIDENDE & andre lokalaviser \\
\hline VEST-TELEMARK BLAD & andre lokalaviser \\
\hline VESTERAALENS AVIS & andre lokalaviser \\
\hline VESTLANDSNYTT & andre lokalaviser \\
\hline VESTNYTT & andre lokalaviser \\
\hline VIGGA & andre lokalaviser \\
\hline VIKEBLADET VESTPOSTEN & andre lokalaviser \\
\hline YTRE SOGN AVIS & andre lokalaviser \\
\hline YTRINGEN & andre lokalaviser \\
\hline ARBEIDERAVISA & nisjeaviser \\
\hline ÁVVIR & nisjeaviser \\
\hline COMPUTERWORLD & nisjeaviser \\
\hline DAG OG TID & nisjeaviser \\
\hline DAGBLADET Sportsmagasin & nisjeaviser \\
\hline DAGENMAGAZINET & nisjeaviser \\
\hline DAGENS NÆRINGSLIV & nisjeaviser \\
\hline DAGENS NÆRINGSLIV, lørdag & nisjeaviser \\
\hline FINANSAVISEN & nisjeaviser \\
\hline FISKAREN & nisjeaviser \\
\hline FISKERIBLADET & nisjeaviser \\
\hline KLASSEKAMPEN & nisjeaviser \\
\hline KORSETS SEIER & nisjeaviser \\
\hline MORGENBLADET & nisjeaviser \\
\hline NATIONEN & nisjeaviser \\
\hline NY TID & nisjeaviser \\
\hline SOGN AVIS & nisjeaviser \\
\hline STALL-SKRIKET & nisjeaviser \\
\hline TIPS & nisjeaviser \\
\hline UKEAVISEN LEDELSE & nisjeaviser \\
\hline UTROP & nisjeaviser \\
\hline VÅRT LAND, fredag - lørdag & nisjeaviser \\
\hline VÅRT LAND, mandag - torsdag & nisjeaviser \\
\hline
\end{tabular}





\section{CHAPTER 9}

\section{Concluding Remarks}

This book has investigated how institutions shape the incentives of economic agents and the subsequent effects on local policy outcomes. Chapter 3 theoretically explains that when grading standards are at the discretion of individual schools, those schools with higher shares of socially disadvantaged students have an incentive to choose a lower grading standard because this will maximize the wage sum of their students. Data from Dutch secondary schools provides evidence. The fact that in chapter 5 school choice is found to have a beneficial effect on both academic achievement and grading standards adds another piece to the school competition puzzle. While more research has to be done on what may be driving down grade inflation under a competitive regime, the effects on academic achievement are in line with economic theory - in contrast to what many other studies find. This suggests that institutionalizing the ability to choose generates incentives for schools to provide high quality education. Likewise, in chapters 7 and 8 we have shown that the institution of mass media provides strong incentives for politicians to behave in a certain way. In providing parts of the population with information, television and newspapers introduce incentives for politicians to shape local policies in a way that the informed voters see fit.

So far, we have not gone far beyond uncovering incentives that are brought about by the institutions and the possible mechanisms of agent behavior that emerge. The book especially has not done much to recommend or reject "right" or "wrong" policies. The reason is that except for the topic of school choice, the issues discussed in this book do not easily lend themselves to taking a pro or con stance in them nor is it the main purpose of 
this book to do so.

However, if one were bent on it, pointing out policy implications from the school competition and the local government efficiency chapter would be fairly easy. Both of these studies employ as an outcome a variable that most would judge as being beneficial from a social welfare point of view. In the case of competition the distributional analysis not only suggests that no one is hurt by school competition but because the competition-induced achievement gain is largest in the bottom half of the achievement distribution, it even seems to narrow the gap between high and low achievers a bit. Hence, school choice may cautiously be described as a tool for promoting social equality. In addition, the institution of school choice is all the more desirable because it may be implemented at little cost especially when compared to many other educational policy measures that have been implemented in the past and that are more or less uncertain in their effects (reductions in class size are the leading example).

In the case of local government efficiency, things are similar. Once one is willing to accept the efficiency index as an appropriate measure of how prudent a local government handles taxpayers' money, there seems little to argue about. Efficiency reacts to increases in the information level in the population, and so at the end of chapter 8 local newspapers are referred to as a cheap way of enhancing efficiency. However, this is unconditionally true only if these newspapers aren't kept alive by financial support from the government. While many argue that government should aid local newspapers in staying in business, another policy implication could be that keeping them alive by government subsidization may not have all out positive effects. The positive accountability effect would persist, yet the net effect may be negative when translating the efficiency gains into monetary terms and weighting them against the cost of keeping newspapers around that would otherwise succumb to market pressures and go out of business. Incidentally, the Norwegian government operates a controversial system of press subsidies which is to a large extent geared towards preserving small local newspapers. ${ }^{92}$

We should be very wary of deriving policy implications from the other two topics that have been discussed in the course of this book. Even though it is obvious that the media in the US have an influence on how federal grants are spent, it is unclear what the verdict on

\footnotetext{
${ }^{92}$ See Skogerbø (1997) for a detailed description of the history of Norwegian newspaper subsidies.
} 
this effect should be. The first reason is that even in the absence of television, spending is very likely to be distorted due to other incentives faced by politicians. Whether the media changes this for the better or worse from a social welfare perspective is hard to say. A very tentative recommendation can be given whenever one believes that the bias introduced by local television stations should indeed be eliminated: a reduction of incentives for politicians to overspend on the media cities in comparison to other places can be attained by ensuring that each jurisdiction - even the most remote one - receives ample media coverage. Things get even more tricky, when it comes to the research on minorities and educational standards. The main implication for the political debate would be that when it comes to minorities in the education system, resorting to the simple concept of discrimination in order to describe their situation is insufficient, as there seem to be much more complex mechanisms at work.

All of these policy implications, however, are merely logical consequences of what is the bottom line of this book: Institutions shape incentives and therefore they matter a great deal for local policy outcomes. 



\section{References}

Adams, W.C. (1980), Local Television News Coverage and the Central City, Journal of Broadcasting 24(2), 253-265.

ÅHLin, A. (2003), Does school competition matter? Effects of a large-scale school choice reform on student performance, Uppsala University Working Paper Series 2.

Alesina, A., R. Baqir and W. Easterly (1999), Public Goods And Ethnic Divisions, Quarterly Journal of Economics 114(4), 1243-1284.

Althaus, S. M. and T. C. Trautman (2008), The impact of television market size on voter turnout in american elections, American Politics Research 36(6), 824-856.

Baron, D. P. (2006), Persistent media bias, Journal of Public Economics 90, 1-36.

BARrow, L. (2002), School choice through relocaton: Evidence from the Washington, D.C. area, Journal of Public Economics 86, 155-189.

Bayer, P., F.V. Ferreira and R. McMillan (2005), Tiebout sorting, social multipliers and the demand for school quality, NBER Working Paper W10871.

Belfield, C. and H. Levin (2002), The effects of competition on educational outcomes: A review of US evidence, Review of Educational Research 72, 279- 341.

Besley, T. and R. Burgess (2002), The Political Economy of Government Responsiveness: Theory and Evidence from India, Quarterly Journal of Economics 117(4), 1415-1452.

Besley, T. (2006), Principled Agents? The Political Economy of Good Government, Oxford: Oxford University Press. 
Besley, T. and A. Prat (2006), Handcuffs for the Grabbing Hand? Media Capture and Government Accountability, American Economic Review, 96(3), 720-736.

BetTs, J. (1998a), The impact of educational standards on the level and distribution of earnings, American Economic Review 88, 266-275.

BetTs, J. (1998b), The two-legged stool: The neglected role of educational standards in improving America's public schools, Economic Policy Review 4, 97-116.

Betts, J. and R. Costrell (2001), Incentives and equity under standards-based reform, Brookings Papers on Education Policy, 9-74.

Betts, J. and J. Grogger (2003), The impact of grading standards on student achievement, educational attainment, and entry-level earnings, Economics of Education Review $22,343-352$.

Bishop, J. (1997), The effect of national standards and curriculum-based exams on achievement, American Economic Review 87, Papers and Proceedings, 260-264.

Bishop, J. (1999), Are national exit examinations important for educational efficiency?, Swedish Economic Policy Review 6, 349-398.

Bishop, J. and F. MAne (2004), Educational Reform and Disadvantaged Students: Are They Better Off or Worse Off?, CESifo Working Paper Series No. 1309, CESifo Munich.

BLACK, S. (1999), Do better schools matter? Parental valuation of elementary education, The Quarterly Journal of Economics 114, 577-599.

Borck, R. and S. Owings (2003), The political economy of intergovernmental grants, Regional Science and Urban Economics 33(2), 139-156.

Borge, L.-E., Falch, T. and P. Tovmo (2001), Produksjonsindeks for kommunale tjenester (An aggregate output measure for local government services), Report, ALLFORSK, Norwegian University of Science and Technology.

Borge, L.-E., T. Falch and P. Tovmo (2008), Public sector efficiency: the roles of political and budgetary institutions, fiscal capacity, and democratic participation, Public Choice 136(3), 475-495. 
BorJas, G. (1980), The Relationship Between Wages and Weekly Hours of Work: The Role of Division Bias, Journal of Human Resources, 409-423.

Borland, M. and R. Howsen (1993), On the determination of the critical level of market concentration in education, Economics of Education Review 12, 165-169.

Bradley, S., G. Johnes and J. Millington (1999), School Choice, Competition and the Efficiency of Secondary Schools in England. Lancaster University Management School Working Paper 1999/003.

Brasington, D. (2005), Public and Private School Competition: The Spatial Education Production Function, Department of Economics Working Paper Series, Working Paper 2005-09, Louisiana State University.

Brunello, G. and L. Rocco (2008), Educational Standards in Private and Public Schools, Economic Journal, 118(533), 1866-1887.

Centraal Bureau voor de Statistiek, Kerncijfers postcodegebieden 2003.

Centraal Bureau voor de Statistiek, Nederland regionaal, accessed via http://www.CBS.nl.

Centraal Bureau voor de Statistiek, Kerncijfers wijken en buurten 2001-2005.

Chan, W., H. Li, and W. Suen (2007), A signalling theory of grade inflation, International Economic Review 48, 1065-1090.

Chernozhukov, V. and C. Hansen (2005), An IV Model of Quantile Treatment Effects, Econometrica, 73(1), 245-61.

Chernozhukov, V. and C. Hansen (2006), Instrumental Quantile Regression Inference for Structural and Treatment Effect Models, Journal of Econometrics, 132(2), 491525.

Chernozhukov, V. and C. Hansen (2007), Inference Approaches for Instrumental Variable Quantile Regression, Economics Letters, 95(2), 272-77.

Chernozhukov, V. and C. Hansen (2008), Instrumental Variable Quantile Regression: A Robust Inference Approach, Journal of Econometrics, 142(1), 379-98. 
Cheshire, P. and S. Sheppard (2003), Capitalising the Value of Free Schools: The Impact of Supply Constraints and Uncertainty, ERSA conference papers ersa03p8, European Regional Science Association.

Corneo, G. (2006), Media capture in a democracy: the role of wealth concentration, Journal of Public Economics 90, 37-58.

Costrell, R. (1994), A simple model of educational standards, American Economic Review 84, 956-971.

Costrell, R. (1997), Can centralized educational standards raise welfare?, Journal of Public Economics 65, 271-293.

De Borger, B. and K. Kerstens (2000), What is known about municipal efficiency? The Belgian case and beyond. In J.L.T. Blank (Ed.), Public provision and performance, 299-330, Amsterdam: North-Holland.

DeE, T. (1998), Competition and the Quality of Public Schools, Economics of Education Review 17, 419-427.

De Graaff, T. , C. Gorter, and P. NiJkamp (2001), Effects of ethnic geographical clustering on educational attainment in the Netherlands, Tinbergen Institute Discussion Papers 01-028/3, Tinbergen Institute.

DellaVigna, S. and E. Kaplan (2007), The Fox News effect: media bias and voting, Quarterly Journal of Economics 122(3), 1187-1234.

Denessen, E., P. Sleegers and F. Smit (2001), Reasons for School Choice in the Netherlands and in Finland, National Center for the Study of Privatization in Education Occasional Paper 24, Columbia University.

Denessen, E., G. Driessena and P. Sleegers (2005), Segregation by choice? A study of group-specific reasons for school choice, Journal of Education Policy 20, $347-368(22)$.

De ViJlder, F. (2000), Dutch education: A closed or an open system? Or: The art of maintaining an open system responsive to its changing environment, http://www.oecd.org/dataoecd/1/33/1917370.pdf. 
Dixit, A. and J. Londregan (1996), The Determinants of Success of Special Interests in Redistributive Politics, Journal of Politics 58, 1132-1155.

Djankov, S., C. Mcleish, T. Nenova and A. Shleifer (2003), Who owns the media?, Journal of Law \& Economics 46(2), 341-81.

Doksum, K. (1974), Empirical probability plots and statistical inference for nonlinear models in the two-sample case, Annals of Statistics, 2, 267-277.

Downs, A. (1957), An economic theory of democracy, New York: Harper and Row.

Dronkers, J. (1995), The existence of parental choice in the Netherlands, Educational Policy 9, 227-243.

Dronkers, J. (1999), Is het eindexamen wel gelijkwaardig tussen scholen? Discrepanties tussen de cijfers voor het schoolonderzoek en het centraal examen in het voortgezet onderwijs. Farewell address from the chair of educational sciences of the University of Amsterdam.

Dronkers, J. (2004), Do public and religious schools really differ? Assessing the European evidence, in: Wolf, P.J. and Macedo, S. (Eds.), Educating Citizens: International Perspectives on Civic Values and School Choice, Brookings Institution Press, Washington DC, 287-314.

Epple, D. and R. Romano (1998), Competition between private and public schools, vouchers, and peer group effects, American Economic Review 88, 33-62.

Epple, D., E. Newlon, and R. Romano (2002), Ability tracking, school competition, and the distribution of educational benefits, Journal of Public Economics 83, 1-48.

Figlio, D. and M. LuCAS (2004), Do high grading standards a®ect student per- formance?, Journal of Public Economics 88, 1815-1834.

Friedman, M. (1955), The role of government in education, in: Robert A. Solo (Ed.), Economics and the Public Interest, Rutgers University Press, New Brunswick, N.J, $127-134$.

Fuchs, T. and L. Wössmann (2004), What accounts for international differences in student performance?, CESifo Working Paper No. 1235, Munich. 
Gabszewicz, J. J., D. Laussel and N. SonnaC (2001), Press advertising and the ascent of the 'Pensee Unique', European Economic Review 45(4-6), 641-651.

Geller, C., D. Sjoquist and M. Walker(2006), The Effect of Private School Competition on Public School Performance in Georgia, Public Finance Review 34, 4-32.

Gentzkow, M. (2006), Television and Voter Turnout, Quarterly Journal of Economics 121(3), 931-972.

Gentzkow, M. and J. M. Shapiro (2006), Media Bias and Reputation, Journal of Political Economy 114(2), 280-316.

Gibbons, S. and O. Silva (2008), Urban Density and Pupil Achievement, Journal of Urban Economics 63(1), 631-650.

Groseclose, T. and J. Milyo (2005), A measure of media bias, Quarterly Journal of Economics 122(3), 1191-1237.

Hamilton, J. T. (2006), All the news that's fit to sell, Princeton: Princeton University Press.

HanusheK, E. (2002), Publicly provided education, in: A. Auerbach and M. Feldstein (Eds.), Handbook of Public Economics 4, Amsterdam: Elsevier, 2047-2141.

HanusheK, E. and S. Rivkin (2003), Does public school competition affect teacher quality, in: Hoxby, C. (Ed.), The Economics of School Choice, University of Chicago Press, 23-47.

Helsley, R. W. (2004), Urban political economics, Handbook of Regional and Urban Economics 4, in: J. V. Henderson and J. F. Thisse (Eds.), Handbook of Regional and Urban Economics, Amsterdam: Elsevier, 2381-2421.

HerczyÑski, J. and M. Herbst (2005), Public School Choice and Student Achievement. Evidence from Poland. MPRA Working Paper 6138.

Horrigan, J., K. Garrett and P. Resnick (2004), The Internet and Democratic Debate, Pew Internet \& American Life Project, http://www.pewinternet.org/ / media//Files/Reports/2004/PIP_Political_Info_Report.pdf.pdf, accessed on March 31, 2009. 
HoxBy, C. (1994), Do private schools provide competition for public schools?, NBER Working Papers 4978.

HoxBy, C. (2000), Does competition among public schools benefit students and taxpayers? The American Economic Review 90, 1209-1239.

Hsien, C.-T. and M. Urquiola (2006), The effects of generalized school choice on achievement and stratification: Evidence from Chile's voucher program, Journal of Public Economics 90, 1477-1503.

Høst, S. (1999), Newspaper Growth in the Television Era - The Norwegian Experience, Nordicom Review, 20(1).

InSPECTIE VAN HET ONDERWIJs, Kwaliteitskaart Voortgezet Onderwijs, uitgaven 19982004, Steinmetz Archief, Amsterdam.

IYIGUN, M. (1999), When would educational standards help improve scholastic achievement?, International Finance Discussion Papers No. 648, Board of Go- vernors of the Federal Reserve System, Washington.

JACOB, B. (2005), Accountability, incentives and behavior: The impact of high-stakes testing in the Chicago public schools, Journal of Public Economics 89, 761-796.

JEPSEn, C. (1999), The effects of private school competition on student achievement, Northwestern University Working Paper 99.

Jürges, H., W. Richter, and K. Schneider (2005), Teacher quality and incentives: Theoretical and empirical effects of standards on teacher quality, Finanzarchiv N.F. 61, 298-326.

Jürges, H., K. Schneider, and F. BüChel (2005), The effect of central exit examinations on student achievement: Quasi-experimental evidence from TIMSS Germany, Journal of the European Economic Association 3, 1134-1155.

Kalseth, J. and Ratts $\varnothing$, J. (1998), Political control of administrative spending: The case of local governments in Norway, Economics and Politics 10, 63-83.

Kaniss, P.C. (1997), Making Local News, Chicago: University of Chicago Press. 
Karsten, S., G. Ledoux, W. Meijnen, J. Roeleveld and E. Van Schooten (2006), Choosing segregation or integration?: The extent and effects of ethnic segregation in Dutch cities, Education and Urban Society 38(2), 228-247.

KASKI, Institute for Applied Research on Religion of the Radboud University Nijmegen, supplied data on catholic population by postcode.

KeE, P. (1995), Native-Immigrant Wage Differentials in the Netherlands: Discrimination?, Oxford Economic Papers 47, 302-317.

Kelejian, H. H. and Prucha, I. (1998), A Generalized Spatial Two Stage Least Squares Procedure for Estimating a Spatial Autoregressive Model with Autoregressive Errors, Journal of Real Estate Finance and Economics, 17 (1), 99-121.

Koenker, R. and G. W. Bassett (1978), Regression quantiles, Econometrica, 46, 33-50.

Lazarsfeld, P., P. Berelson and H. Gaudet (1944), The people's choice : how the voter makes up his mind in a presidential campaign, New York: Duell, Sloan and Pearce.

Levin, J. (2004), Differences in Educational Production Between Dutch Public and Religious Schools, National Center for the Study of Privatization in Education Occasional Paper 93, Columbia University.

Levitt, S. and J. SNyder (1997), The Impact of Federal Spending on House Election Outcomes, Journal of Political Economy 105(1), 30-53.

LindBeck, A. and J. Weibull (1987), Balanced-Budget Redistribution as the Outcome of Political Competition, Public Choice 52, 273-297.

Marlow, M. (1997), Public education supply and student performance, Applied Economics 29, 617-26.

Marlow, M. (1999), Spending, school structure, and public education quality, Economics of Education Review 19, 89-106.

Martinez-Vazquez, J., and B. Seaman (1985), Private schooling and the Tiebout hypothesis, Public Finance Quarterly 13, 293-318. 
Migué, J.L. and Belanger, G. (1974), Toward a theory of managerial discretion. Public Choice 17, 27-43.

Ministerie van Onderwijs Cultuur en Wetenschappen, Onderwijs in Cijfers 2003.

Mueller, D. C. (2003), Public Choice III, Cambridge: Cambridge University Press.

Mullainathan, S. and A. Shleifer (2005), The Market for News, American Economic Review 95(4), 1031-1053.

NAPOLI, P.M. and M.Z. YAN (2007), Media Ownership Regulations and Local News Programming on Broadcast Television: An Empirical Analysis, Journal of Broadcasting \& Electronic Media 51(1), 39-57.

NechybA, T. (1999), School finance induced migration and stratification patterns: The impact of private school vouchers, Journal of Public Economic Theory 1, 5-50.

Niskanen, W.A. (1971), Bureaucracy and representative government. Chicago: Aldine Atherton.

Niskanen, W.A. (1975), Bureaucrats and politicians. Journal of Law and Economics 18, 617-643.

Ontes, W. and P. Portney (2001), The political economy of environmental policy, Resources for the Future Discussion Paper 01-55, Washington.

Oettinger, G. (2002), The effect of nonlinear incentives on performance: Evidence from "ECON 101", Review of Economics and Statistics 84, 509-517.

Oliver, P.E. and D.J. Myers (1999), How Events Enter the Public Sphere: Conflict, Location and Sponsorship in Local Newspaper Coverage of Public Events, American Journal of Sociology 105(1), 38-87.

Patrinos, H. (2002), Private education provision and public finance: The Netherlands as a possible model, NCSPE Occasional Paper No. 59.

Persson, T. and G. Tabellini (2000), Political Economics, Cambridge: MIT Press.

Petrova, M. (2008), Inequality and media capture, Journal of Public Economics 92, 183-212. 
Popkin, S.L. (1991), The Reasoning Voter, Communication and Persuasion in Presidential Campaigns, Chicago: University of Chicago Press.

Prenzel, M., J. Baumert, W. Blum, R. Lehmann, D. Leutner, M. Neubrand, R. Pekrun, H.-G. Rolff, J. Rost, and U. Schiefele (Eds.) (2005), PISA 2003: Ergebnisse des zweiten internationalen Vergleichs - Zusammenfassung, IPN - LeibnizInstitut für die Pädagogik der Naturwissenschaften an der Universität Kiel, available under http://pisa.ipn.uni-kiel.de/Ergebnisse_PISA_2003.pdf.

PrIOR, M. (2006), The incumbent in the living room: the rise of television and the incumbency advantage in US House elections, Journal of Politics 68(3), 657-673.

Randsell, T. (2004), Factors Determining California's Share of Federal Formula Grants, Public Policy Institute of California, 2nd Edition.

ReinikKa, R. and J. Svensson (2005), Fighting corruption to improve schooling: evidence from a newspaper campaign in Uganda, Journal of the European Economic Association 3, 259-267.

Revelli, F. and P. Tovmo (2007), Revealed yardstick competition: Local government efficiency patterns in Norway, Journal of Urban Economics, 62(1), 121-134.

Revelli, F. (2008), Performance competition in local media markets, Journal of Public Economics 92, 1585-1594.

Ritzen, J., J. van Dommelen and F. De Vijlder (1997), School finance and school choice in the Netherlands, Economics of Education Review 16, 329-335.

Roper, B.W. (1985), Public Attitudes Towards Television and Other Media in a Time of Change. New York: Television Information Office.

Rothstein, J. (2007), Does Competition Among Public Schools Benefit Students and Taxpayers? A Comment on Hoxby (2000), American Economic Review, 97(5), 20262037.

Sander, W. (1999), Private Schools and Public School Achievement, The Journal of Human Resources 34, 697-709.

SAndström, M. and F. Bergström (2005), School vouchers in practice: competition will not hurt you, Journal of Public Economics 89, 351-380. 
Skogerbø, E. (1997), The Press Subsidy System in Norway. Controversial Past - Unpredictable Future?, European Journal of Communication, 12(1), 99-118.

Snyder, J.M. and D. Strömberg (2008), Press coverage and political accountability, NBER Working Paper Series, No. 13878.

Sociaal en Cultureel Planbureau, Statusscores postcodegebieden 2002.

Strömberg, D. (2001), Mass Media and Public Policy, European Economic Review 45, 652-663.

Strömberg, D. (2004a), Mass Media Competition, Political Competition, and Public Policy, Review of Economic Studies 71(1), 265-284.

Strömberg, D. (2004b), Radio's Impact on Public Spending, Quarterly Journal of Economics 119(1), 189-221.

Svaleryd, H. and J. Vlachos (2009), Political Rents in a Non-Corrupt Democracy, Journal of Public Economics 93, 355-372.

Sørensen, R. J. (1984), The urban causes of financial stress: An analysis of Norwegian municipalities and the economic resource-squeeze, Housing, Theory and Society, 1(3), $165-178$.

Tiebout, C. (1956), A pure theory of local expenditures, Journal of Political Economy $64,416-424$.

Van Ours, J. and J. Veenman (2002), From Parent to Child: Early Labor Market Experiences of Second-Generation Immigrants in the Netherlands, IZA Discussion Paper 649.

WALFord, G. (2000), Funding for private schools in England and the Netherlands. Can the piper call the tune?, NCSPE Occasional Paper No. 8.

Weimer, D. and M. Wolkoff (2001), School performance and housing values: Using non-contiguous district and incorporation boundaries to identify school effects, National Tax Journal 54, 231-253.

Wildasin, D. (1987), Theoretical Analysis of Local Public Economics, in: E. Mills (Ed.), Handbook of Regional and Urban Economics 2, Amsterdam: Elsevier, 429-476. 
Wikström, C. and M. Wikström (2005), Grade inflation and school competition: An empirical analysis based on the Swedish upper secondary schools, Economics of Education Review 24, 309-322.

Wössmann, L. (2003a), Schooling resources, educational institutions and student performance, Oxford Bulletin of Economics and Statistics 65, 117-170.

Wössmann, L. (2003b), Zentrale Prüfungen als Währung des Bildungssystems: Zur Komplementarität von Schulautonomie und Zentralprüfungen, DIW Vier-teljahreshefte zur Wirtschaftsforschung, 220-237.

ZANZIG, B. (1997), Measuring the impact of competition in local government education markets on the cognitive achievement of students, Economics of Education Review 16, 431-441.

Zorlu, A. (2002), Ethnic and Gender Wage Differentials, University of Amsterdam AIAS Research Report 13. 